Automobile Collision Data: An Assessment of Needs and Methods of Acquisition

February 1975

NTIS order \#PB-244867

\section{OFFICE OF TECHNOLOGY ASSESSMENT}

Automobile Collision Data

AT Mssesent of reces

axb ninwoos of accossirace

Frasulk 17, 1375

peranes at net efouest or

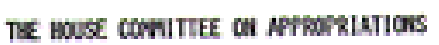

thwspotation SUACom!TEE

purpurs woek cowinact OTA CII or Econchics \& science PhWING, IN. $120018 \mathrm{rw}$ Statet $\mathrm{X}, \mathrm{X}$.

Nessivstce, D, C, mos. 
Technology Assessment BOARD

OLIN E. TEAGUE, TEXAS, CHAIRMAN CLIFFORD P. CASE, N.J., VICE CHAIR MAN

EDWARD M. KENNEDY. MASS. MORRIS K. UDALL, ARIZ.

ERNEST F. HOLLINGS, S.C. GEORGE E. BROWN, JR., CALIF.

HUBERT H. HUMPHREY. MINN. CHARLES A. MOSHER, OHIO

RICHARD S. SCHWEKER, PA. MARVIN L. ESCH, MICH.

TED STEVENS. ALASKA

EMILIO Q. DA DADDARIO

\section{Congress of the United States \\ Office of Technology Assesiment \\ EMILIO O. DADDARIO DIRECTOR \\ DANIEL V. DE SIMONE}

WASHINGTON, D.C. 20510 DEPUTY DIRECTOR

The Honorable George H. Mahon

Chairman

Committee on Appropriations

U. S. House of Representatives"

Washington, D. C. 20515.

Dear Mr. Chairman:

On behalf of the Board of The Office of Technology Assessment, we are pleased to forward to you the following report on Automobile Collision Data. This study was requested as an evaluation of the automotive crash recorder program proposed by the National Highway Traffic Safety Administration (NHTSA). As the assessment progressed, the implications for automobile collision data as a "whole became apparent and the report has been so titled to provide a more accurate indication of its scope.

This report is being made available to your Committee in accordance with Public Law 92-484.

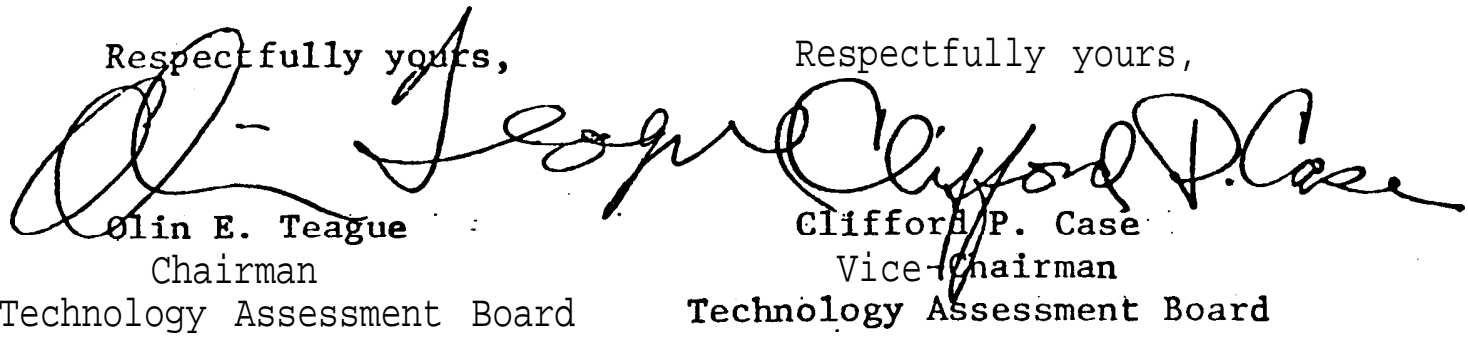




\section{PREFACE}

Highlights of the study findings which are especially relevant to the four questions posed by the House Appropriations Committee in its letter of request are summarized below. (The Committee letter is appended).

1. Cost and Adequacy of Current NHTSA Programs

The National Highway Traffic Safety Administration has spent a total of $\$ 15.8$ million during the last three years gathering and analyzing automobile crash data. The data collected by NHTSA is inadequate to provide a basis for effective safety standard setting or measurement of the benefits of the standards in force. The inadequacies of the system are: too few reports are gathered too slowly; the file is biased toward severe injury accidents; reports do not include adequate quantitative measures of causal severity; and, the information recorded in accident reports is not that which is essential to answering the specific questions of rulemakers, accident researchers and car designers.

2. Use of Existing Crash Recorders

There are 1800 installed (disk-type) crash recorders. These provide a 3-axis acceleration time history over the actual impact interval. This information would probably be adequate to determine crash severity had a severity index been explicitly defined. After the index is defined, these same recorders might be used as part of a specialized crash severity research program.

Currently these recorders provide a limited independent measure of crash severity in air-bag equipped cars. They are also giving NHTSA practical experience in the retrieval, readout and analysis of crash records, the reliability of recorders themselves, and the reactions of fleet owners to crash recorder installations. 


\section{3* Improving the Data Base}

NHTSA has not provided a sampling plan to support requested appropriations for crash data acquisition programs in the last three years. In order to rectify the inadequacies of the existing data base and the current crash data acquisition system, a comprehensive sampling plan must be developed.

The rate of acquisition of collision reports should be , increased to 500,000 to 1,000,000 per year at an estimated cost of \$3-10 million annually. Causal severity should be measured and reported. This could be done by using disk recorders at a cost per report of about \$133. Alternately, vehicle deformation could be measured and analyzed to determine severity at a cost of about $\$ 20$ per report. However, if a cheap crash severity measuring device could be developed, it would eliminate the tedious measurement and analysis of vehicle deformation.

The consequences of not getting data are, first, sustaining a continuing societal 10SS of at least $\$ 22$ billion per year in automobile death, injury and damage without developing adequate tools to correct the problem; and second, imposition of $\$ 7$ billion to $\$ 14$ billion in consumer costs for meeting existing, proposed, and planned future motor vehicle safety standards whose benefits will continue to be uncertain.

Current NHTSA programs (multidisciplinary accident investigation, air cushion restraint system evaluation, fatal accident reporting, pedestrian-cyclist accident survey) should be continued. They are necessary to answer specific safety questions. . . . -

\section{Further Considerations}

If sophisticated tape crash recorders were used, there may be secondary benefits to driver training programs. For example driver errors may be more readily determined and the effectiveness of driver training may be better measured.

If crash recorders are installed, there is the possibility that their readings could be used in liability cases. This matter should be examined more fully in the legislative process. 
jamiel. WintTrn. mise.

JOIFN HOONEY, N.Y.

acnritTL. PIST.S. PLA

goc. Tuins, trion.

ri) ranop,inglard, mase.

WILLIAM H.HATCH,IF, NV.

DAlurL J. Flood, ra

TOMASIET.D, OKLA.

GRDICE E. SIHWLEY, BLL

JOIN M. SUCK, W. VA.

JOHIN J FLYYHT. | R.. GA.

Mral SMIISH, IOWA

HOHENT N. GIAIMO, CONN.

ULIA MUULL.H 14 ANSEN, VIASH.

JOSKPH P. ADOAEDO, N.Y.

JOIN N MC FALL, CALIP.

EOWAHO J, FATTE N, N.\&

clant.hate o. Long, ma.

CIONEY R. YATES, ILL

NOD CASE, TEX.

FiranK E. EVAFis, colo

GAVIOR. OUEY, WIS.

COWARO R. HOYBAI., CALIF.

LOUIS STOKES, OW110

J. COWARO 1 ? OUSIA, INO

X. GUVIIT MC KAY, UTAH

1 UMHLVILI.AIA.

Cis THCIIEL, N, ORI:Q.

mogine O. TIELTIAN, R.l.

DH.e CHATrEIt., JH., FLA

VII. L D. 41 UIALISUN, MO
(Cangress of tibe anited sotates

3louse of sienursentatives

Committee on Appropriations

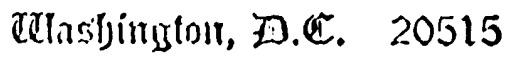

November 19, 1974

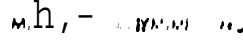

- cromoa.ceror mar mo.mirm

mictiam Ce. mimniral onilo

noninTH. MieIII I.. ILL

911 VioO. Curdrr.,mais.

mir.uN 44. DAVIS, wis.

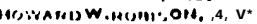

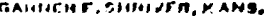

JOSR PMM, IAC OAOC, $\triangle A$

NAKX ANOHCWB.N. OAK.

LnUIS C, WY MAN. M.M.

IUAT L. TAICOIT, CAL

Wiruorel WYAM, OO

JaCricowaHOS, ALA.

WIILI,IAM]. SCIIIMI.F,IUWA

1? OML.HT C. MC, WrN, N.Y.

JOINA T. MAY CHS, INO.

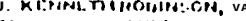

CIAME NCE R.APILLI R, (), 10

CAHE. n. IUUTH, N.C.

VICTCR V. VEYTEY, CALIF.

LA WHFNCECOUE,HLIPA, PA.

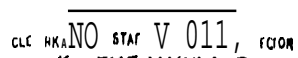

TELCPHOHC,

CAPITOL 4-312!

rXt. $25 \mathrm{~mm}$

on

Honorable Edward M. Kennedy

Chairman

Technology Assessment Board

Washington, D. C. 20510

Dear Mr. Chairman:

On behalf of Congressman John J. McFall, Chairman of the Transportation Subcommitee, and Congressman Silvio 0. Conte, the Subcommittee's Ranking Minority Member, I am transmitting the attached request for a technology assessment with regard to automobile crash recorders. with kindest personal regards
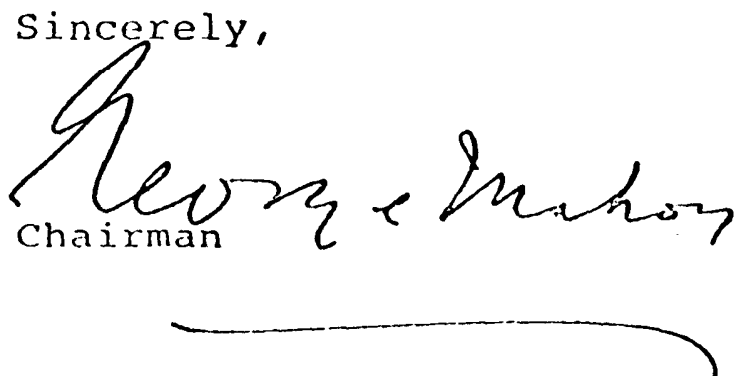


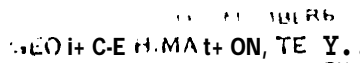

.LAT+C-E H.MA $T+O N$, TE Y.minmian

JA. WEL WhITI RT,Migo,

Jokns.ungeter. N.Y.

nocint L. PIKY S.PLA

Cric cimassatal, La

iunarior. II dLamo mase.

h.LLIANII.PATCIER KY.

Dailit L J TLUOPA.

TOMSTFCO.OKLA

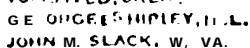

J OHN J . rLYYNT,JR.. OA.

NEALSMITH, IOWA

RODITI N. GIAIMO, CONN.

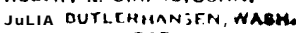

JosErih: AD DACTON.Y.

JOHN

EOWAN O J.PATTIN, J,

CLATENCE D LONG. MOO

SIONEY P. YATES, MOO

GONCASTY, TEX.

mankc. eVANS, colo.

Davio $R$. noEY, wis.

EDWATID R. F? OYOAL, CALHP.

LOUIS sTOKES, OHIO

J. EOWARDPOUSH, INO

U. GUNNMG KAY, UTAH

TOM BEVILL, ALA.

EDITHGREen, OREO.

ROBSiTt O. TIERNAN, R.I.

DILL CMUPELL. IR. FU.

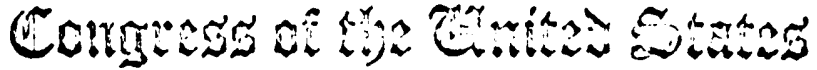

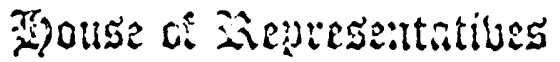

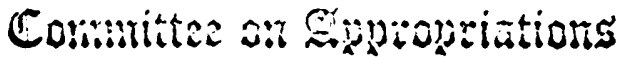

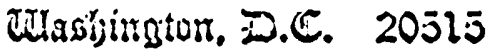

November 19, 1974
MHRORITY MEMBETS

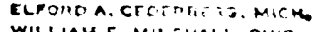

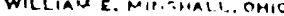

MOOFRT H. MICHEL.ILL.

S.LVIOO. COITTE, DAass.

GlePlPA R. DA:BS. YhIS.

hollano Ri. moBsison, n.t.

GAMMER E. 5NITIEER, FANE.

JOSEPH PA. MCLACE. PA.

MAOK ANORE: 'S. It. WIAK.

LCUIS C. WYMAAN. H. H.

Bunt L. TALCOTt, CALIF.

WeNBLLL WATT, ongo.

JACK EOWAMOS, ALA.

WILIAN S. SCHERLE, IONA

MOEERT C. MICEKEN. N.Y.

DOHNT, NIYERS, WID.

J. KENNETH ROBINSON, VA.

CLAREitCE E. MILLER, CMIO

CARL B. FUTH. N.C.

vieter: v, verser, CNifif.

UWRENCE CCUGHLIN, PA

C. W. BILL YOUNG, FLA.

CuRKKANOST, OIRECTOA

KOTH P. MNALANO

TELEPHONE:

CAPITOL A-312I

oxr. s2mi

OP

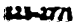

Honorable George H. Mahon

Chairman

Committee on Appropriations

U.S. House of Representatives

Washington, D. C.

Dear Mr. Chairman:

The Conference Report to H.R. 15405 (Department of

Transportation and Related Agencies Appropriations Bill, 1975) states that: "The conference agreement contains no funds for the crash recorder program. The Committee intends to request an evaluation of this program by the Office of Technology Assessment. "

The purpose of this program, as proposed by the National Highway Traffic Safety Administration (NHTSA), is to assemble detailed data on actual collisions so as to develop realistic automobile design standards. NHTSA proposed the installation of 100, 000 crash recorders in vehicles used in ordinary driving. Total cost of the 5 year program including installation of the recorders and monitoring and analysis of the data was estimated at $\$ 14.5$ million in 1973 . An alternate approach has also been proposed by NHTSA. This entails the controlled crashing of unoccupied vehicles along with computer $s$ emulations of automobile crashes. The cost of this program has been estimated as approximately the same as the crash recorder program.

Although the committees of both Houses have heard extensive testimony on this program over the past three years, substantial question and differences still exist on the necessity for gathering additional information through the installation and monitoring of the requested crash recorders. 
Page 2 - Honorable George H. Mahon

Since this issue remains unresolved, the Conference Committee on H.R. 15405 decided to call upon the Office of Technology Assessment for assistance.

We therefore request that the Technology Assessment Board consider approving an assessment that would address the following issues:

1. How much has NHTSA spent in each of the past three years to gather accident data? Is that data sufficient, or is further data on the characteristics of automobile collisions necessary for effective NHTSA standardssetting? If the existing data base is inadequate; in what ways is it inadequate?

2. An evaluation of the type of data being produced by existing crash recorders and an explanation of how this data is being used by NHTSA should be conducted.

3. If the data base is inadequated, how might an adequate data base be obtained and what are the consequences associated with obtaining the data in different ways (including the possibility of not obtaining the necessary data)? The cost effectiveness of the crash recorder and the crash impact approaches proposed by NHTSA should be examined.

4. Secondary consequences of implementing these or other program should be identified and evaluated. Examples of these secondary consequences include legal questions associated with the existence of actual physical data from an accident and the potential value (to driver training program) of a knowledge base concerning how drivers actually respond in accident situations. For each type of approach investigated, the implementation costs to the Federal Government $t_{t}$ industry and consumers should be identified.

We appreciate your assistance in transmitting this request to the Chairman of the Technology Assessment Board.

Sincerely,

\section{(Bignod)}

John J. McFall

Chairman, Subcommittee on

Transportation Appropriations (signed)

Silvio O. Conte

Ranking Minority Member

Subcommittee on Transportation Appropriations 


\section{Contents}

In this volume:

Page

1. Introduction and Summary 1

2. The Need for Mere and Better Crash Data 9

3. Characteristics of An Adequate Data Collection Program

4. Alternatives For An Adequate Data Acquisition Program

5. Federal Responsibility and Expenditures For Collision Data Gathering

6. Legal Aspects of Crash Recorders 68

References

Bound Separately:

Appendices 


\section{INTRODUCTION AND SUMMARY}

At the request of the House Appropriations Committee, the Office of Technology Assessment, through contract OTA-C11, engaged Economics \& Science Planning, Inc. (ESP) to undertake a study of the need for and means to assemble detailed data on actual automobile collisions so as to develop realistic automobile design standards. The study examined the desirability, utility, design and cost of crash recorders and of the alternate approaches to gathering collision data, including computer crash simulation, controlled laboratory crashes and their correlation with observed vehicle deformations, and methods to improve the accuracy of accident investigation reporting and to increase the utility of national crash data files. Specific data collection programs previously proposed to Congress by the National Highway Traffic Safety Administration were studied and evaluated. This report contains the results of this effort.

We have concluded that the current national accident data base is inadequate to resolve the uncertainties in NHTSA's current and proposed motor vehicle safety programs. One of the major deficiencies is data relating collision forces and actual fatalities and injuries. The need has been clearly expressed by Professor B. J. Campbell (University of North Carolina):

". . when one is forced to use nonhuman subjects [in laboratory crashes] then one is left in the situation of knowing a great deal about the physics of the crash but knowing little of the actual injuries that might have occurred in such a crash. On the other hand, in real world automobile crashes one can learn about the actual outcome in terms of survival and injuries, but the input variables mentioned before are unknown. 
"The need to link these two systems is apparent.

Engineers who design protective systems need to know about stopping distances, forces, decelerations, etc.

But knowing these things is of too little help unless one has a way to relate them to real world injuries."

\section{$\underline{\text { FINDINGS }}$}

1. The existing national data base is inadequate

-- only four of 40 existing standards have been shown to be beneficial based on statistical evidence.

-- the nationwide effectiveness of lap belts in mitigating fatalities is still unknown after five years; statistical evidence is available from only one state.

-- there is an immediate need for more and better crash data

- to support rulemaking and to estimate the benefits of proposed safety standards

- to determine the effectiveness of existing safety standards

- to determine causes of accident, injury and fatality to aid crashworthy vehicle design

- to identify new safety problems as they develop

- for predicting the impact of trends in motor vehicle design on accident incidence and outcome 
Auto Collision Data

February 17, 1975

Page 3

-- Larger crash data collection expenditures than the $\$ 5$ million to $\$ 6$ million now programmed annually appear to be justified:

- Motor Vehicle accidents cost society $\$ 22$ billion to $\$ 44$ billion annually.

- Present safety standards cost consumers $\$ 2.5$ billion annually

- proposed and possible safety standards could cost an additional $\$ 4$ to $\$ 12$ billion annually.

- Present and planned safety standards add weight to automobiles which increases gasoline consumption.

2. A Comprehensive Accident Data Program

-- must be designed with great care to assure that

- it is representative and avoids inadvertant biases

- it will answer the outstanding critical safety questions

- it is adequate in rate and quantity

- it provides uniformity in reporting and format

-- should be reviewed and approved by a broadly based body of experts before it is implemented.

-- elements for a comprehensive program could include:

- 500,000 to 1,000,000 crash reports per year for a mass data file at a cost of $\$ 3$ to $\$ 10$ million per year. 
o the measurement and reporting of crash severity either by vehicle deformation measurement or a cheap and widely installed crash severity recorder, at a cost of $\$ 10$ to $\$ 20$ million per year.

- some measurement of crash dynamics using some mix of simulated accident reconstruction (SMAC) and collision history (disk or tape) crash recorders at a cost of $\$ 2$ million to $\$ 4$ million

- supplementary surveys to answer specific questions and the existing special programs now costing $\$ 5$ to \$6 million per year

- a cheap crash severity recorder at a development cost of about $\$ 500,000$

o field trials of planned safety improvements whose costs are high and whose benefits are uncertain (as an example, the cost of a field trial of passive restraints would be $\$ 30-\$ 60$ million)

3. The Federal Government, not states, manufacturers or insurance companies, should support the central data collision activities.

-- It is a national problem.

-- The Motor Vehicle Safety Standards are promulgated by the Federal Government.

-- The data has to be obtained in an unbiased and uniform manner throughout the nation.

-- The Federal Government has the resources and ready access to the sources of information. 
4. Crash recorders provide data that may be admissible in a court of law.

5. Program alternatives include the following:

- Doing nothing to improve the current crash data acquisition system. If this course is followed, \$22 to $\$ 44$ billion in societal losses will continue to be incurred each year without developing adequate tools to analyze and correct the problem; \$7-14 billion or more in consumer costs will be imposed yearly by current, proposed and advanced motor vehicle safety rule making whose benefits, in most cases, will continue to be uncertain.

- Upgrading current data collection programs without adding a mass data acquisition system. This course will neither provide statistically convincing measures of the reduced incidence of death or injury resulting from incorporation of safety features nor will it give a timely response to questions regarding the impact of vehicle design changes.

- Providing a mass accident data acquisition proqram at a cost of $\$ 3$ to $\$ 10$ million yearly. This course will begin to permit timely statistical determination of safety system benefits and identification of automotive safety problems. However, crash severity measures will be inadequate and it will be difficult to associate injury with crash severity.

- Upgrading mass accident data acquisition proqram to provide accurate severity reporting at a cost of $\$ 10$ to $\$ 20$ million annually. This action would finally provide timely determination of safety benefits with ascertainable accident severity incidence and associated injury and fatality exposure bridging the gap between laboratory and field experience. 
Auto Collision Data

February 17, 1975

page 6

- Use of acceleration time-history (disk) recorders. A small $(10,000$ to 20,000 recorders; $\$ 2-4$ million $)$

program will permit: generating baseline statistical

information such as severity distribution of all collisions;

the calibration of vehicle deformation estimates as a severity measure; and calibration of computer simulated crash reconstruction (SMAC). A program as large as large as 100,000 disk recorders -- $\$ 10$ million -- would overdo it from the standpoint of research and be inadequate from the standpoint of mass data gathering.

Development of a cheap and proliferable causal severity measurement device at an estimated development cost of $\$ 500,000$ and a production cost of approximately $\$ 2$ per unit will provide a device capable of widespread installation that permits ready read out of crash severity magnitude and direction by an untrained investigator. The need for careful deformation measurement and transformation of these measurements to equivalent barrier speed would be eliminated.

providing a federally sponsored field trial of uncertain and/or expensive safety aids. This program will permit the evaluation of safety aids, where normal market forces do not operate, prior to their being mandated on a national scale. (In the case of passive restraints, the one time cost would be $\$ 30-\$ 60$ million. )

This study was accomplished by an extensive literature survey; by independent analysis by members of the ESP staff; by analysis of specific assigned topics undertaken by knowledgeable members of the automobile accident research community; and through an Automobile Collision Data Workshop, convened January 16 and 17, 1975, at which the requirements for, and various approaches to, better collision data gathering were presented and discussed in depth by experts in all aspects of the problem. Individuals who participated in the Workshop were the following: 


\begin{tabular}{|c|c|}
\hline Lynn Bradford & $\begin{array}{l}\text { National Highway Traffic Safety } \\
\text { Administration }\end{array}$ \\
\hline Paul Browinski & AVCO Systems Division \\
\hline B. J. Campbell & $\begin{array}{l}\text { Highway Safety Research Center } \\
\text { University of North Carolina }\end{array}$ \\
\hline Charles Conlon, Jr. & AVCO Systems Division \\
\hline J. Robert Cromack & Southwest Research Institute \\
\hline John Edwards & Ford Motor Company \\
\hline M. D. Eldridge & $\begin{array}{l}\text { National Highway Traffic Safety } \\
\text { Administration }\end{array}$ \\
\hline Vincent J. Esposito & $\begin{array}{l}\text { National Highway Traffic Safety } \\
\text { Administration }\end{array}$ \\
\hline William Fitzgerald & AVCO Systems Division \\
\hline John Garrett & Calspan Corporation \\
\hline Howard P. Gates, Jr. & Economics \& Science Planning, Inc. \\
\hline Lawrence A. Goldmuntz & Economics \& Science Planning, Inc. \\
\hline Walton Graham & Economics \& Science Planning, Inc. \\
\hline James Hofferberth & $\begin{array}{l}\text { National Highway Traffic Safety } \\
\text { Administration }\end{array}$ \\
\hline John F. Hubbard, Jr. & Center for Auto Safety \\
\hline Paul R. Josephson & Center for Auto Safety \\
\hline Charles Kahane & $\begin{array}{l}\text { National Highway Traffic Safety } \\
\text { Administration }\end{array}$ \\
\hline Edwin A. Kidd & Calspan Corporation \\
\hline Phil Klasky & Teledyne Geotech \\
\hline Gene G. Mannella & $\begin{array}{l}\text { National Highway Traffic Safety } \\
\text { Administration }\end{array}$ \\
\hline Don Mela & $\begin{array}{l}\text { National Highway Traffic Safety } \\
\text { Administration }\end{array}$ \\
\hline
\end{tabular}


Auto Collision Data

February 17, 1975

page 8

$\begin{array}{ll}\text { Charles A. Moffatt } & \begin{array}{l}\text { National Highway Traffic Safety } \\ \text { Administration }\end{array} \\ \text { David Morganstein } & \text { Center for Auto Safety } \\ \text { James O'Day } & \text { Highway Safety Research Institute } \\ \text { University of Michigan } & \text { Insurance Institute for Highway } \\ \text { Brian O'Neill } & \text { Safety } \\ \text { L. M. Patrick } & \text { Wayne State University } \\ \text { Steven J. Peirce } & \begin{array}{l}\text { National Highway Traffic Safety } \\ \text { Administration }\end{array} \\ \text { Louis W. Roberts } & \text { Transportation Systems Center, } \\ & \text { Department of Transportation } \\ \text { A. J. Slechter } & \text { Ford Motor Company } \\ \text { John Versace } & \text { Ford Motor Company } \\ \text { Richard Wilson } & \text { General Motors Safety Research and } \\ & \text { Development Laboratory }\end{array}$

We wish to acknowledge our gratitude to these individuals not only for their participation in the Workshop, but for their continuing assistance during the study effort and preparation of this report. 
Auto Collislon Data

February 17, 1975

Page 9

2. THE NEED FOR MORE AND BETTER CRASH DATA

The following paragraphs will discuss the general objectives of crash data collection, identify some specific data needs that are not now satisfied, and point out serious inadequacies in the current data file and acquisition systems. It will be shown that these needs and limitations lead to a requirement for mass acquisition of crash data, supplemented by special surveys and large scale real-life experiments.

a. THE OBJECTIVES OF COLLISiON DATA COLLECTION

The cost to society of automobile death and injury is conservatively estimated ${ }^{2 /}$ at $\$ 17$ billion annually. The vehicle damage adds at least another $\$ 5$ billion yearly-3/ The total, $\$ 22$ billion per year, corresponds to an average of $\$ 2200$ in losses per each U.S. automobile during its lifetime.

The specialists in auto safety have, as their concerted objective, the reduction of this enormous waste. A body of collision data is needed that will provide a substantial part of the means to determine the causes of accidents, of injuries, and of damage.

Professor Lawrence Patrick of Wayne State University expressed the consensus view of the Workshop participants as follows:

"PREMISE

1. The only valid way to establish safety needs for automobiles is through examination of field data.

2. The only valid way to evaluate the effectiveness of safety measures is through analysis of their effect on accident data.

CONCLUSION

Accident data are essential." 
The National Highway Traffic Safety Administration is responsible, under the National Traffic and Motor Vehicle safety Act of 1966, * for the promulgation of Federal Motor Vehicle Safety Standards to which vehicles manufactured for sale or use in the United States must conform. Under the Motor Vehicle Information and Cost Savings Act (1972)** the Secretary of Transportation is also responsible for setting standards for damage-limiting bumpers and for evaluating automobile damageability and crash-worthiness.

Safety standards put into effect to date cost the consumer about \$2.5 billion annually ${ }^{4 /}$ and standards proposed will cost another $\$ 4$ billion or more each year $2 /, 4-/$. In addition, standards suggested in Advance Notice of Proposed Rulemaking would cost $\$ 4$ billion per year in first costs plus another $\$ 4$ billion in added fuel costs when fully implemented. While the more than 40 existing standards, which were based on intuition, judgment and limited experience, are believed to yield in the aggregate a societal benefit greater than their consumer cost, 2 / only four of them (seat belts, energy absorbing steering column, HPR glass and head restraints) have been shown by any authority to be beneficial based on convincing statistical evidence. The problem is that the body of data is inadequate.

Thus an initial objective of crash data collection and analysis from the standpoint of the Government rulemaker, is that of evaluating the efficacies of the existing standards to determine which should be kept on the books and which should be eliminated.

\section{Public Law 89-563.}


A second objective from the standpoint of rulemaking is that of providing the necessary statistical support to estimates of benefits of a projected safety or damage-limiting standard. In the next section there will be discussed a projected rule that is controversial because of inadequate supporting data.

A third objective is the early identification of problem areas in automobile damage and injury so as to permit designing effective motor vehicle and highway safety programs.

The foregoing objectives from the standpoint of rulemaking have their parallel from the standpoint of the automobile manufacturers. C. Thomas Terry of General Motors has summarized $8 /$ the objectives of gathering accident data in the field:
a. Evaluation of production safety systems.
b. Prediction of performance of proposed safety systems.
c. Identification of problem areas and evaluation of proposed solutions on a cost/benefit basis.
d. Estimation of human tolerance to impact.

Automobile manufacturers are, of course, vitally concerned with the relative merits of specific alternative designs as well as with the validation of safety standards to which they are required by law to conform.

A number of universities and institutes, both profit and nonprofit, have been for years involved in research in accident causation, injury causation and designs of vehicles and roads that will reduce accidents and injuries. They need accident data to discover causes of accidents and injuries; armed with this information they can accomplish and test in their laboratories design modifications and provide valuable advice to NHTSA and automobile manufacturers. 
Auto Collision Data

February 17, 1975

Page 12

Finally, there is a need for national planners to predict the impact of new trends in automobile designs. Fuel and resource conservation programs, encouraged if not mandated by the Federal Government, will lead to lighter, lower power-to-weight ratio automobiles. Data on collision frequencies and outcome are needed as a function of these parameters to inform Federal officials.

b. UNSATISFIED NEEDS FOR CRASH DATA

The body of specialists concerned with automobile collisions -- the rulemakers, safety researchers, accident statisticians, car designers, insurers, and public interest people -- overwhelmingly agrees that there is a grave and compelling need for more and better crash data. The need is expressed by Dr. Edwin A. Kidd of CALSPAN Corporation 1 / in the following way:

"It is essential that NHTSA have a data bank for surveillance and effectiveness studies related to the impact of standards on accident, injury and fatality frequencies. The relatively small output of the special federal teams and/or the higher quantity, but low content State data banks are inadequate for the purpose. In addition to information on the general accident environment, vehicle damage and occupant injuries, details of the impact environment -- velocity at impact, change in velocity during impact and possibly, vehicle deceleration -- are required for a sample of 100,000 to 500,000 automobiles annually." 
Auto Collision Data

February 17, 1975

Page 13

Professor B. J. Campbell, Highway Research Center, University of North Carolinâl, states:

"In acquiring automobile accident data several

approaches are used in the U.S. : First, are intensively investigated accident crashes of which several thousand have been collected. The advantage of this approach is that the cases are extremely detailed with photographs and good injury data. The most important disadvantage is that by virtue of the changing sampling criteria and the small sample size, the ability to generalize these few cases to the population is restricted heavily.

I believe too much reliance has been made on this type of data for guiding NHTSA decisions. It leads one to situations in which too much is made of a small number of cases."

The critical need for better collision data to support rulemaking can be illustrated by the passive protection provisions of Motor Vehicle Safety Standard 208. Estimates of the cost to consumers of meeting passive protection requirements range from $2 /, \sim / \$ 220$ to $\$ 400$ per car, or a gross cost of $\$ 1.5$ billion to $\$ 3$ billion per year more than belt restraints now cost. There is also significant uncertainty in the incremental benefits that may be realized from passive protection. Estimates range from 3,000 to 8,900 more deaths prevented, and from 130,000 to 492,000 more injuries prevented. 
One crucial lack of data leading to uncertainty can be pinpointed: the number of lives saved and injuries prevented by a restraint system in frontal collisions is estimated by NHTSA from a graph showing the percentage of injuries and deaths as a function of "equivalent barrier test speed."* This graph is shown in Exhibit A (Figure 4). The "equivalent barrier test speed" is that speed which would produce as much car damage, when the car is driven into a rigid barrier, as the car suffered in an actual collision.

The fatality curve of Figure 4 is based on judgment estimates of barrier equivalent speed of 51 fatal frontal collisions by General Motors and a small (unstated) number by Ford Motor Company; in Figure 3 of Exhibit A the NHTSA curve is replotted for comparison with the companies' judgment data.

In making an estimate of the fraction of lives saved by a restraint system, NHTSA attributes to the system a barrier equivalent speed below which it is effective and above which it is not effective (a conceptual convenience). On the basis of laboratory crashes with dummy and cadaver occupants, lap belts are taken as effective to $25 \mathrm{mph}$, lap-shoulder harnesses to $30 \mathrm{mph}$, and air-bag passive restraints to $35 \mathrm{mph} .6 /$ The intersections of these speed lines with the fatality curve of Exhibit A, Figure 4, then yield NHTSA's estimate of fraction of lives saved in frontal collisions. For example, the intrinsic effectiveness of the lap-shoulder harness in preventing fatalities in frontal collisions is thus deduced $6 /$ to be 37\%, and for all collisions (of which frontals constitute 50\%), is estimated at 31\%. Yet extensive field experience in sweden shows lap-shoulder harnesses have an overall fatality prevention effectiveness of 90\%. The lap belt alone is estimated by NHTSA to have intrinsic fatality prevention effectiveness of $20 \%$ in frontal collisions, with 22\% for all collisions. Yet extensive field experience from North Carolina indicates an overall fatality prevention effectiveness with lap belts of $75 \%$.

* Technically, these curves are cumulative distribution functions for barrier equivalent speed for fatal collisions and injury collisions. 


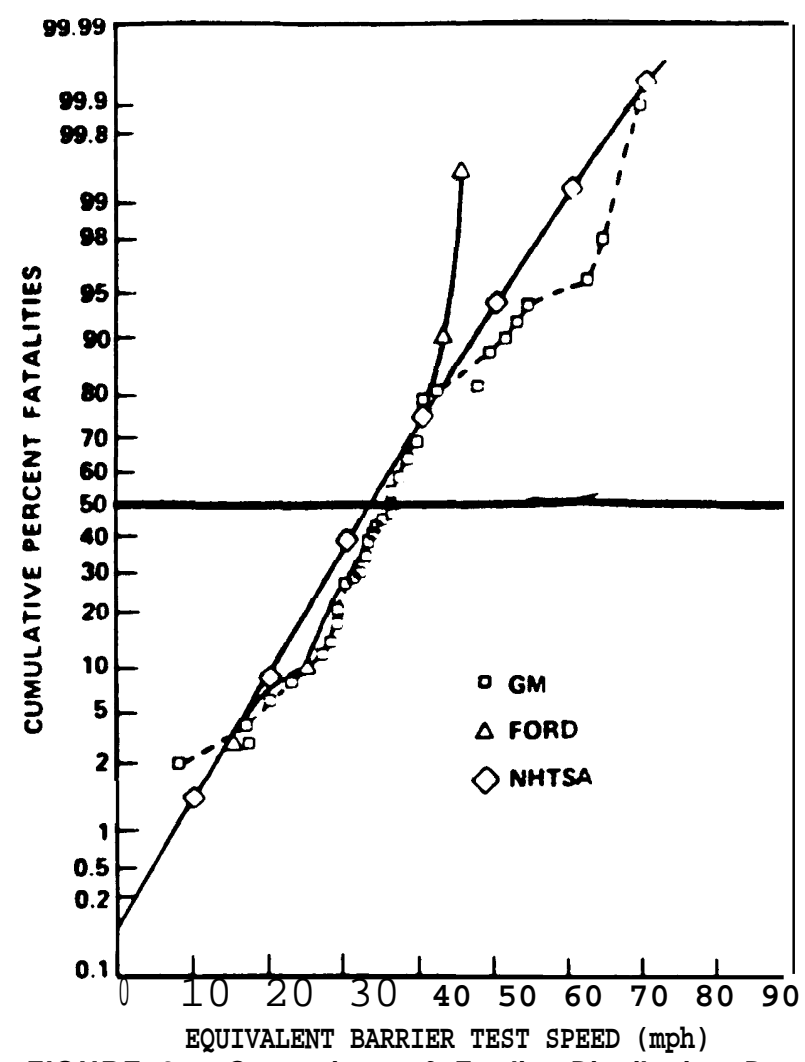

FIGURE 3 - Comparison of Fatality Distribution Data (Frontal Collisions)

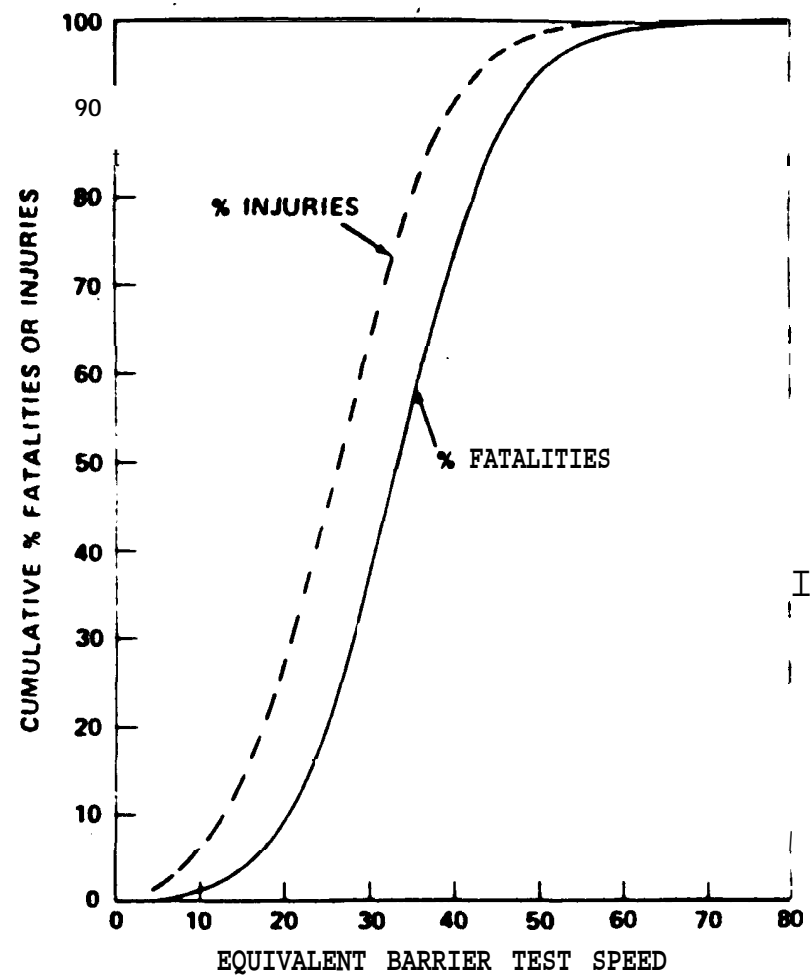

FIGURE 4- Cumulative \% Fatalities Injuries within Equivalent Test Speed Range

EXHIBIT A 
These discrepancies can be explained in three principal ways, any of which may be correct: 1) The Swedish and North Carolina experience is not representative of the population of U.s. car collisions; 2) The barrier equivalent speeds up to which restraint systems are effective are underestimated by NHTSA; or 3) The barrier equivalent speeds at which fatalities occur were overestimated in the original material of Ford and General Motors.

All of these questions can be resolved by more and better data.

The uncertainty about these curves as a basis for rulemaking is confirmed by National Highway Traffic Safety Administrator James Gregory in Congressional testimony: . . we have gone out on an advanced notice of proposed rulemaking at the same time that we went out with the passive restraint notice to say that we are moving in the direction of a standard for occupant crash protection at the level of 45 to 50 miles per hour. We figure when we get there we will have pretty much attained what is cost effective and technologically feasible in today's world.

"We feel, by the way, that this would still be worthwhile doing. Yet, as we move toward that, without quantitative data, without persuasive data, even in the public interest, without being able to substantiate a standard we feel is reasonable and in the public interest, the challenge would be sufficient to provide that type of occupant protection. . .

"...The reason I have to be rather vague about this is that most curves that have been derived by experts and from data that have been collected get very fuzzy when you get much above 40 miles an hour as far as what percentage of the fatalities occur at these particular speeds.*

Excerpts from Dr. Gregory's testimony before the Transportation Subcommittee of the Committee on Appropriates, House of Representatives, 93rd Congress 2nd Session 1974, Part 3, pp. 41 - 43 [emphasis ours]. 
Auto Collision Data

February 17, 1975

Page 17

...To establish crashworthiness, we need to know what to do to an automobile and what we need to do to the occupants from the standpoint of restraint protection under a given crash condition. These precise data we now lack.

"At the present time we cannot make a judgment with accuracy and that makes us guess. And those guesses could cost, unnecessarily as far as the consumer is concerned, untold millions of dollars for protection that we may actually not need. . . "**

The doubts the Administrator expresses about the curves at speeds of $40 \mathrm{mph}$ and above, we believe, as indicated earlier, also should apply to speeds lower than $40 \mathrm{mph}$.

The kinds of information needed to mitigate much of the uncertainty about the prospective incremental benefits of passive restraints are, first, a file of representative collision data from which it is possible to derive the incidence figures for injury and fatality of belted occupants, in order to establish as a baseline the capabilities for the current belt restraints; second, results of a large-scale field experiment to establish the relative capabilities of passive restraints; and third, representative files of fatal and injury collisions (involving unrestrained and restrained occupants) for which causal severity magnitudes such as BEV have been quantitatively established. With this information the lifesaving and injury prevention potential of restraint systems and the speeds to which the systems are effective can be established.

Excerpts from Dr. Gregory's testimony before the senate Committee on Appropriations (Hearings on FY 1974 supplemental appropriations, HR 11576) 93rd Congress, first session, part 2, pp. 1509-1510. [emphasis ours] 
Auto Collision Data

February 17, 1975

page 18

Fundamental to the statistics of accidents are the

cum ulative probability distribution functions of severity

for all accidents, for injury accidents, and for fatal

accidents. These, though badly needed, are not now being

obtained from large quantities of real-life accident data.

In order to establish them, measurement and reporting of causal severity is required.

c. LIMITATIONS OF THE CURRENT DATA SYSTEM

In a later section we address the question of collision

data requirements. The basic needs can be summarized as follows:

(1) The data should be representative of the population of u. s. automobile crashes.

(2) The data should be gathered in sufficient quantity to be useful, at a sufficient rate to be timely.

(3) The data should be in adequate detail and precision to permit its analysis to determine causes of accidents, injury and death (and the functional relationships between these causal factors and the probabilities of accidents, injury and death) ; and to permit answering questions that may arise relative to traffic safety and motor vehicle safety standard efficacy.

The inability of the current files to meet each of these needs is expressed by several investigators.

o'Day of the Highway Safety Research Institute, says: 9 /

"A random sample is the best way of insuring represennativeness. Unfortunately, no random sample of United States crashes exists." 
Auto Collision Data

February 17, 1975

Page 19

Kidd 15/ comments:

"For too long, those concerned with accident studies of the effects of safety standards already in force have had to make do with either too small samples of reasonably good data or relatively large samples of data whose content is inadequate for the purpose. In the first category is the data bank (and "bank" is too grandiose a term) that has resulted from the individual federal teams of multidisciplinary, professional investigators. These teams can serve useful purposes in special studies, in discovery of problems that would otherwise go undetected and, particularly, in the area of accident causation. By their very nature, they cannot provide a sufficiently large data sample relevant to the implementation of standards aimed at injury and fatality reduction without excessive expenditure of funds."

MDAI -- Multidisciplinary Accident Investigation'14/ -- is conducted by about 20 teams scattered throughout the country and sponsored by the National Highway Traffic Safety Administration and the Motor Vehicle Manufacturers Association. These teams have been performing clinical in-depth studies (both on-scene and off-scene) of selected accidents in the United States, primarily on new cars, since 1969. The accidents selected for data collection have been strongly influenced by the specific interests of the individual teams. Although the information gathered is accurate and detailed, only about 6,000 cases have been investigated and 2,500 of these have entered the computerized file in the five years since the program started. The MDAI favors accidents in which there was injury or severe damage or in which there were large disparities between the degree of damage and the degree of injury; as a consequence, there is significant bias in the file. B. J. Campbell states, 10 / "I believe too much reliance has been made on this type of data for guiding NHTSA decision. It leads one to 
Auto Collision Data

February 17, 1975

Page 20

situations in which too much is made of a small number of cases." According to Marie Eldridge of NHTSA, "As a system for producing statistical information needed for supporting our safety standards, the on-scene in-depth investigations cannot be regarded as cost effective. The average cost per case is about $\$ 2,000$. The cost decreases to about $\$ 800$ per in-depth case if the on-scene investigation requirement is eliminated. " Moreover, as indicated by O'Day, "The present collection of MDAI cases is a sample of an undefined and relatively undefinable population, thus limiting severely the capability to draw inferences to the national accident picture."

A program that has long been established but only recently has become operational is "FARS" -- the Fatal Accident Reporting System.16/ This system involves NHTSA collection of state data on all fatal accidents, with recording into a uniform format that will permit central storage, retrieval, sorting and analysis. Police data plus later medical reports are included. Reports are made on each occupant, each vehicle and each accident, so that about 200,000 reports are expected to enter the file yearly. Since the file will cover all and only fatal accidents, it will be representative, but only of fatal accidents. Without supplementary information from a sample.of all accidents whose intrinsic severity distribution is the same as that for the fatals, inferences cannot be drawn as to, for example, whether sobriety or use of belt restraints affects the incidence of fatalities in crashes.

A much more representative collision data sample, structured to meet limited objectives, is being collected by NHTSA. 14/ From five selected regions of the country "Level II" data is being obtained on new cars in tow-away involvements for the purpose of evaluating active and passive restraint systems. Information is assembled from the police report, a doctor's report, photographs, a brief vehicle investigation, and driver interviews. Data is collected on all 
occupants, whether injured or not, but information gathered is limited to that needed for the statistical analysis of restraint system effectiveness. The design of the sampling process was accomplished centrally, by NHTSA, so that the process will be free of the biasing influence of the investigators (a serious problem in MDAI investigations). The cost is about $\$ 100$ per crash. The sampling plan has been designed in such a way that NHTSA expects to be able to make national estimates based on poststratification.

NHTSA has under development a system for sampling pedestrian and bicyclist accidents in several hundred localities. This is a "bilevel" investigation effort in which there is a supplementary investigation carried out by police (with the added costs borne by NHTSA or others) to establish the nature and location of the accidents and factors affecting visibility. It will answer questions at the level of detail needed to determine gross behavior and countermeasures.

The States, of course, collect accident reports in great number. The reporting thresholds vary from state to state. Within a State, sampling may not be representative or uniform. For example, a city with a high crime rate may devote little effort to investigating and reporting traffic accidents, while even the slightest crash may be reported in smaller towns. Efforts by the NHTSA to use collision data files directly from the states have proved unsuccessful primarily because of the nonuniformity of reports and the consequent inability to properly combine, analyze and process the information. A second problem related to the sheer volume of records that was derived from the states. 
Auto Collision Data

February 17, 1975

Page 22

On review of the information required on HS Form 214 used in the Fatal Accident Reporting system (FARS) we observe that certain information critically required by both rulemakers and injury researchers is not supplied by the reporters. Specifically, provision of vehicle crush measurements that could be converted to Equivalent Barrier Impact Speed (EBS) using the method of $\mathrm{K}$. L. Campbel1이 would make possible construction of the cumulative distribution function of EBS in fatality accidents, a function needed by the rulemakers in analysis and prediction of the effectiveness of restraint systems. Provision of information on the vehicle interior points of impact, occupant's height and weight and more detail on the precise nature of injuries suffered by injured and killed occupants would provide vital injury cause information.

It is clear from the foregoing that there is no existing national crash data collection program that is designed to meet national needs. As indicated earlier, NHTSA has contracted with the Highway Safety Research Institute of the University of Michigan to design a national accident data sampling system based on a probability sample. NHTSA hopes that through control of the selection of accidents that a sample can be acquired whose characteristics can be generalized to the national crash population.

d. MASS ACCIDENT DATA ACQUISITION

In summary, to meet data needs and to overcome the limitations of the current national data files and collection systems, a mass accident data acquisition system is needed. In addition, measurement and reporting of accident causal severity is important to the classification and analysis of accidents and 
Auto Collision Data "

February 17, 1975

Page 23

often can be important to drawing credible inferences as to the projected benefits of proposed safety standards. The following chapter will discuss the problems of design of the data acquisition system and of measurement of causal severity in more detail.

The need for more and better data does not mean the current data collection programs should be abandoned. However, each of these programs should be reviewed as to its specific objectives and upgraded as necessary to meet them. For example, MDAI team investigations should conform to a sampling plan rather than being entered into to satisfy the personal interests of the investigators. An effort should be made to get causal severity information and information on injury mechanisms into FARS reports.

An extremely important characteristic of the Fatal Accident Reporting system that might be overlooked as "just a detail" is that it provides uniformity in the reporting from all states, using computerized forms. This uniformity makes it possible to combine, sort and analyze data. Extension of this uniformity to general accident reporting systems used by states would enormously simplify the central collection and analysis of mass accident data, and should be encouraged through a system of incentives.

Even with a very good mass accident data acquisition system in being and operating, it will not be possible to answer certain questions that were unanticipated at the time the system was designed. Supplementary data acquisition systems will be needed to answer such questions; the restraint system 
Auto Collision Data

February 17, 1975

Page 24

collection system and the pedestrian cyclist system now operating are examples of systems designed and needed to answer specific questions at this time.

Mass accident data acquisition may not, by itself, answer questions with regard to the benefit of a projected safety standard. When the costs of such a standard are large, or the benefits uncertain, it may be necessary to undertake a large scale experimental program to provide the needed answers. 
Auto Collision Data

February 17, 1975

Page 25

Section 3, following, is necessarily quite technical. However, much of the discussion is summarized in the introduction to Section 4. Readers more interested in the various alternatives for remedying deficiencies in the existing data may wish to proceed directly to Section 4. 
Auto Collision Data

February 17, 1975

page 26

\section{CHARACTERISTICS OF AN ADEQUATE DATA COLLECTION PROGRAM}

In Section 2 the general needs of an adequate accident data collection program have been identified and the inadequacies of the present system have been presented. In this section, three characteristics of a satisfactory data collection program are discussed: the quantities and rate of data acquisition, the importance of an unbiased sampling plan and the measurement of causal crush severity.

\section{a. QUANTITIES AND RATES OF DATA COLLECTION}

It is reasonable to require the data collection system to provide timely evaluation of the effects of automobile design changes, whether voluntary or made in compliance with official safety standards. This suggests that the national data collection system should be designed to gather vital information within a single year.

As Kidd points out,$\underline{15} / \sim_{\text {Definition }}$ of the total number of accident cases required annually for an adequate national data bank can be made if (1) the questions to be asked of the system can be identified both for the present and future; (2) the accuracy with which the particular data elements can be measured is known or can be appropriately examined; and (3) the statistical analysis techniques to be employed can be agreed upon."

But rate depends also on the speed with which results must be realized. Rapid feedback from the field is essential to the evaluation of the effectiveness of changes, so as either to reinforce the decision made by the designer or rulemaker or to dissuade him from an erroneous decision. 
In the case of general accident statistics, the population of crashes does not represent the statistically stable ideal (stationary time series) because of continually changing mixes of car sizes and weights, changing rules under which cars are operated (for example, the Federal $55 \mathrm{mph}$ speed limit), changes in the quality and extent of highways, variation from season to season and year to year in total miles driven, and modifications to vehicle designs, both voluntary and in compliance with safety standards.

The allowable lag in production of statistics, based on the foregoing considerations, appears to be about one year. This, in turn, suggests that a sufficient body of data should be gathered within one year to detect differences in injury incidence as a result of actions on the part of the government or the carmakers.

In the following paragraphs we will estimate what this may mean in terms of the number of reports required per year and, if causal severity were to be obtained through the use of crash recorders, the number of crash recorder installations that would be needed. Some less important data might be acquired over longer periods, lessening the amount of data required annually.

We have previously indicated that one objective of collision data gathering is the construction of cumulative distribution functions for severity for all accidents, all injury accidents, and all fatal accidents. The first of these is needed to provide reference or baseline statistical information from which other important statistics may be derived; the second and third are needed to validate the rationale used in rulemaking. A statistical technique* permits prediction of the number of

* The Kolmogoroff-Smirnov test; see, for example, "Nonparametric Statistical Inference." J.D. Gibbons, McGraw Hill 1971. 
Auto Collision Data

February 17, 1975

page 28

observations in a random sample that would be required to construct these distribution functions with a confidence of xpercent that the function derived from the sample will be within $Y$ percent of the true distribution. Table 1 tabulates the number of samples required for several levels of confidence and accuracy.

$\underline{\text { Table } 1}$

Number of Observations Required To Construct Cumulative Distribution Functions

\begin{tabular}{|c|c|c|c|}
\hline \multirow{2}{*}{$\begin{array}{c}\text { Deviation } \\
\text { From } \\
\text { "Truth" } \\
\end{array}$} & \multicolumn{3}{|c|}{ Confidence Level } \\
\hline & $80 \%$ & $90 \%$ & $95 \%$ \\
\hline $1 \%$ & 11,449 & 14,884 & 18,496 \\
\hline $2 \%$ & 2,862 & 3,721 & 4,624 \\
\hline $3 \frac{0}{0}$ & 1,272 & 1,653 & 2,055 \\
\hline $4 \%$ & 716 & 913 & 1,156 \\
\hline $5 \%$ & 458 & 595 & 740 \\
\hline $8 \%$ & 179 & 233 & 289 \\
\hline $10 \%$ & 115 & 150 & 185 \\
\hline
\end{tabular}

The table indicates the number of reports that would be required to construct distribution functions of severity if severity could be measured for each year. 
The tabulated numbers represent also the number of reports needed in a segregated category to construct a severity distribution function for that category. Taking a typically acceptable statistical level of 95\% confidence, 5\% accuracy, 740 fatality reports would be required to construct a severity distribution function for fatalities; 740 injury reports would be required to construct severity distribution function for injury cases. Suppose it were desired to examine the distribution function for car weights in injury cases, independent of all other factors; again, 740 reports would be required in which weight was stated.

The need for a large number of annual reports arises when a particular set of events to be examined has low probability of occurrence in the sample. Suppose, for example, one wishes to determine the distribution of car weight in rollover injury accidents for two categories of occupants: belted and unbelted, 740 reports in each of the two categories would be required. Injury accidents constitute 33\% of reportable accidents, and the probability that an injury accident was a rollover $3 /$ is about $8 \%$. Perhaps 25\% of those injured wore belts. Thus $0.67 \%$ of reportable accidents were rollover-injury-belted, and to find a sample of 740, an aggregate of 111,000 reports in the 'reportable accident" category would be required. (This same set of reports would provide more than enough unbelted-rollover-injury events.) If only injury accidents were reported, a sample of 37,000 reports would suffice. If the same analysis were to be done for fatal rollover accidents drawn from a mass accident file, the file would have to number 3,500,000 to find 740 fatal-rollover-belted events. The reason for the much larger data file in this case is that there are far fewer fatalities than injuries.

$$
0.25 \times 0.08 \times 0.333=0.0067 \text {. }
$$


Analysis of infrequent events requires many input reports. But the fact that events are infrequent does not make them unimportant. The best example of this is traffic fatalities, which, though infrequent, cost society almost as much as automobile injuries and damage combined.

Suppose that a new restraint system modification were implemented, and one wished to confirm, to a confidence level of 95\%, that it reduced the incidence of occupant fatalities in the population of all accidents by $10 \%$ over the old restraint system.* Assuming the old system had a (perfectly known) fatality rate (when used) of $0.06 \%$. We are seeking to verify that the new restraint system gives a fatality rate of $0.054 \%$ or less. The use rate on the new restraint system is expected to be 50\%. An upper bound on the number of accident reports required to determine the fatality incidence to the desired accuracy is found to be 768,000 . If this were to be accomplished in the first year of the new installation, reports would be needed on about $30 \%$ of all accident involvements of new U.S. automobiles. Clearly, reports on fatal accidents alone would not be useful, as fatality incidence could not be determined.

The foregoing calculation makes use of an expression for the number of samples $\mathrm{n}$ required to determine with accuracy $\sigma$ a proportion $\mathrm{p}$ in the population from which the sample is drawn, namely:

$$
\mathrm{n}=\frac{\mathrm{p}(1-\mathrm{p})}{\sigma}
$$

Clearly, if the same question were restricted to side impact accidents a sample of 768,000 side impact accidents would be needed, but since side impacts constitute $1 / 6$ of all accidents and were drawn from a sample of all accidents, that sample would have to number 4.6 million.

A practical example of the kind of question NHTSA and safety researchers seek answers to. 
Auto Collision Data

February 17, 1975

Page 31

One can now see, from the examples given, the extent to which numbers of reports required depend on the questions asked. Efficient sampling to minimize the number of samples requires a basic set of questions to provide baseline statistics with supplementary surveys to obtain the answers to specific questions.

Based on the previous examples of questions that might be asked of an accident file, we believe that 500,000 to 1,000,000 cases per year, collected in accordance with a carefully designed sampling plan, is needed by NHTSA and others.

We determine now the number of crash recorders that would be needed to determine accident severity distributions if recorders were the chosen technique to measure accident severity. The number of recorders required depends on the probability occurrence of the type of collision. About $7.5 \%$ of all cars are involved in reportable accidents, $2.5 \%$ in injury accidents, and $0.04 \%$ in occupant-death accidents each year.

Table 2 indicates the number of recorders required to get the needed data each year to construct severity distribution function curves to 5\% accuracy (5\% corresponds to approximately $2 \mathrm{mph}$ in estimate of barrier equivalent impact speed). The figures in the column headings are the probabilities that a recorder equipped car will be involved in an accident of the type indicated; 100\% recovery of recorder data is assumed. $30 \%$ of involvements are considered to be of "reportable" severity: that is, that the damage to the vehicle is of sufficient extent, or that there is an injury, either of which would require reporting the accident to police. 
$\underline{\text { Table } 2}$

Number of Recorders Required to Secure in One Year Data Needed to Construct Severity Distribution Functions to $5 \%$ Accuracy

\begin{tabular}{|c|c|c|c|}
\hline $\begin{array}{c}\text { Confidence } \\
\text { Level }\end{array}$ & $\begin{array}{l}\text { Accidents Above } \\
\text { a "Reportable" } \\
\text { Severity Level } \\
\mathrm{P}=0.075\end{array}$ & $\begin{array}{l}\text { Injury } \\
\text { Accidents of } \\
\text { All Types } \\
\mathrm{P}=0.025\end{array}$ & $\begin{array}{l}\text { Fatal-to-Occupant } \\
\text { Accidents of All } \\
\text { Types } \\
\mathrm{P}=0.0004\end{array}$ \\
\hline $80 \%$ & 6107 & 18,320 & $1,145,000$ \\
\hline $90 \%$ & 7933 & 23,800 & $1,487,500$ \\
\hline $95 \%$ & 9867 & 29,600 & $1,850,000$ \\
\hline
\end{tabular}

If it were further required to construct these distribution functions for smaller classes of accidents (frontal, side, rear, rollover) the number of recorders required, for $90 \%$ confidence and an accuracy of 5\%, would be as shown in Table 3 . (Based on accident type probabilities given in references 3 and 6.)

\section{Table 3}

Number of Recorders Required to Secure in One Year Data Needed to Construct Severity Distribution Functions With 90\% Confidence of 5\% Accuracy

\begin{tabular}{|l|c|c|c|}
\hline & $\begin{array}{c}\text { Accidents Above } \\
\text { a } \begin{array}{c}\text { "Reportable" } \\
\text { Severity Level }\end{array}\end{array}$ & $\begin{array}{c}\text { Injury } \\
\text { Accidents }\end{array}$ & $\begin{array}{c}\text { Fatal } \\
\text { Accidents }\end{array}$ \\
\cline { 1 - 2 } Frontal & 16,190 & 64,324 & $2,917,000$ \\
Side & 46,665 & 58,048 & $5,313,000$ \\
Rear & 27,355 & 170,000 & $29,750,000$ \\
Rollover & 198,000 & 297,500 & $9,297,000$ \\
\hline
\end{tabular}


Auto Collision Data

February 17, 1975

Page 33

As the cell size becomes smaller -- that is, as the data is subdivided into more and more classes of interest -- the number of reports needed in each cell for the construction of the particular distribution function of severity remains the same; but the number of recorders required to assure that required number of reports in each cell increases rapidly. Clearly, either a very large number of recorders would need to be installed in the U.S. automobile fleet, perhaps one in each car, or alternate methods of obtaining a measure of severity, such as measuring structural deformation of the automobile, should be used.

If a very cheap (say, \$2) crash recorder does not become available, then it is clear that crash recorders become impractical because of costs as a means of measuring severity for mass accident data files, which are needed to evaluate events of low probability yet events of great importance.

b. THE NEED FOR DEFINITION, MEASUREMENT AND REPORTING OF CAUSAL CRASH SEVERITY

Throughout earlier sections of this report, reference has been made to accident severity. It is important to note that what is meant is intrinsic or causal severity, as opposed to the severity of the outcome of crash, such as the degree of injury or damage. As indicated earlier, selection of a sample based on outcome inherently biases the sample and masks the effects of design changes. What is needed, instead, is a bank of data that will permit determining, for a given causal severity or range of causal severities, the outcome as a function of other factors -car weight, occupant age, passenger compartment design, etc. 
For example, in establishing bumper standards, it would be useful to know, first, the probability distribution for causal crash severity and second, the relationship between costs to repair car damage and the severity of the collision in the absence of damage limiting bumpers. From this information could then be predicted the gross benefits of new bumpers that prevented damage in accidents up to a specified severity level.

In determining the efficacy of an existing motor vehicle safety standard for occupant protection, it is important to be able to establish how the probability of injury (or degree of injury) is affected by meeting the standard. This implies a need to develop a file of crash reports whose inclusion is based on causal severity level (as opposed to outcome), so that the incidence of injuries can be compared for cars that meet the standard and those that do not. Stratification of the data by causal severity levels would make it possible to draw inferences about benefit of the standard as a function of severity. Without the severity measure, the levels of exposure of uninjured occupants cannot be determined, and the basis for finding and comparing injury incidence is lacking.

It has been pointed out in an earlier section that there are doubts about the validity of the NHTSA curves of the cumulative distribution functions of barrier equivalent impact speed (BEV or EBS) for injury accidents and fatality accidents. Validating these curves from real-life accident data would require measurement and reporting of the causal severity of fatal and injury accidents .

The measurement and reporting of causal severity in crashes provides a relatively unbiased method of screening crashes for investigation and introduction into a file. Once the severity distribution function for all crashes is established with sufficient 
accuracy, reports can be identified by severity level, and only the number of reports needed in each stratum can be selected for admission to the file. Knowledge of the severity distribution functions both for the population and for the file permits analysis of the constrained file and extending inferences to the universe of crashes. At the same time, the size of the file can be reduced by preventing the entry of 'the voluminous reports of low severity crashes whose frequency is high.

B. J. Campbel1의 feels that acrucial need in the field of crash injury is the means to forge a meaningful link between laboratory test crash data and events as they occur in the field:

\begin{abstract}
"In the staged crashes in the laboratory, telemetric procedures are used for recording data and one can justify in considerable detail the physical system in which the crash occurs -- the ' $g$ '-forces, the rate of onset, delta ' $\mathrm{V}$ ' etc. But when one is forced to use nonhuman subjects then one is left in the situation of knowing a great deal about the physics of the crash but knowing little of the actual injuries that might have occured in such a crash. On the other hand, in real world automobile crashes one can learn about the actual outcomes in terms of survival and injuries, but the input variables mentioned before are unknown.
\end{abstract}

"The need to link these two systems is apparent. Engineers who design protective systems need to know about stopping distances, forces, decelerations, etc. But knowing these things is of too little help unless one has a way to relate them to real world injuries."

Clearly, a measure of real-world crash severity would help provide such a link. 
Auto Collision Data

February 17, 1975

Page 36

The question remains as to what constitutes a proper causal severity measure, or "Vehicle Crash Severity Index (VCSI) "19,22 This question is independent, of course, of what parameters are being or can be measured, such as vehicle deformation, acceleration time history, speed at impact, etc.

The severity measure that has been used in tests, some crash reports from the field, and in motor vehicle safety standards is Barrier Equivalent Impact Velocity (BEV or EBS). It is of interest to examine whether this is a reasonable measure of causal severity, both as regards occupant injury and vehicle damage.

What injures unrestrained and loosely restrained occupants is the so-called "second collision" of the occupant with the interior of the automobile, such as the windshield, dashboard, B-pillar, etc., or with the restraining belts or air bag. The speed with which an occupant impacts an interior element has fair correlation with the injuries he suffers. The speed of impact is determined by the average car acceleration component in the direction from the object to the occupant and the distance between the two:

$$
V=\prime \quad 2 \overline{\mathrm{ad}}
$$

The commonly used head injury criterion is:

$$
\text { H I C }=\left[\frac{\Delta V}{\Delta t}\right]^{2.5} \frac{\Delta t}{g^{2.5}}
$$


Auto Collision Data

February 17, 1975

Page 37

Where $\Delta t$ is the time duration and $\Delta V$ is the head speed change during the hardest bump. If the final head speed is zero and there is only one bump, this becomes

$$
\mathrm{H} \text { I } C=V^{2.5} /(\Delta t)^{1.5} g^{2.5}
$$

or, in terms of car average acceleration during the crash, is:

$$
\text { H I C }=2.38 \mathrm{a}^{1.25} \mathrm{~d}^{1.25} /(\Delta \mathrm{t})^{1.5} \mathrm{~g}^{2.5}
$$

Thus, we observe that the criterion for head injury severity increases with car acceleration during the crash interval, but at a slightly greater rate.

If the occupant is tightly restrained, he is subjected to the same acceleration as the occupant compartment of the automobile. The forces he experiences are in proportion to this acceleration and the weight of his own body. It has been determined by investigators 3 / that human tolerance limits can be best expressed in terms of the acceleration to which a person is subjected during the crash interval. It is important to note that rapid variations of acceleration with time are not felt by the unrestrained occupant in crashes in which his motion has a forward component relative to the car, as he is in "free flight" until he impacts the interior. The fully restrained occupant feels these changes (called "jerk") but there is no evidence to indicate that they inflict more than minor punishment; the damage to the restrained occupant appears to result from the average level of acceleration he is subjected to during the crash.

Thus we observe that the two most important measures of injury tolerance can be related directly to vehicle acceleration during the crash. The next question is whether and how barrier impact velocity is related to this acceleration. 
Auto Collision Data

February 17, 1975

Page 38

Running a car into a barrier causes deformation of the car ("crush"). It has been found in the laboratory that there is a linear relationship observed between impact speed and residual crush. The average acceleration during the crash- $3 /$ is:

$$
a=-\frac{V_{0} k}{2}
$$

where $V_{0}$ is the barrier impact speed and $k$ is a measure of the "stiffness" of the car. Thus we observe that the car acceleration is directly proportional to the barrier impact speed, but also $t$. the stiffness, which is higher in small cars than it is in full size vehicles.

We conclude, therefore, that barrier impact speed is a reasonable indicator of injury-related causal severity provided that car stiffness is taken into account.

K. L. Campbeli이 has evolved a sophisticated approach to relating vehicle damage to collision severity. In this approach the dynamic force-deflection characteristics are used to estimate the energy absorbed in plastic deformation of the vehicle. A linear force-deflection characteristic is the simplest (but not necessarily the most accurate) model leading to the observed linear relationship between impact speed and crush distance, and is used by campbell. The energy can then be expressed as an equivalent barrier speed (EBS or BEV). The approach has been partly validated for frontal impacts in angle and offset barrier tests: The BEV estimates based on vehicle damage differed from the true impact speeds in the angle barrier case, over impact speeds ranging from 18 to $31 \mathrm{mph}$, by an average of $-0.35 \mathrm{mph}$, with a standard deviation of $2.85 \mathrm{mph}$; and in the offset barrier case, over a narrow range of impact speeds around $30 \mathrm{mph}$, by an average of $-0.01 \mathrm{mph}$, with a standard deviation of $1.64 \mathrm{mph}$. The input 
information items required to make the estimate were the crush coefficients as determined from pure frontal barrier tests for each of the various automobiles, together with the actual detailed crush measurements in the test impacts. K. L. Campbell believes that the technique can be extended to side and rear impacts; such $a_{n}$ extension would, of course, require determination of side and rear crush coefficients. The crush coefficients, as defined by K. L. Campbell, are the slope and intercept of the curve of impact speed as a function of crush distance. The slope is identical to the reciprocal of the "stiffness" constant we used in the previous paragraphs.

A. B. Volvo employed a series of eleven full-scale frontal barrier, car-to-car and car-to-pole impact tests ${ }^{2} /$ to obtain data on crush characteristics of the Volvo model 140 automobile. This information was used in conjunction with detailed measurements of deformation incurred in real-life impacts to estimate barrier equivalent speeds for 128 collisions.

In uncomplicated collisions, we believe that similarity between real-life collision-caused vehicle deformation and that produced in a laboratory staged crash having the same point and direction of impact, implies correspondence between the forces and rates of application. Thus measurements of vehicle deformation can be analyzed, compared with the outcome of staged crashes, and used to estimate barrier equivalent impact speed. However, it is not possible to say that equivalence of deformation always implies equivalent dynamic forces.

Average acceleration during the crash interval appears to be a reasonable measure of causal crash severity. There are several methods by which it can be measured: 
(1) By a crash recorder that records acceleration time history (later to be time-averaged over the crash interval to get a severity measure) absent a cheap crash recoder, that directly averages accelerations over the crash interval. The limitation of this approach relates to the large number of recorders required for mass accident files designed to illuminate rare events and the substantial expense associated therefore with this technique. For special measurements such as severity distribution functions, the number of recorders required becomes much smaller, and then this technique of severity measurement becomes appropriate.

(2) By measurement of vehicle deformation (the vehicle is its own crash recorder) and conversion to barrier equivalent speed or average acceleration. The limitation of this approach relates to the limited availability of calibrated deformation information derived from laboratory crashes. Another limitation for mass accident files is the limited ability of police, at the scene of an accident, to judge deformation either using the calibrated crash deformation information, or some other technique, in a consistent reliable manner.

(3) By computer reconstruction of the collision ${ }^{5} /$ (SMAC) in an iterative simulation process that is driven to match the reconstructed accident to real-life observations of skid marks, vehicle positions, etc. Momentum changes, in conjunction with known vehicle stiffness characteristics, can be used to estimate crash accelerations. The limitation of this technique is that it requires trained investigators who can estimate the initial conditions of the crash so as to initiate the computer simulation. If the simulation does not converge to the actual disposition of vehicles after the crash, the estimated initial conditions must be revised. 
It must be recognized that the crash severity index is a vector, and has magnitude and direction. Two linear accelerometers are necessary to measure its components in the horizontal plane. A third (vertical) component is measured with experimental crash recorders, but does not appear to be very useful.

A problem arises in using vehicle deformation to measure damage-related crash severity; obviously, the cause and the outcome are related. If the outcome is defined as physical deformation, the relationship is one to one. If the outcome is defined as cost to repair, the cause and the outcome are not identical. There is also a flaw in the use of acceleration during the crash interval as a measure of causal severity: if vehicle exteriors were softened, so that average collision accelerations were lowered, average severity would decrease even if the average impact speeds remained the same. So the injury mitigating effects of vehicle softening would be obscured in the collected data. Similarly, where vehicle crush is used to determine severity, if vehicles are designed using resilient materials that do not permanently deform, the average severity would decline despite unchanged average impact speed.

Thus we believe it is important that the National Highway Traffic Safety Administration undertake the job of defining causal crash severity in the most useful and realistic way.

There are several measures of severity currently in use that are quite crude and inaccurate and should be supplanted by better methods. 
Auto Collision Data

February 17, 1975

page 42

The deformation extent, a quantity somewhat related to severity, is often reported in Level II (greater depth than the police report) and Level III (in-depth) investigations. The deformation extent is one element of the collision deformation classification (CDC) code assigned in accordance with the Society of Automotive Engineers recommended practice SAE J224a. However, SAE recommended practice J224a warns "The extent number should not be used as a tool for determining severity or energy required to duplicate the damage. For vehicles of the same basic type, it does serve as a tool for gathering together vehicles which have similar damage characteristics. "

Some reports give the full CDC (sometimes known as "VDI") code, * which describes the direction of force, general area of deformation, specific horizontal area, specific vertical area, type of damage distribution, and extent. The Fatal Accident Reporting system reports only impact points and an abbreviated damage extent number.

Pollee reports often include estimates of traveling speed prior to impact, a very poor indication of severity because of the uncertainty of the effects of braking just prior to impact. Sometimes "impact speed" is estimated and reported; again this is a very dubious measure of severity because it is neither uniformly defined nor readily estimated. It may be, depending on the investigator, either speed relative to the ground at the instant of impact of speed relative to the struck or striking object. Ford Motor Company-, in an analysis of the differences between investigators' reports of impact speed and the speed

See, for example, reports on crash recorder equipped cars, reference 19. 
changes indicated by crash recorders, found differences as great as $40 \mathrm{mph}$ and a standard deviation of $11.9 \mathrm{mph}$ in 20 collisions involving crash recorder equipped cars. The average was a speed overestimate of $14.7 \mathrm{mph}$ by the investigators.

MDAI teams and other in-depth investigators may report their judgment estimates of equivalent barrier speed (EBS) based on their background of understanding of the relationship between EBS and vehicle deformation in laboratory crashes.

To summarize,

(1) Average acceleration during the crash interval is a reasonable measure of the intensity component of a causal crash severity index, but has some deficiencies as such.

(2) NHTSA should, with the approval of the accident research and statistical community, settle on and begin to use an acceptable definition of crash severity index.

(3) If average acceleration during the crash interval is the appropriate measure, there are several ways of measuring or estimating it with reasonable accuracy.

(4) Several indices of severity currently in use are so erroneous, misleading, or ill-defined, as to be valueless, and should be either upgraded or discarded. 
c. THE CRITICAL IMPORTANCE OF AN UNBIASED, RELEVANT, AND ADEQUATE SAMPLING PLAN THAT IS APPROVED BY EXPERTS

In order to meet requirements for collision data collection, it is necessary to generate a plan for sampling and to implement it. The plan should call for collection of a representative sample of crash data in quantity sufficient to be useful at a rate sufficient that the data is timely, and in enough detail and with enough accuracy to permit answering outstanding essential questions.

Thus there are three separable issues:

(1) The methods of assuring that the sample is representative.

(2) The quantities and rates of data gathering.

(3) The information content, detail, and accuracy of reporting.

The problem of securing a representative sample is a difficult and subtle one. To quote Versace (Ford Motor Company) $16 /$ on the need for scientific sampling:

"Not only is an increased quantity of data required but the sampling of the accident universe must be by sophisticated protocol. The last of the three reasons given above implies the need for a disciplined approach to the data, to avoid ending up with data which are biased in the factors underlying them. That requires a scientific approach to data collection, not just pouring more dollars into it and 
Auto Collision Data

February 17, 1975

Page 45

cranking up the administrative machine to get a bigger program going but doing it in the same old way, Data gathering programs must be designed by the same people as will design the analyses that will be applied to the data. No less expertise than the Census Bureau applies, or the Gallup Poll, will suffice. Fortunately, NHTSA has been bringing in very competent people of late, people who know that a data collection scheme must be designed from the start with the method of analysis of the resulting data a key determiner of how the data should be gathered."

The importance of representativeness of the sample is hard to overstate. $8 /, 9$. The sample should be representative of the entire population of automobile collisions or have an accurately known relationship to that population. If the sample is selected in some way -- that is to say, if the sample is biased -inferences drawn from the sample may be faulty. For example, consider a sample in which only injury accidents are represented. If, say, wearing' belts reduces the risk of injury 50\%, belted occupants will be underrepresented by 50\% in the sample. Two incorrect inferences might be drawn by a naive observer:

1) occupants in accidents don't wear their belts; 2) most of the belted occupants in the sample were injured; obviously belts are not very effective.

Despite the importance of avoiding sample bias, much of the material in the existing national files is heavily biased and, until recently, little thought was given to rectifying this deficiency. NHTSA has contracted with the Highway safety Research Institute of the University of Michigan to evolve a national crash data sampling plan which, presumably, will be based on sound statistical principles. 
Auto Collision Data

February 17, 1975

Page 46

The questions to be asked of the data file determine the sampling plan: that is, the selection of regions to be sampled and, within those regions, the collisions on which information is to be collected; the quantity and rate of acquisition of case reports; and the information -- kind and reporting precision -required in each report.

Examples of such questions are:

(1) How effective have the requirements of MVSS 206 (which specifies crash load requirements on locks, latches, and hinge systems) been in preventing occupant ejections? In preventing occupant injury? Are there significant differences in capability between makes and models of automobiles?

(2) How effective are belt restraint systems (specified by MVSS 208) in preventing injury and death? How does the effectiveness vary with accident severity? Car weight? occupant age?

(3) At what collision severity level should the bumper system prevent damage to the automobile? Should the requirements be different for front and rear bumpers? For different car sizes and weights?

(4) How important is car visibility in preventing collisions? Are the requirements of MVSS 108 (for lighting) effective in satisfying the needs for nighttime visibility? 
(5) What are the factors in passenger compartment design that are of significance in contributing to or preventing occupant injury? To what extent do the characteristics of the occupant himself influence the injury picture? What are the interactions of these factors?

As an example, the last question suggests a number of items of information required for inclusion in reported crash data. According to Lawrence Patrick of Wayne State University-, "complete injury data must be included in the accident data. Sex, age, weight, height, and general physical condition are all important factors. . . The type and degree of injury of each occupant including the minor bruises and abrasions and going through the severe bone and soft tissue damage are required. It is important to have complete data on the restraint systems used and the interior components of the vehicle that caused the injury." Also needed, according to Professor Patrick, are impact velocity (as a measure of severity) and direction, location of the impact, seating positions of the occupants, vehicle rigidity, and vehicle interior design.

The design of the sampling plan is critical to the utility of the bank of data that will be acquired through the sampling process. If the reported information is inadequate, crucial questions that one wishes to ask of the file will be unanswerable. If the sample fails to represent the U.S. crash universe, or contains biases, the answers to questions may be quite wrong. And if the quantities of cases on which answers are based are inadequate, the confidence one can assign to the answers is low.

Thus we believe that the National Highway Traffic Safety Administration should proceed urgently with the development of a sampling plan (hopefully, the contract with HSRI will provide the necessary result; if not, it should be augmented). 
Auto Collision Data

February 17, 1975

Page 48

When completed, but before the plan is implemented, it should be submitted to, reviewed by and approved by a jury of nationally known experts representing the disciplines of accident and injury research, motor vehicle design, rulemaking, and statistical sampling and analysis. 
Auto Collision Data

February 17, 1975

Page 49

\section{ALTERNATIVES FOR AN ADEQUATE DATA ACQUISITION PROGRAM}

The elements of an adequate data acquisition program have been previously described as comprising a mass data acquisition system with acceptable crash severity capability, a precision crash dynamics measurement system and special investigatory procedures such as multidisciplinary accident investigating teams (MDAI) and fatal accident reports (FAR).

Section 3 has described the quantitative requirements for mass accident data collection. It has been indicated that approximately 500,000 to 1,000,000 accident reports per year are needed to obtain early warning of motor vehicle hazards and to obtain confirmation of the effectiveness of various safety programs in a timely way to a reasonable level of significance. The exact number of annual accident reports needed depends on the level of detail of the desired results, the frequency of the event being investigated, the desired accuracy and confidence level of the information being obtained and the time by which the information is desired.

For example, if one wishes to determine the fatality rate in rollovers of belted drivers in one year to an accuracy so that the standard deviation is 30\% of the mean, 130,000 accident reports would be needed. However, if one wished to determine the probability distribution function of car weight in cases where belted drivers are killed in rollovers to an accuracy of 5\% with a confidence of 95\%, 3,500,000 accident reports would be needed.

The kind of data needed for this mass acquisition system is generally agreed to be a causal severity index, vehicle identification number, road and visibility data, injury scale, restraint 
Auto Collision Data

February 17, 1975

Page 50

system and usage, driver and occupant descriptions and seating positions, with many other items required, perhaps on a special survey basis, to answer specific questions.

There are a number of ways to obtain a causal severity index. If cheap (\$2) two axis crash recorder can be developed --and there are some concepts worthy of exploration--their installation on production cars is justified. This possibility is more fully discussed later in this section.

In the absence of a cheap crash recorder, vehicle deformation should be used as a causal severity index. There are at least two major approaches, one following the lead of Professor B.J. Campbell at the University of North Carolina, and the other following the approach of Professor Lawrence Patrick at Wayne State University, the Biomechanics Research Center and practiced in a recent Volvo-Wayne state University study $\cdot^{24} /$

The State of North Carolina uses police reports of severity reported by the TAD system.* Police training has evidently been sufficiently good to obtain useful reports ${ }^{-} /$although the data base has been small and the severity reporting system quite simple. The disadvantage of this approach is summarized by Griffin: $1 /$

A police officer using the TAD system rates severity on a 1 to 7 scale by matching the damaged vehicle with a manual of photographs of typical accidents. 
"Rural accidents tend to be more severe than urban accidents, therefore, police level data for a given state must be generalized with caution, even within that state.

"It is not simple to generalize police level data from one state to other states. States differ with respect to traffic density, number of interstate highways, and weather conditions. All of these factors interact with accident types and configurations, and thereby affect the benefits to be derived from a safety device.

"Finally, police level data are not recorded in detail. Levels of vehicle damage and occupant injury are evaluated by an officer who may be trying simultaneously to summon medical aid, direct traffic, and determine whether or not a

law has been broken. Under these circumstances, the data yielded by these investigators is very good, but necessarily the collection of data should not be considered the officer's area of expertise or his major area of responsibility."

Professor Campbel1이 $f_{e e 1} s$ the cost of improved police reporting could be nominal and that it would be important to extend the North Carolina system, or some improvement of it, to a number of states that might together provide $600,000-1,000,000$ reports which would be less biased than those from rural North Carolina alone.

It is difficult to accurately determine the cost of this system, but \$3-10 per report is approximately correct, or a total of $\$ 10$ million for one million reports. However, there is some question of the adequacy of police data for many needs. 
professor Patrick's approach to the recent Volvo experiment니 might be utilized to improve the reporting of causal severity by police. Staged crashes of major U.S. models, front, side and rear into poles, barriers and cars at three speeds could be used to obtain calibrated deformation data. The one-time cost of such a program is estimated* to be $\$ 3-5$ million. There are a number of possible ways to use these data. Police could be trained to photograph** the damaged vehicle from a few aspects after having placed appropriate identification placards and scales on the damaged vehicle. The film could be subsequently processed at various centers

to derive the severity data by analysis of the photographs and by comparison with the calibrated deformation data. The total accident report including police and medical data, if any, could be assembled at the photographic analysis center.

Alternatively, it might be possible to train police equipped with appropriate templates to measure the collision deformation in conformance with a handbook based on the calibrated deformation data from the staged crashes. Appropriate supplies, compensation and incentive would have to be provided to local police. A cost of \$10-20 per accident report might be sustained by more detailed analysis of this reporting system. Therefore this type of mass accident data system might cost a total of \$25-30 million for the first year including non-recurring capital as well as operating costs.

Conversations with Professor Patrick.

$\mathrm{M}_{\mathrm{r}}$. John Garrett of Calspan reports some success in Western N. Y. comparing estimates of severity from police photographs with estimates of professional accident investigation teams. 
In Section 2 there was also described the need for some precision reference data. This need was stressed by almost every participant in the Workshóp. 10, 11, 13, 14l. In particular sume 10,000 sophisticated recorders with an accuracy of $1-2 \mathrm{mph}$, are needed to obtain in one year's time a representation of the probability distribution of severity of accidents (above the police reporting threshold) with severity (barrier impact speed), to an accuracy of 5\% and at a confidence level of 95\%. If this representation of the distribution of severity were limited to frontals only, the confidence level would be only 80\% with an accuracy of 5\%. Alternatively, 20,000 recorders could be used to obtain this distribution for frontal collisions to an accuracy of 5\% at a confidence level of 95\%. The cost of sophisticated crash recorders in these quantities is approximately $\$ 200$. Therefore the total cost of this basic program is between $\$ 2$ and $\$ 4$ million plus the cost of data retrieval and analysis.

The cost per accident report from the sophisticated crash recorder** would be approximately $\$ 2,000$ the first year, declining to $\$ 1,000$ over the first two years, $\$ 500$ over the first four years, $\$ 200$ over the first ten years. This is the normal characteristic of the flow of benefits over a period of time from an initial capital expense.

This corresponds to a 3.8 - 7.6\% change in the cumulative distribution of fatalities or an annual dollar cost equivalence of approximately $\$ 250-500$ million in estimating the effectiveness of occupant restraint systems.

* * Described later in this section. 
Auto Collision Data

February 17, 1975

Page 54

The SMAC system of computer-aided accident reconstruction could also be used to obtain precision reference data, and is competitive with the sophisticated crash recorder. It is our opinion that the SMAC system, while extremely clever and promising, has not completed its development cycle, and must be operated by full time professionals. These might be specially trained police. However, some means would have to be found to compensate state and city police for performing NHTSA work. If a SMAC van is to operate around the clock, a crew of eight per vehicle would be required. If as many as 100,000 accidents were to be investigated per year with 500 vans, a total crew of approximately 4000 men would be required at an annual cost of $\$ 60$ million. Thus, the manpower cost seems to limit the SMAC system to obtaining relatively small numbers of reports, say 10,000 per year or lower. The SMAC system like the sophisticated crash recorder, seems most useful for special data gathering programs requiring precision severity data. If 2500-5000 accidents are to be investigated per year, perhaps 15-20 vans would be required at a total manpower cost of $\$ 1.8-2.4$ million plus the cost of equipped vans and processing centers, or roughly $\$ 500 \mathrm{pe}_{\mathrm{r}}$ case.

These costs should be compared to the current costs of MDAI investigations at $\$ 2000$ per case on scene and $\$ 800$ per case off scene, FAR reports at $\$ 15$ per case, Level II reports at $\$ 100$ per report.

Some safety devices, particularly those with uncertain performance and high cost to the consumer, could be subjected to a field test prior to general introduction. Some Federal agencies, The Food and Drug Administration, for example, do require extensive tests of products before general use. These tests, if properly designed and monitored, could yield invaluabl data on the benefits from such devices. 
Auto Collision Data

February 17, 1975

Page 55

However, a safety feature like the 5mph bumper or passive restraints can probably not be sold on a trial basis depending on market forces alone. Therefore, Federal sponsorship would be necessary to design the field trial, pay the cost of installation and monitor the results. This process would be expensive but, when viewed against huge consumer costs, may be worthwhile.

Such a test has been suggested for passive restraint systems by the National Motor Vehicle Safety Advisory Council, a body advisory to the Secretary of Transportation, by a Resolution adopted by an 11 - 5 vote on November 19, 1974.*

It is the feeling of a number of both the academic and automotive participants in the Workshop, and the authors of this report, that a field trial of 100,000 - 200,000 passive restraint systems is necessary.

The size of the field trial of passive restraints arises from the following considerations. If one assumes that the passive restraint is effective in reducing fatalities by $50 \%$, then it would require three years of field trial of 200,000 equipped cars to determine the probability density of severity given a fatality to an accuracy of $10 \%$ with $80 \%$ confidence. On the other hand, if one wished to determine whether the fatality rate in all passive restraint equipped cars had decreased by 50\% to an accuracy of $20 \%$, 125,000 installations would be required to obtain an answer in one year. If on the other hand, one wished to determine the performance to the same accuracy in light cars as compared to heavy cars, one would have to wait two years, assuming the 125,000 car sample was split equally between heavy and light cars.

See Appendix L. 
Auto Collision Data

February 17, 1975

Page 56

For this field trial to be unbiased, these systems would have to be installed in small and large vehicles in representative parts of the country with a representative set of drivers. Since market forces cannot be depended upon to provide this, it is probably in order for the Federal mandator of the proposed regulation to support the trial. The cost of such a program could be $\$ 30-\$ 60$ million.

In summary, an extensive mass accident data system of one million reports annually may cost

(1) \$3-10 million annually using the North Carolina approach of upgrading police reporting, plus the cost of improvements in severity estimation;

(2) \$10-20 million annually using the Wayne State - Volvo approach to obtaining accident severity, pIus the costs of reporting factors other than severity, plus a one-time cost of $\$ 5$ million for calibrated vehicle crash data and other capital expenditures:

(3) \$10 million annually to obtain severity information alone if a cheap (\$2) crash recorder could be developed and installed on 50\% of all new production. One would have to add. to this cost the cost of collecting the records, analyzing the data and coalescing this information with other accident information in a mass data file. 
Auto Collision Data

Page 57

These several approaches are potentially mutually supportive rather than competitive. There is presently no such thing as a cheap recorder, so one cannot depend on it for severity data. Should one be developed, it would be extremely useful for mass accident data. A serious effort toward this objective should be undertaken. If the Wayne State - Volvo approach to obtaining accident severity could be developed to apply to the U. S. problem, then it might be used in conjunction with the North Carolina approach as a better method of estimating severity.

A needed tool for precision research on the crash dynamics of a few thousand accidents annually may be obtained by either SMAC simulation or precision crash recorders.

(1) \$2-4 million first cost for 10,000 to 20,000 sophisticated crash recorders plus the cost of the facilities and personnel needed to analyze and correlate the data produced as an annual expense.

(2) \$2-2.5 million annually for personnel on vans plus the vans themselves and analytical equipment.

It would seem possible to put emphasis on one or another of these programs. In doing this NHTSA should take into account the somewhat higher first costs of the crash recorder program as compared to the somewhat higher annual operating costs of the SMAC program. Obviously this cost analysis must be viewed against the differences in the kind of data obtained from the two approaches. The SMAC vans do get trained investigators to the scene. NHTSA can best evaluate if this capability is justified in view of the multidisciplinary accident investigating teams. Since MDAI teams report on 1500-2000 cases per year from a perspective that is broader than crash dynamics, it seems advisable to maintain this capability. 
The field trial of 100,000 - 200,000 passive restraint equipped cars in a representative sample would cost $30-60$ million dollars first cost plus annual analysis expense.

Thus in addition to the current accident program of approximately $\$ 5$ million covering such activities as MDAI, FAR, Level II reports, NHTSA and the Congress should consider adding a mass accident data system that might cost $\$ 5-20$ million annually, a precision crash dynamics system (probably sophisticated crash recorders) at a first cost of $\$ 2-4$ million, and finally a field evaluation of passive restraints costing $\$ 30$ 60 million. Table 4 summarizes the existing programs and the recommended alternatives for the additional data that we deem to be required.

The genesis of this OTA study was an issue concerning sophisticated crash recorders and their proper use in accident data retrieval.

Two types of crash recorders have been developed under NHTSA sponsorship.

one of these, commonly known as the "tape recorder," was developed by AVCO Systems Division, Wilmington, Massachusetts. It is designed to measure and record vehicle parameters before, during and after a crash. The time history of the following quantities is recorded prior to the crash: 


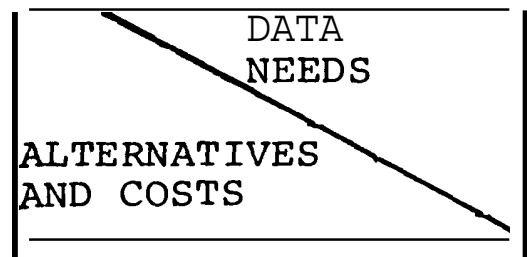

Yedical and Police Reports Using TAD

vedical and Police Reports Using VDI or CDC

redical and Police Reports Taking Photos to be zompared to Zalibrated Crashes

Medical and Police Report Using Cheap Irash Recorders if Available

Domputer Simulation (SMAC) $(1 b-20$ Vans)

\section{\begin{tabular}{l}
$\mathrm{MA}$ \\
$\mathrm{R}$ \\
\hline
\end{tabular}}

\$3- \$10 Per Report, North

Carolina Prototype

Upgraded Severity Capability as

Compared to system Above

$\$ 10-\$ 20$ Per Report Wayne State - Volvo Prototype, Probably the Best Severity been Demonstrated for this file

$\$ 10$ Per Report for Severity Plus \$3-\$10Per Report for all other information

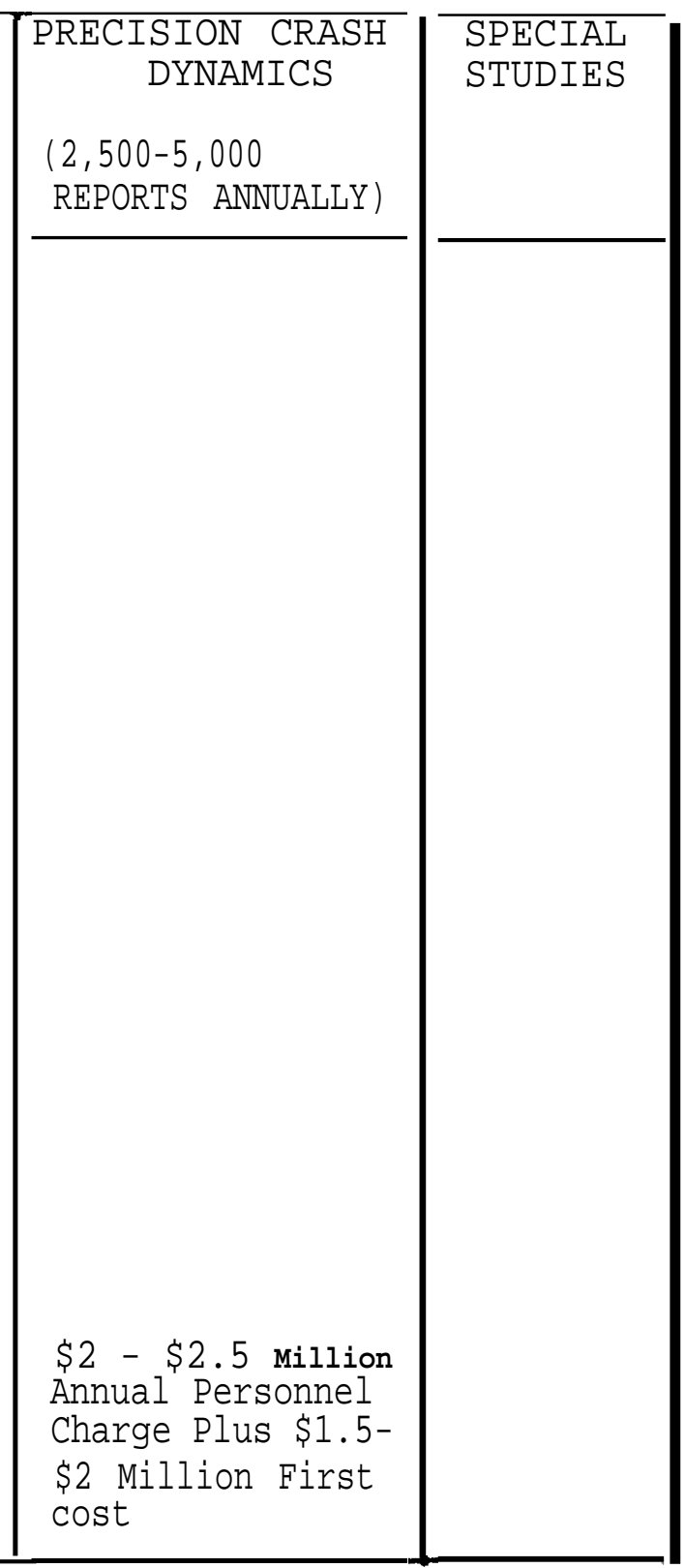


Auto Collision Data

February 17, 1975

page 60

Table 4 - continued

\begin{tabular}{|c|c|c|c|}
\hline $\begin{array}{l}\text { DATA } \\
\text { ALTEEDS } \\
\text { AND COSTS }\end{array}$ & $\begin{array}{l}\text { MASS } \\
\text { ACCIDENT } \\
\text { FILE }\end{array}$ & $\begin{array}{c}\text { PRECISION CRASH } \\
\text { DYNAMICS }\end{array}$ & SSPECIAL STUDIES \\
\hline $\begin{array}{l}\text { Sophisticated Crash } \\
\text { Reonrds } \\
: 10,000-20,000) \\
\text { - }\end{array}$ & & $\begin{array}{l}\text { \$2- \$4 Million First } \\
\text { costs Plus Annual } \\
\text { Analysis \& Maintenance } \\
\text { costs of } \$ 0.5-\$ 1 \\
\text { Million }\end{array}$ & \\
\hline $\begin{array}{l}\text { Multidisciplinary } \\
\text { ZAccident } \\
\text { Investigation } \\
\text { reams (MDAI) }\end{array}$ & & & $\begin{array}{l}1500 \text { Reports/year } \\
\text { At } \$ 2000 \text { Per } \\
\text { Report on Scene, } \\
\$ 800 \text { Per Report } \\
\text { Off Scene }\end{array}$ \\
\hline $\begin{array}{l}\text { Fatal Accident } \\
\text { Reporting System }\end{array}$ & & & $\begin{array}{l}55,000 \text { Death } \\
\text { Reports Per Year } \\
\text { Contemplated At } \\
\text { a Cost of } \$ 1 \\
\text { Million, Uncertain } \\
\text { Severity Indica- } \\
\text { tions }\end{array}$ \\
\hline $\begin{array}{l}\text { Level II } \\
\text { Restraint System } \\
\text { Investigation }\end{array}$ & & & $\begin{array}{l}\text { Analysis of } \\
\text { Restraint System } \\
\text { Effectiveness } \\
\text { From Police and } \\
\text { Medical Reports, } \\
\$ 100 \text { Per Case }\end{array}$ \\
\hline $\begin{array}{l}\text { Field Trial of } \\
\text { Uncertain and/or } \\
\text { Expensive Safety Aids }\end{array}$ & & & $\begin{array}{l}100,000-200,000 \\
\text { Car Field Trial } \\
\text { of Passive } \\
\text { Restraints } \$ 30- \\
\$ 60 \text { Million One } \\
\text { Time Cost }\end{array}$ \\
\hline
\end{tabular}


Auto Collision Data

February 17, 1975

page 61

Brake pressure (200-2000 psi, accuracy $\pm 7 \%$

Steering wheel motion $\left(1260^{\circ}\right.$, accuracy $\pm 3 \%$ )

Speed (as derived from the speedometer cable)

(o - $120 \mathrm{mph}$, speedometer accuracy)

Longitudinal and lateral vehicle acceleration

$\pm 1 \mathrm{~g}$, accuracy $\pm 5 \%$

During the crash is recorded the time history of:

Longitudinal acceleration $\left( \pm^{+} 50 \mathrm{~g}\right.$, accuracy $\pm 3 \%$

Lateral acceleration $( \pm 50 \mathrm{~g}$, accuracy $\pm 3 \%$ )

Vertical acceleration (in vehicle coordinates)

$( \pm 50 \mathrm{~g}$, accuracy \pm 3\%)

Prior to the crash, the recorded data are sampled at a 20 per second rate. During the crash, the recorded data are sampled at a 200 per second rate. The duration of the tape record is from 6 minutes prior to the crash to 10 seconds after the crash. A garden variety endless-loop 8-track cartridge is used as the storage element.

Recording is done in digital (PCM) format. The total system includes each of the several sensors, a crush sensor and a recorder, packaged separately.

The other recorder, commonly known as the "disk recorder," was developed by Teledyne Geotek, Garland, Texas. It is a single unit that records, only during the crash interval, the time history of lateral, longitudinal accelerations. The range of accelerations measured is $\pm 50 \mathrm{~g}$, with an accuracy of $\pm 8 \%$. 
The disk recorder is much simpler and less expensive than the tape recorder, and has been purchased and installed in experimental quantities by NHTSA. 1050 have been installed in fleets throughout the country, including air bag equipped cars.

The tape recorder is intended to provide data that could give useful information on the handling, braking, speed and forces experienced by the vehicle prior to the crash. Both recorders provide a crash-acceleration time history, which yields information on the forces to which the vehicle was subjected during the crash, and which, if properly interpreted, can give magnitude and direction of crash severity.

In Fiscal Year 1975 testimony, a total cost estimate of $\$ 10$ million for a crash recorder program was presented. This program would have procured 100,000 disk recorders as compared to the previous 85,000 disk recorders (at $\$ 75$ per unit) and 15,000 of the more expensive tape recorders for a total cost of $\$ 15$ million. The program costs include support for initial purchase and funds allocated for analysis of the data provided by the recorders.

The Transportation Systems Center of the Department of Transportation (Mr. Louis Roberts) has examined the feasibility of a somewhat cheaper, all solid state, more accurate alternative to the Teledyne Geotek disk recorder, and have concluded that such a unit could be built at a unit cost of $\$ 125$ in quantities of 100,000. With this recorder, three-axis accelerations would be measured to $1 \%$ 
C. Y. Warner and Joseph Free of Brigham Young University, and Brian Wilcox and Donald Friedman of Minicars, Inc.* have proposed as a severity measuring device a very simple two-axis integrating accelerometer whose outputs are change in velocity during the crash interval. The Breed Corporation is also developing two cheap crash recorders. One will provide information indicating that the crash resulted in a velocity change of more than $30 \mathrm{mph}$. This is accomplished by a latching system. The other system provides a direct reading of crash severity. A combination of Coulomb and viscous forces acting on a mass provide a system that is insensitive below a threshold, responds to the vehicle change in velocity during the crash, and latches after the crash indicating the change in velocity experienced.

We believe that development of a cheap and simple severity measuring and recording device is highly desirable. There appear to be many feasible design alternatives to the Warner device, and they should be examined. A recorder that is designed to measure average acceleration during the crash interval, as opposed to velocity change alone, should be considered. Lynn Bradford, NHTSA crash recorder program manager, concurs that only the two horizontal components of acceleration need be sensed, and that the third axis can be omitted. 
Auto Collision Data

February 17, 1975

Page 64

\section{FEDERAL RESPONSIBILITY AND EXPENDITURES FOR COLLISION DATA GATHERING}

The Federal Government through the Department of Transportation, has undertaken the responsibility for setting safety and damage-limiting standards for motor vehicles. The costs of standards put into effect thus far is more than $\$ 2.5$ billion annually. It would appear that prudent and responsible rulemaking would imply that each such standard should be promulgated only after acquiring through data collection and large scale experiment a thorough understanding of the frequency of occurrence of the hazards to which the standard was addressed, the extent to which a design to the standard would mitigate the outcome in terms of damage or injury, and the consequent benefits as related to the estimated costs. But because of the dearth of data, rulemaking has been based instead on guesswork and judgment. Fortunately, two standards (energy absorbing steering column and belt restraints) appear on the basis of limited evidence to be highly successful. Two others, HPR glass and head restraints, appear to be beneficial; but the others remain to be evaluated, and in the meantime, their costs continue to be borne by the public.

Motor vehicle collision loss is an enormous national problem that requires centrally coordinated solutions, both in terms of motor vehicle standards and highway designs. Implicit are both the need and the responsibility for centrally supported collection of collision data, representative of all the states, from which may be drawn inferences regarding the need for and benefit of vehicle and highway design changes. The establishing of a central collision data file further implies a need and responsibility for standardization of reporting systems and formats so that input data from 
many sources can be combined. The federal government should undertake these responsibilities as the central and coordinating activity for collection of crash data.

In addition to the question of responsibility, there is the question of capability. On this question, John Versace of Ford Motor Company ${ }^{16} /$ has the following comment.

\begin{abstract}
"Mass accident data acquisition, processing, analysis, and broad scale distribution requires great effort and much resource. Only the federal government has the necessary resource and easy access to the agencies which can supply information. Furthermore, it seems that it is the responsibility of the federal government to assemble data which will allow an accurate public review of the real dimensions of the crash and injury problem on our highways."
\end{abstract}

The current level of Federal expenditure for the collection and analysis of automobile collision data is \$5-6 million yearly. A few examples will be presented to illustrate that the justifiable levels of expenditure may be much higher than the current amounts.

1. Each traffic fatality is a catastrophe that costs society approximately $\$ 200,000.2 /$ current Federal expenditures or collision data gathering average less than $0.06 \%$ of the cost of traffic deaths.

2. 28 million automobile accidents cost the United States \$22 billion annually. Federal expenditures to collect data average less than 22 c per accident-involved automobile, and less than 0.03 of total losses (see Figure 1). 


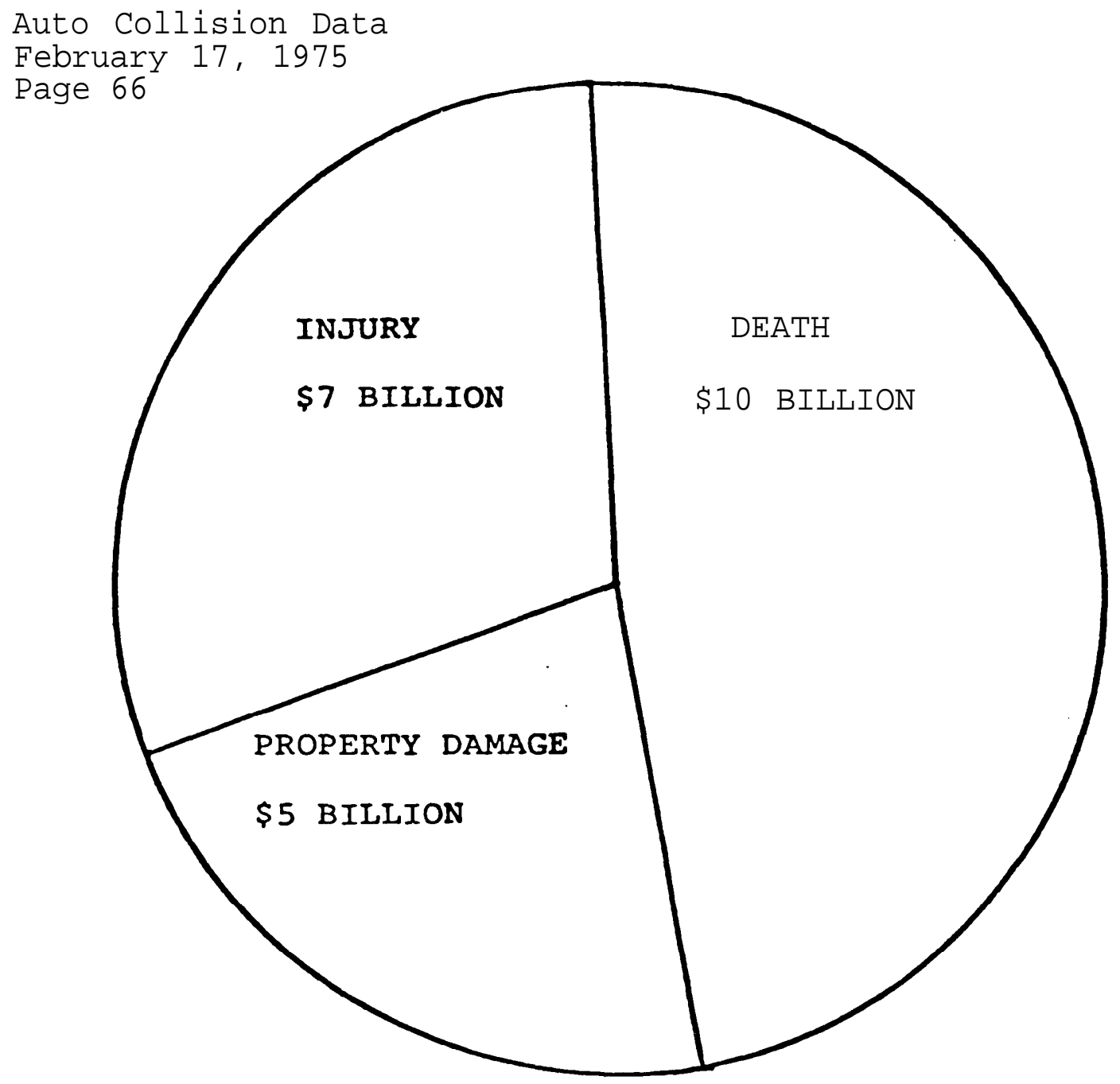

ANNUAL COST OF MOTOR VEHICLE ACCIDENTS

\$6 Milion

NHTSA EXPENDITURES ON CRASH DATA COLLECTION

FIGURE 1. Comparison of the cost of motor vehicle accidents with Federal expenditures to acquire and analyze crash data. 
Auto Collision Data

February 17, 1975

Page 67

3. The cost of $5 \mathrm{mph}$ no-damage bumpers front and rear has been estimated as $\$ 119$ per car (first cost) plus about $\$ 100$ in added lifetime fuel costs. The total consumer expenditure required to equip all cars is about $\$ 2.2$ billion per year. Because of the paucity of hard statistics or the frequency distribution and cost of low-severity accidents whose damage the bumpers tend to mitigate, there is an uncertainty of at least $10 \%$ or about $\$ 200$ million, in the estimate of the benefits; this uncertainty alone is more than 30 times the current Federal data collection expenditures.

4. Continuing uncertainties about the effectiveness of seat belts lead to differences in estimates of numbers of lives saved (at 50\% belt usage) of at least 8000 annually representing a societal gain or loss of $\$ 1.6$ billion. This uncertainty is more than 250 times the current Federal expenditures on data collection and analysis.

Thus high levels of expenditure appear justified by the magnitude of the motor vehicle collision loss program and its uncertainties. They are not necessarily required to do the job. The actual amounts needed must be determined after the development of a comprehensive plan that specifies in detail the information needed, the quantities of data and rates at which it is to be gathered, and how the plan is to be implemented.

The benefits of a data collection and analysis effort can be easily seen when it is used to resolve a choice between two approaches to solving a problem. The benefits are less obvious, just as in any research effort, when the outcome is unpredictable in terms of establishing the measures and costs of reducing damage, injury and death. 
Auto Collision Data

February 17, 1975

Page 68

\section{LEGAL ASPECTS OF CRASH RECORDERS}

Questions that are often brought up with regard to automobile crash recorders are (1) whether crash recorder evidence is adminsible in a court of law; (2) should it be admitted?; (3) can it be prevented from being admitted?

There is a useful parallel in the inflight recorders installed in commercial airplanes. In the event of a crash, the data in these recorders is read out and interpreted by the Federal Aviation Administration or National Transportation Safety Board staff personnel. Section 701 (e) of the Federal Aviation Act forbids the use of the NTSB report in any suit or action for damages arising out of an accident. The original policy considerations were that if such possibly legally damaging reports could be used in court, it would inhibit possible sources of information important to the cause of NTSB in promoting safety. But it is possible to get the FAA or NTSB staff member who read out the recorder to testify as to the facts and thus the "facts", data read or heard from the recorders can be received as evidence toward the proof or defense of an allegation of negligence. Neither the airlines nor the government has any privilege to exclude or restrict such evidence.

Similarly one could expect that automobile crash recorder data could be admitted in evidence in a court of law; but there would be the usual problem of qualifying the evidence. In the absence of a stipulation of the opposing party as to the authenticity of the data and the reliability and accuracy of the recorder, the moving party would successfully have to demonstrate to the court the reliability and accuracy of the recorder and the expertise of the person who read out the data. 
On the question of whether crash recorder data should be admitted, the main point again is whether the recorder is reliable, accurate, properly read out, and provides a record of the particular event in question. The data of itself is not dispositive of liability, but merely serves as certain evidence of the event. As indicated earlier in this report, there is good correlation between the crash severity a recorder might measure and the extent of crash deformation to the vehicle in which it is installed; and it would be difficult to refuse evidence on the crash severity magnitude as interpreted from vehicle deformation. Thus if the recorder provides good evidence of the event, it seems appropriate that that evidence should be admitted.

It may be possible to restrict through legislation the admissibility of crash recorder evidence, particularly if the recorders are government-owned and the records are retrieved and interpreted by government employees. Consider, however, the objective of a very simple and widely used integrating accelerometer that is conveniently and reasily read by any police accident investigator without special training. It would appear difficult to prevent testimony by a layman -- say a tow-truck operator or an auto mechanic -- as to what he saw immediately after the accident.

In summary, we believe that (1) the data from a crash recorder would be admissible, if it meets necessary qualifications, in a court of law; (2) the data should be admitted if it is good evidence; (3) it will be difficult to prevent admitting crash recorder data, even by Federal law, if the record can be easily read by an untrained person. 


\section{REFERENCES}

1. More Sophisticated Data Collection for an Improved Accident Data System, Edwin A. Kidd, Calspan Corporation, January 27, 1975; included as Appendix A of this report.

2. Review and Critique of National Highway Traffic Safety Administration's Revised Restraint System Cost Benefit Analysis, Economics and Science Planninq, January 22, i $9:$.

3. Cumulative Regulatory Effects on the Cost of Automotive Transportation (RECAT), Office of Science and Technology (White House), February 28, 1972.

4. Letter from Richard Wilson, General Motors Corporation February 4, 1975. Included as Appendix E to this report

5. Passive Protection at 50 Miles Per Hour, U. S. Department of Transportation, National Highway Traffic Safety Administration, June 1972 .

6. Analysis of Effects of Proposed Changes to Passengers Car Requirements of MVSS 208, Motor Vehicle Programs. National Highway Traffic Safety Administration, Department of Transportation, August 1974 .

7. Analysis of the Benefits Derived from Certain Presently Existing Motor Vehicle Safety Devices: A Review of the Literature, Lindsay I. Griffin III, University of North Carolina, December 1973.

8. National Accident Data Systems, C. Thomas Terry, General Motors Environmental Staff, Proceedings, Automotive Safety Seminar, June 20-21, 1973. 
9. Statistical Inference from Multidisciplinary Accident Investigation, James O'Day, Highway Safety Research Institute, University of Michigan, August 1974, (Department of Transportation Report--DOT-801 111) .

10. Statement by B. J. Campbell, Highway Safety Research Center, University of North Carolina, Automobile Collision Data Workshop, January 17, 1975. Included as Appendix C to this report.

11. S ummary of Remarks at the Automobile Collision Data Workshop, Lawrence Patrick, Wayne State University. January 20, 1975; included as Appendix D to this report.

12. Statistical Rationale for the Number of Automobile Crash Recorders Purposed for Procurement and Installation by NHTSA; National Highway Traffic Safety Administration (Received February 5, 1975) ; included as Appendix F to this report.

13. Crash Recorders and Alternate Methods of Defining Crash Severity, James O'Day, Highway Safety Research Institute, University of Michigan (received February 8, 1975) ; included as Appendix $G$ to this report.

14. Adequacy and Limitations of Current Data Systems, Marie D. Eldridge, National Highway Traffic Safety Administration, January 16, 1975; included as Appendix H to this report.

15. A Discussion of Data Gathering Systems, Edwin A. Kidd, Calspan Corporation, January 16-17, 1975; included as Appendix I to this report.

16. Mass Accident Data Acquisition and Why It's Needed, John Versace, Ford Motor CO., January 16, 1975; included as Appendix $J$ to this report.

17. Reports on Traffic Accident Research, Volvo, March 1973, A.B Volvo, Car Division, Gothenburg, Sweden.

18. Position Statement on an Expanded, Low-Cost National Accident Data Collection Program. J. R. Cromack, B. J. Campbell, L. Patrick and B. O"Neill, February 7, 1975; included as Appendix $K$ to this report. 
Auto Collision Data

February 17, 1975

Page 72

19. Automotive Recorder Research - A Summary of Accident Data and Test Results. S. S. Teel, S. J. Peirce and N. W. Lutkefedder, Proceedings of SAE 3rd International Conference on Occupant Protection, July 10-12, 1974.

20. Energy Basis for Collision Severity, Kenneth L. Campbell, General Motors Corp., Proceedings of SAE 3rd International Conference on Occupant Protection, July 10-12, 1974.

21. Ford Motor Co. submission to NHTSA Docket 74-15, Higher Speed Protection Requirements, September 19, 1974.

22. Automotive Recorder Research and Its Effects on Future Vehicle Safety, S. S. Teel and N. W. Lutkefedder, National Highway Traffic Safety Administration (undated) .

23. The Mechanics of Automobile Collisions, Felix Rosenthal et al, Naval Research Laboratory Memorandum Report 2417, May 1972 .

24. Comparison of Three point Harness Accident and Laboratory Data, L. Patrick, N. Bohlin and A. Anderson; Wayne State University, Aug. 20, 1974.

25. Resolution of the National Motor Vehicle Safety Advisory Council, November 14, 1974. 


\title{
OFFICE OF TECHNOLOGY ASSESSMENT
}

\author{
Automobile Collision Data \\ AN ASSESSMENT OF NEEDS AND METHODS of ACQU SITI ON
}

FEBRLARY 17, 1975

PREPARED AT THE REQUEST OF

THE HOUSE COMM TTEE ON APPROPRI ATI ONS

VOLUME II

PREPARED UNDER CONTRACT OTA C I

ECONOM CS \& SCI ENCE PLAN NG, INC.

120018 TH STREET N W

WASHINGTON, D. C. 20036 
$\underline{\text { APPENDICES }}$

$\underline{\text { Page }}$

$\underline{\text { APPENDIX A }}$

More sophisticated Data Collections for an Improved Accident Data System. Edwin A. Kidd, Calspan Corporation, January 27, 1975.

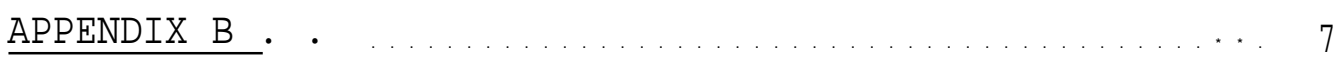

Letter from John Versace, Ford Motor Co., February 6, 1975.

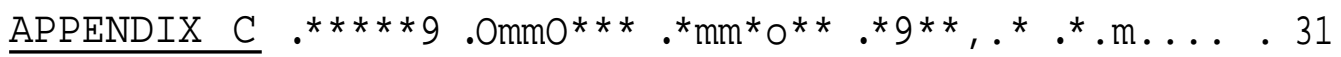

Statement at the Automobile Collision Data Workshop, B. J. Campbell, Highway Safety Research Center, University of North Carolina, January 17, 1975.

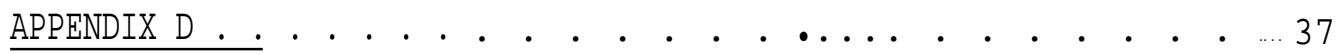

Summary of Remarks at the Automobile Collision Data Workshop, Lawrence Patrick, Wayne State University, January 16, 1975.

APPENDIX $E$

Letter from Richard Wilson, General Motors Corp., February 4, 1975.

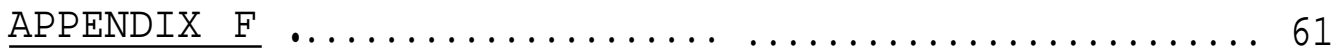

Statistical Rationale for the Number of Automobile Crash Recorders Proposed for procurement and Installation by NHTSA; National

Highway Traffic Safety Administration (received February 5, 1975).

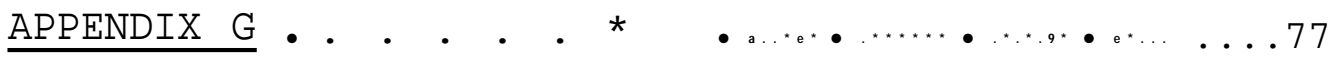

Crash Recorders and Alternate Methods of Defining Crash Severity, James O'Day, Highway Safety Research Institute, University of Michigan (received February 8, 1975). 
Page 2

$\underline{\text { Page }}$

APPENDIX $\mathrm{H} \quad \ldots \ldots \ldots \ldots \ldots \ldots \ldots \ldots \ldots \ldots \ldots$

Adequacy and Limitations of Current Data Systems, Marie D. Eldridge, National Highway Traffic Safety Administration, January 16, 1975.

$\underline{\text { APPENDIX I }}$

A Discussion of Data Gathering Systems, Edwin A. Kidd, Calspan Corporation, January 16-17, 1975.

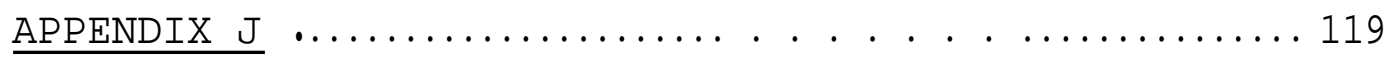

Mass Accident Data Acquisition and Why It's Needed. John Versace, Ford Motor Company, January 16, 1975.

$\underline{\text { APPENDIX } K}$

Position Statement on an Expanded, Low-Cost National Accident Data Collection Program, J. R. Cromack, B. J. Campbell, L. Patrick and B. O'Neill, February 7, 1975.

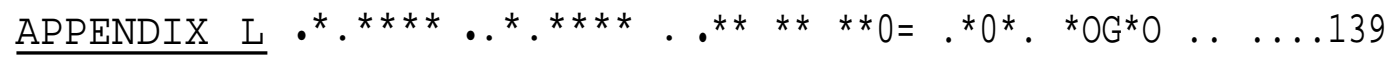

Resolution of The National Motor Vehicle Safety Advisory Council, November 14, 1974 .

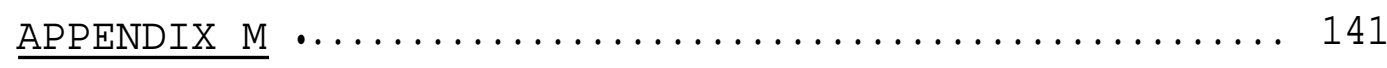

The Need for Standardization in Reporting Collision Damage and Injury in Traffic Accidents, J. Robert Cromack, January 16-17, 1975.

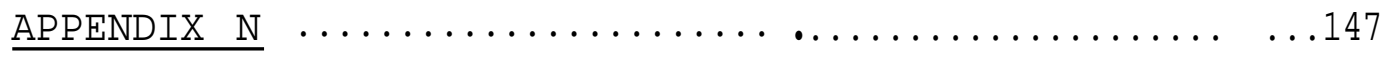

Regulatory Rulemaking Based on Less Than Total Information, David Morganstein, Center for Auto Safety, and L. A. Goldmuntz, Economics \& Science Planning, Inc., Received February 21, 1975.

$\underline{\text { APPENDIX } O}$

Automobile Collision Data Workshop: Agenda; Scheduled Presentations; Salient Residual Issues. January 16-17, 1975.

APPENDIX P

Letter from John Garrett, Calspan Corp., March 12, 1975, and Attachment. 
APPENDIX A

\begin{abstract}
MORE SOPHISTICATED DATA COLLECTIONS
$\mathrm{FOR}$

AN IMPROVED ACCIDENT DATA SYSTEM
\end{abstract}

Edwin A. Kidd

CALSPAN CORPORATION

January 27, 1975 


\section{MORE SOPHISTICATED DATA COLLECTION FOR AN \\ IMPROVED ACCIDENT DATA SYSTEM}

EDWIN A. KIDD

CALSPAN CORPORATION

January 27, 1975

\section{NEED}

It is essential that NHTSA have a national data bank for surveillance and effectiveness studies related to the impact of standards on accident, injury and fatality frequencies. The relatively small output of the special federal teams and/or the higher quantity, but low content state data banks are inadequate for the purpose. In addition to information on the general accident environment, vehicle damage and occupant injuries, details of the impact environmmt -- velocity at impact, change in velocity during impact and possibly, vehicle deceleration -- are required for a sample of 100,000 to 500,000 automobiles annually. 


\title{
CANDIDATE SYSTEMS
}

\author{
Candidate systems for achieving the required information are: \\ - Crash recorders, with accident, vehicle and \\ occupant information supplied by "conventional" \\ investigations by police and/or special teams.
- Off-scene computer reconstruction of accidents as reported by police and/or special teams.
- Computer aided investigation and reconstruction of accidents (e.g., SMAC) using appropriately equipped police and/or special teams.

\begin{abstract}
Use of crash recorders alone to provide data on the impact environment for the required number of accident cases would be prohibitive in cost. For example, if accidents of tow-away severity or higher are of principal interest, then 30-40 times as many automobiles must be equipped with crash recorders as the number of accidents needed annually for analysis*. Also, and most important, the crash recorder only provides a portion of the data required; conventional investigative methods must still supply accident and vehicle descriptions, vehicle deformation, occupant injuries, restraint system use, etc.
\end{abstract}

\footnotetext{
* Additional cost for each accident case would be 30-40 times the cost of each crash recorder installation.
} 
Off-scene computer reconstruction (SMAC) of the more extensively reported accidents now resulting from the special team studies has already been demonstrated. A modest amount of additional work on SMAC is required to increase the generality of the reconstruction of the various accident types. Also, application of this reconstruction aid to accidents as presently reported by police should be studied with the objective of determining the minimum information required for each accident.

The computer aided investigation and reconstruction of accidents by police offers the most promise for the attainment of the large data base required. If the use of appropriately equipped accident investigation vans is determined by individual police agencies to be beneficial for their present activities, in terms of overall efficiency, then the mechanism for providing all of the necessary accident data for NHTSA will be accomplished. Providing the police with equipment that will be cost/beneficial for their present needs will obviously provide the means for the attainment of the data required by NHTSA at the lowest cost. Also, the digital format of the accident descriptions and reconstructions that would be output from this equipment would result in minimal data processing for a fast response data bank.

\section{RECOMMENDED APPROACH}

The overall objective is the attainment of a consistent, coherent data bank that will be adequate both in size and specific content for the purpose and is practical in terms of development time and cost.

Whether police or special teams are used as the basic collection agency need not be decided immediately. What should be decided as soon as possible is the efficacy of the computer aids to reconstruction and 
investigation that have already been developed. The crash recorder may play a role in further validating these aids; it cannot be seriously considered as the ultimate data collection method because of prohibitive cost. A decision to continue with special teams should include the provision of demonstrated aids for these teams. If police want these aids and their efforts can be integrated into a national data system, then it appears axiomatic that a police based system would provide the most for the least cost.

A program is outlined below for achieving the improved accident data system:

1.) Install crash recorders in special automobiles, e.g., air bag equipped vehicles, for additional validation of computer reconstruction aids.

2.) Accident Reconstruction

a.) Continue validation of SMAC via staged crashes (including crash recorders) for a broad accident spectrum.

b.) Determine accuracy achievable on police reported accidents and establish minimum data requirements as function of accuracy achievable.

3.) On-Scene Reconstructions

a.) Accident vans for special investigative teams to improve data consistency and achieve more accurate reconstructions. 


\title{
b.) Field trials with police agencies to determine accident reporting and/or accident reconstruction configurations.
}

4.)

\author{
As the result of 1,2 , and 3 (above), establish \\ national data collection system elements.
}

\section{TIMING AND APPROXIMATE COST}

Aggressive pursuit of this plan would provide detailed requirements and set up of the overall system within two years. Meanwhile, the present multilevel data collection centers would continue to provide data, but with a transition toward the final system in the second year.

An acceptable, complete data system could be achieved at a cost of five to ten million dollars annually. Actual costs to NHTSA are dependent upon the usefulness and acceptability of the investigation and reconstruction aids to selected police agencies and their subsequent integration into the system. 
APPENDIX B

LETTER FROM JOHN VERSACE

FORD MOTOR COMPANY

February 6, 1975

$-7-$ 
Ford Motor Company

20000 Rotunda Drive Dearborn, Michigan 48121 : Mailing Address:

P.O. Box 2053

Dearborn, Michigan 48121

February 6, 1975

Mr. Howard P. Gates, Jr.

Economics \& Science Planning

1200 18th Street, N.W.

Washington, D.C. 20036

Subject: OTA Automobile Collision Data Workshop

Dear Howard:

It did take some time in a very busy schedule to meet

with you and to put our thoughts down, but we appreciate the opportunity to express our understanding of, and our position on the subject of accident data. In regard to societal costs: the Ford Motor Company submission to Docket 74-15 -- Advance Notice Concerning Higher Speed Protection Requirements -- contains some estimates of the additional consumption of resources entailed in trying to meet a high speed requirement.

It is difficult to determine all the ways in which inadequate accident data would lead to unnecessary expansion of costs, but we believe this one example will provide a general picture of the possible magnitude of such expense. I don't believe we conclude that raising the crash requirements is the wrong thing to do, but rather because the cost implications are so great nothing less than a commensurately significant analysis and determination of need -- which has not been done -- should precede any decision.

It is easy to lose sight of the fact that a good intention, or want, or objective gets converted, by means of a regulation, into very specific operational requirements and specifications which the manufacturer must meet, specifications which may have little to do in the last analysis with the intentions of the regulation. However, the regulation, in its specific detail, is often defended on the basis of its motivation rather than on what the particular requirements of the regulation are 
Mr. Howard P. Gates, Jr.

February 6, 1975

Page 2

likely to actually accomplish. Specifically, in this case, if it is deemed desirable to provide better protection for those people who are in high speed crashes, then it may or may not follow that running an automobile into an immovable wall at 45 or $50 \mathrm{mph}$, and then comparing readings gotten on accelerometer in dummies against some mandated criterion level somehow validly signifies accomplishment of the societal goal which motivated the standard. The likelihood of gross erosion of relevance is probably nowhere better seen than in the accident avoidance series of standards, where little or no validation has been attempted.

A contrary argument is likely to be heard: that the need is so great we cannot wait for all the evidence to be in, that utterly adequate evidence will never be forthcoming, and thus we must act now. But such an argument seems to beg the question: for how can we know we must act now -- especially with some particular countermeasure -- if that determination depends on having adequate data? A variant on this argument is that it can do no harm and might do some good. But, without data there is no assurance that particular countermeasures will do no harm, and certainly a cost without a compensating benefit is a net harm.

I am attaching a COPY of the Ford docket submission on the higher speed protection requirements proposal, but you will probably want to give special attention to the brief summary, "societal Cost Implications of Inadequate Accident Data," which puts forth the main points made there.

In addition, I am attaching an updated copy of the remarks which I made at the Workshop. They are essentially the same as the statement I read, but there have been some additional clarifications which I felt were appropriate in view of the discussions which took place at the meeting.

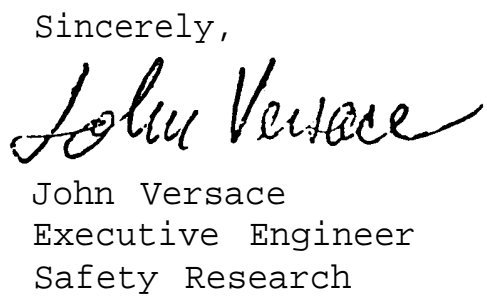

Attachments 
The demonstration of need for any safety standard must ultimately be established by accident data -- in all its forms -- if objective safety standard performance levels are to be achieved. If standard performance levels are established on a subjective basis, the possibility of very high societal cost with inadequate return for that cost is very real.

As an example of proposed performance levels which could have severe societal cost implications consider NHTSA's Advanced Notice of Proposed Rulemaking (ANPRM), Docket 74-15 Notice 1. This ANPRM proposes to increase frontal barrier crash requirements from $30 \mathrm{mph}$ to $45 / 50 \mathrm{mph}--$ an increase in crash energy management requirements of 125 to 177\% above that required today. The notice also proposes to implement the rule on september 30, 1980.

Ford Motor Company's response to this notice is attached. It presents the implications of implementing such a proposal in terms of increased car weight and car length. For example, to meet the frontal crash requirement alone, a 1974 Ford would be 500 pounds heavier and 16 inches longer; a 1974 Pinto would be 600 pounds heavier and 37 inches longer. Additional weight would be required to meet side and rear impact, roof crush, and fuel system crash requirements currently in being or presently proposed in other standards.

Weight increases of the magnitude discussed above imply completely redesigned cars -- not modifications to on-going designs. In addition to new metal structures, the added weight would require higher performance powertrain and running gear (brakes, suspensions> steering systems, etc.. . . . ) which in turn would tend to weigh more. Ford Motor Company markets 16 domestically manufactured car lines built from eight separate body shell platforms. To completely redesign these platforms would involve staggering engineering and investment costs. Annual increased car purchase costs to consumers -- assuming such a gigantic task could be done at all -- would be on the order of billions of dollars annually.

Such a major weight increase in cars would have a two-fold effect on the consumption of energy. The fuel economy of vehicles would deteriorate and secondly, additional energy would be used to manufacture the added weight. 
Fuel economy may be expected to decrease from the current average of 13.6 miles per gallon by about $10 \%$. This represents an increase in fuel usage of 25 million barrels each year. Should this weight increase be applied to the entire vehicle population, the annual fuel economy penalty would be nearly 200 million barrels. In ten years gasoline purchase costs would be on the order of \$5 billion more per year than 1975 .

Adding this weight to 10 million new cars each year would increase manufactured material requirements by about 3 million tons annually. The gross effect of the vehicle weight increases would be to increase the demand for finished steel, steel castings and rubber for the auto industry by about $20 \%$. The energy consumption for manufacturing this added material weight in 10 million new cars each year would approximate 130 trillion B.T.U'S.

If all the cars on the road were at the higher weight levels, the total annual cost increase to consumers would be the sum of the annual cost of the decreased fuel economy (projected at $\$ 5$ billion), pius the higher costs and energy associated with manufacturing the heavier vehicles (projected to be billions of dollars annually). This sustained annual societal cost impact could take place because of a regulation whose need has not been definitely or definitively established. 
National Highway Traffic

Safety Administration

Docket Section -- Room 5108

400 Seventh Street, S. W.

Washington, D. C. 20590

Gentlemen:

Re: Advance Notice Concerning Higher speed Protection Requirements (Docket 74-15: Notice 1)

Enclosed are Ford Motor Company's comments on the Administration's advance notice of proposed rulemaking to increase the frontal barrier crash requirements of Federal Motor Vehicle Safety Standard No. 208, Occupant Crash protection, to 45 or $50 \mathrm{mph}$ effective September, 1980. Ford has also participated in the preparation of comments being submitted by the Motor Vehicle Manufacturers Association and respectfully requests that those comments be incorporated herein by reference.

The comments address the several areas of interest cited by the Administrator in the subject advanced notice of proposed rulemaking. It is appropriate, however, to highlight certain salient points on which the comments expand.

There is the apparent assumption that a 'manifold increase in lifesaving capability of occupant crash protection systems" can be demonstrated merely by increasing the velocity at which a test vehicle impacts a fixed barrier and having the recorded test results satisfy essentially arbitrary criteria. 
National Highway Traffic

Safety Administration

September 19, 1974

As the Administration well knows, there are many

unsettled questions and unresolved issues with regard to Standard 208 including the correlation of test device responses to those of humans, the subjectivity of test procedure, the questionable appropriateness of the criteria, etc. Barrier crash tests are not representative of actual traffic accidents. Meeting some requirement using a test device having a superficial resemblance to a 50 th percentile male adult positioned in a normal seated position is no guarantee that human occupants will survive in actual collisions of apparent equivalent severity.

Despite the uncertainty associated with standard No. 208, in an effort to aid the Administration in defining the potential effects of adopting requirements such as those in this proposal, Ford has conducted a theoretical study related only to front end impacts using a simplified model and idealized assumptions as to restraint systems, structure behavior, etc. That study, as explained in the attached comments, convinces us that the results of the Administration's proposal would be to increase the weight of a vehicle with a Pinto size passenger compartment by about 600 pounds and that of a Ford size vehicle by between 500 and 900 pounds for a $50 \mathrm{mph}$ barrier impact speed. Length increases of as much as 37 inches for the Pinto and 16 inches for the Ford would be required. Specific modifications would be dependent upon restraint systems parameters that are yet undeveloped.

It is obvious that vehicle weight increases of this magnitude will have a pronounced effect on vehicle cost. The engineering and investment costs necessary for major redesigns of all existing cars in a short time period of a few years might best be described as staggering. Based on our analysis to date, Ford would not be able to meet the proposed effective date of September, 1980.

These weight and length increase estimates are based on a simplified, idealized analytical study and we consider them the minimum changes required, if only the requirement for front end impact speed was increased. It is significant that these results are not greatly dissimilar to those that could be derived from an analysis of the vehicle designed and built under the Experimental safety Vehicle programs. It is also significant to note that none of the full sized Experimental Safety Vehicles were successful in meeting the requirements during a 50 mile per hour barrier crash despite, in some cases, the somewhat exotic designs employed. 
Ford believes that the increased speed requirement with its attendant cost and weight increases cannot be justified without an analysis of highway accident data showing that a safety need exists for the proposed increase. The accident impact speed data currently available with which to perform a benefit analysis of higher speed requirements are dependent on subjective human evaluation. Speed estimates in existing data files are thought to be unreliable because they are formed by witnesses or by accident investigators having varying degrees of experience.

The lack of a sound data base with which to evaluate the need for higher speed performance requirements further underscores the need for a large scale crash recorder program to evaluate the actual crash dynamics. The initial results of crash recorder analyses have indicated that impact speeds estimated by police and accident investigation teams are consistently higher than the speed change noted by the recorder.

Ford is currently engaged in a research project under DOT contract to define the performance parameters of a $\mathbf{3 0 0 0}$ pound safety vehicle which will be practicable to manufacture in the mid 1980's. We believe this research will be of value in evaluating future motor vehicle safety needs in the area of higher speed protection. This project is scheduled for completion in April, 1975.

We, therefore, recommend that NHTSA's efforts in the area of higher speed occupant crash protection be concentrated on developing an accurate data base from which the Administration can determine, on an informed basis, the safety need, if any, for a barrier crash test and identify appropriate and practicable test speeds.

At the present time we can only conclude that adopting the proposal advanced in this notice would have the certain effect of increasing weight and vehicle size (with the attendant adverse effects on fuel and material consumption) and consumer cost. The amount of benefit to be gained is only speculative.

If we can be of further assistance in explaining our position, we will be available at the Administration's convenience.

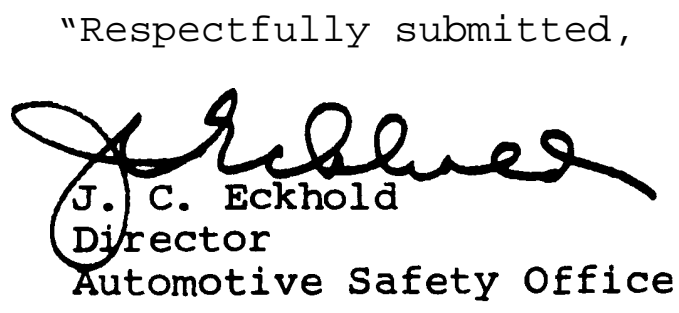

bgw 


\section{HIGHER SPEED PROTECTION REQUIREMENTS \\ DOCKET 74-15; NOTICE 1}

\section{COMMENTS OF FORD MOTOR COMPANY}

Ford Motor Company, with Offices at The American Road, Dearborn, Michigan 48121, as a manufacturers of motor vehicles, is commenting on the Advance Notice of Proposed Rulemaking concerning Higher speed Protection Requirements published in the Federal Register on March 19, 1974 (39 Fed. Reg. 10273).

The Notice states that the Administration is considering amending Federal Motor Vehicle Safety Standard No. 208 (FMVSS 208) to include a 45 or $50 \mathrm{mph}$ frontal crash requirement with a suggested effective date of Septmber 1, 1980 .

In our evaluation of the Administration\% proposal, we found we were impaled by the lack of adequate factual information. Analysis of the available accident data lead us to the conclusion that such data are not sufficiently reliable to assess safety need.

Review of the public record on FMVSS 208 did not disclose the existence of technology which would show that a practicable vehicle could be designed to meet the frontal impact requirements of that standard at $50 \mathrm{mph}$. The domestic ESV's, including the one built by Ford, represent the most comprehensive attempts to comply with such a requirement and all of them failed in that endeavor.

Nonetheless, we have gained some insight into the problem and have prepared the following comments based in part on engineering judgment, relying heavily upon theoretical studies.

\section{Technology}

The Administration states in the Notice that based on research which is extensively documented in the Docket on FMVSS 208, it is of the opinion that technology has advanced to the point where protection can be offered in crashes equivalent to those into a fixed barrier at more than $40 \mathrm{mph}$. We have examined the public record concerning FMVSS 208 and have found no evidence that the Administration has ever conducted the complete test series required by FMVSS 208 even at $30 \mathrm{mph}$, much less at 45 or $50 \mathrm{mph}$. 
Attachment

Page 2

Septmber 19,

Technogy (Cont'd)

None of the domestic experimental safety vehicles built under DOT contracts met the performance requirements of FMVSS 208 at $50 \mathrm{mph}$. These vehicles exceeded the 4000 pound weight objective by between 1000 and 2000 pounds. One such vehicle even used unconventional lightweight materials in an effort to minimize weights. These materials are generally impractical for high volume automotive use because of supply limitations, high cost and lack of adequate manufacturing technology.

More recent higher speed research by NHTSA contractors has concentrated on maintaining passenger compartment integrity independent of programs to develop restraint systems* Advanced structures have not been evaluated in combination with advanced restraint systems in a $50 \mathrm{mph}$ fixed barrier impact test series which would otherwise conform to FMVSS 208 although the intent to do so has been expressed in requests for contract proposals issued by NHTSA.

This was noted by Dr. Patrick Miller of Calspan Corporation in his statement before the Senate Commerce committee on February 21, 1974. He stated that "although impressive structural performance has been demonstrated during frontal collisions, we have not yet developed restraint systems which could take advantage of these advances".

Another problem which has not been adequately considered is the possibility of adverse consequences on occupants of vehicles designed for a 50 mph barrier impact when they are involved in lower speed impacts. The possibility exists that due to increase in vehicle stiffness the injury level in low speed collisions will Become worse.

Many of the crash tests have been conducted at test weights substantially less than that required by FMVSS 208. Under DOT Contract HS-257-2-461, 'Frontal and Side Impact Crashworthiness-Compact Cars" the contractor conducted the crash test without any dummy occupants and with the vehicle weight 700 pounds under that required by FMVSS 208. The effect of added weight is to place even greater demands upon the vehicle structure and, thus, to produce substantially different results.

Further, our review of structural integrity research under NHTSA contracts indicates that these efforts have not been directed toward designs which are practicable in high volume production. The usefulness of the resultant designs for commercial marketing has been inadequate in most cases. For example, the domestic ESV's were five passenger sedans with the occupants tightly packaged while the exterior 
dimensions were equivalent to current vehicles capable of carrying six passengers. One NHTSA contractor raised the body of a Pinto six inches higher off the ground and moved the driver four inches into the rear passenger space. (DOT Contract HS-113-3-746, "Crashworthiness of Subcompact Vehicles")

We anticipate that the structural modifications introduced to meet the $50 \mathrm{mph}$ fixed barrier impact requirement would aggravate any existing car to car impact compatibility problems. The stiffer frontal structure and greater mass would have an effect in frontal, rear and side impacts.

\section{Size and Weight Effects}

There is only minimal data and limited experience with vehicle designs needed to approach a 45 or $50 \mathrm{mph}$ fixed barrier frontal impact requirement. Therefore, we have attempted to extrapolate data from existing cars to determine the size and weight effects of the Administration's proposal. The results of Ford's and other domestic ESV programs, along with additional Ford research, were used even though the ESV's did not meet the occupant protection requirements of FMVSS 208 at $50 \mathrm{mph}$ and exceeded the vehicle weight objective by large margins.

The test data used as a basis for the engineering assumptions and projections were gleaned from recorded force and acceleration measurements upon various anthropometric test devices. Though such data was found to lack repeatability, it nevertheless was averaged and used for directional guidance.

Simplified analytical techniques were used along with assumed performance parameters for advanced restraint systems to derive an estimate of the size and weight increases necessary to meet the proposal.

For purposes of this analysis, the parameters for an advanced air bag system and an advanced belt restraint system were hypothesized to represent restraint systems which are not currently available but which may be possible by September, 1980 .

The results of numerous barrier crash tests were examined to evaluate the performance of various experimental and production belt and air bag restraint systems. Values for effectiveness time, rate of deceleration onset, and equivalent uniform deceleration or "square wave" deceleration were then determined. The key criterion was the $60 \mathrm{~g}$ deceleration limit of FMVSS 208. We concluded that for an 
Attachment

Page 4

September 19, 1974

Size and Weight Effects (Cont'd)

advanced belt restraint system, a deceleration curve with an effectiveness time of 20 milliseconds, a uniform onset rate of $1200 \mathrm{~g} / \mathrm{see}$, and a constant deceleration of $40 \mathrm{~g}^{\prime} \mathrm{s}$ gave an idealized representation of the deceleration which could be produced on the chest of an anthropometric test device. For an air bag, the values of 40 milliseconds effectiveness time, $1500 \mathrm{~g} / \mathrm{see}$ and $48 \mathrm{~g}$ 's were determined. The deceleration levels represent the square wave that would simulate the average of the peaks and valleys of a dynamic curve in which the peaks would still remain under the $60 \mathrm{~g}$ limit of FMVSS 208. Onset rates and effectiveness times were chosen based on predicted future system performance capabilities.

The advanced belt system would include a crash sensor and a preloader device and possibly a load limiting webbing material. The advanced air bag system would require developing improvement to present systems to achieve effectiveness within 40 milliseconds.

The restraint system parameters were used with a simple mathematical model consisting of two point masses representing vehicle and occupant. Idealized occupant stopping distances were determined and then compared with the available vehicle crush and interior occupant space. The vehicle deceleration necessary to produce the assumed occupant deceleration was also computed.

The output of the simple mathematical m-cl thus gives an indication of the amount that a vehicle must be lengthened or stiffened to approach a 45 or $50 \mathrm{mph}$ barrier impact requirement. The length and stiffness increases were used to determine weight effects using engineering judgment based on Ford experimental results and ESV experience, and a review of the ESV's designed by others.

One particular assumption included in the length calculations is that 65\% of the added length will actually crush during impact. Deformed structure would occupy the remaining 35\% of space. The frontal area occupied by relatively incompressible components such as the engine are considered unavailable for vehicle crush. However, the space occupied by the engine was also considered available for the deformed structure. For purposes of this analysis, length added to the vehicle was considered totally usable for computing crush distance up to the point where the 65\% efficiency level was reached. After that point, 1.54 inches of vehicle length were added for each inch of crush length needed. 
The resultant length increases, stiffness, and weights are shown in Fig. 1 for a vehicle with a Ford size passenger compartment and Fig. 2 for one with a Pinto size passenger compartment.

The Ford size car with an advanced air bag system intended to meet a $50 \mathrm{mph}$ impact level would be over 16 inches longer and an estimated 530 pounds heavier than the current Ford. The same car with an advanced belt restraint would only be 2.4 inches longer than the 1974 model but would be nearly 900 pounds heavier.

The Pinto size car with an advanced air bag system intended to meet the same $50 \mathrm{mph}$ requirement would become 37 inches longer and an estimated 600 pounds heavier than the 1974 version. Under the assumptions for the advanced belt restraint, the Pinto would be 18 inches longer and 630 pounds heavier than the existing car.

\section{Front end structural stiffness would have to be} increased substantially for both cars with either restraint system.

Lesser, although dramatic, weight increases would result on both Ford and Pinto size vehicles as shown in Figures 1 and 2 if a $45 \mathrm{mph}$ barrier impact goal were established.

These weight increases are estimates for meeting only frontal impact requirements. No provision has been made in this estimate for increased side, rear and roof structure which we anticipate would be necessary to meet the existing levels of such Standards as FMVSS 214, Side Door Strength, FMVSS 216, Roof Crush Resistance and FMVSS 301, Fuel System Integrity. Structual modifications would be necessary to withstand the increased static or dynamic test loads imposed as a result of the weight added to the vehicle to meet the increased frontal impact speed. The weight increase resulting from these side, rear and roof structural modifications would cause further changes to be made in the frontal structure to meet frontal requirements. These effects would be more pronounced on small cars under 3500 pounds curb weight due to the provisions regarding curb weight in FMVSS 214 and FMVSS 216. Neither is there provision in these weight estimates for revision or deletion of any other standards. 
Attachment

Page 6

Size and Weight Effects (Cont'd)

September 19, 1974

The weight and length additions shown in Figures 1 and 2 were derived, in part, using simplified analytical techniques which do not fully consider the dynamic interactions of vehicle structure, restraint system and test device. They represent minimum levels of vehicle modification which we believe would be necessary to approach the frontal impact performance levels of FMVSS 208 at 45 and $50 \mathrm{mph}$. Restraint system performance parameters were chosen which we believe are possible by 1980, but do not represent any system which we currently have available. Vehicle structures with the necessary frontal crush characteristics would have to be developed. Objective, repeatable conformance demonstration procedures for FMVSS 208 have yet to be developed. We therefore consider these estimated weight and length increases to be minimum levels.

The weight increase shown in Fig. 1 includes that due to structural additions to meet the higher barrier speed requirement plus added weight to upgrade such areas as engine, brakes, suspension and steering. Weight estimates for these other systems were determined by increasing their weight in proportion to the increase in structural weight. This was done by determining the portion of total vehicle weight due to the other systems for several large size vehicles as shown in Fig. 3. The portion of total weight contributed by each system was found to remain fairly constant. The increased weight of these systems was computed by an iterative process based on the added structure weight. This process would add weight to the various supporting systems for each pound of crashworthiness structure added. We realize that in a practical sense weight additions occur in discrete increments.

A similar analysis was conducted for smaller size vehicles to determine the weight additions for a Pinto. (See Fig. 4).

$\underline{\text { cost }}$

We have not determined the cost effect of the proposal, but it is obvious that addition of this amount of weight will result in substantial vehicle cost increases. The engineering and investment cost to redesign all of our vehicles to attempt to meet a 45 or 50 mph requirement would be staggering.

$\underline{\text { Timing }}$

The vehicle modifications required to meet a 45 or 50 mph barrier impact requirement are so extensive that we would be required to redesign all of ouraffected vehicles. After a final rule of this type is established, technology 
Attachment

Page 7

Timing (Cont'd)

September 19, 1974

is available, and practicability is achieved, it would take approximately three years to redesign and retool a single car line family.

Ford normally cannot develop more than two totally redesigned car line families in the same model year due to manpower and facility limitations and available capacity within the tooling industry. It would require a total of four additional years to introduce new designs of all existing passenger car models. However, Ford has never before undertaken a task of this magnitude. Even this cycle is optimistic as it is unlikely the tooling industry could contain the magnitude of such programs if all domestic automobile manufacturers found it necessary to implement similar redesigns.

On the basis of our analysis to date, we could not meet a Septmber, 1980 effective date for all cars, even if the means of meeting the proposed requirements were fully developed. Due to the uncertainties that now exist, we cannot determine whether or not we can meet this date even on one car line.

A new car body and chassis design is produced for a minimum of three years and in many instances can exist for eight years before a major redesign. Therefore, the redesign program that would be required by the proposal would probably obsolete relatively new car lines before the end of their normal cycle with additional cost consequences.

The precise timing effects of the Administration's proposal have not been determined. Small cars would cease to exist as they are known today and large cars might well become impracticable due to increased size. We do not know what vehicle model mix the market would support if it is artificially constrained by a requirement which has such a pronounced effect on vehicle size.

Accident Data Analysis

Ford and others have previously noted the unreliable nature of reported accident speeds available for analysis. The source of data errors and some of the methods which have been used to adjust these data are shown in Exhibit I. Recent crash recorder results have confirmed that reported crash speeds are usually too high. 
Attachment

Page 8

September 19, 1974

Accident Data Analysis (Cont'd)

Twenty accident cases involving vehicles equipped with crash recorders were summarized in SAE Paper 740566 by S. S. Teel et $a l^{1}$ of the National Highway Traffic Safety Administration (NHTSA). The results of an analysis comparing each case vehicle's velocity change, as reported by the police and/or an accident investigation team, are summarized below. The impact speeds used in this analysis and their differences are contained in Exhibit II.

The accident cases in Teel's paper which contained the necessary information were used to construct a sample of the population of differences between velocity "changes estmated by an accident investigator and the velocity change experienced by the vehicle, as reflected by the crash recorder. The sample of 22 differences as tested for normality using the Kolmogorov-Smirnov test ${ }^{2}$ and the hypothesis that the population of impact velocity change differences is normally distributed could not be rejected. Although our sample of accident cases is small, it indicates that the distribution of the difference in estimates is a bell-shaped curve centered at $14 \mathrm{mph}$ (the sample mean) with an estimated standard deviation of $11.9 \mathrm{mph}$. Using these figures, we are $95 \%$ confident that ten percent of the reported impact speeds overestimate the true change in velocity by at least $35 \mathrm{mph}$ while one-quarter of them overestimate the true change in velocity by at least $25 \mathrm{mph}$.

An interval which contains the true mean difference between the estimated and the recorded velocity change of a vehicle in an accident, with 99\% confidence, was constructed using the students-t distribution. This interval, $7.1 \mathrm{mph}<$ Mean Difference < $21.4 \mathrm{mph}$, indicates that, on the average, accident investigators can be expected to overestimate accident impact speeds by from 7 to $21 \mathrm{mph}$. Our

1 Teel, S. S., Pierce, S. J., and Lutkefedder, N. W., "Automotive Recorder Research --A Summary of Accident Data and Test Results", SAE 740566, 3rd International Conference on Occupant Protection, July, 1974 .

2 Lilliefors, H. W., "On the Kolmogorov-Smirnov Test for Normality with Mean and Variance Unknown", JASA, June, 1967. 
Accident Data Analysis (Cont'd)

accident sample also indicates that impact speeds can be overestimated by as much as $40 \mathrm{mph}$. These large overestimates do not depend on the magnitude of the crash recorder velocity change.

\section{As an alternative statistical test, a non-} parametric test, the Wilcoxon Matched-Paris Signed-Ranks Test, also indicates that estimated impact speeds from accident investigators are positively biased. Based on crash tests, Teel concludes that changes in velocity reported by crash recorders are accurate to within $\pm 2 \mathrm{mph}$. Therefore, as a conservative approach, the differences between the estimated and the recorded changes in velocity in Exhibit II were reduced by 5 mpht ad the Wilcoxon test was re-run to determine if the velocity differences could be due to the crash recorder accuracy. The results still indicate that impact speeds estimated by police and accident investigators are too high.

The lack of a sound data base with which to evaluate the need for higher speed performance requirements further underscores the need for a large scale crash recorder program to evaluate actual crash dynamics. 
EXHIBIT I

September 19, 1974

THE TREATMENT OF RECORDED IMPACT SPEEDS

- A Summary-

Methods which have been used to deal with reported impact speeds from the ACIR accident case file are summarized below.

A. Cooke, Conrad H., "Safety Benefits of The Occupant Crash Protection Standard", January, 1971.

Cooke reduced all reported traveling speeds by 10 mph to obtain his estimated impact 'speeds.

B. Mela, Donald F., "A Source of Substantial Error In Estimating The Distribution of Traveling Speed For Accident-Involved Vehicles .*O", DOT, Septmber 3, 1968.

Mr. Mela stated that, by using the estimated impact speeds to determine speed distributions, "the fraction of vehicles in the speed ranges 20-30 mph and 70-80 mph is overestimated by a factor of 3, and the fractions below $20 \mathrm{mph}$ and above $80 \mathrm{mph}$ are overestimated by a factor of 17". If this statement is true, then it suggests that some variable type of correction factor (and not a constant $10 \mathrm{mph}$ as cooke used) be applied to the estimated impact velocities in the ACIR file.

c. White, S. B., Nelson, C., "Some Effects of Measurement Errors in Estimating Involvement Rate as a Function of Deviation from Mean Traffic Speed", Journal of Safety Research, Volume 2, June, 1970.

White and Nelson show that even if errors in estimation are non-systematic, an overestimate of high-speed frequency would be found. That is because any error of measurement always serves to inflate the variance of the distribution of reported values, regardless of the nature of the data. Thus, reported variance (i.e., the meansquare deviation from the mean) is equal to the sum of "true)' variance and "error" variance. White and Nelson point this out, in suggesting that high speed estimates would tend to be exaggerated. They state that "errors in estimating speeds of accident-involved vehicles causes the 
involvement rate, when plotted as a function of the speed deviation, to be U-shaped -overestimated for large derivations (from the mean) and underestimated for small deviations". White and Nelson refer to traveling, not impact, speed, but the principle is the same in either case.

D. Grush, E. S., Henson, S. E., and Ritterling, o. R., 'Restraint System Effectiveness", Report No. S-71-40, Ford Motor Company, September 21, 1971 .

In this report, ACIR impact speeds were converted to barrier-equivalent velocities. The following factors were considered in the conversion: the estimated relative closing speed; the weight differential; a center of gravity adjustment; and an accident location adjustment. A second method of obtaining the barrier-equivalent value for each accident-involved vehicle was based on photographs of the vehicle damage and the study showed that this latter method produces better results.

E. Mason, R. R., D. W. Whitcomb, "The Evaluation of Accident Impact Speed", CAL Report No. YB-3109-V-1, August, 1972 .

This report presents several formulas, one for each type of vehicle impact, which can be used to estimate a vehicle\% impact speed. It provides some insight into how Calspan may estimate impact speeds. 
EXHIBIT II

September 19,1974

IMPACT VELOCITY CHANGES

\begin{tabular}{|c|c|c|c|c|c|}
\hline \multirow{2}{*}{$\begin{array}{c}\begin{array}{c}\text { Recorder } \\
\text { Number }\end{array} \\
1086\end{array}$} & \multirow{2}{*}{$\begin{array}{l}\begin{array}{c}\text { Crash Recorder } \\
\text { Velocity Change } \\
\text { (mph) }\end{array} \\
20\end{array}$} & \multicolumn{3}{|c|}{$\begin{array}{c}\text { Accident } \\
\text { Investigator } \\
\text { Estimated } \\
\text { Velocity Change } \\
\text { (mph) } \\
\end{array}$} & \multirow{2}{*}{$\begin{array}{l}\text { Difference } \\
\text { (mph) } \\
+40\end{array}$} \\
\hline & & & $60+$ & & \\
\hline 485 & 15 & & 50 & & +35 \\
\hline 485 & 15 & 50 & to 6 & & +35 \\
\hline 642 & 10 & & 30 & & +20 \\
\hline 322 & 5 & & 25 & & +20 \\
\hline 335 & 6 & 25 & to 3 & & +19 \\
\hline 641 & 13 & & 30 & & +17 \\
\hline 694 & 9 & & 25 & & +16 \\
\hline 596 & 10 & & 25 & & +15 \\
\hline 596 & 10 & 24 & to 2 & & +15 \\
\hline 596 & 10 & & 25 & & +15 \\
\hline 641 & 13 & 25 & to 3 & & +12 \\
\hline 642 & 10 & 22 & to 2 & & +12 \\
\hline 306 & 19 & & 30 & & +11 \\
\hline 463 & 19 & & 30 & & +11 \\
\hline 463 & 19 & & 30 & & +11 \\
\hline 485 & 15 & & 25 & & +10 \\
\hline 25 & 18 & 25 & to 3 & & +7 \\
\hline 352 & 15 & & 22 & & +7 \\
\hline 463 & 19 & & 20 & & +1 \\
\hline 94 & 11 & & to & 3 & -6 \\
\hline 352 & 15 & & 5 & & -10 \\
\hline
\end{tabular}

Reference: Teel, S., S., Place, S. J. and Lutkefedder, N. W., "Automotive 'Recorder Research -- A Summary of Accident Data and Test Results", SAE 740566, 3rd International Conference on Occupant Protection, July, 1974. 


\section{$\overline{\text { EORD }}$}

SUMMARY: LENGTH AND WEIGHT INCREMENTAL EFFECT SEOR FRONTALIMPACT

\begin{tabular}{|c|c|c|c|c|c|c|c|c|c|c|c|c|c|c|}
\hline \multirow[b]{2}{*}{ S P E E } & \multirow[b]{2}{*}{$\begin{array}{c}\text { RESTRAINT } \\
\text { SYSTEM } \\
T \quad Y \quad P \\
\end{array}$} & \multirow[b]{2}{*}{$\begin{array}{r}\text { AVERAGE } \\
\mathbf{g}^{\prime} \mathbf{s} \\
\mathbf{S} \cdot \mathbf{W} \cdot \mathbf{E} \\
\end{array}$} & \multirow[b]{2}{*}{$\begin{array}{c}\text { WHEELBAS } \\
\text { LENGTH } \\
\text { INCREASE } \\
\end{array}$} & \multicolumn{8}{|c|}{ VEHICLE WEIGHT Additions (LBS. ) } & \multirow[b]{2}{*}{$\begin{array}{l}\text { CURB } \\
\text { WEIGHT } \\
\text { LLBS }\end{array}$} & \multirow[b]{2}{*}{$\begin{array}{c}\text { INCREMEN } \\
\text { OVER } \\
\text { BASE } \\
\left(\frac{0}{0}\right) \\
\end{array}$} & \multirow[b]{2}{*}{$\begin{array}{c}\text { FMVSS } 208 \\
\text { TEST } \\
\text { WEIGHT } \\
\text { (LBS) } \\
\end{array}$} \\
\hline & & & & STRUCTURE & $\begin{array}{l}\text { RESTRAINT } \\
\text { SYSTEM }\end{array}$ & $\begin{array}{l}\text { BUMPER } \\
\text { SYSTEM } \\
\end{array}$ & $\begin{array}{l}\text { ENGINE } \\
\text { SYSTEM }\end{array}$ & $\begin{array}{l}\text { DRIVELINE } \\
\text { SUSPENSION } \\
\text { AND BRAKES }\end{array}$ & $\begin{array}{c}\text { FUEL } \\
\text { SYSTEM } \\
\text { INCLUDING } \\
\text { FUEI } \\
\end{array}$ & $\begin{array}{l}\text { STEERING } \\
\text { SYSTEM }\end{array}$ & $\begin{array}{r}\text { TOTAL } \\
\text { WEIGHT } \\
\text { INCREASE }\end{array}$ & & & \\
\hline 30 & Product ion & 11.3 & $\varangle$ & & & . & - Base- & 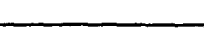 & & & $\Leftrightarrow$ & 4400 & Base & 5600 \\
\hline 45 & A & 19.3 & 6.0 & 182 & 20 & 21 & 53 & 69 & 6 & 7 & 358 & 4759 & $8 \%$ & 5958 \\
\hline 45 & B & 22.5 & 0 & 283 & 20 & 31 & 81 & 104 & 9 & 10 & 538 & 4938 & $12 \%$ & 6138 \\
\hline 50 & A & 19.6 & 16.2 & 282 & 20 & 31 & 80 & 104 & 9 & 10 & 536 & 4936 & $12 \%$ & 6136 \\
\hline 50 & B & 26.0 & 2.4 & 483 & 20 & 52 & 134 & 172 & 14 & 17 & 892 & 5292 & $20 \%$ & 6492 \\
\hline
\end{tabular}

Restraint Jype A: Air bag - $40 \mathrm{msec}$. effectiveness - $1500 \mathrm{~g} \mathrm{sec}$. onset - $48 \mathrm{~g}$ max.

Restraint Type B: Seat belt with sensor and preloader - $20 \mathrm{msec}$. effectiveness - $1200 \mathrm{~g} / \mathrm{Sec}$. onset $40 \mathrm{~g} \mathrm{max}$.

1/ Square Wave Equivalent of vehicle deceleration pulse based on impact speed and total crush distance.

$2 /$ Crush length increases in excess of 5 inches are adjusted by a $65 \%$ efficiency factor 
Figure 2

|9

September 19, 1974

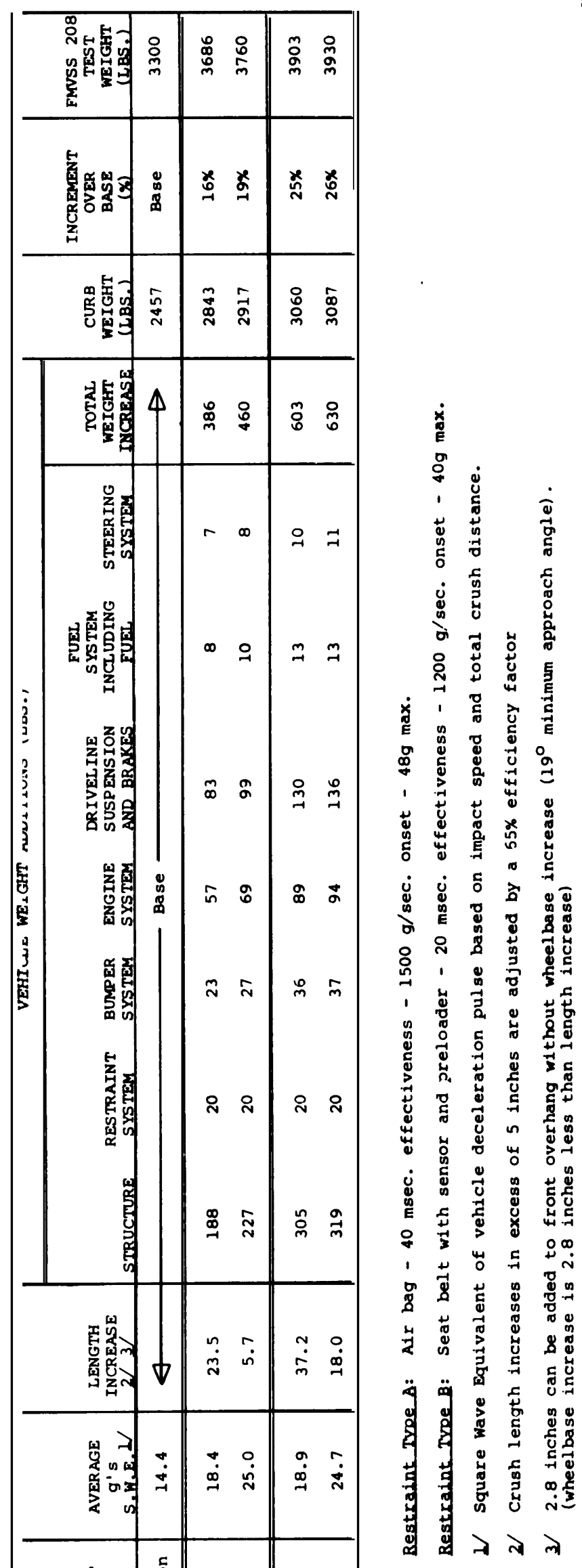

\begin{tabular}{|c|c|c|c|}
\hline 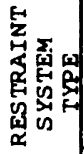 & 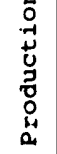 & $<\infty$ & $<\infty$ \\
\hline 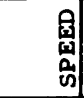 & 요 & $\because \%$ & in is \\
\hline
\end{tabular}




\section{Figure 3}

WEIGHT OF VARIOUS VEHICLE SYSTEMS

AS A PERCENTAGE OF TOTAL WFIGHT

\begin{tabular}{|c|c|c|c|c|c|}
\hline & $\underline{\text { RSV* }}$ & TORINO & FORD & LINCOLN & AVERAGE \\
\hline Curb_Weight:: $, \ldots \ldots, \ldots$ & 3000 & 4030 & 4398 & $5373 !$ & \\
\hline $\begin{array}{l}\text { Percentage of } \\
\text { Curb Weight: }\end{array}$ & & & & & \\
\hline Bumper Systems & $6.0 \%$ & $15.9 \%$ & $5 \bigcirc 4 \%$ & $5 \bigodot_{6 \%}$ & $5.8 \%$ \\
\hline Engine & 15. $6 \%$ & $14 \cdot 2 \%$ & $15 \cdot 8 \%$ & $150 \%$ & $15.0 \%$ \\
\hline $\begin{array}{l}\text { Suspension } \\
\text { Driveline } \\
\text { Brakes }\end{array}$ & 21. $3 \%$ & $19.8 \%$ & 18. $5 \%$ & $17 \cdot 5 \frac{0}{0}$ & $19.3 \%$ \\
\hline
\end{tabular}

Fuel System: To maintain the current Ford vehicle 1.6\% range fuel system weight should be increased at-the rate-of .01415 lb. per lb. of added vehicle weight. The fuel tank weight is approximately $17 \%$ of the total fuel system weight.

$\begin{array}{llllll}\text { Steering } & 2.0 \% & 1.5 \% & 2.3 \% & 1.8 \% & 1.9 \%\end{array}$

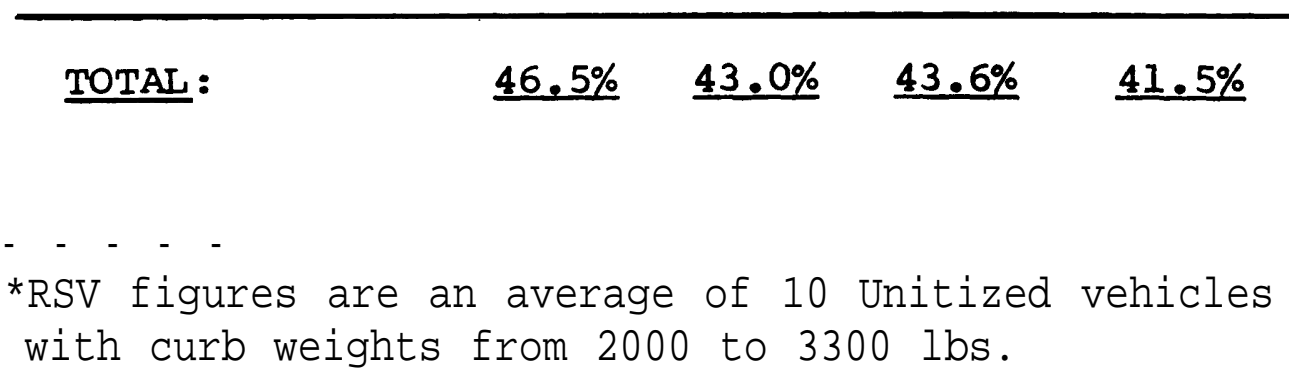


Figure 4

WEIGHT OF VARIOUS VEHICLE SYSTEMS

AS A PERCENTAGE OF TOTAL WEIGHT

PINTO MUSTANG MAVERICK GRANADA

\begin{tabular}{|c|c|c|c|c|c|}
\hline Curb Weight: & 2457 & 2753 & 2831 & \multirow[t]{2}{*}{331.9} & \\
\hline \multicolumn{5}{|l|}{$\begin{array}{l}\text { Percentage of } \\
\text { Curb Weight: }\end{array}$} & \\
\hline Bumpers & $6.1 \%$ & N. A. & $6.0 \%$ & $5.7 \%$ & $5.9 \%$ \\
\hline Engine & $14 \cdot 0 \%$ & 14. $6 \%$ & $14 \cdot 996$ & $15 \cdot 9 \%$ & $14 \cdot 9 \%$ \\
\hline $\begin{array}{l}\text { Suspension } \\
\text { Driveline } \\
\text { Brakes }\end{array}$ & $21 \cdot 3 \%$ & $21 \cdot 7 \%$ & $22 \cdot 1 \%$ & $21 \cdot 3 \frac{0}{0}$ & 21. $6 \%$ \\
\hline Fuel System: & \multicolumn{4}{|c|}{$\begin{array}{l}\text { To maintain the current Pinto vehicle } \\
\text { range fuel system weight should be } \\
\text { increased at the rate of .01415 lb. per } \\
\text { lb. of added vehicle weight. The } \\
\text { fuel tank weight is approximately } \\
17 \% \text { of the total fuel system weight. }\end{array}$} & $2.0 \%$ \\
\hline Steering & $1.7 \%$ & $1.5 \%$ & $2.0 \%$ & $1.7 \%$ & $1.7 \%$ \\
\hline TOTAL: & $45.1 \%$ & & $47.0 \%$ & $46.6 \%$ & $46.1 \%$ \\
\hline
\end{tabular}


APPENDIX C

STATEMENT AT THE AUTOMOBILE COLLISION DATA WORKSHOP

B.J. Campbell

HIGHWAY SAFETY RESEARCH CENTER

University of North Carolina

January 17, 1975 
STATEMENT BY B. J , CAMPBELL Uni versi ty of North Carol i na H ghway Saf ety Research Center

Presented at

Aut onobile Colli si on Data Wbrkshop

Sponsored by

Economics \& Sci ence Pl anning

In acqui ri ng automobi le acci dent data several approaches are used in the U.S. : First, are intensi vel y investi gated acci dent crashes of which several thousand have been collected. The advantage of this approach is that the cases are extrenely detailed wi th photographs and good inj ury data. The nost i mportant di sadvantage is that by vi rtue of the changing sampling criteria and the small sample size, the ability to general ize these few cases to the population is restricted heavily.

I believe too much reliance has been made on this type of data for gui ding NHSA decisions. It leads one to si tuations in which too mach is made of a snal I number of cases. For example, in interpreting the 35 or 40 crashes in which ai $r$ bags are present sone feel the crashes support ai $r$ bags because rel ativel y few noderate or serious inj uries occur. However, what if these ai $r$ bag cases were matched with several hundred cases in which no protective systens are used at al (i.e. no belt or bag)? What if one found pretty much the same proportion of injuries in both seri es? Wbul dn't that suggest that $\mathbf{4 0}$ cases is $\mathrm{j}$ ust not enough?

Second is an approach called the tri-level system There the sam ples are Iarger, but the negative aspect is that the reporting threshold is based on accident severity which resul ts in el i minating certai $n$ cases in which safety bel $t$ and perhaps other safety device effectiveness is greatest. 
Thi rd, and at the other extrene from indi vi dual case studies is the attempt to use an enti re state acci dent data system as the basi s on which to do research and make decisions. The bi ggest advantage in this case is the perspective gai ned from very Iarge sample si zes and the ability to partition and control the data. But on the negative si de many such systens contai $n$ too few content variables of interest. The qual ity of reporting may be poor and the inj ury data is crude.

In my opi ni on a crucial need in the field of crash inj ury is the means to forge a meani ngf ul Ii nk between I aboratory test crash data and events as they occur in the field. Mich can be gai ned from Iaboratory sl ed and full-scal e crash tests invol ving dumies, Cadavers or even Ii ve subjects, and al so mach can be gai ned from the study of actual crashes on the hi ghway. But each I acks a significant variable.

In the staged crashes in the I aboratory, tel enetric procedures are used for recording data and one can specify in consi derable detail the physi cal system in which the crash occurs--the "g"-forces, the rate of onset, del ta "v" etc. But when one is forced to use nonhuman subjects then one is left in the situation of knowing a great deal about the physics of the crash but knowing little of the actual inj uries that might have occurred in such a crash. On the other hand, in real world aut onobile crashes one can learn about the actual outcones in terns of survi val and i nj uri es, but the i nput variables menti oned before are unknown.

The need to I ink these tuo systens is apparent. Engi neers who desi gn protecti ve systens need to know about stopping di stances, forces, decel erations, etc. But knowing these things is of too little help unl ess one has a way to rel ate them to real world inj uries. An 
ill ustration of the need for this data Iink is the NHTSA anal ysi s conducted in connecti on wi th the ai $r$ bag. Thi s NHSA anal ysi s initial ly indicated that I ap and shoulder bel ts nould only reduce fatalities by 35-40 percent, and that Iap bel ts al one nould be of al nost no benefit at al I in reducing injuries. These concl usi ons were presumbly based in I arge measure on resul ts of crash tests i nvol vi ng cadavers and dumies. The probl em is that these concl usi ons di sagree sharply with studies of tens of thousands of crashes that have occurred on the hi ghways. Studi es from all over the vorld indicate that in actual crashes injuries are reduced by lap bel ts, and that Iives are saved, and that the degree of Ii fesaving is much hi gher than 35 or 40 percent NHSA has indi cated.

It is the very occurrence of this type of di sagreenent that shows that the anal ysi s system in each sector (I aboratory vs hi ghway) by itsel $f$ is inadequate and that means must be found to bridge the gap. The pri mary advantage of a crash recorder program uould be a means to forge thi s I ink between the two data systens. It would fi nally be possi ble to gather data on a few thousand actual hi ghway crashes in which crash conditions, the decel erations, the forces, the amplitudes and so forth would be knowable as well as the inj ury.

By using these several thousand crash recorded events as a cal ibrati on standard it would be possible to work outward to the hundreds of thousands of other actual crashes in which recorders weren't avai I able, and the thousands of I ab tests in which recorders are avai l able but human inj ury is not.

It is not necessary to have an "infinite" number of crash recorders in the fiel d, only enough to validate other approaches. I personal ly 
do not see the crash recorder program as an end in itself but one whi ch voul d support and val i date other types of crash studies.

My remarks do not suggest the level of detai I needed from the crash recorder, but in any case, the program will be expensive. For si $x$ million dollars one could equi p 100,000 cars with crash recorders that cost $\$ 60$ each. It nould al so be possi ble to equi $p$ nore cars with a si mpler, l ess costly crash recorder.

It is for others to deternine the needed complexity of the crash recorder. Perhaps it is not necessary to have a crash recorder that records force ti ne hi stories in three di mensi ons. Mabe vertical accel erati ons can be sacrificed.

Perhaps it nould al so be usef ul to consi der a "tri-l evel" crash recorder program this could invol ve a nodest number of cars equi pped wi th a very compl ex recorder and a I arger number of cars equi pped with a si mpler, I ess expensi ve recorder system

As a prel ude to the programit might be appropriate to have a research project to synthesi ze past Iaboratory crash data to try to agree what measure in the field is the one that would account for the nost i nj ury vari ance. Wbul d it be i mpact speed, barri er equi val ent vel oci ty, del ta "v" or what?

The crash recorder, of course, is not the onl y need in studying and understanding actual crashes. Mich better and much I arger collections of hi ghway crash cases are al so necessary. I stated my belief that too much rel $i$ ance has been $p l$ aced on the smal $I$ number of intensi vel $y$ investi gated crashes. Thi s country needs a mul ti-state data col lecti on program which uoul d accumul ate records on 600, 000 to 1, 000, 000 acci denti nvol ved vehi cl es per year. Thi s nould requi re three to fi ve states the si ze of North Carol i na. 
For a surprisingly snal l addi ti onal cost it nould be possible to col lect that many cases with reasonably good def ormati on data, an operati onal ly defi ned i nj ury scal e, vehicle identificati on numbers, belt usage, and vari ous file linkage numbers to cross-link accident data and dri ver history files, road data, etc. It is extrenel y i mportant to have this quantity of data in order to get ti mel y answers to questi ons. If a safety devi ce has gone astray or a dangerous car is coming onto the market-- we need to know it soon--not after ten years.

I noul d be pleased at some future ti me to discuss some of the characteri stics such a multi-state data system should have. 


\section{APPENDIX D}

\section{SUMMARY OF REMARKS \\ AT THE \\ AUTOMOBILE COLLISION DATA WORKSHOP}

Lawrence Patrick

Wayne State University

January 16, 1975 


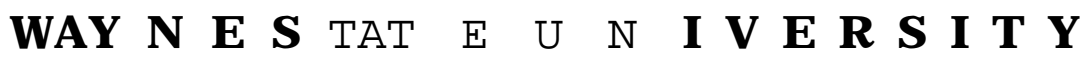 \\ BI OMECHAN CS RESEARCH CENIER \\ CQLEEE OF ENG NEER NG \\ 5050 ANTHONY WAYNE DRI VE \\ DETRO T
TELEPHOE:
M CHA GAN 48202}

January 20, 1975

Mr. Howard Gates

Economics \& Science Planning

1200 18th Street

N.W. Washington, D.C. 20036

SUBJECT: ESP Meeting, January $16 \& 17,1975$

Dear Mr. Gates:

As requested at the captioned meeting, I am enclosing herewith prints of the slides I used in my presentation together with a brief summary of my remarks. In the interest of brevity, the remarks are presented in outline form.

PREMISE

1. The only valid way to establish safety needs for automobiles is through examination of field data.

2. The only valid way to evaluate the effectiveness of safety measures is through analysis of their effect on accident data.

CONCLUSION

Accident data are essential.

CRITERIA FOR DATA COLLECTION

1. Sufficient data must be obtained for statistical analysis. Collection of accident data is expensive so it must be optimized for the number of variables, depth of study, and type of collision to minimize the cost per accident. The present MDAI studies cost approximately $\$ 2500.00$ apiece, and include greater detail than is necessary. With modification of the collection procedure accident data in sufficient depth should be available at a cost of under $\$ 400.00$ per case. Other data should be gathered on a large sample basis in even less detail at a considerably lower cost.

2. Complete injury data must be included in the accident data. Sex, age, weight, height, and general physical condition are all important factors in analyzing accident data. The type and degree of injury of each occupant including the minor bruises and abrasions and going through the severe bone and soft tissue damage are required. It is important to have complete data on the restraint systems used and the interior components of the vehicle that caused the injury. 
Mr. Howard Gates

Economic \& Science Planning

January 20, 1975

3. Complete vehicle crash data are essential to permit an estimate of the collision severity. The crash data in addition to the usual photograph should include measurements of vehicle deformation. A standard means of recording deformation of the vehicle would be beneficial.

4. Reference collisions are required to establish severity of the accident from the crash data and deformation measurements. Eventually the reference collisions and deformation data can probably be replaced by a data recorder. The data recorder should be relatively simple and the cost should be low enough to permit installation in all vehicles. A crash severity signature is required which gives crash severity in the most meaningful terms. This does not necessarily require triaxial acceleration time histories. The Barrier Equivalent Velocity that has been used extensively is not necessarily the best measure of severity, but is one that has been used extensively and should continue to be used until a better measure of severity is developed.

\section{DATA ANALYSIS}

1. Standardized injury and deformation reporting is essential to keep the results of investigations by different groups in different parts of the country on a uniform basis. The AIS scale and the VDI should be considered for the immediate future and utilized until a better scale is devised.

2. The effect of sex, age, weight, size, position in vehicle, direction of impact, restraint systems etc. should be established. This will permit an accurate judgement to be made of the area of safety improvement that should be stressed.

3. Probability of injury as a function of collision severity is essential. It should be recognized that some individuals are going to be injured severely at low severity clue to inherent weaknesses. Fundamentally, it is necessary to protect the maximum number of people from the maximum number of exposures. From a design standpoint, it is essential to establish an acceptable degree of injury under the most severe collision conditions. It is recommended that the AIS-3 injury be the maximum acceptable injury with no injury as the ultimate goal.

EXAMPLE: WSU-VOLVO STUDY as follows:

1. The WSU-VOLVO study was divided into four major divisions

a. Accident Investigation - complete injury data including the AIS rating and complete vehicle deformation measurements. 
Mr. Howard Gates

Economic \& Science Planning

January 20, 1975

b. Staged Collisions - complete deformation data in terms of impact speed.

co Simulation Tests - records of injury criteria as a function of simulated speed.

d. Analysis - Injury data related to severity and test data.

The accident investigation was conducted by the Volvo investigation team with special instructions to meet the requirements of this study. The staged collisions included frontal force, barrier, pole, and car to car collision. The collision simulations were made in the laboratory in a modified Volvo automobile with instrumented dummies as the occupants using the same stopping distance and deceleration pulse as measured from the staged collisions.

2. Accident criteria established to minimize the number of variables include:
a. Frontal force collisions only.
b. Belted front seat occupants (one or more).
c. No unbelted rear seat passengers or other heavy objects in the rear seat.
d. No external secondary impact of substantial severity.

3. With these stipulations, a total of 128 accidents were investigated with 169 occupants in a two year period. During this time there were eleven staged collisions at Volvo and 72 simulated tests at Wayne.

4. Figure 1 is a plot of the injury as a function of Barrier Equivalent Velocity with three injury areas for each occupant. As noted from the legend, the data are divided into head, neck, and chest injuries for each occupant with the driver and right front passenger position differentiated. The figures at the bottom of the graph refer to the number of body areas at each velocity for which there were no injuries. It is important to note that AIS-3 injuries were found at velocities ranging from 10 to $53 \mathrm{mph}$ with the major number clustered at about $30 \mathrm{mph}$.

Figure 2 is a bar graph showing the distribution of injury as a percent of the number of occupants in $10 \mathrm{mph}$ increments. At the 0 to $9 \mathrm{mph}$ level approximately $90 \%$ of the occupants had no injury and the remaining $10 \%$ sustained only minor injuries. In the 50 to $59 \mathrm{mph}$ range all occupants had some injury with one third having the AIS-1 injury and two thirds having AIS-3 injury. It is obvious that as the $\mathrm{BEV}$ increases the injury also increases. 
Mr. Howard Gates

Economic \& Science Planning

January 20, 1975

Figure 3 is a sketch of the rib cage with rib fractures and sternum fractures illustrated. In the field study all of the rib fractues occurred on the inboard side which is the side which the belt applies the force to the ribs. The fractures have all been put on one side although in the field there were fractures to the driver and passenger and consequently they were on both the left and the right side of the rib cage.

5. The accident investigating team carefully measured the deformation of the vehicle at six different points on the front as shown in Figure 4. A computer program was developed to record the six deformation measurements in graphical form. Figure 5 shows the deformation for the staged barrier collisions. These were all normal frontal force collisions and consequently the deformation is symmetrical. Figure 6 shows the same data obtained from the measuring fixture in the field accident study. It will be noted that in this figure the impacts are to poles and/or asymmetrical impacts which result in a different pattern than the barrier results. It was necessary to interpolate the field data to provide the closest BEV for the analysis. It is felt that the overall barrier equivalent velocity assigned to each collision is considerably more representative of the collision severity than in previous studies.

6. Figure 7 shows the rib fractures for male and female as a function of velocity. It should be noted that the age of the occupant should be included as another variable. However, the figure shows that the female has a greater number of ribs fractured than the male.

7. Figure 8 is a graph of cumulative injury risk as a function of abbreviated injury scale with velocity as a parameter. The data are plotted for the $10 \mathrm{mph}$ increments. The dash lines indicate that the data are extrapolated with insufficient data for an exact definition of the curve. However, the data show a distinct family of curves. Additional data is required to delineate the curves with greater accuracy. The same data are shown in Figure 9 with abbreviated injury as a function of barrier equivalent velocity. This graph permits an estimate of the likelihood of injury in a given frontal force collision.

\section{AMOUNT OF DATA REQUIRED}

1. The collection of accident data requires a substantial amount of data with extreme accuracy desirable but not necessary. For example, there is no need to have a collision severity to within plus or minus "one mile per hour". This is especially true since we really don't know what the barrier equivalent velocity means or whether some completely different severity index should be used. With the large number of variables including impact velocity, impact direction, rigidity of vehicle, rigidity of object struck, location of impact on car, occupant location, occupant age, sex, height, weight, physical condition, tolerance 
Mr. Howard Gates

Economic \& Science Planning

January 20, 1975

to acceleration environment, posture, vehicle interior design, and restraint systems, it is more important to have a substantial amount of data with reasonable detail rather than a small number of cases that have been investigated to a great depth.

2. With the large number of variables it is necessary to have a large number of recorders in the vehicle population in order to obtain a reasonable number of accidents with the recorders in the car. The most desirable situation is one in which each car manufactured is equipped with a recorder installed at the factory.

CRASH RECORDER REQUIREMENTS

1. The crash recorder should be installed in a large number of vehicles. Consequently, it must be low in cost.

2. The recorder does not have to be ultra-accurate (such as plus and minus one percent on the acceleration and time scale), since the analysis will be based on a large amount of data rather than a small sample which would require the greater accuracy.

3. The crash recorder should be based upon a "severity index" that has yet to be developed depending upon the injury potential to the occupants. Such a recorder could be an integrating accelerometer with electronics to perform necessary operations on the accelerometer output to provide the severity index. Other means that might be satisfactory include fracture of a number of elements in the accelerometer or the deformation of an element in the accelerometer. The exact function to be measured and the method of measuring it has to be developed.

4. The crash recorder should be developed in conjunction with the data analysis group to insure maximum utility from the installation of the recorder.

5. The recorder should be sealed to prevent tampering and to guarantee that when the record is interpreted it has not been damaged prior to being collected by the investigator. It should be designed to give a record for a collision in excess of some predetermined severity such as a $10 \mathrm{mph}$ barrier equivalent or greater. This will avoid the danger of having a recorder in multiple crashes which could confuse the data or give false results. Obviously the recorder must be rugged enough to withstand the collision without damage.

I believe that you or Dr. Goldmuntz requested a copy of my curriculum vitae and list of publications. They are enclosed.

I thoroughly enjoyed the meeting on January 16th and 17th and feel that it was productive in that I learned considerably from it. Hopefully, the goals of the meeting will be achieved. Bob Cromack has the preliminary writeup that we came up with during our working 
Mr. Howard Gates

Economic \& Science Planning

January 20, 1975

lunch on Friday. He is going to have it typed up and sent to the rest of us (Brian $\mathrm{O}^{\prime} \mathrm{Neill}$ and David Morganstein). We will review it and approve or modify it for final submission.

An invoice for my expenses is enclosed in accordance with our agreement.

It was a pleasure to work with you on this program. If I can be of any further assistance, please don't hesitate to call on me.

Sincerely,

Patrot

L. M. Patrick

Professor

LMP : ldd

ENCLOSURE 


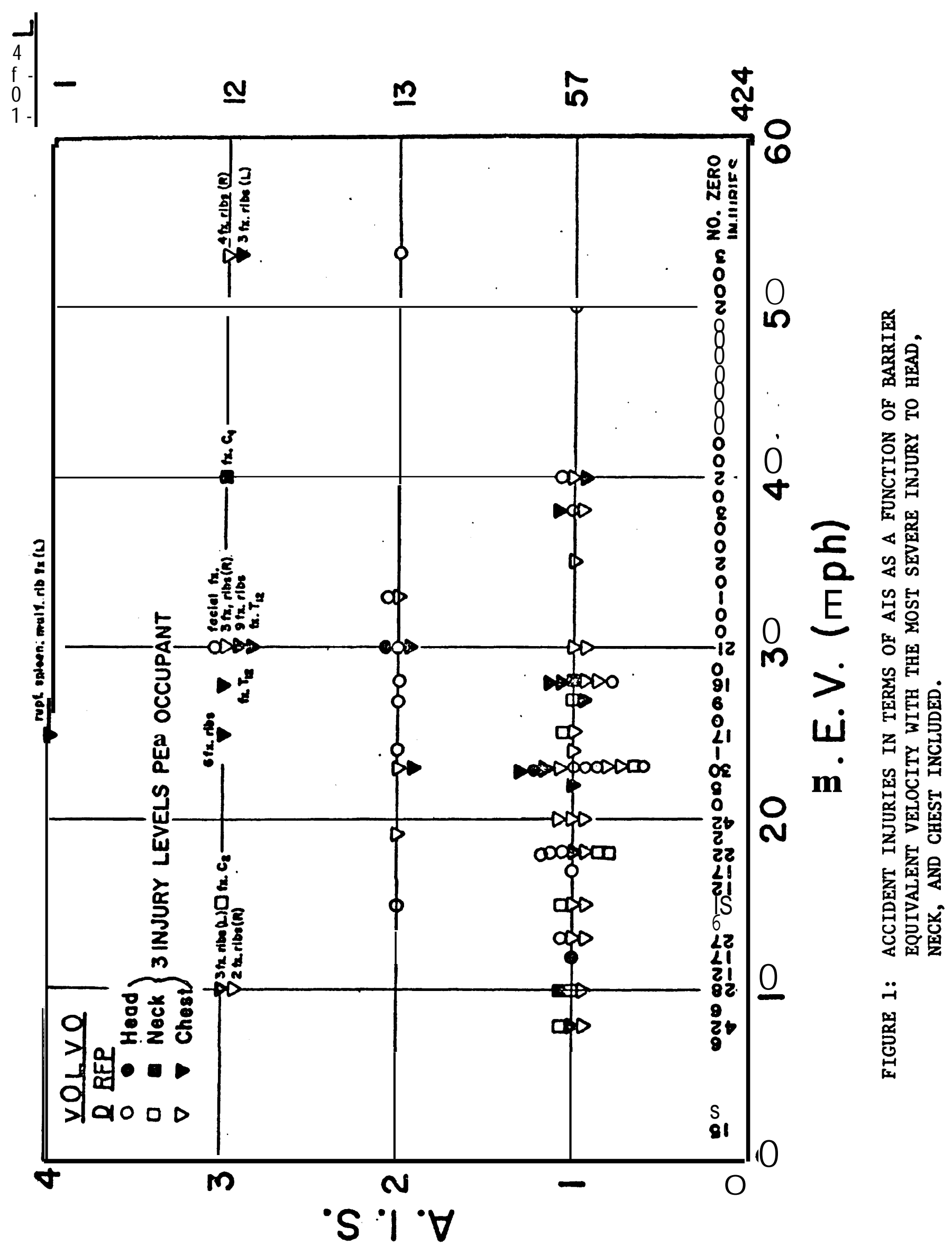




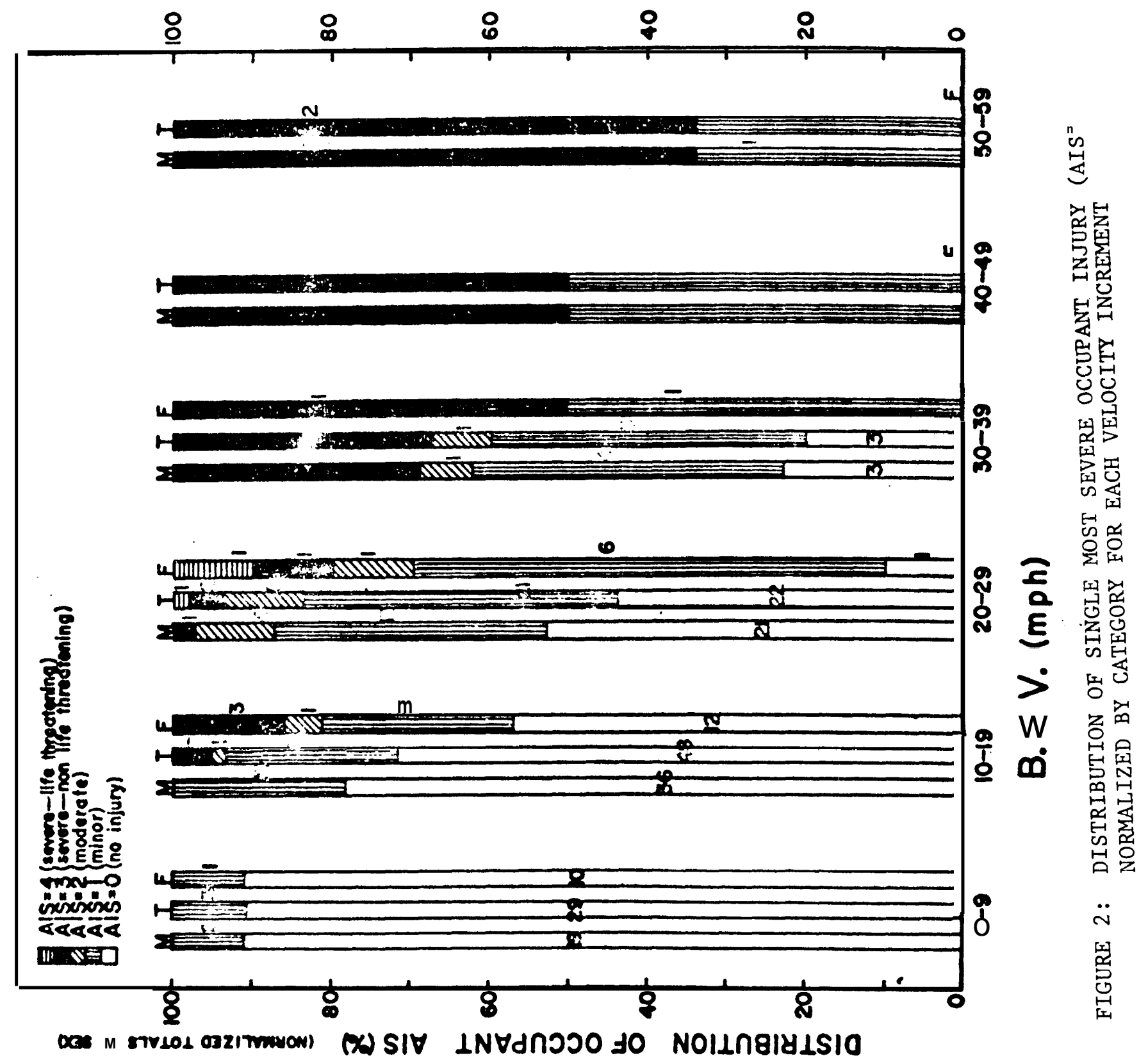




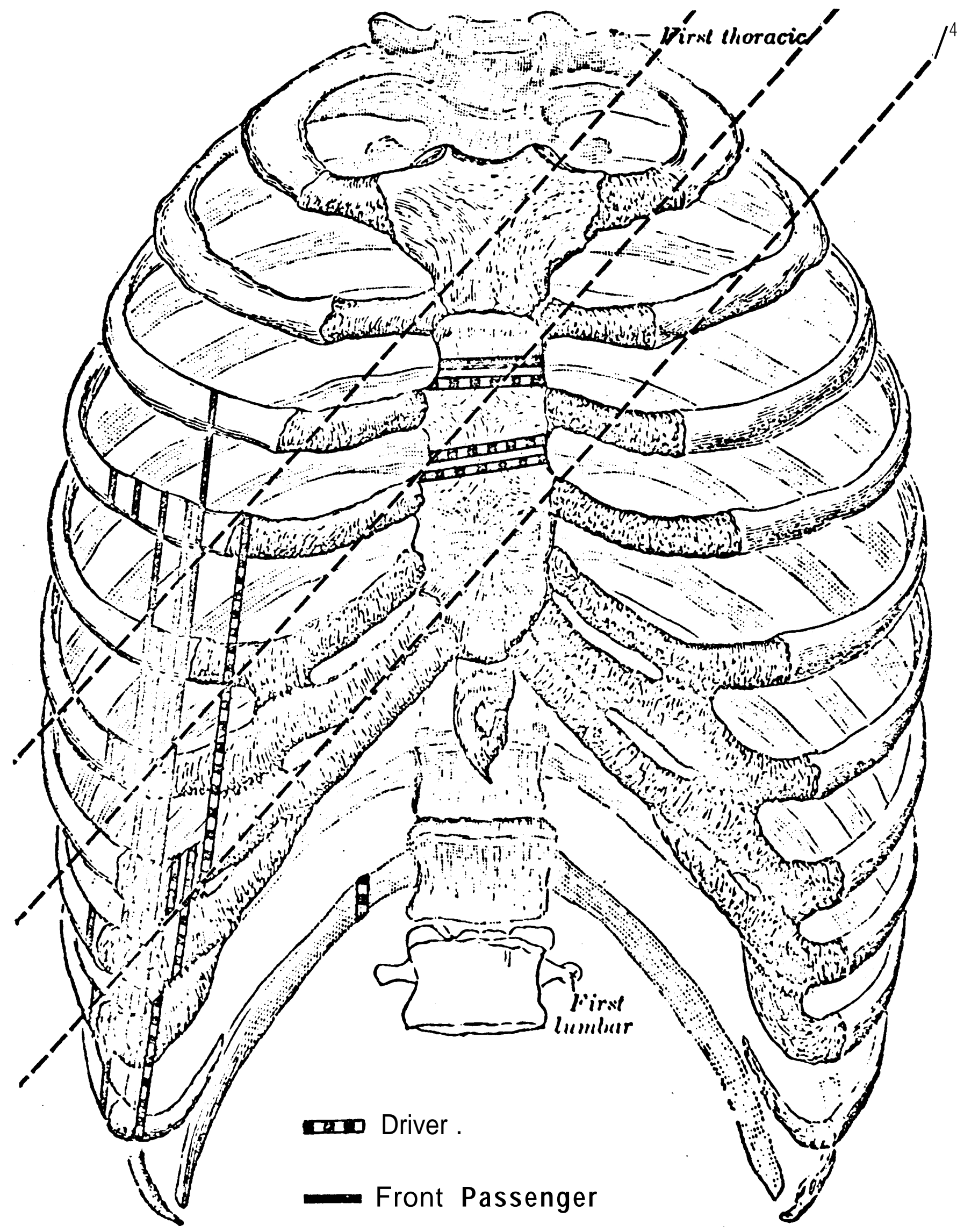

FIG. 3: ALL RIB AND STERNAL FRACTURES (WITH PASSENGER INJURIES TRANSFERRED TO THE DRIVER'S SIDE) 


\section{$\underline{\text { Vertical }}$}

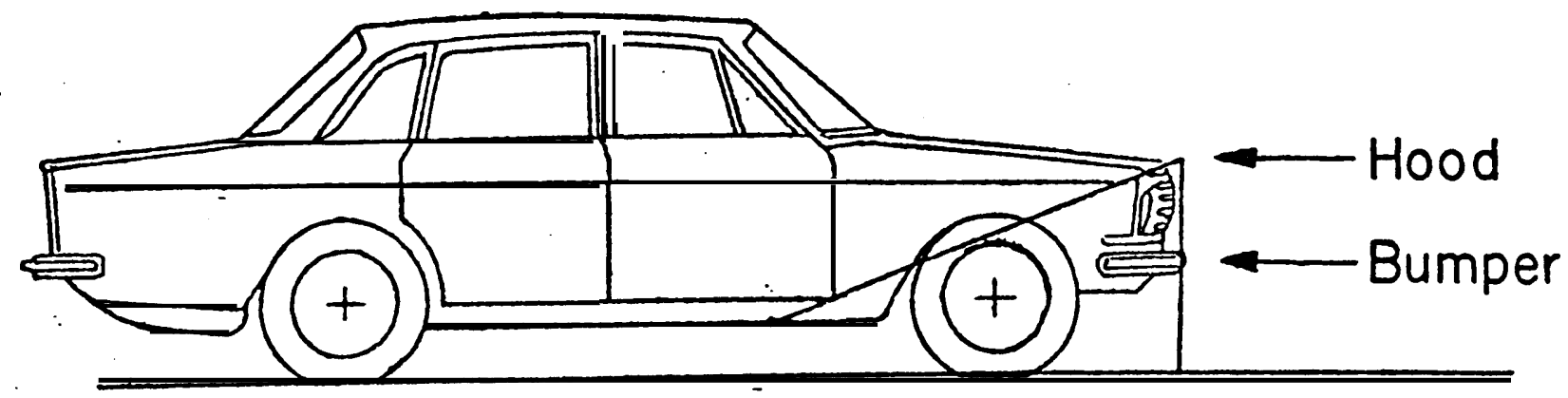

Horizontal

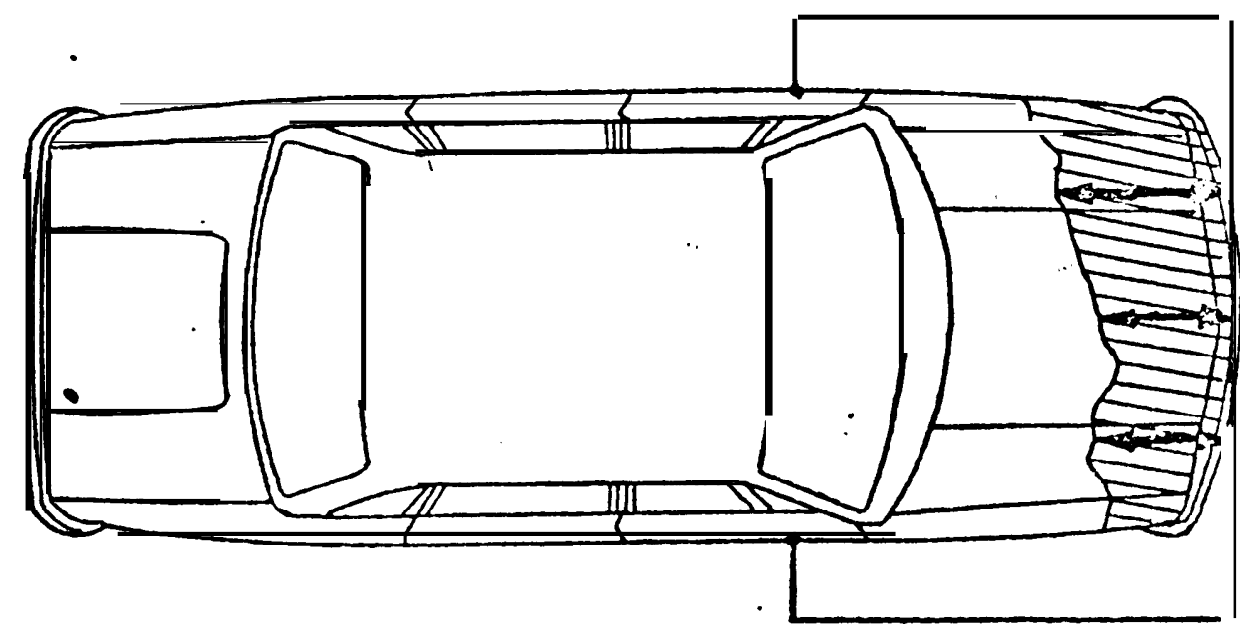

Left $\uparrow$

Middle I

Right

FIGURE 4 : DIAGRAM SHOWING MEASUREMENTS TAKEN WITH FRONT END DEFORMATION FIXTURE. 


\section{VOLVO TEST VEHICLES \\ 20, 30 AND $50 \mathrm{MPH}$ BARRIER COLLISION}
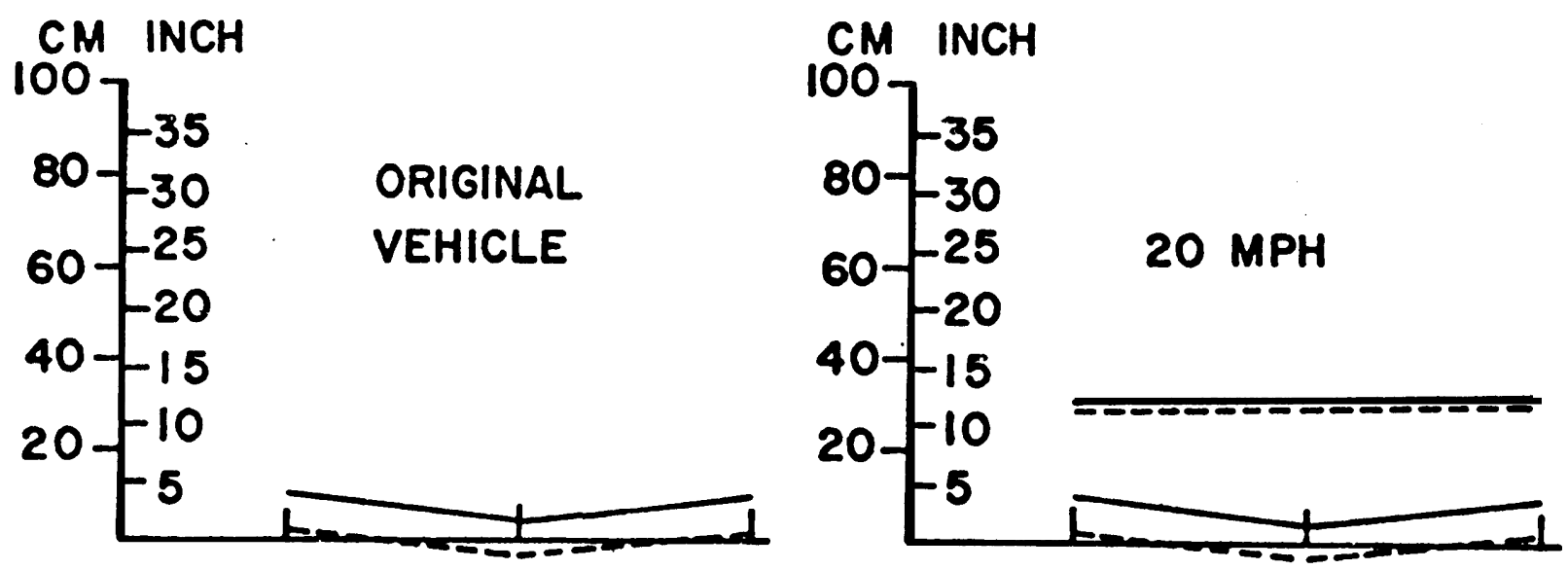

CM INCH

100

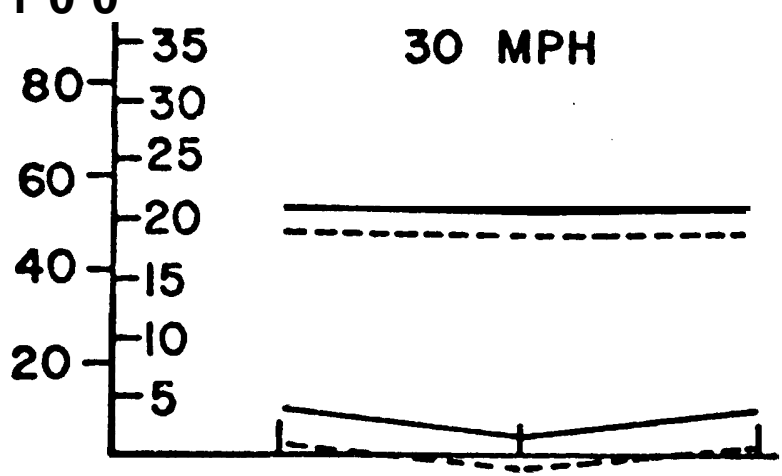

CM INCH
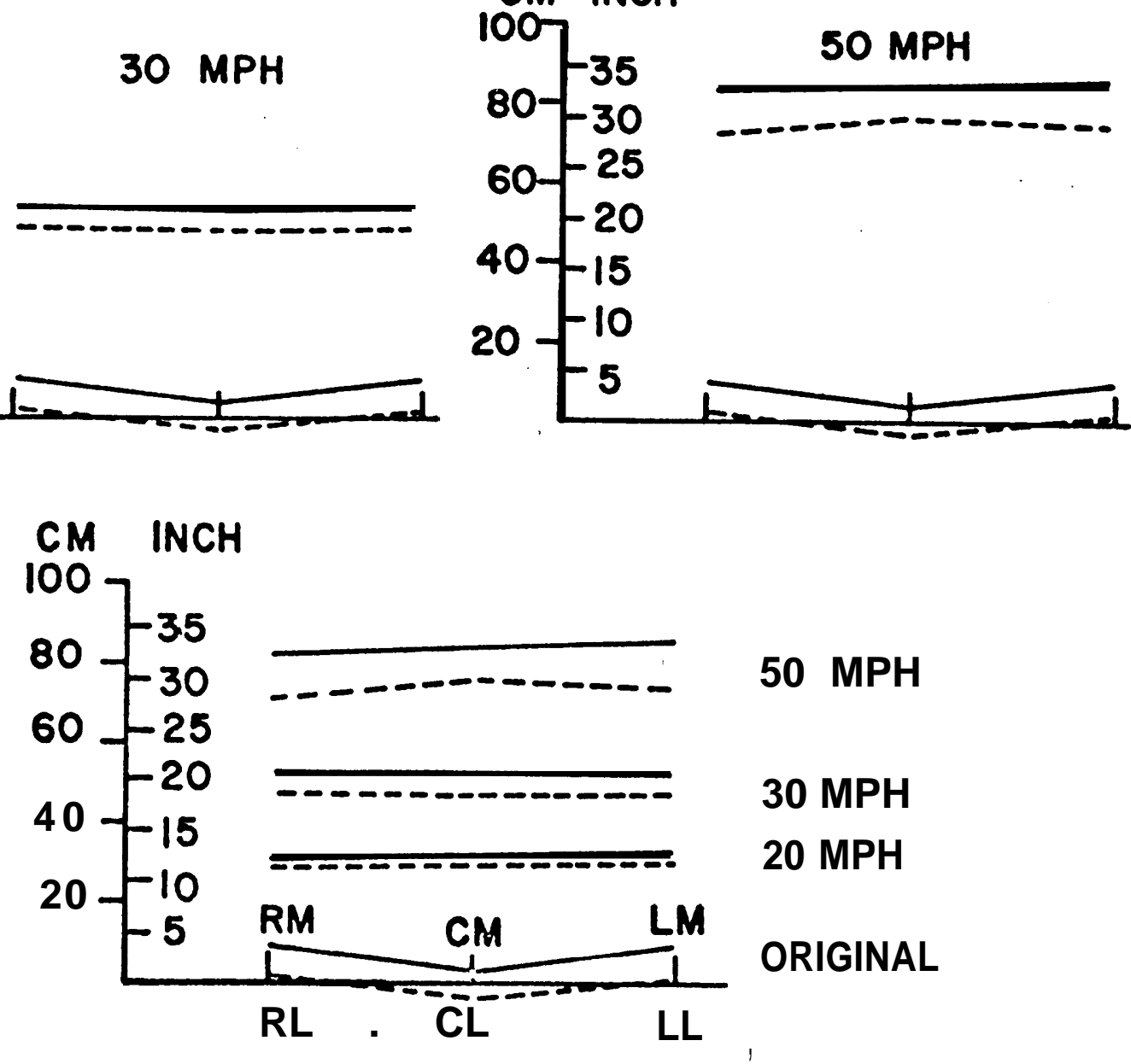

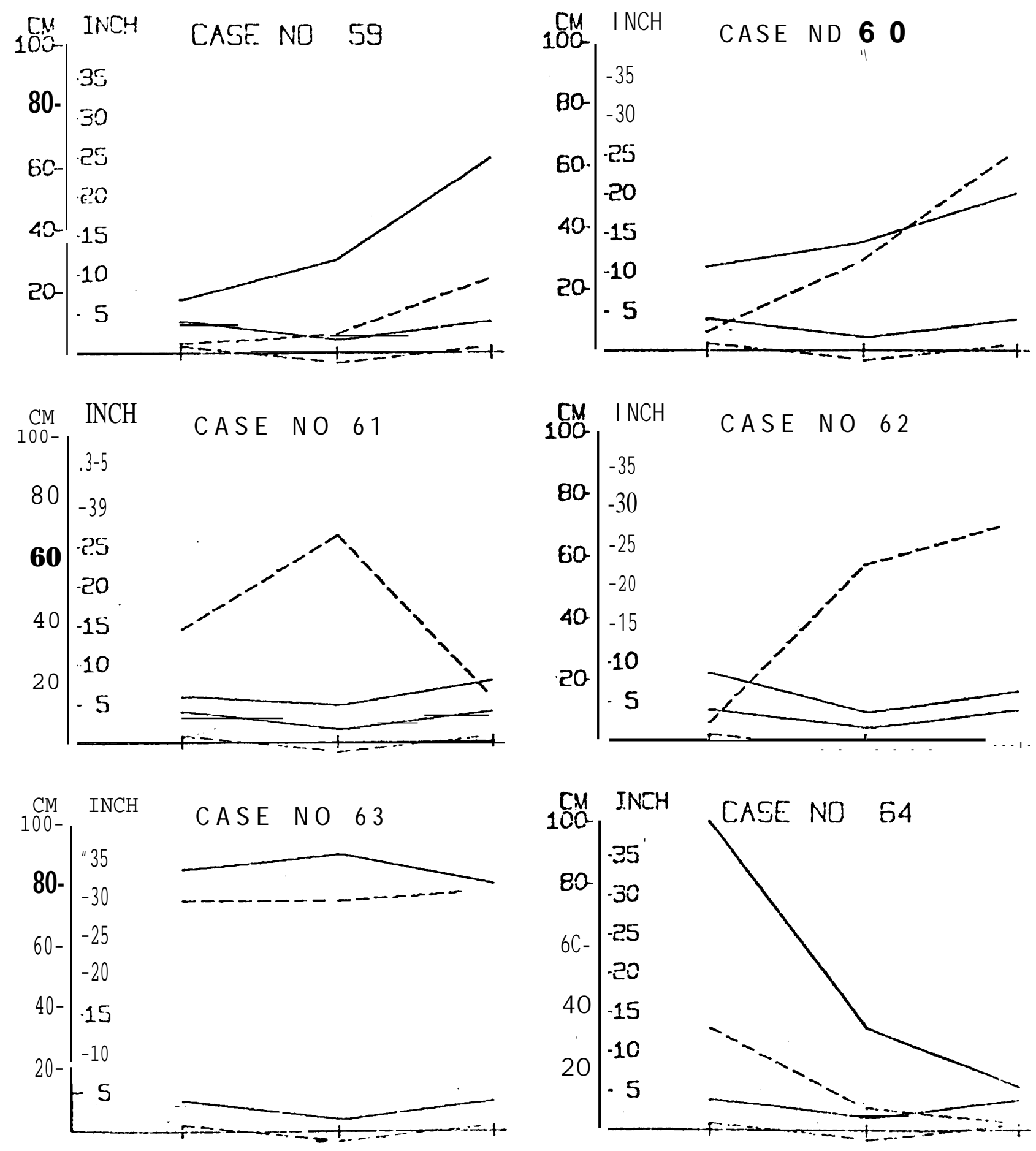

'FigURE 6 : " DEFORMATiON DATA FROM EIGHT OF The ACCident CASEs . 


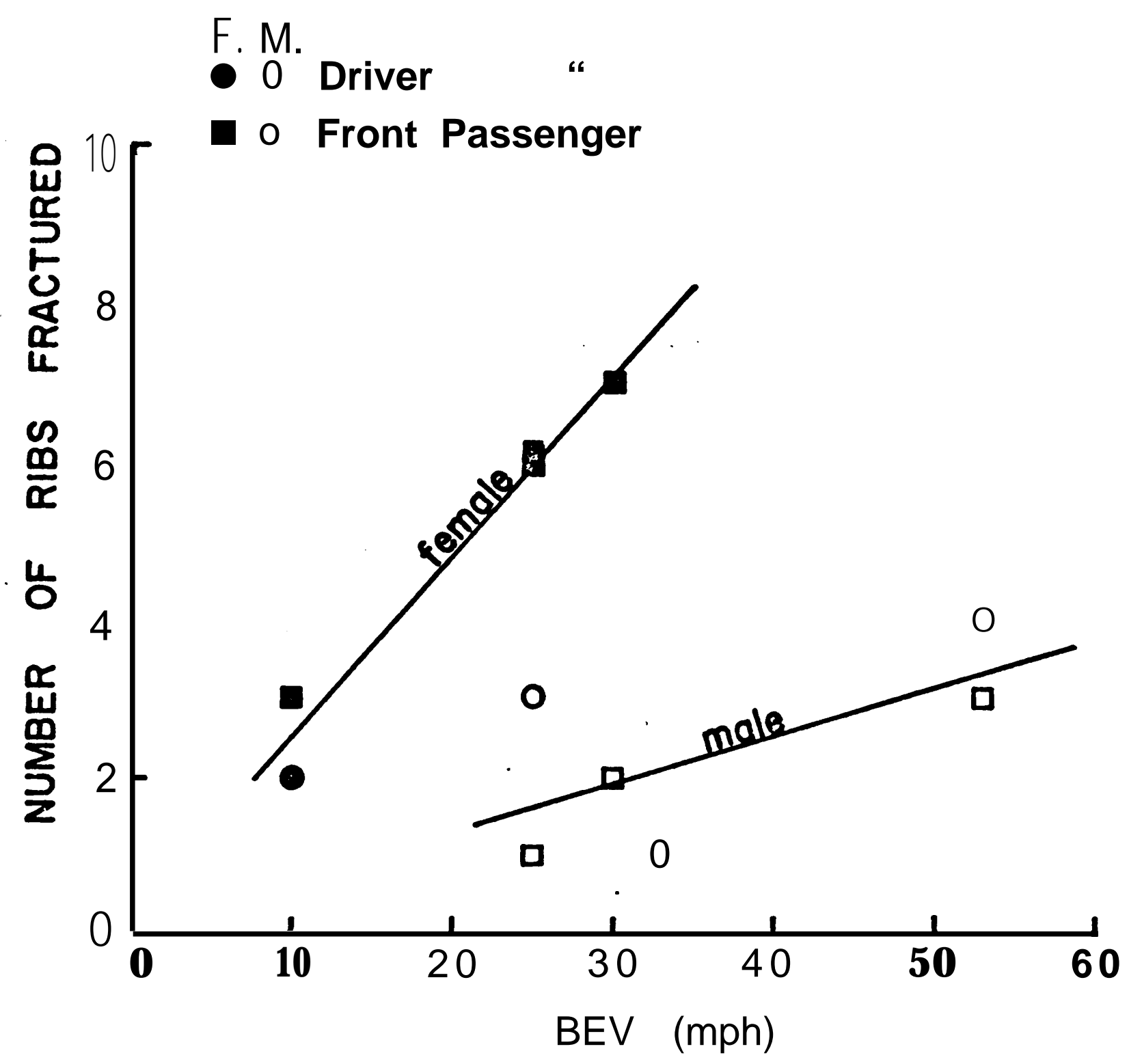

FIGURE 7 : RIB FRACTURES FOR MALE AND FEMALE OCCUPANTS AS A FUNCTION OF BARRIER EQUIVALENT VELOCITY. 


$$
\begin{array}{lcl}
0 & 0-9 & \mathrm{MPH} \\
+ & 10-19 " \\
\square & 20-29 " \\
\Delta & 30-39 " \\
\nabla & 40-49 " \\
\nabla & 50-59 "
\end{array}
$$

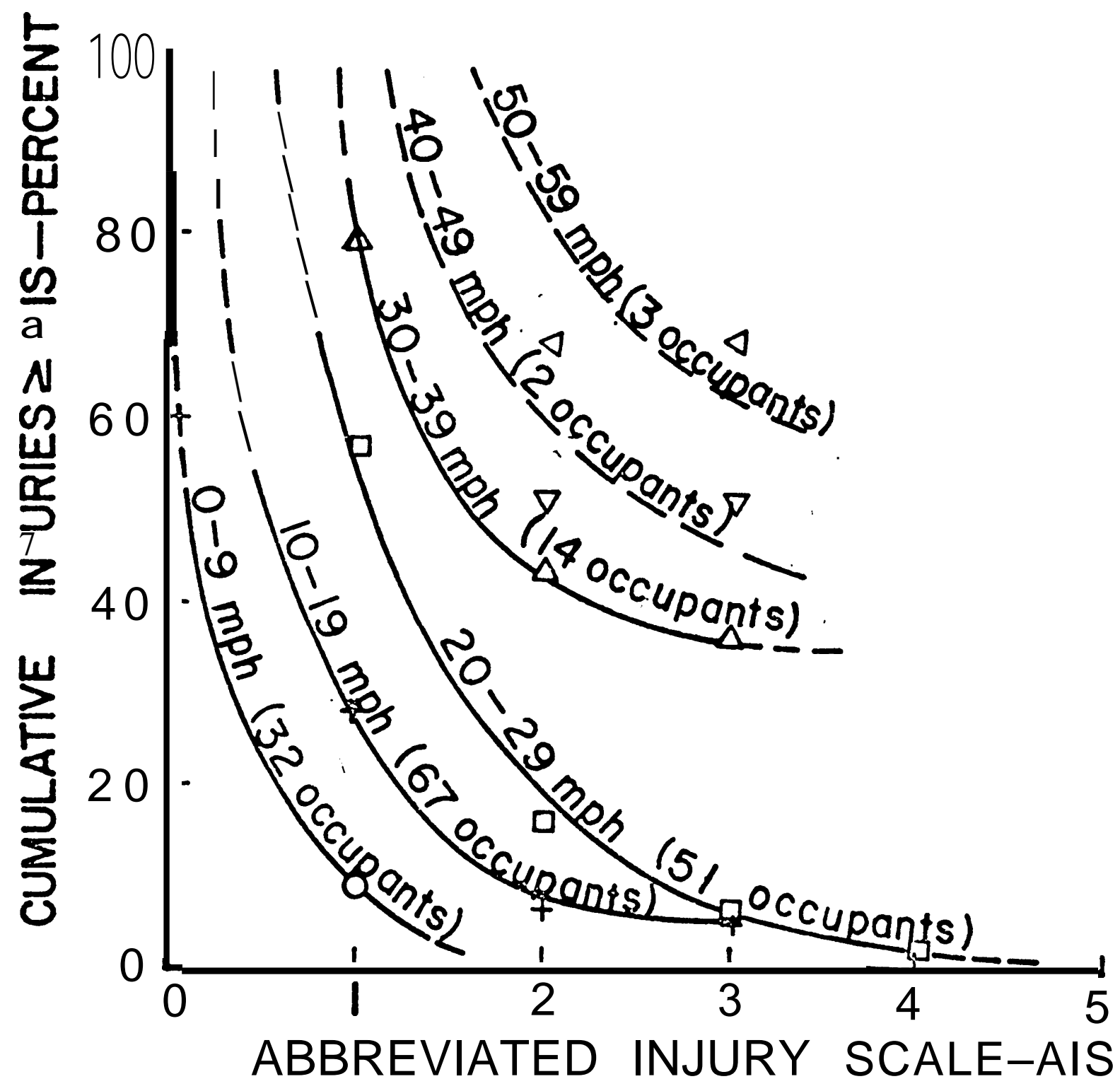

FIGURE 8: PERCENT OF CUMULATIVE INJURIES, EQUAL TO OR GREATER THAN, A GIVEN AIS LEVEL FOR $10 \mathrm{MPH}$ INCREMENTS . 


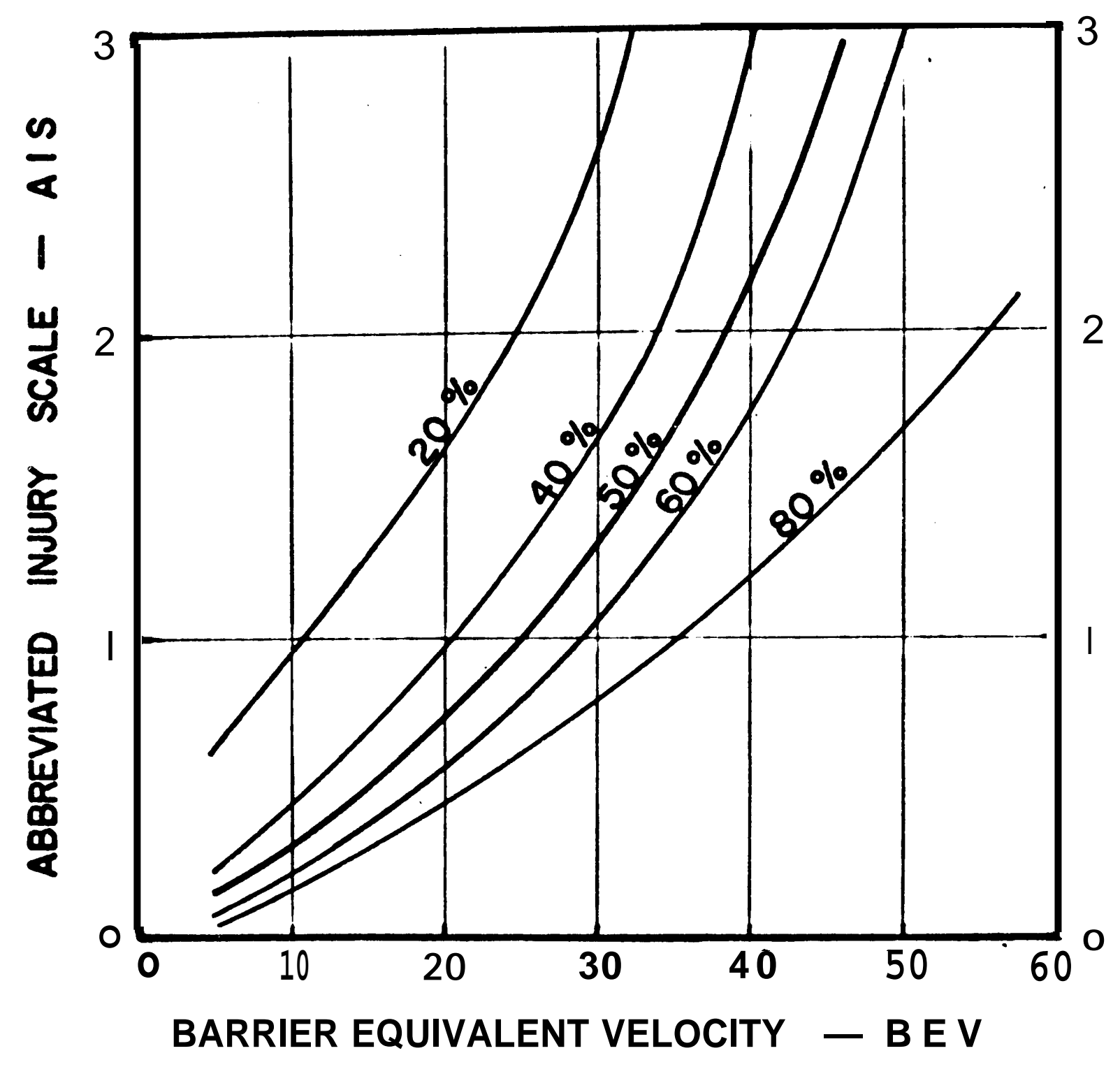

FIGURE 9 : INJURY AS A FUNCTION OF BARRIER EQUIVALENT VELOCITY FOR CUMULATIVE PER CENT OF INJURY 
APPENDIX E

LETTER FROM RICHARD WILSON

GENERAL MOTORS CORPORATION

February 4, 1975 


\section{GM \\ General Motors Environmental Activities Staff Safety Research and Development Laboratory}

General Motors Proving Ground, Milford, Michigan 48042

February 4, 1975

Dr. Lawrence A. Goldmuntz

Economics and Science Planning

1200 18th Street, N.W.

Washington, D.C. 20036

Dear Dr. Goldmuntz:

You are to be complimented on your recent Automobile Collision Data Workshop. The free interchange of ideas from such a wide cross-section of data gatherers and data users should be most useful as you formulate your recommendations to the Office of Technology Assessment. I was happy to participate and hope the following comments and the attached material will add to your study.

GM believes there is a need for better accident data so that the true benefits of safety standards can be assessed along with their cost of implementation. This applies to current standards just as well as it does when considering future rulemaking. The value of better data is to improve vehicle safety and to decrease the risk of making an incorrect decision on a standard. The incorrect decision may result in enacting or failing to rescind a standard which is not cost beneficial, or, on the other hand, rescinding or failing to enact a cost beneficial standard. NHTSA should move ahead only with those standards on which they have sufficient information to support a favorable benefit/cost relationship.

You specifically asked for an estimate of the "potential societal cost of not having better accident data". One way to look at this is to consider that the cumulative cost to the consumer for safety standards to date is estimated to be approximately $\$ 245$ per car (exclusive of bumper provisions). An additional $\$ 250$ per car are forecast if proposed new safety standards take effect. This $\$ 495$ per car total related to current and proposed safety standards (bumper standards would be a further addition) translates to about $\$ 5$ billion per year if applied to production rates of 10 million cars per year. The need for reliable benefit data against which these costs can be evaluated is urgent. Accident data is one source for such information.

Basic requirements for a better accident data system have been presented before. GM has discussed NADS* and the University of Michigan Highway Safety Research Institute has presented SIR**. Other plans may be

* National Accident Data System - Paper by Terry and Schneider given at GM's June 1973 Automotive Safety Engineering Seminar (copy attached).

** National System for Collecting Multipurpose Accident Data - paper by O'Day given at the June 1974 Experimental Safety Vehicle Conference. 
forthcoming from your workshop. While exact data system costs have not been formally worked out, they likely are in the area of 10 to 20 million dollars a year. If better accident data could increase the benefit/cost of safety standards by even a few percent (one percent of the above $\$ 5$ billion would represent $\$ 50$ million), the \$10 to $\$ 20$ million government investment per year seems very reasonable.

As a specific example, we estimate the cost of continued use of side guard beams, needed to meet MVSS 214, to be about $\$ 10$ to $\$ 12$ per car. Applying this cost to 10 million cars per year, this single item of standard represents a total amount to the consumer of $\$ 100$ to $\$ 120$ million per year. And yet, the current state of accident data does not even allow a determination of whether side guard beams have had any benefit or not. Again, $\$ 10$ to $\$ 20$ million per year for better data seems a minimum expenditure when viewed as a critical ingredient guiding the public's investment of billions of dollars in the costs of their cars.

I hope your project will pull together our country's need in the accident data area. We are convinced there is a need for this type of better decision-making information. I look forward to your final report.

Very truly yours,

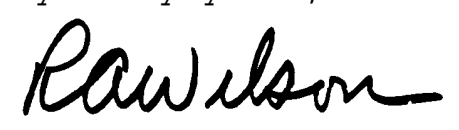

R. A. Wilson

Engineer-in-Charge

\section{$R A W / c l w$}

Attach. 


\section{National Accident Data System}

C. Thomas Terry - Section Engineer

Richard W. Schneider - Senior Project Engineer

Safety R \& D Laboratory

GM Environmental Activities Staff

Field accident data which reflect what is truly happening $m$ the field today are necessary (1) for the automobile industry to evaluate performance and guide future designs and (2) for the NHTSA to evaluate standards and guide future rule making. This type of data system is not available now. The multilevel system recommended by GM to accomplish this would use the expertise already available in many of the NHSTA-Sponsored multidisciplinary accident investigation teams. The system consists of several study areas which include exposure data and levels 1, 2 and 3 accident data. Another requirement of the system would be a central facility which would process the data and make it available to both NHTSA and industry.

On June 12, 1970, at a Data Accident Investigation workshop* in Brussels, Belgium, GM outlined why field

accident data is needed by automobile manufacturers. These needs to collect accident data are:

\section{Data Needs}

1. Evaluate present safety system $\%$,

2. Predict performance of proposed safety systems.

3. Identify problem areas \& evaluate solutions on cost/benefit basis.

4. Estimate human tolerances to impact

\section{Evaluation of Production Safety Systems}

Early accident investigators saw the results of automobile accidents and identified those vehicle components which were producing frequent and severe types of trauma. This early work supported the introduction of items such as the high penetration resistance (HPR) windshield in 1966 and energy absorbing steering columns in 1967. These investigators were able to measure the relatively large performance improvements of those safety systems. More subtle changes in safety performance can be found only by data collection programs that are refined enough to exhibit statistical trends. For example, it is generally agreed that further changes made to the present windshield will result in a smaller improvement in injury reduction compared to that made in 1966. Measuring this potential change in performance will require a sophisticated accident data collection program.

* R. A. Wilson \& C.T. Terry, NATO Accident Investigation Workshop, FIELD ACCIDENT RESEARCH - GM's APPROACH, unpublished presentation, Brussels, Belgium, June 12, 1970

\section{Prediction of Proposed Safety Systems}

Before implementing any change to safety systems already in the field, the performance of the new safety systems must be predicted. This is the second principle way in which accident data is used.

If the prototype safety system is an improvement on a production item such as the current windshield, then the field data gathered in evaluating the current windshield's performance is used as the injury pattern baseline. The modified system is then tested in the laboratory to compare its performance with the present system. This laboratory comparison provides data to subjectively project how the new windshield might modify the present injury pattern in the field. In this way, the prediction can be made with some confidence as to the performance in the field of the proposed new system.

If a completely new safety system, such as the air cushion restraint system is proposed, the injury patterns which the new system could somehow influence must be identified. In the case of the air cushion restraint, available accident data might be used to identify the injury patterns in frontal collisions where the air cushion is envisioned to be most useful. The air cushion's effectiveness, as determined from laboratory tests, could then be used to predict how the present injury patterns could be modified by the introduction of this new restraint system.

\section{Identification of Problem Areas and Evacuation of Proposed Solutions on a Cost/Benefit Basis}

This identification of problem areas requires an over-view of the total injury picture. The over-view consists of the frequency of particular injuries caused by various components and the severities of these injuries. The areas where the most improvement can and should be made are generally where the highest frequency of most severe injuries occur. A relationship between frequency and severity should indicate the areas of high payoff - those areas where the most good can be done. Once these high payoff areas are identified, the priorities of safety development can be established by cost/benefit studies.

As solutions to the more obvious problem areas are incorporated, the identification of the less obvious problem areas becomes more difficult. To identify the less obvious problem areas will require incorporating even more rigorous data collection programs. It may be possible that a point of diminishing returns will be reached. That is, the time and cost of acquiring even more detailed information may not justify the insignificant amount of improvement made from the data derived. To reach this point is a noble goal indeed. 


\section{Estimation of Human Tolerances to Impact}

The three uses of the field accident data discussed above are specifically aimed at changing the design of the vehicle to reduce the frequency and severity of injuries. A different use of the data is to isolate particular accident situations so that information concerning human tolerances to impact can be generated.

Occasionally, from a large source of accident data, a particular occupant injury in a well-defined automobile accident situation can be attributed to a particular vehicle component. When this infrequent situation arises, and the mechanism of injury is understood, correlation of the accident or "field experiment" with a similar laboratory experiment is attempted. If the "field experiment" can be correlated to the laboratory, the occupant's impact situation might be quantified and the human tolerance to a particular type of trauma can be estimated. For example, an instrument panel may be identified as the cause of a particular type of head injury, A series of similar instrument panels are impacted in the laboratory until the damage to the instrument panel in the accident case is reproduced. The forces and accelerations to produce the damage in the laboratory are then correlated to the injury produced in the field, In this way, the human tolerance is quantified for this particular type of injury.

These needs remain as valid today as they did three years ago. Further mentioned were the qualities of a good field accident data system:

\section{Data Qualities}

1. Rapid feedback

2. Random data sample

3. Current model data

4. Data compatibility

\section{Rapid Feedback}

A prime goal in automotive safety is the reduction of injuries and deaths due to automobile accidents. The more injuries prevented and lives saved, the better the job is done. improved safety systems must be incorporated as rapidly as practicable to achieve this goal. An orderly implementation of improved safety systems depends in large measure on the collection and assessment of field accident data. Only after a sufficient amount of statistical and in-depth data is collected can problem areas be identified and further improvements be recommended and implemented.

\section{Random Data Sample}

Besides the quantity of data gathered, a random sample is essential to insure its quality. Basically, random data is needed so that conclusions aren't erroneously based on the consequences of a unique accident, or limited number of accidents. False accident and injury patterns can be created by generalizing from a small sample of non-random cases. In the past, most sources of accident data have not been random. Most accident investigations typically have been biased by geography, injury level, damage level, or other accident selection techniques. A valid data sample must be representative of the real world.

\section{Current Model Vehicles}

Each year safer automobiles are produced. Measuring these advances in safety performance from one year to the next requires a valid data baseline. it should be realized that resources are limited and it would be virtually impossible to collect enough data on the total vehicle population in one year. The most efficient use of resources is to concentrate investigation on the most useful data source - current model vehicles. Of course, as current model data is collected each year, in time, a data bank will be built which will allow a comparison of newer automobiles with trends based on many years.

\section{Compatibility of Format}

If various data sources are ever to be combined to form large data banks, they must, at least, be in the same basic format. This means that the same information is recorded for each accident and some means of easily combining information from different sources is provided. This is particularly important when in-depth data is being collected because of its inherent complexity.

However, even when it is physically possible to combine data from various sources, it is not always advisable. Each investigator tends to bias his accident selection in some manner such as injury only, rural only, etc. Since the data base for each investigator is usually different, a direct statistical comparison of their data is not advisable.

Again, these characteristics are still desirable today as they were three years ago. There is no known source today which satisfies all of these qualities. The one key quality which bears emphasis is the random data sample. The random data sample criteria implies that the accident cases selected are representative of the national accident experience. This representativeness is critical for sound decision making regarding automobile design and government rule making. 
Making decisions with national implications in highway safety using only data from rollover accidents in North Carolina is no more valid than predicting the Gross National Product from monitoring only the construction industry in Utah.

\section{Current Data Status}

In the three years since that NATO workshop, some other factors have become obvious regarding the value of accident investigation.

1. The information received not only can be used by the industry for evaluation and direction, but also can apply to Government at all levels for rule making.

2. Variation in the interpretation of current accident data results from two factors:
a. Different analysis techniques
b. Different data sources

Variation of results due to the first cause i.e., different analysis techniques, is healthy and promotes various problem solving strategies to be explored and compared. However, differences due to the second source are generally inefficient and result in problems of interpretation. This problem will remain unsolved until the many various data collection efforts are coordinated so that their results can be combined. This combination into a representative data set will then allow, the safety experts to base decisions on a sound technical basis.

These previously stated needs and system characteristics coupled with the conflicting conclusions which result from the uncoordinated data collection activities around the country have led GM to propose what is called a National Accident Data System.

Before outlining the proposal for such a system, one point should be stressed: the system being proposed is not the best system that theoretically could be designed. In fact, it is several steps away from being an optimum design. But it is also many steps closer to an optimum system than anything that exists today. Rather than wait for that perfect system to be implemented, it is imperative that the obvious contradictory nature of various data sources be eliminated now so that valid cost/benefit studies can be used in achieving the goal of reducing injury and death on the highway. Each change made to the system after it is begun should be directed toward the desired optimal system.

The proposal itself tries to incorporate many of the data collection activities that are now in existence while eliminating other unnecessary ones. But the design is primarily dictated by the desire to establish a coordinated National Accident Data System in a relatively short period of time.

\section{DATA COLLECTION}

The proposed system involves designating certain geographic regions of the country as sample areas where extensive surveying and profiling will be conducted. This is analogous to taking a Gallup Poll of the nationwide accident experience. Since many of the existing Multidisciplinary Accident Investigation (MDAI) teams sponsored by the NHTSA are somewhat randomly located and because expertise already is available from the teams, we are proposing that selected MDAI teams would form the nucleus for the data collection system. This proposal would convert existing MDAI teams into multi-level programs such that each team has the responsibility of coordinating the gathering of the following levels of information within their specific regions:

1. Exposure data (non-accident)

2. Level 1 accident data

3. Level 11 accident data

4. Special accident studies

Teams which could not reliably supply all these levels of information would not be included in this program.

\section{Exposure Data}

Exposure data is profile information on the number and types of people, vehicles and roads in the area. this information is used to define the universe in which the accidents are recorded. Ideally, when all the regions are combined, the exposure should be "representative" of the total United States. Capturing data of this nature allows the various combinations of vehicles/drivers/roads to be described whether in an accident or not. Most of this information is available in existing state operational files. The system should allow specific surveys of additional data to also be conducted. For example, it may be necessary to establish how many miles various age groups drive annually.

\section{Level I Accident Data}

This level requires collecting a standard police report on all accidents in the region which meet a predetermined severity threshold. An alternate to the standard form would be a form with a common core of information with other elements decided upon by the local jurisdictions. This level of information briefly defines the nature of all accidents in the area. This information, coupled with the exposure data, make possible the computation of accident rates, such as 
fatalities/miles driven, accidents/make and model, or accident/driver age. Since the accidents described in this file contain both injury and no-injury cases, computing the probability of an injury occurring is also possible. Definitions or specifications of variables within each region and from region to region must be consistent. This standardization of definitions between regions is imperative, and will provide the program with one of its greatest challenges and one of its greatest advantages over current programs Emphasis upon the training of the police investigation people is important for this level of data. Definition of what an accident is or of what the various injury levels are must be explicitly stated and uniformly interpreted. Again, flexibility should allow specific, supplemental information to be collected when needed. As an example, the police could be asked to ascertain whether the head restraint was in the "up" or "down" position in a rear end accident.

\section{Level II Accident Data}

This level of data would collect information on all accidents in the region which involve a recent model vehicle and an injury. Information on all vehicles involved in the accident would be required. The injury may in fact occur in an older vehicle which impacted the recent model vehicle. This level data has been most valuable from the manufacturer's viewpoint and has historically been the source of injury causation information. Extending the coverage to include older vehicles would allow comparison of vehicles of different ages. in the past, information of this type collected by GM and other has led to improved vehicle design, examples being HPR windshields and the energy absorbing steering assembly. The information gathered would define the injury severity, the causes of the injury, the accident description, a measure of its severity, and some information relative to the cause of the accident. This information will allow the assessment of new safety systems as they are introduced such as air cushion restraint or starter-interlock webbing systems. Gathering the data on all accident modes and injuries will allow relevant safety evaluation tests to be specified. By combining this data with the Level I Accident Data, it may be possible to evaluate the relative safety performance of various makes and models of vehicles. The current thinking is that the information would be gathered on a modified version of the GM Field Form by investigators working for the MDAI teams. As with the present Field Form, a series of photographs will be required to supplement the information. The form would be expanded to collect information on pre-crash and post-crash phases of the accident which are not presently addressed on our existing form. This part of the system would also allow extra information to be collected on items of specific interest which are not in the GM Field Form. For example, the investigators may be asked to see if the starter interlock system has been defeated or if it had any effect on the occupant's usage.

\section{Level Ill Accident Data}

These special studies are performed to see why particular problem areas exist. The special studies conducted are based on the Level I or Level [1 information already gathered. For example, a special investigation could be undertaken to more closely examine why a particular class of vehicles for "over-represented" in a particular type of accident. The investigation may find that this type of vehicle is popular for owner modification which could result in unstable handling characteristics.

\section{DATA COMPILATION}

The next logical question is what to do with the data after it is collected in its relatively rough form i.e., police reports, GM Field Form, and photographs. To keep the interpretation of raw data consistent from area to area, it is proposed that the data be collected in a central location. At this location, the Level I data would be entered directly into a data bank. The information from the detailed Field Form and photographs in the Level II system would be analyzed and the final information entered into an automated data system. By centralizing this function, the number of subjective judgments are made more or less to be consistent because of the relatively few number of people involved. This situation is similar to that which is now used with the General Motors-MIC program, and has been found to be quite satisfactory. We feel the overall quality of data will be enhanced by increasing the consistency of the data. This central facility would not only provide common data entry and storage facilities, but would also offer a retrieval system for interested data users.

\section{PROGRAM IMPLEMENTATION}

Since this program should benefit the industry as well as the Government, it is recommended that joint Government/industry support for the implementation and annual operation of this program be solicited. The industry support could logically be under the auspices of either MVMA or SAE. Specifically, it is felt that the program offers a great opportunity for joint efforts between Government and the industry toward achieving a common goal. There are actions required of both industry and government to implement the proposed program. The program is a national goal and therefore should be funded with Federal monies. However, the 
industry should be willing to participate in initiating the program and continue support to the end that the data will be valid and available.

After this program is initiated, data acquisition could begin in less than a year. As shown in Figure 1.

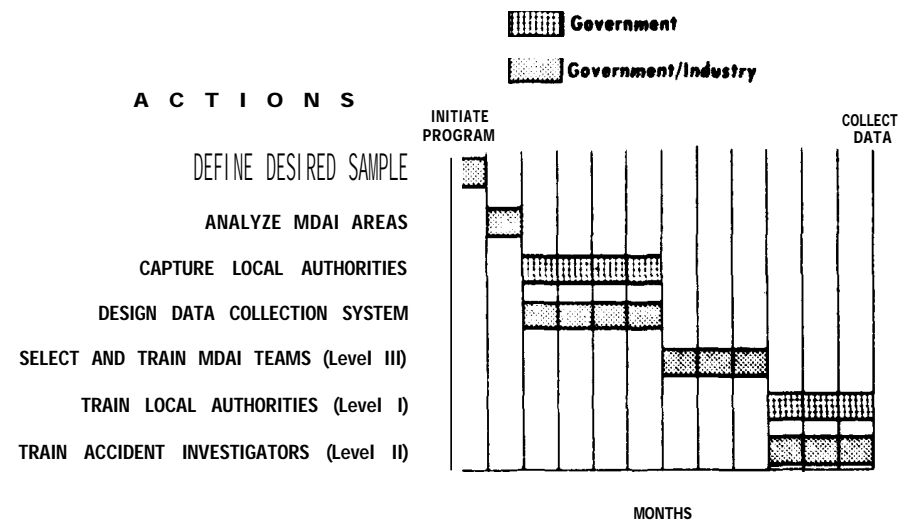

Figure 1

\section{SUMMARY}

Although this system is not a new idea, it is the basic simplicity which is most appealing. The program has been outlined in general terms only, although it has been given much more detailed thought as this general outline was developed. Rather than explore the details at this time, support is being solicited for the overall plan of action in the hope of gaining cooperation from other groups in the detailed planning phases of the program. Again, the payoff from such a system would be high, and achievable in a relatively short period of time.

It is GM's intent to act as a catalyst in the design and implementation of a National Accident Data System and encourage any of you today to accept this challenge with us.

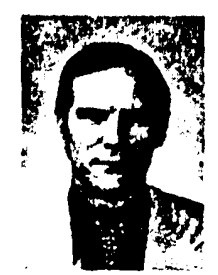

C. Thomas Terry

C. Thomas Terry is a Section Engineer responsible for the Field Accident Research activity at the safety Research and Development Laboratory located at the GM Proving Ground.
His responsibilities include the collection and analysis of field accident data

He received a Bachelor of Science Degree in Civil Engineering from Rose Polytechnic Institute, Terre Haute, Indiana, and a Master of Science in Engineering Mechanics from Wayne State University, Detroit, Michigan. Mr. Terry joined General Motors in 1969 and was assigned to the biomechanics area with responsibilities in human simulation and volunteer testing. He was chairman of the SAE Crash Test Dummy Subcommittee during this time.

Mr. Terry then joined the Field Accident Research group in 1970 and was promoted to his present position in 1971. In 1972 he assumed the role of Chairman of the Motor Vehicle Manufacturers Data Collection Co-ordinating Subcommittee.

Among his publications are:

"Radiological Studies of Organ Displacement Due to Vertical Accelerations" presented at the 18th Annual Conference of Engineering in Medicine and Biology, November 1965, Philadelphia, Pennsylvania.

"Review of Mathematical Models of Response to Acceleration, " presented at the Winter Annual Meeting of the American Society of Mechanical Engineers, November 1966, New York, New York.

"A viscoelastic Model of the Human Spine Subjected to $+g_{z}$ Accelerations, " Journal of Biomechanics, Vol. 1, pp 161-168, Pergamon Press.

“Field Accident Research-GM's Approach, ” R. A. Wilson, C. T. Terry, presented at NATO Accident Investigation Workshop, Brussels, Belgium, June 12, 1970.

“Benefits of the In-Depth Case Study, " presented at 1972 Annual Meeting of Society of Automotive Engineers, January 10-14, 1972.

“National Accident Data System, " C. T. Terry, R. W. Schneider, GM Automotive Safety Seminar, June 2\&21, 1973.

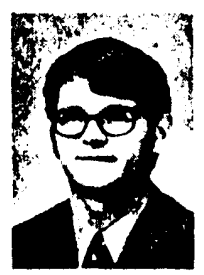

Richard W. Schneider

Richard W. Schneider graduated from Grinnell College where he received the degree of $B . A$. in 1969 and a Masters Degree of Business Administration in 1971. He joined General Motors Proving Ground in 1971 where he was involved with field accident research. Mr. Schneider is currently senior project engineer with the Safety Research and Development Laboratory at the Proving Ground and active in the area of field accident research. He is a member of Operations Research Society of America. 
STATISTICAL RATIONALE FOR THE

NUMBER OF AUTOMOBILE CRASH RECORDERS

PROPOSED FOR PROCUREMENT AND INSTALLATION BY NHTSA

National Highway Traffic Safety Administration

February 5, 1975

(date of receipt) 
STATI STI CAL RATI ONALE FOR THE NUMBER OF AUTOMDBI LE CRASH RECORDERS PROPOSED FOR PROCUREMENT AND I NSTALLATI ON BY NHTSA

National Highway Traffic Safety Administration

(Received February 5, 1975)

The statistical justification for the number of crash recorders requested by NHSA depends primarily on the answers to two general questi ons.

A If $\mathbf{N}$ crash recorders are instal led in passenger cars, what number of crashes will be recorded annual ly in each category, or "cell" of interest? For example, how many frontal i mpacts with impact speed $(\Delta v) 30$ mph or nore will be recorded by the crash recorders?

B. G ven the answers to question $A$, will these numbers provide adequate inf or mati on on the crash envi ronment. Thi s i nvol ves statements about the precisi on and accuracy of vari ous esti mates of rates, proportions or di stri butions, such as confi dence I i mits or error standard devi ati ons.

Fi gure 1 summarizes mach of the basi $c$ factual information needed to answer question A The figure shows numbers of crashes of vari ous types that woul d be expected in 1 year from a crash recorder fl eet of 100,000 vehicl es. The numbers are deri ved from NHSA's experience with the current restrai nt systens study and ot her acci dent studies. The esti mated recovery rate for crash recorders in acci dents is 64 percent; this is a judgment factor on which there are few rel evant data. 
Fi gure 1 shows an initial fleet of 100,000 recorders, and it is easy to nodify the figure to obtain two other useful sets of figures. If one adds three zeros to each number in the figure, the resul ting numbers are esti mates of the nunbers of crashes occurring with the enti re U. S. - aut onobi le popul ati on in 1 year. If the numbers are each di vided by 1,000 , the result is the percent in each category. For example, we can see that about 1.6 percent of the vehicl es each year will be invol ved in towanay crashes from which the recorder is recovered.

Fi gure 2 ill ustrates the problem of esti mating the cumul ati ve di stri buti on of crash speeds. ("Speed" may refer to any measured val ue such as $A v$, barri er equi val ent vel oci ty (BEV), travel ing speed, etc.). The figure shows a "true" di stributi on functi on, represented by the sol id curve, and an empi rical di stributi on, obtai ned through the recorder, and represented by the stepped graph. The maxi mum vertical di stance $D$ bet ween the two curves is a random variable. As the number of observations increases, the probability that Dwil exceed any speci fi ed val ue decreases; i. e. , the empi rical di stri buti on functi on approaches the true popul ati on di stributi on f unction. The fol l owing table shows the numbers of observati ons needed to obtai $\mathbf{n} 80$. and 90 percent confidence that the maxi mum devi ati on between true and empi rical di stributi on functi ons does not exceed a specified val ue. 
Figure 1 - Yiel d from 100, 000 Crash Recorders in 1 Year

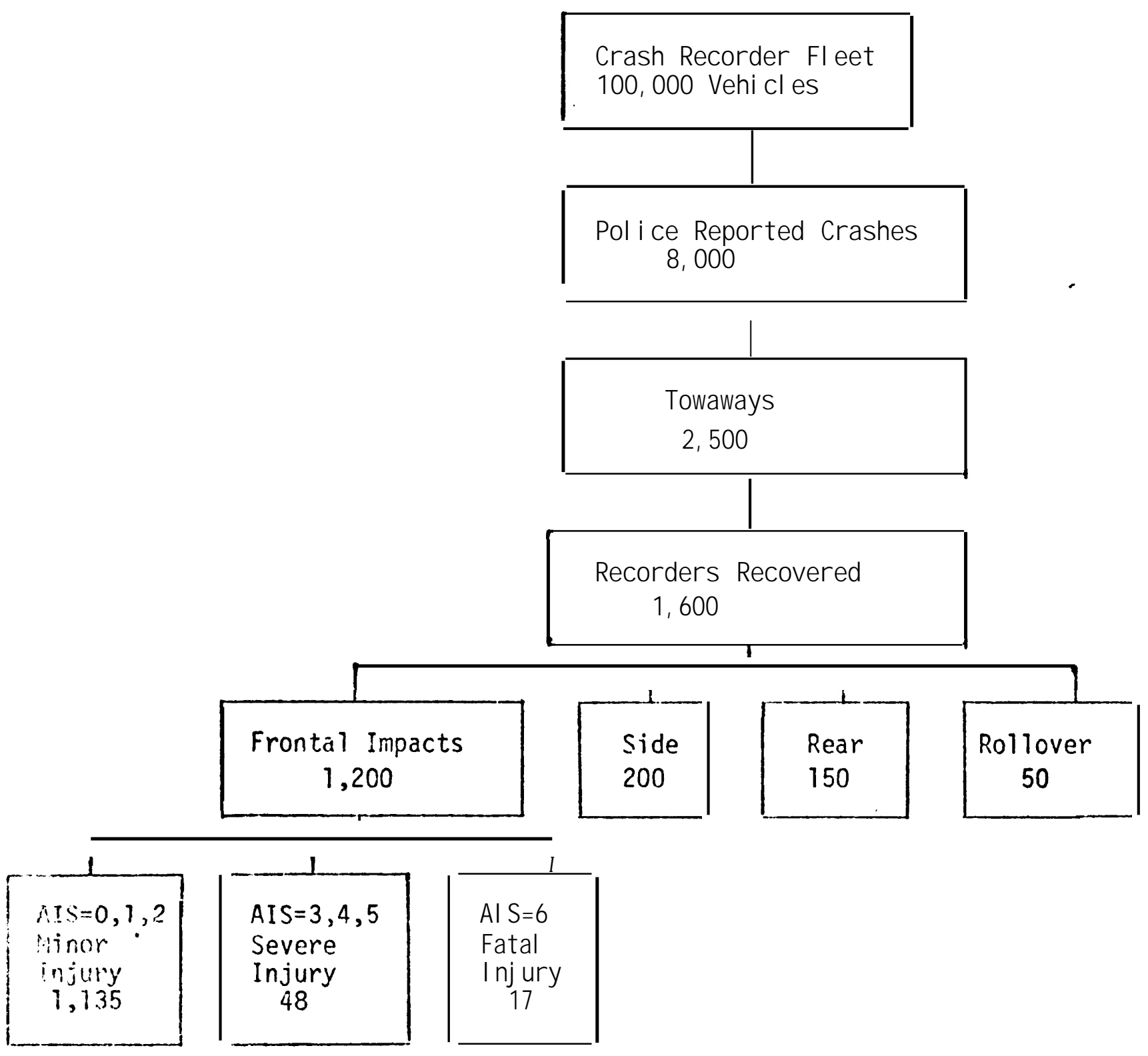

(1)

(2) 
Figure 2 Cuml ative Distributi on of Crash Speeds

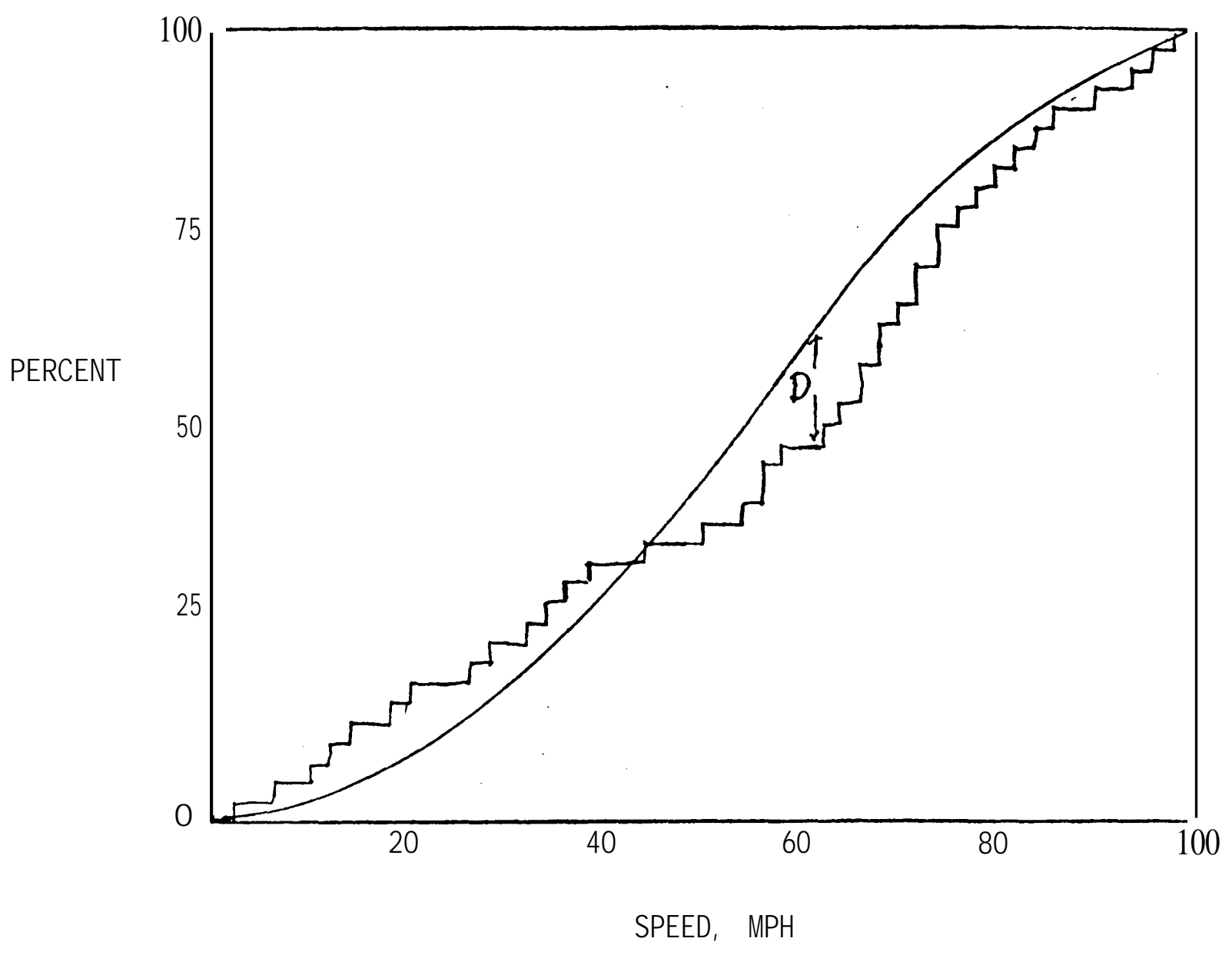


Table $1 . \quad$ Nunber of Observati ons Requi red for Speci fi ed Conf $i$ dence That Mexi mum Devi ati on Bet ween

Empi ri cal and Hypotheti cal Di stri buti on Does Not Exceed .

Val ue Shown

\begin{tabular}{|c|c|c|}
\hline \multirow{2}{*}{ Maxi mum } & \multicolumn{2}{|c|}{ Conf $\mathrm{i}$ dence Level } \\
\cline { 2 - 3 } Devi ati on & 80 Percent & 90 Percent \\
\hline .01 & 11,449 & 14,884 \\
.02 & 2,862 & 3,721 \\
.03 & 1,272 & 1,653 \\
.04 & 716 & 931 \\
.05 & 458 & 595 \\
.08 & 179 & 233 \\
.10 & 115 & 150 \\
\hline
\end{tabular}


In esti mating the fraction of the crashes that fall into a category of i nterest (e.g., i mpact speed over $30 \mathrm{mph}$ ), we are concerned wi th the variability of an observed proportion $f$ in a sample froma population in which the "true" proportion is p. In I arge samples ( $>25)$ the observed fraction is di stributed normal ly with mean $p$ and standard deviation:

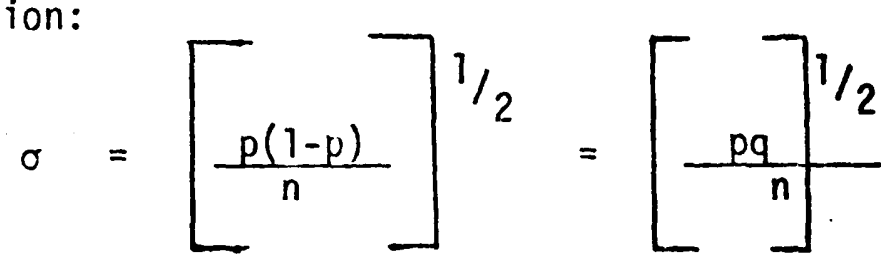

where $n$ is the sample size. The greatest variability occurs when $\mathbf{p}=\mathbf{. 5}$, in whi ch case the formul a reduces to

$$
\sigma=\frac{1}{2 \sqrt{n}}
$$

So if we specify a probability (confidence level) that the observed resul ts shal I not devi ate by nore than $D$ from the popul ati on proporti on $p$, the requi red sampl e si ze can be esti nated. Tabl e 2 shows maxi mum sampl e si zes required at t no conf $i$ dence I evel s. 
Tabl e 2. Sanpl e Si ze Requi red to Esti mate a Proportion wi th Error Less Than D

\begin{tabular}{|c|c|c|}
\hline $\begin{array}{l}\text { Mexi mum Devi ati on D } \\
\text { From Popul ati on } \\
\text { Proporti on }\end{array}$ & \multicolumn{2}{|c|}{ Conf i dence Level } \\
\cline { 2 - 3 }, 01. & 80 Percent & 90, Percent \\
\hline .02 & 4,107 & 6,767 \\
.03 & 1,027 & 1,692 \\
.04 & 256 & 752 \\
.05 & 164 & 423 \\
.08 & 84 & 231 \\
.10 & 41 & 106 \\
\end{tabular}


The preceding material will now be applied to let us reach sone concl usi ons on how many crash recorders NHTSA shoul d purchase and i nstal I .

1. To estimate the proportion of fatal crashes at barrier equivalent velocity below a stated speed, close to a million recorders would be needed. From line (6) of Figure 1, we see that these would yield 170 frontal impact fatalities in a year and 510 in 3 years. This would permit us to state, for example with 80-per cent confidence, "the percent of fatalities in frontal impacts in which BEV exceeds a stated speed is $\mathrm{x} \pm 3$ percent" after 3 years of data collection with 1,000,000 recorders. For deaths in crashes other than frontal, the requirements range from at I east six times as great for side crashes to at most 24 times as great (i.e., 24,000,000) for rollover crashes. The costs to determine any of these fatality distributions directly with the crash recorder appear to be prohibitive.

if we use the inj ury criterion of either fatal or severe inj ury . (AS > 3), ( see Ii ne 6, Figure 1) the requi red numbers reduce by a factor of approxi matel y 4, but are still very high.

2. A more li nited goal is to determine the distribution of barrier equi val ent speeds in crashes by i mpact type. Thi s information is an essential input for crashworthi ness design. In this case, the distribution of BEV s for frontal crashes can be determined qui te well in a year to about \pm 03 wi th 100,000 recorders> The error in esti mating a si ngle proporti on (f or exampl e, the fraction of BEV under $30 \mathrm{mph}$ ) will be I ess 
than . 02 with 80 percent confidence and less than .03 with 90-percent confidence. For si de and rear i mpacts, the BEV di stri buti on can be esti nated wi thi $\mathbf{n} \pm .80$ with 85 -percent confidence.

3. Table 1 shows that to reach 80 -percent confidence that the di stributi on of i mpact speeds observed with a crash recorder is wi thi $n$ \pm 03 of the "true" distribution function of observed population of crashes, it is necessary to record 1, 272 crashes.

The number of recorders needed to be sure of 1,272 recordings depends upon the frequency of the crash type that is of interest. The foll owing table shows the number needed for several crash types of interest. These numbers assure us at the 80-percent confidence l evel that the maxi mum error does not exceed \pm 03 .

\begin{tabular}{|l|c|r|r|}
\multicolumn{1}{|c}{ Impact Di recti on } & Severi ty Level & $\mathbf{1}$ Year & $\mathbf{3}$ Years \\
\hline Frontal & Fatal & $7,490,000$ & $\mathbf{2 , 5 0 0 , 0 0 0}$ \\
Frontal & AIS $>3$ & $1,960,000$ & $\mathbf{6 5 3 , 0 0 0}$ \\
Frontal & Towavay & $\mathbf{1 0 6 , 0 0 0}$ & 35,000 \\
Si de & Towavay & $\mathbf{6 3 6 , 0 0 0}$ & 212,000 \\
Rear & Towavay & $\mathbf{8 4 9 , 0 0 0}$ & $\mathbf{2 8 3 , 0 0 0}$ \\
Rol I over & Towanay & $\mathbf{2 , 5 4 6 , 0 0 0}$ & $\mathbf{8 5 2 , 0 0 0}$ \\
\hline
\end{tabular}

4. Another goal of the crash recorder program is to "cal i brate" other measures of crash severity. Some cheaper, l ess accurate, even biased measurements may becone very usef ul if thei $r$ bi ases are consi stent and if we can esti mate thei $r$ error di stributions. For exampl e, we might use vehi cl e defornati on more readi ly if we know how 
to associ ate a speed with each point on the vehicle danage scal e and could determine the expected errors. The situation is anal ogous to using a rul er that is 1 inch too long. If we knew the "true" val ues corresponding to the erroneous ones gi ven by the rul er, we would be able to use the rul er and make corrections.

To accomplish this cal i bration it would be necessary to consi der separatel y vehicles whose def ormati on characteri sti cs di ffer substantially. A ni ni mum of four groups woul d be requi red, correspondi ng to vari ous cl asses of vehi cles. Addi ti onal ly, it is necessary to consi der the type of obj ect struck: soft or hard, concentrated or di stri buted. . Fi nal ly, the cal $i$ bration needs to be done for at l east five points on a speed curve, preferabl y nore. There could be a requi rement for up to 80 groups of observations or cell s $(4 \times 4 \times 5)$.

With a fl eet of 100, 000 crash recorders, NHSA coul d obtai n 1, 200 frontal crash i mpact recordings in a year, which is an average of $1,200 \div 80=15$ per group, and many groups woul d have much I ess than 15 observati ons. Over a peri od of $\mathbf{3}$ years the average group si ze noul d reach 45 . If one assunes a $\mathbf{5} \mathbf{~ m p h}$ standard devi ation for the i naccurate measurements, then with 15 measurements the mean for each measured poi nt on a speed curve will be determined with 90 -percent conf $i$ dence to withi $n$ 1. $3 \mathrm{mph}$. For a $10 \mathrm{mph}$ standard deviation in the neasurenents to be cal $\mathrm{i}$ brated, the 90-percent limits will lie $12.5 \mathrm{mph}$ from the mean. 
Concl usi ons:

1. Instal I ing 100,000 recorders would permit a reasonably accurate determination of i mpact speeds for frontal towavay crashes in a year's ti me. Less accurate determi nati ons of si de and rear crash speed di stri buti ons for towaways would be avai I able by the end of 3 years. These statements rest on the assumpti ons that:

(a) The energy crisis and $55 \mathrm{mph}$ speed Ii mit will not reduce the rate of crashes drastically.

(b) NHSA can fi nd a way to get a representati ve sample of crashes.

2. W'th 100,000 recorders, it will be possible to "cal ibrate" the vari ous proxy measures used by acci dent i nvesti gators with an acceptable degree of accuracy.

3. The recorder program does hel p provi de a basi s for rul enaki ng. The NHTSA rul emaking or gani zati on was qui te cl ear in the requi renent for data which onl y recorders can provi de. Attached are 4 charts which state the appl $i$ cati on of recorder data. The standard writers have consi stentl y provi ded positi ve support to the recorder program because of the addi ti onal di nensi ons they provi de the techni cal data base upon whi ch standards are based. 


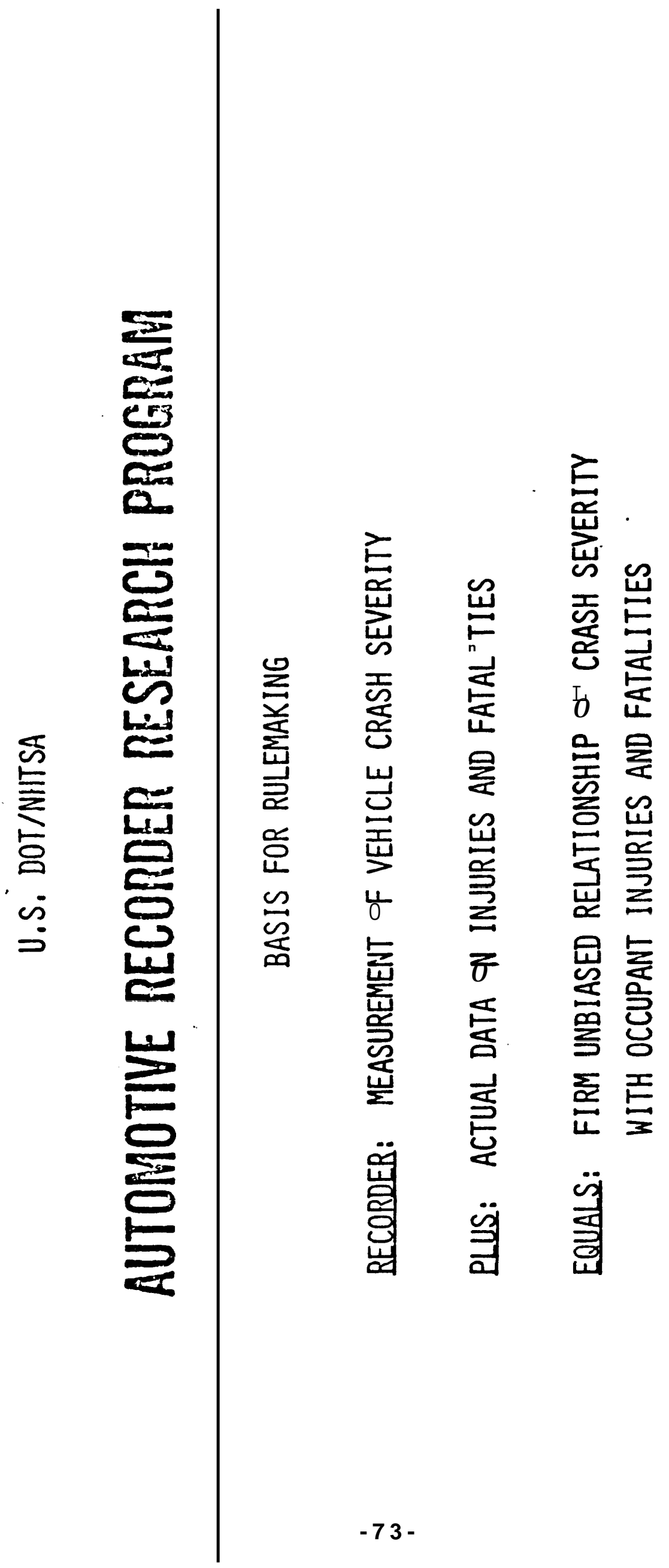




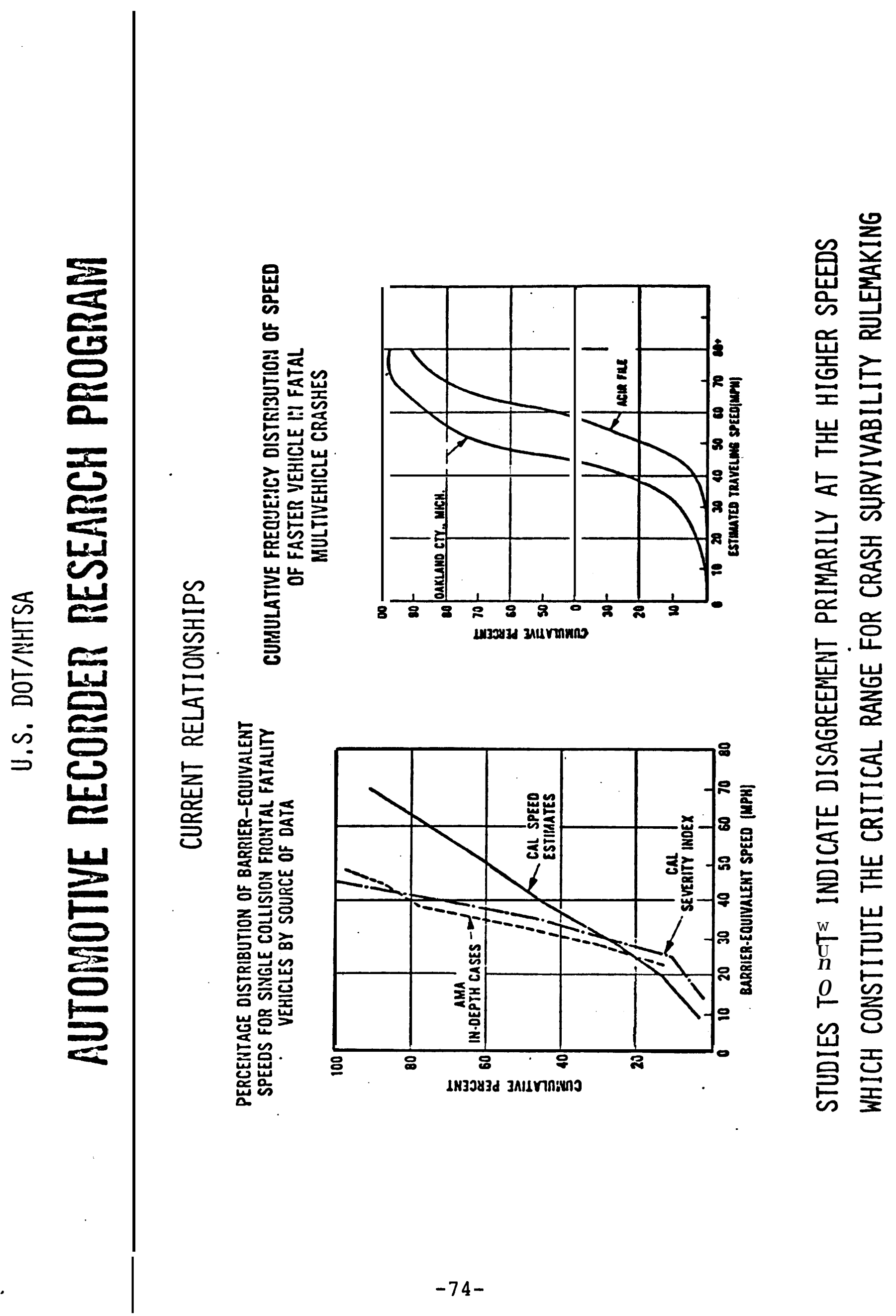




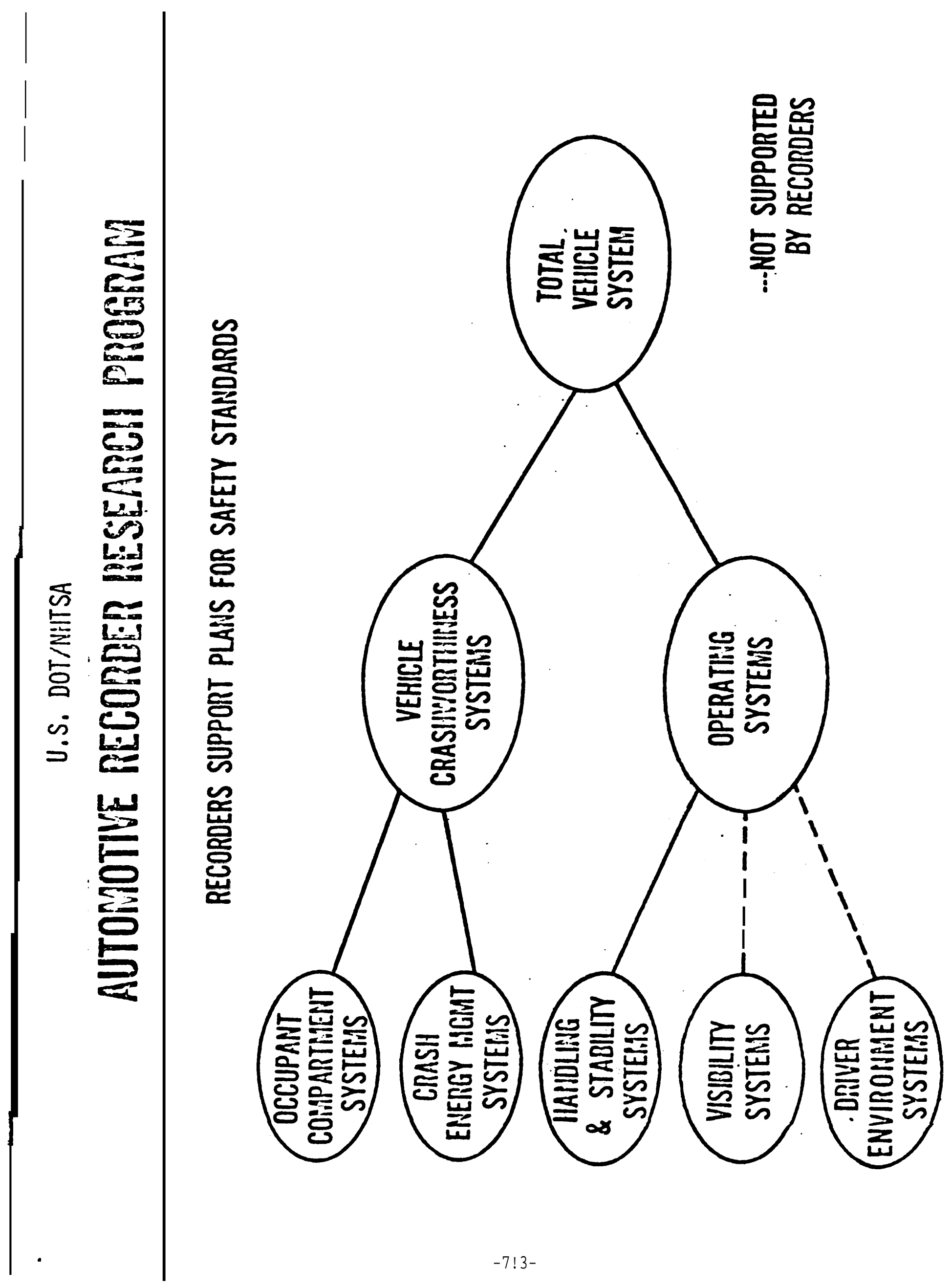




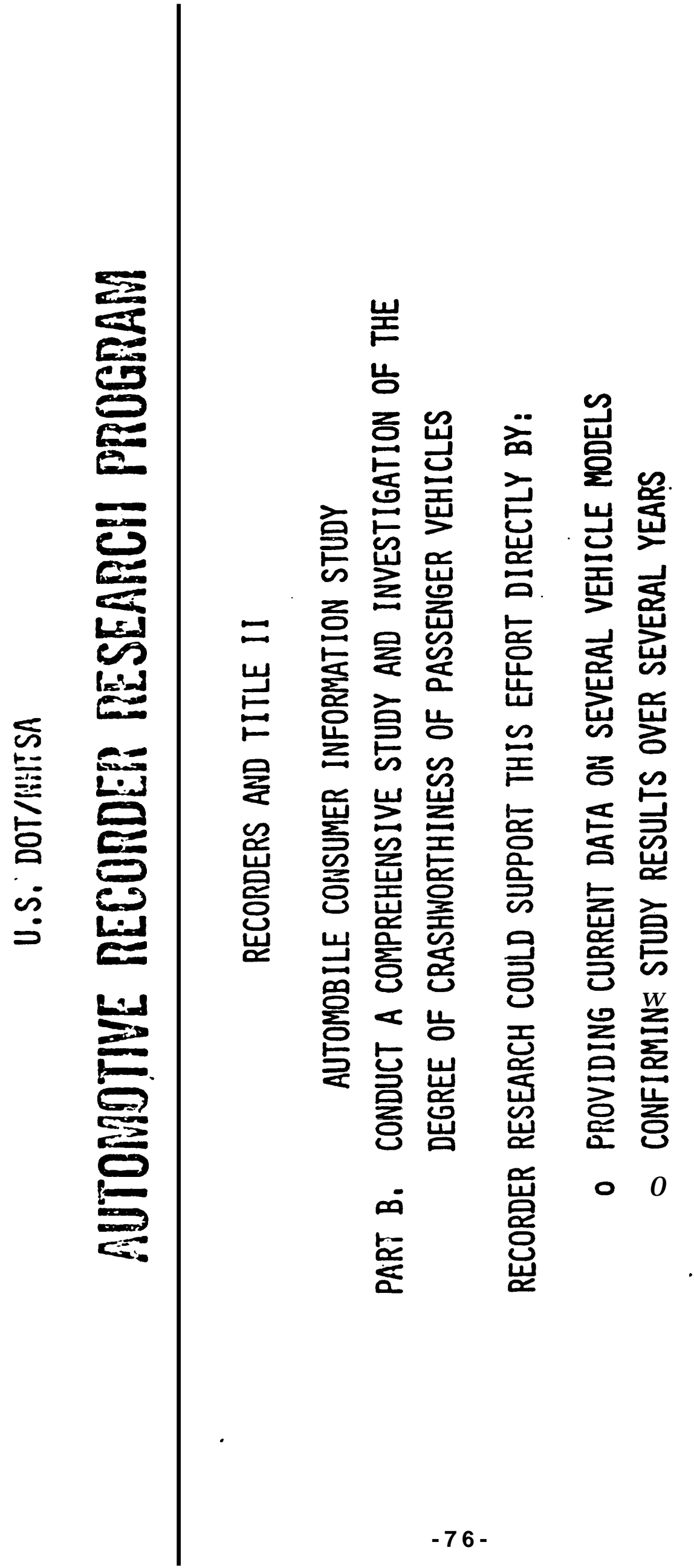


APPENDIX G

CRASH RECORDERS

AND

ALTERNATE METHODS OF DEFINING CRASH SEVERITY

James O'Day

HIGHWAY SAFETY RESEARCH INSTITUTE

University of Michigan

February 8, 1975

(date of receipt) 
Crash Recorders and Alternative Methods of Defining Crash Severity

James O'Day, Highway Safety Research Institute, university of Michigan Received February 8, 1975

Precise and representative data on highway crashes in the United States have potential value in enactment of standards, design of new vehicles, and in the evaluation of recent safety improvements. Accident data collected to date have been intended to serve many purposes, and one of the consequences of such a multipurpose activity is that it may not solve any specific problem as well or as economically as would an experiment designed specifically for one purpose.

One of the measures desired by many concerning the U.S. fatal accident population is the cumulative distribution of fatalities by crash severity. This has frequently been put in the form shown in Figure 1 with the abscissa being a barrier equivalent speed. It is clear that if we knew the exact crash speed (defined in an understandable and meaningful way) for each fatal crash in the U.S. for, say, one calendar year, the curve ' plotted from that data would precisely define the population. If we could sample randomly within the same population we could define this curve with a degree of precision which depended on the sample size.

The crash recorders which have been proposed for installation are, of course, not capable of infinite precision nor do they necessarily report thebarrier equivalent speed used in the wording of the standard. The test sequences in controlled crash tests reported indicate a 95\% error of less than 2 miles per hour in the derived velocity change $(\Delta \mathrm{V})$. The sample size required to achieve a precision in the vertical scale to that in the horizontal scale may be computed from a knowledge of the slope using the Kolmogorov-Smirnof test. For large numbers of cases $(\mathrm{N}>100)$ the error in percent (95\% bound) may be computed from:

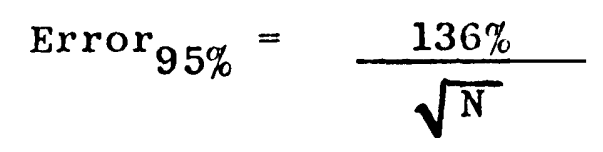


For a $2 \mathrm{mph}$ error in $\Delta \mathrm{V}$, and a slope of the distribution of approximately 2.5 (percent/mph) the required sample size would" be 740 cases. There would be some gain, of course, in an infinite sample; but a more usual practice would be to define the sample size as above so as to increase the total error only by the square root of two.

\section{SAMPLING CONSIDERATIONS: "}

In order for the data for a sample to truly represent the national population, the sample must be properly drawn. If there is a bias in the sample, the output will not be representative. For example, if the mean age of the fatal occupants in the sample were ten years older than the mean age in the U.S. vehicle fatal population-- and with the assumption that 10 years of age were equivalent to 5 miles per hour in fatality probability, the curve of Figure 1 would exhibit a bias of the order of $12.5 \%$ in a downward direction. There are, of course, a number of other possible biasing factors. If all cars in the sampled group were full size (and the total population contained a large proportion of small cars) the distribution would be affected in the opposite direction. The biases given as examples here are estimates for illustration only, but they are not unreasonable. To get the true representation one must either sample in such a way as to eliminate the biases (e.g., random sampling) or collect enough additional information to adjust the data to correct for unwanted bias.

NUMBER OF INSTALLATIONS NECESSARY FOR 740 FATAL CASES

There are a number of ways of computing the number of installations necessary to compile 740 fatal crashes over some period of time. A simple one will be used here. With approximately 100,000,000 passenger cars in the U.S. and about 40,000 in-car fatalities per year, only one in 2500 passenger cars would have a fatality in it in a year. 740 fatalities, then, would require 
$\mathbf{1 , 8 6 5 , 0 0 0}$ installations. If a three year period were acceptable this reduces to approximately 622,000 installations. If a larger error were acceptable (say twice as large), we no longer need 740 fatalities but only $1 / 4$ that number--and the sample could be further reduced to 155,000. So in three years with 155,000 installations there is a potential for defining the desired cumulative curve with a precision on the order of $\pm 10 \%$. The various options are shown in graphical form in Figure 2.

\section{DIS CUSS ION}

The statistical considerations above are based on a precise and complete sample. The mechanics of achieving this are not trivial. Placing a number of recorders in a sample of new cars biases the sample against older cars in the general population. And if these new cars were then distributed to the general population a high percentage of recovery would be difficult if not unlikely.

Placing the devices in a fleet (for example by agreement with an insurance company) should increase the probability of recovery--perhaps to a very high value. But this same action is likely to result in a non-representative sample in terms of age, sex, or car size. Adjusting such data to draw inferences to the national population is a questionable practice.

\section{ALTERNATIVES}

A number of crash severity measures can be viewed as alternatives to the crash recorder. None have the advantage of producing a direct acceleration-time trace during impact. But most are applicable in principle to all cars. These include the CDC (Collision Deformation Classification) --a newer version of the VDI (Vehicle Damage Index), the SMAC computer programs developed by the CALSPAN Corporation, comparison of detailed crush measure- 
ments on accident involved vehicles with results of instrumented crash tests (as described by Campbell in SAE paper 740565) or by Patrick (in an analysis of Volvo crashes). In addition, the TAD scale as applied by several police agencies is a crude measure of crash severity with the potential for relatively universal employment. Each of these will be discussed briefly below.

The CDC (or VDI)

The CDC was developed as a means of recording crash damage in a simple codable form. It consists of 6 elements--the clock direction of impact, four letter codes indicating the location of the damage (vertically and horizontally) and the general nature of the object struck, and a numeric code (1 through 7) indicating the extent of deformation. An experiment conducted by Cromack at Southwest Research Institute, and reported in an SAE paper, indicates that the $\mathrm{CDC}$ as presently defined can, in general, be assigned consistently by a trained investigator. The CDC, however, is not directly convertible into a measure of the crash dynamics because it depends in part on the structural characteristics of the particular car under investigation. Further, it was not developed primarily as a substitute for a measurement of the deceleration characteristics of the crashed vehicle, but rather as a simple codable record of crash damage.

The data elements contained in the CDC, however, when related to a knowledge of the vehicle structure (and perhaps other information about the crash circumstances) could permit a computation of some of the crash dynamics. An experiment could be conducted (largely with existing data) to define the ability of the CDC to predict much of the output desired from crash recorders. If an initial experiment looks promising, a large number of crash recorders in vehicles which are also measured with a CDC could lead to either (1) a calibrated CDC, (2) a redefined CDC which is more useful in the context of defining crash dynamics, or (3) both. The CDC has the advantage that it can be applied to any accident vehicle after the crash without benefit of additional 
instrumentation, and thereby reducing the problem of sample selection. It has the disadvantage, at present, that its capabilities for providing a measure of crash dynamics are not well known, and that these capabilities must depend on better knowledge of vehicle structure than is generally available in the literature.

\section{The SMAC Programs}

The MAC development is intended to provide computer assistance to the reconstruction of a traffic' accident. The method involves inputting certain observational and factual data into the computer, and iterating a solution which best fits the final rest positions of the vehicles involved. The iterative computer programs can be run from data acquired with a special observational tool (the SMAC van) or can be run with data taken by manual methods. In the latter instance, in particular, the technique should be applicable to a large number of collision analyses.

The present SMAC programs are limited to the ground plane, and, as a result, are not able to handle certain odd collision configurations-- such as rollovers, or vehicles running down an embankment. To the best of my knowledge the SMAC program output has hot been compared directly with crash recordings, although from some of the remakers at the recent conference $I$ would assume that NHTSA has either started to make such comparisons or has done some. Crash recordings have been used to compute A V. This output of the SMAC programs has been validated to some extent. In addition to the ground plane limitation, these programs are also limited by the accuracy of input data on the structural characteristics of the vehicle. However, the capability exists for removing these deficiencies. The problem of this point seems to be one of choosing the optimum tradeoff of input data requirements and modeling sophistication versus the detail and accuracy of the resulting output. 
ments on accident involved vehicles with results of instrumented crash tests (as described by Campbell in SAE paper 740565) or by Patrick (in an analysis of Volvo crashes). In addition, the TAD scale as applied by several police agencies is a crude measure of crash severity with the potential for relatively Universal employment. Each of these will be discussed briefly below.

\section{The CDC (or VDI)}

The CDC was developed as a means of recording crash damage in a simple codable form. It consists of 6 elements--the clock direction of impact, four letter codes indicating the location of the damage (vertically and horizontally) and the general nature of the object struck, and a numeric code (1 through 7) indicating the extent of deformation. An experiment conducted by cromack at Southwest Research Institute, and reported in an SAE paper, indicates that the CDC as presently defined can, in general, be assigned consistently by a trained investigator. The CDC, however, is not directly convertible into a measure of the crash dynamics because it depends in part on the structural characteristics of the particular car under investigation. Further, it was not developed primarily as a substitute for a measurement of the deceleration characteristics of the crashed vehicle, but rather as a simple codable record of crash damage.

The data elements contained in the CDC, however, when related to a knowledge of the vehicle structure (and perhaps other information about the crash circumstances) could permit a computation of some of the crash dynamics. An experiment could be conducted (largely with existing data) to define the ability of the CDC to predict much of the output desired from crash recorders. If an initial experiment looks promising) a large number of crash recorders in vehicles which are also measured with a CDC could lead to either (1) a calibrated $\mathrm{CDC}$, (2) a redefined CDC which is more useful in the context of defining crash dynamics, or (3) both.

The CDC has the advantage that it can be applied to any accident vehicle after the crash without benefit of additional 
instrumentation, and thereby reducing the problem of sample selection. It has the disadvantage, at present, that its capabilities for providing a measure of crash dynamics are not well known, and that these capabilities must depend on better knowledge of vehicle structure than is generally available in the literature.

\section{The SMAC Programs}

The SMAC development is intended to provide computer assistance to the reconstruction of a traffic' accident. The method involves inputting certain observational and factual data into the computer, and iterating a solution which best fits the final rest positions of the vehicles involved. The iterative computer programs can be run from data acquired with a special observational tool (the SMAC van) or can be run with data taken by manual methods. In the latter instance, in particular, the technique should be applicable to a large number of collision analyses.

The present SMAC programs are limited to the ground plane, and, as a result, are not able to handle certain odd collision configurations-- such as rollovers, or vehicles running down an embankment. To the best of my knowledge the SMAC program output has not been compared directly with crash recordings, although from some of the remakers at the recent conference I would assume that NHTSA has either started to make such comparisons or has done some. Crash recordings have been used to compute A V. This output of the SMAC programs has been validated to some extent.

In addition to the ground plane limitation, these programs are also limited by the accuracy of input data on the structural characteristics of the vehicle. However, the capability exists for removing these deficiencies. The problem of this point seems to be one of choosing the optimum tradeoff of input data requirements and modeling sophistication versus the detail and accuracy of the resulting output. 


$$
y=
$$




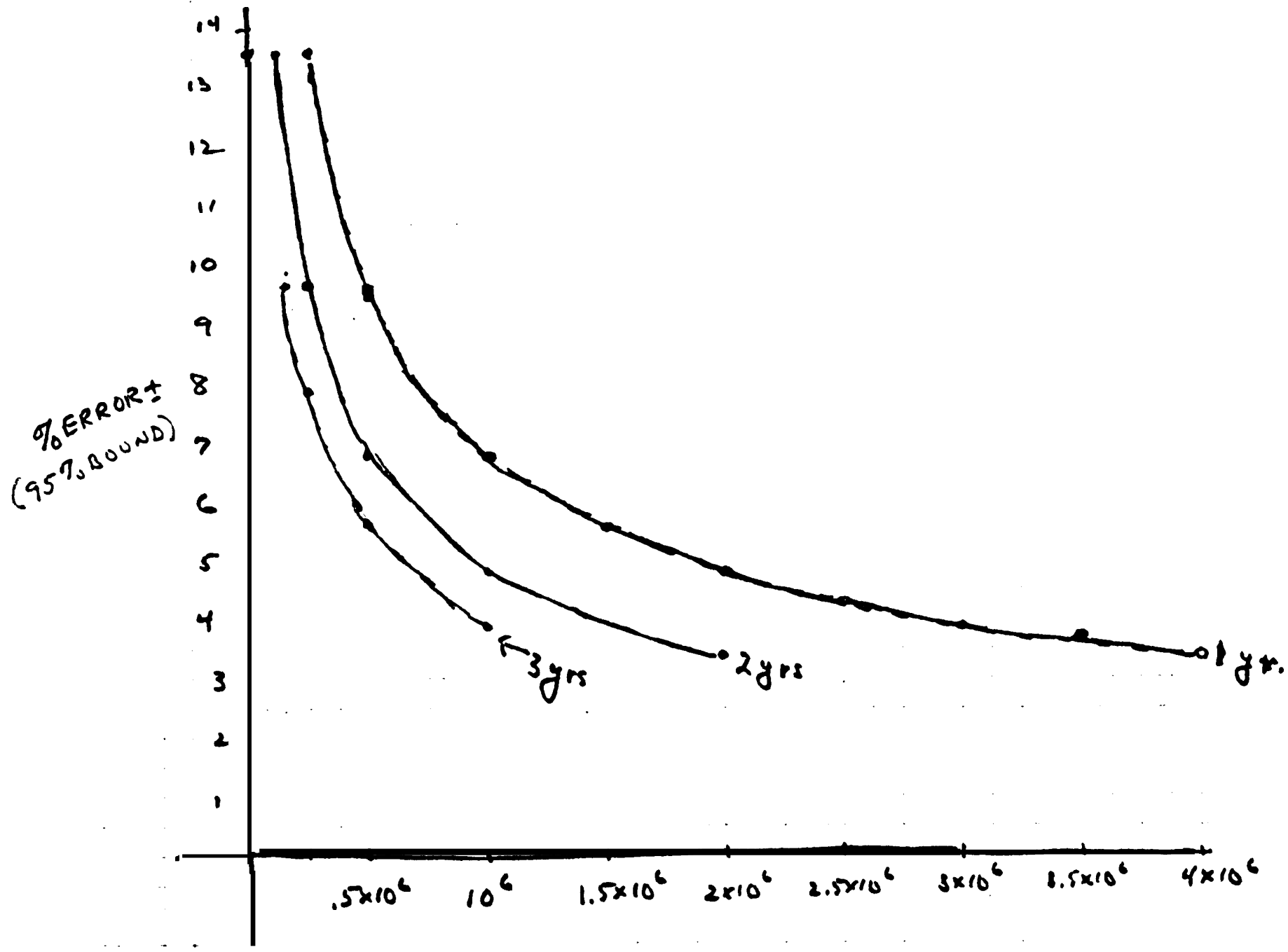

TOTAL INSTRUMENTED VEHICLE POPOLATION

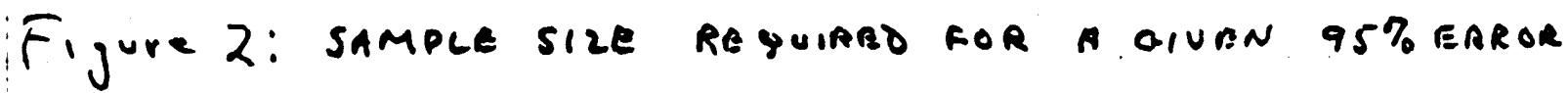
BOUND FOR 1,2 , ANO 3 YEAR PAOGAAMS. 


\section{APPENDIX H}

ADEQUACY AND LIMITATIONS OF CURRENT DATA SYSTEMS

Marie D. Eldridge

NATIONAL HIGHWAY TRAFFIC SAFETY ADMINISTRATION

January 16, 1975

$-87-$ 


\section{ADEQUACY AND LIMITATIONS OF CURRENT DATA SYSTEM \\ Remarks By \\ Marie D. Eldridge, Director \\ office of Statistics and Analysis \\ National Highway Traffic Safety Administration \\ AUTOMOBILE COLLISION DATA WORKSHOP CONEERENCE \\ January 16, 1975 -Rosslyn, Virginia}

In the very short time available to me this morning, I'm going to try to give you some highlights about the capabilities and limitations of our current data systems. I will also try to indicate where we see improvements within the near future.

However, before talking about the capabilities or the limitations, we really need to ask "capabilities or limitations for what?" So let's briefly talk about the objectives of our accident data systems.

First, we have to classify and count accidents. We need to determine the frequencies of accidents and classify them by their causal mechanisms, by their injury-producing potentials.

Second, we need adequate measurements of accident consequences, injuries, property damage or broader measures such as societal costs, a much neglected area and subject to great controversy but still one on which utlimately our decisions have to rest.

Third, we need to be able to describe, or model, crash injury mechanisms, that is, to relate the causal mechanisms and injury-producing potential to the actual occurrence of crash in-jury. This is particularly important in predicting the effects of proposed safety countermeasures. We have to 
describe functional relationships between numerous factors which at present are considered separately. All of these things that I have mentioned enter into the process of determining the efficacy and the benefits of existing or proposed safety measures.

Let us consider the criteria by which we should assess our crash data collection systems. It is my view that a comprehensive approach and a comprehensive consideration of all the data requirements that combine to give us the needed information is essential. It just won't do to get vey high accuracy in estimating speeds if at the same time the sample of accidents for which we obtain this information cannot he used to generalize and cannot provide us with the proper support for a rule that will apply to the whole country. High accuracy in one part of the data system can easily be nullified by weakness in another and, to quote an old saying there is no need to put a micrometer on the end of the yard stick.

\section{View Graph II}

I have listed in this view graph some of the criteria that we may use in assessing crash data systems. There are many ways of doing this but this may help provide a framework for discussing our present systems. First of all, there is the quality of the data. We are concerned with its representativeness and in our ability to generalize from it to a national crash population. A sample that contains only new cars or only auto fleets is not representative. Frequently, we may have a situation in which sample populations as defined are representative, but in fact, because of missing data or non-returns, we don't get an unbiased sample. 
A second criterion is accuracy of information. One of the reasons we are here today is the inaccuracy of certain information that we are now getting in crashes, namely the various speed parameters.

A third criterion is the ability of the system to be responsive and timely. The data need to be collected and processed quickly enough that the information is available before the decision has to be made. The sample sizes have to be large enough that we can have confidence in the decisions based on the results. At the same time we have to concern ourselves with costs arid make tradeoffs between costs and precision. Next there is the breadth or extensiveness of coverage of the information provided by the system in the many parts of our highway safety information matrix. And last but not least the cost efficiency.

\section{View Graph III}

If we had a great deal of time we could consider all this at the data item level or individual field level, but even to cover this matrix in any detail will have to be left for possible discussion later in the conference. I will simply mention that under exposure items we have the characteristics of the vehicle occupants and the amounts of driving by various driver types, their characteristics, licensing, training and so on. We have under vehicle exposure the counts of vehicles by type, travel amounts, their conditions, size, etc. The 
environmental exposure includes such things as traffic density, speed limits, highway types, design and so on. We could go down this matrix cell by cell and fill in the types of things that need to be considered. The final and very difficult quality has to do with the cost-efficiency of the data systems. When a decision involves a high cost or an extreme inconvenience, a great deal of effort will generally have to go into the data collection and analysis. However, we also wish to keep our data collection efficient in the sense of not collecting information for which there is no need or employing personnel or equipment more skilled or more accurate than is really necessary.

IV. Now let us turn to the capabilities of some of our current data collection systems. Basically, we have two types of systems. The first is based primarily on the state or local traffic and related records systems. The second type involves special investigative work. The state records are kept primarily for purposes other than safety analysis. However, we utilize their records for the Fatal Accident Reporting System, which is essentially a census or 100 percent sample of fatal motor vehicle accidents and for the planned National Accident Reporting System, which will be a probability sample of all accidents, of a given threshold. The accuracy of the information provided through the State traffic record systems varies of course. In some areas of particular interest to us it is quite poor. Speed causal factors and restraint systems usage, for example, may be misreported or unreported frequently. Timeliness is generally not a problem. It usually takes only a few months before an accident is in the file and therefore accessible to us. As far as the 
quantity of information is conerned, the State Traffic Record Systems are likely to provide us with a large number of cases for the more frequent types of accidents and the items of highest interest, but it is surprising how often in other circumstances we run out of data. The most obvious example is in making comparisons between makes and models of cars. When we get to some types of vehicles that are not on the road in large numbers, we have a very hard time collecting enough accidents to have a useful sample. The breadth of the information provided is generally not adequate. Impact speed for example is reported only in one state; traveling speed in about half the States and not for all accidents even in those States. Restraint system usage is not reported in most States and in many where it is reported, it is not reported for uninjured occupants. In-jury information and causal factors are sketchy. Post crash information, societal cost and property damage are usually not in the file.

It has been generally recognized that we can not obtain adequate information to support the standards by relying solely on these basic records oriented data systems. The second type of accident data collection system - those in which specific data collection efforts are sponsored or paid for by either the Federal Government or some other interested organization in the safety field such as MVMA or the Insurance Institute for Highway Safety. In these systems the investigation is likely to be carried out wholly or in part by professional accident investigators, resulting in substantially more extensive information. NHTSA has under way three types of sponsored studies. 
Fi rst is the Mul ti di scipli nary Acci dent Investi gati on teans. These teans do both on-scene and of f-scene in-depth i nvesti gati ons. Teans have been performing cl inical in-depth studies of sel ected acci dents in the U. S. , pri marily on new cars, si nce 1969. The representati veness of the sample that has been produced up to this ti me is poor. Different teans have been covering acci dents most rel evant to thei $r$ special interest. That si tuati on is gradual ly changing. The accuracy is generally good. Neverthel ess, there is consi derable room for i mprovenent. We have no capability for getting a ti me hi story of the crash forces and accompanying accel erati ons except through computer si mul ation such as the SMAC program At present we have about 6,000 MDA cases in the file. Many of these were not the result of on-scene investigation. There is detai I on nost aspects of the accident with the excepti on of exposure. As a system for producing statistical information needed for supporting our safety standards, the on-scene in-depth investi gations cannot be regarded as cost effective. The average cost per case is about $\$ 2,000$. The cost decreases to about $\$ 800$ per in-depth case if the on-scene investi gati on requi rement is El i mi nated. This does reduce the accuracy of reconstructi on of the accident and of course affects the esti mate of speed.

At a sonewhat l ower I evel of detai I NHSA has devel oped a system in conj uncti on wi th MNA to coll ect a probability sample of towavay invol venents of new cars in five sel ected regions of the country primarily for the purpose of eval uating acti ve and passi ve restrai nt systens. 
Data are

assembled from the police report, a doctor's report, photographs, a brief vehicle investigation, and driver interviews performed by field technicians. for the Data items collected are restricted to those needed/statistical analysis of restraint systems effectiveness. This is an example of what we may term a Level II study. We expect to make national estimates based on post stratification. The accuracy of the information in the selected data items' should be good, nearly as good as what comes from the multidisciplinary in-depth investigations. The quantity will be adequate to match the needs for estimating safety belt effectiveness. Because of the small numbers it is not likely to give us what we need for estimating air cushion effectiveness, very soon. As far as the breadth of the file is concerned, it is designed for calculation of crash injury rates and evaluation of restraint systems effectiveness. It does not address exposure or accident causation. Speeds and occupant contact points are not determined. The cost is around $\$ 100$ per case.

A third type of sponsored system is basically a bilevel investigation or one in which there is a supplementary investigation carried out by police with NHTSA or other funds added to take care of added costs. We have under development a system for sampling pedestrian and bicyclist accidents

in several hundred localities. The system is designed to answer questions at the level of detail that we 
nced to determine gross behavior and provide some good input for countermeasures. The data to be collected is primarily concerned with the nature and location of pedestrian and cyclist accidents as well as certain other items affecting visibility which would not normally be collected in the state accident reporting system. The cost per case is expected to be high primarily because of the relative rarity of pedestrian and bicyclist accidents and because in order to get an adequate probability sample that will properly represent rural areas, it is necessary to include localities with a very low frequency of accidents. The set-up time in preparing to get the supplemental investigations done in small localities is the same as it is in large localities, but the data rate is low and the total cost is increased disproportionately.

v.

AS we look ahead to potential improvement in the capabilities of our current systems that may be in sight we are really moving in two directions. The first is to create a national accident sampling system based on a probability sample. We have a contract under way with the Highway Safety Research Institute at Ann Arbor to help develop this system that will include some of the current investigative efforts but provide for sufficient. control of the selection of accidents that we will get a sample from which we can generalize to national crash populations.

The second area in which we anticipate improvements is in determining crash dynamics. These efforts, are of courses of paramount importance to this workshop. The work with the crash recorder is being covered by my colleague, Lynn Bradford. The other approach, SMAC, the computer simulation of the accident dynamics will be dealt with by our representatives from Calspan but I would like to say a few words about our experience with it. 
This program uses vehicle rest positions and impact damage to calculate impact velocities, the velocity change during the crash, acceleration pulse and predicted damage. The goal is to reconstruct the accident crash dynamics in sufficient detail that inputs needed by our standards makers are available. The use of the SMAC program may permit us to get, at a reasonable cost, an adequate representative sample of crashes once our national accident sampling program is up and running. However, it should be pointed out that the crash recorder is clearly a very valuable tool in developing necessary refinements to the SMAC program. Ideally, and this is IF

a moderate size "if",/the crash recorder and the SMAC work hand in hand well enough, we can succeed in reducing considerably the numbers of crash recorders required down stream. Precise calibration of the SMAC program will enable us to use Level 2 data for crash dynamics at a reasonable cost. Currently the cost per case, using the SMAC program is $\$ 150$.

In the short time available to me I have had to gloss over lightly much of the work related to crash data. Three members of my staff are here to provide detailed back-up and to join in any subsequent discussion of these points. They are Don Mela, Dr. Charles Kahane and Dr. Charles Moffatt. Before finishing these very brief remarks, I want to repeat a point I made earlier. We need to consider all relevant aspects of the data systems in a comprehensive fashion before making decisions on any of them separately. While we may not be able to devote that amount of detail to all aspects of the data systems in this conference I think that at least the major aspects should be considered before coming to any conclusions or decisions. 


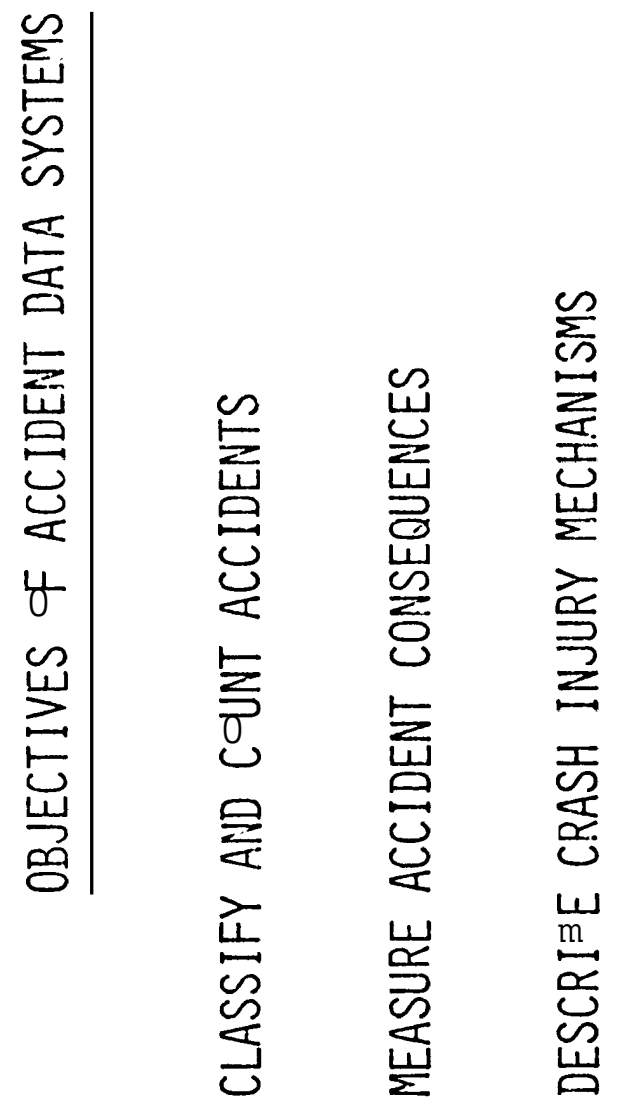




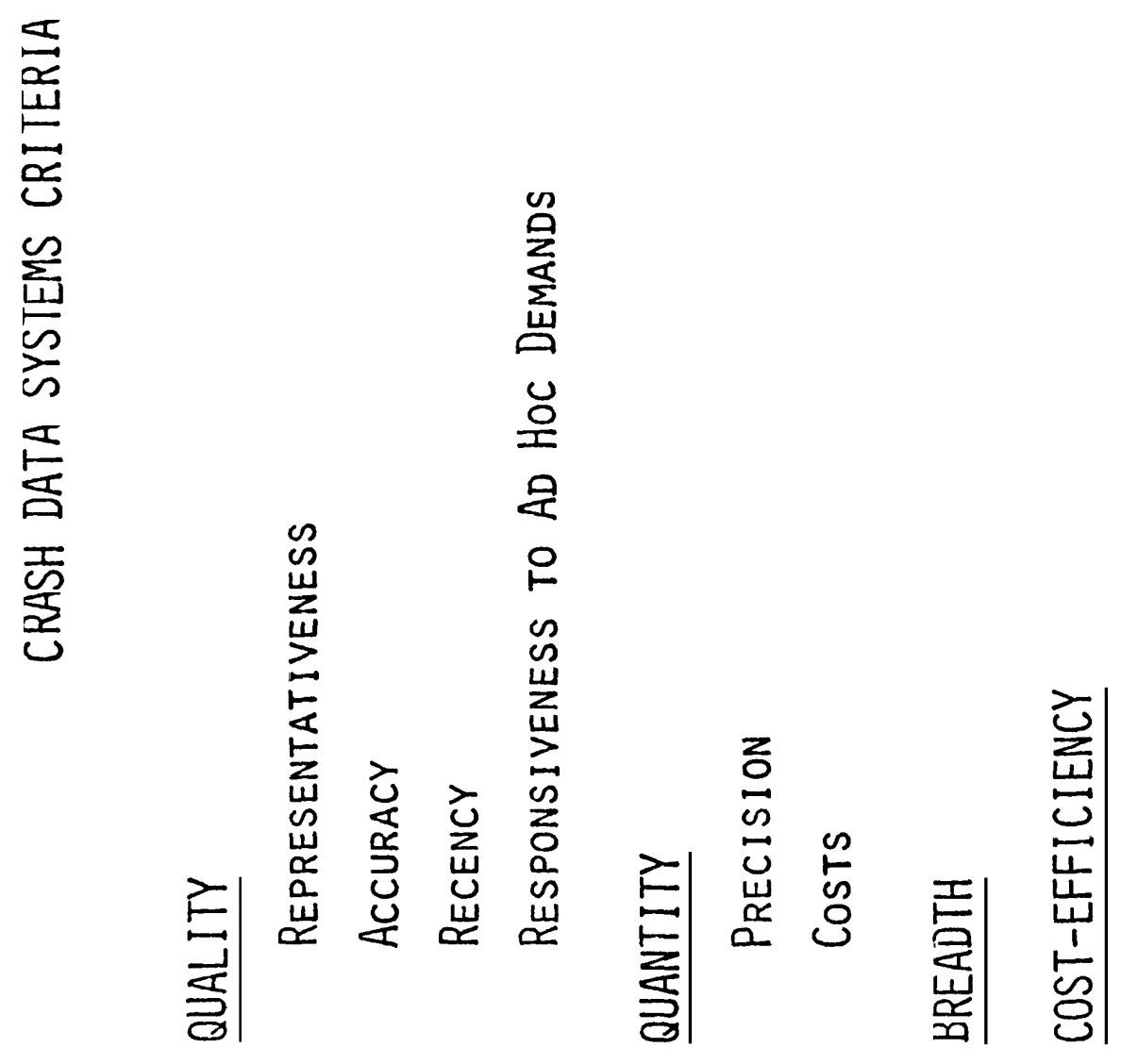




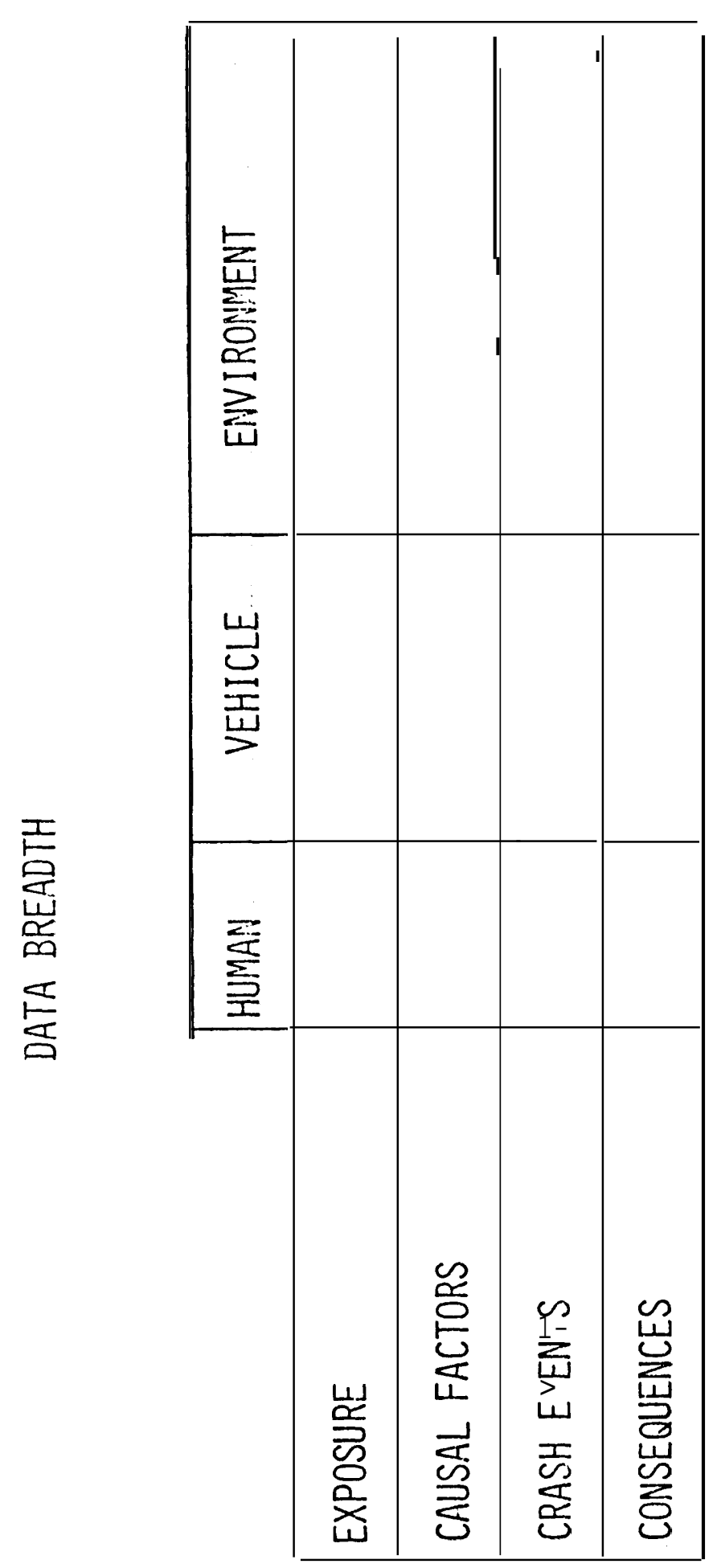

-99- 

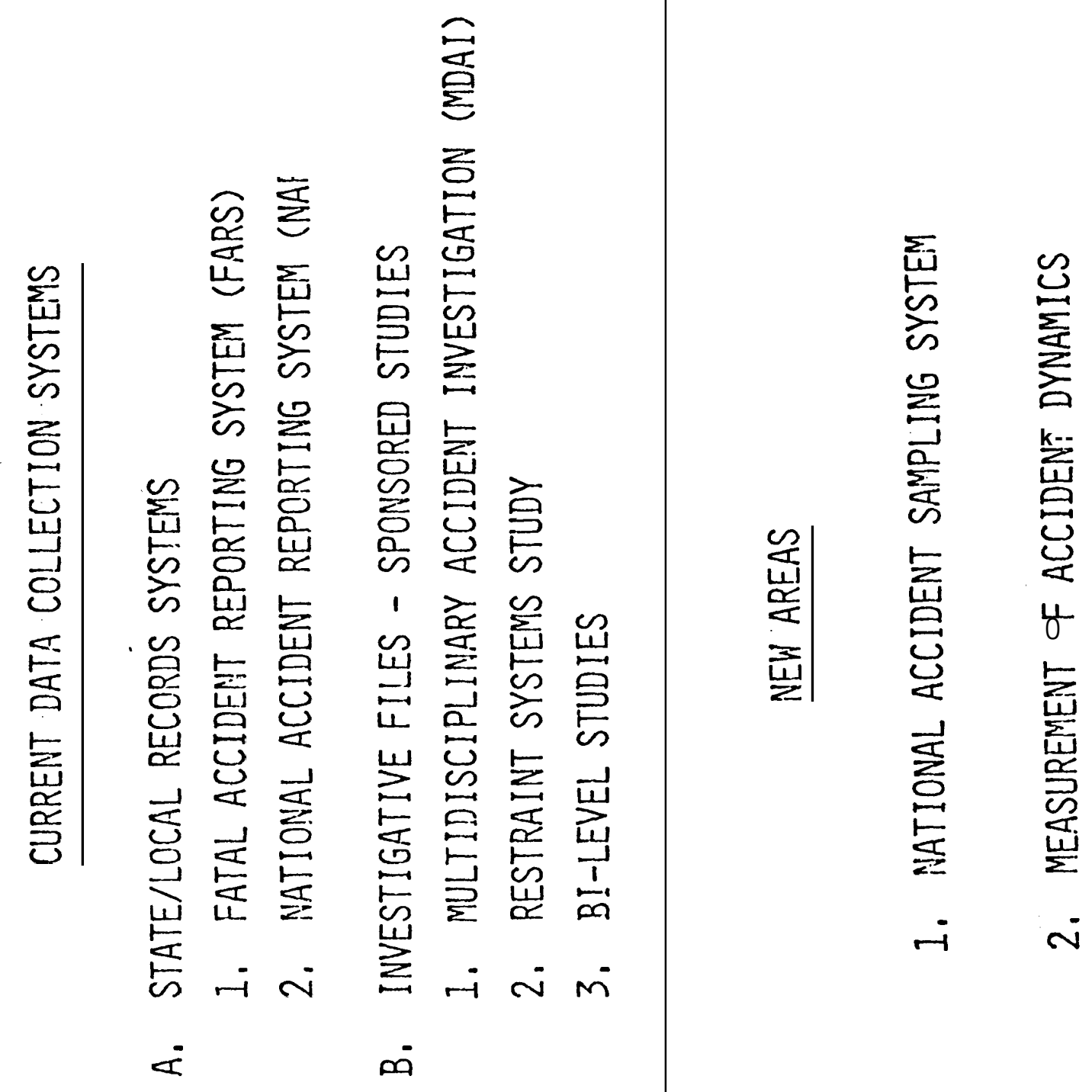


\section{APPENDIX I}

ADISCUSSION OF DATA GATHERING SYSTEMS

Edwin A. Kidd

CALSPAN CORPORATION

January $16 \& 17,1975$

- 101- 


\section{$\underline{\text { INTRODUCTION }}$}

A data sampling plan that provides an accident data file that is representative of the national population is important. A system for data processing, storage and retrieval to allow early determination of trends in accident, injury and fatality frequencies is essential. But the most critical problems are those concerned with the collection of consistent, coherent data on individual accident sequences with a volume far exceeding that now available.

For too long, those concerned with accident studies of the effects of safety standards already in force have had to make do with either too small samples of reasonably good data or relatively large samples of data whose content is inadequate for the purpose. In the first category is the data bank (and "bank" is too grandiose a term) that has resulted from the individual federal teams of multidisciplinary, professional investigators. These teams can serve useful purposes in special studies, in discovery of problems that would otherwise go undetected and, particularly, in the area of accident causation. By their very nature, they cannot provide a sufficiently large data sample relevant to the implementation of standards aimed at injury and fatality reduction without excessive expenditure of funds.

In the second category are the presently available state data banks of relatively low content data obtained through the use of routine police and driver reporting. These data have been valuable in demographic studies, in the broad-look definition of trends and in statements concerning the magnitude of the overall problem, primarily in fatality frequency. In most cases, such data is totally inadequate in content and precision and, despite the relatively large numbers available at relatively low cost, cannot adequately define injury and fatality reduction resulting from standards implementation. 
There is a third category of data collection systems that has evolved over the past few years that lies between the very detailed team approach and the routine police reporting as established independently by the states. The potential exists with this multi-level approach at selected centers around the country (present examples include Calspan in New York, HSRI in Michigan, and HSRC in North Carolina) for a combined data bank that would be a major step toward the attainment of a greatly increased sample size with, and most important, accurate individual accident data with the content required for the purpose.

proper utilization of the potential of these data centers can be realized only if investigator and accident reconstruction aids are implemented that will allow the police to obtain the necessary information with orders of magnitude improvement in accuracy. Local and state police already have the charter to investigate accidents. There are no unsurmountable problems in providing them with the new tools that have been developed for collecting the data that would be the basis for a national data bank sufficient for NHTSA needs in surveillance and effectiveness studies.

\section{Data Requirements}

The list of specific data elements in each accident that are deemed to be essential can hardly ever be complete for the serious analyst. However, the routine and continuous collection of accident data can be tedious, time consuming and costly. Every effort must be made to keep the data requirements to a sufficient set commensurate with the need.

Such sets have been defined a number of times for various ongoing studies. The one presented in Figure 1 is stated in somewhat general terms as it is required, in this instance, primarily for the comparison of data gathering techniques. 
DESCRIPTION OF

GENERAL ACCIDENT INFORMATION

SPECIFIC VEHICLE INFORMATION

OCCUPANT INFORMATION

DRIVER INFORMATION

IMPACT ENVIRONMENT
INDICATION OF DETAIL

SINGLE OR MULTIVEHICLE, RURAL OR URBAN HIGHWAY CATEGORY, PROPERTY DAMAGE ONLY OR INJURY, OBJECT STRUCK, OVERALL SCENE DESCRIPTION, ROAD SURFACE, AMBIENT CONDITIONS

MAKE, MODEL, VIN, IMPACT DIRECTION AND DEFORMATION (VDI OR IMPROVED EQUIVALENT), AVAILABLE RESTRAINT SYSTEM, LOADED WEIGHT, TIRES, INOPERATIVE SYSTEMS PRIOR AND AFTER IMPACT

SEX, AGE, HEIGHT AND WEIGHT, INJURY (MEDICAL REPORT), SEATED LOCATION, USE OF RESTRAINT SYSTEM

DETAILS AS IN OCCUPANT ABOVE PLUS DRIVING EXPERIENCE, TRAINING, CONVICTIONS, PHYSIOLOGICAL CONDITION, PSYCHOLOGICAL INDICATIONS, ACTIONS PRIOR TO AND DURING ACCIDENT SEQUENCE

SPEED AT IMPACT, RESULTANT SPEED CHANGE TIME HISTORY, COMPARTMENT DECELERATION

Figure 1 ACCIDENT DATA REQUIREMENTS 
Even this rather simplified listing appears formidable. However, to some degree each of these elements or approximations thereof are being obtained, by one means or another, by some of the present ongoing programs. There is no element in the outline presented in Figure 1 that is not germane to existing standards. If we settle for a system that provides accurate information less than this and/or only for a quantity of a few hundred or even a few thousand cases, NHTSA cannot do the job it has been directed to do.

Definition of the total number of accident cases required annually for an adequate national data bank can be made if (1) the questions to be asked of the system can be identified both for the present and future; (2) the accuracy with which the particular data elements can be measured is known or can be appropriately approximated; and (3) the statistical analysis techniques to be employed can be agreed upon. This is not meant to imply that such analyses and decisions should not be made. However, there are no statistical procedures that can adequately overcome the past and current inaccuracies with which such extremely important data elements as impact speed and speed change have been reported if they have been reported at all.

$-\quad-$

There will need to be a parallel effort of statistical analyses to indicate what questions can be addressed with acceptable statistical significance as a function of particular sample sizes along with the determination of the funds that can be made available. The financial impact of standards on the consumer has been and will be considerable - billions of dollars annually. Figure 2 presents an average cost per car for the FMVSS to date based upon idividual autombile manufacturer's data. It seems prudent to schedule funding for the primary surveillance effort -- accident data collection -commensurate with the far reaching decisions that depend upon such data. 


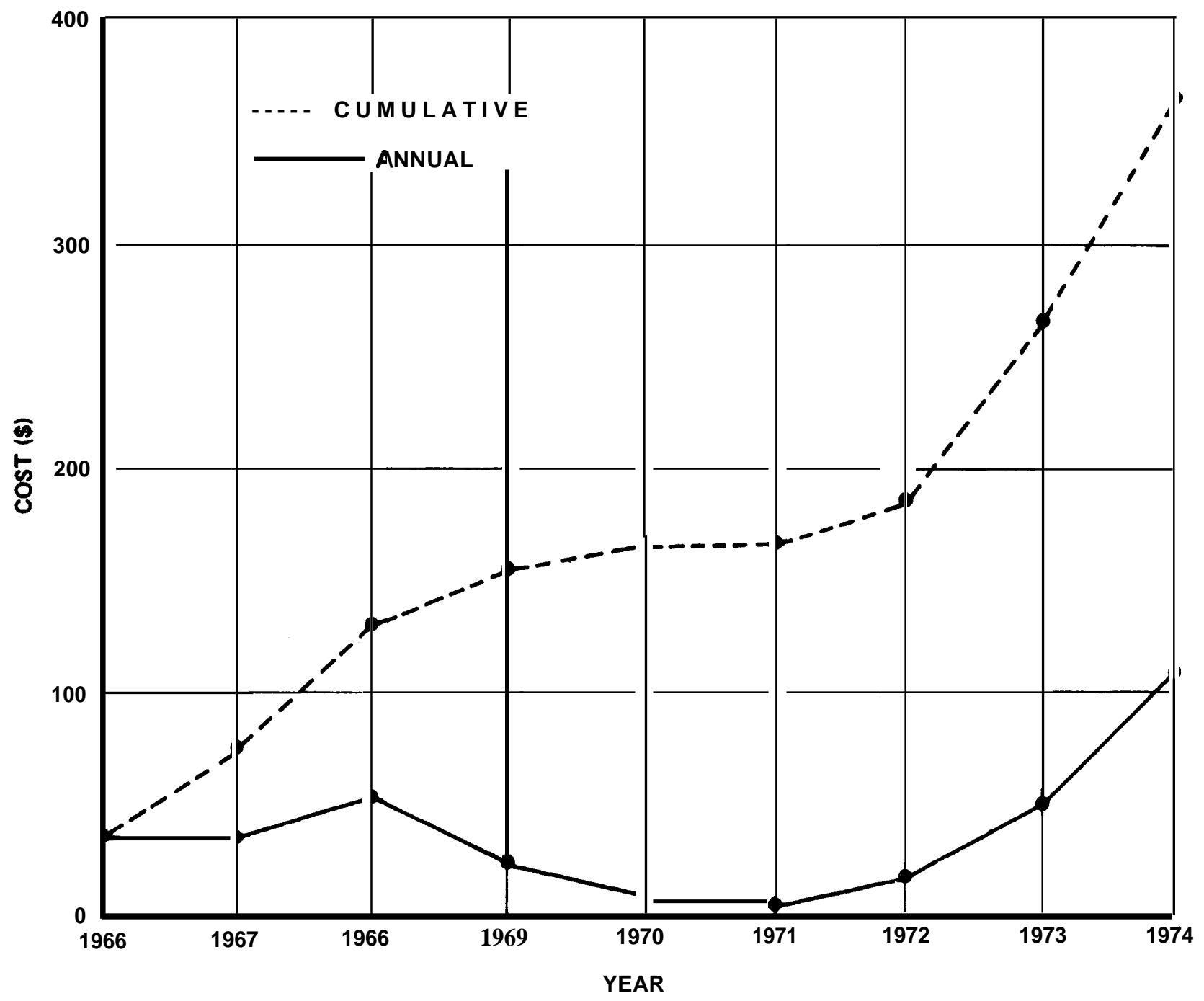

Figure 2 AVERAGE COST IMPACT OF FMVSS ON AUTOMOBILE PRICE 
In order to obtain the data required on each accident, every accident analyst would gladly utilize whatever data gathering techniques are available. Ideally, crash recorder information, police and driver reports, intensive investigation team reports and on-scene reconstructions of the accident through computer aids to investigators would all be gratefully accepted by every serious analyst for each accident. In fact, no analyst would refuse any available high speed photographic coverage (in color, of course).

Obviously, it is neither practical nor essential that all of these systems be provided for the achievement of the basic national data bank. It has already been stated that the intensive investigation teams may have other purposes but cannot provide the data in the quantity required. It has also been noted that existing state data, comprised of merged police report, vehicle registration, and driver licensing files do not provide the content required for the evaluation of safety standards.

\section{Crash Recorders}

Crash recorders can only provide a portion of the desired information as a supplement to continuous accident investigations. At best, a recorder can provide only the information outlined in Figure 1 under "Impact Environment" plus driver control actions during the accident sequence and an identification of the vehicle in which it is installed. Despite the fact that the information a crash recorder is designed to obtain is the impact environment, and that this is the data now totally lacking or sadly inaccurate, a detailed accident investigation would still be required to provide the essential general accident, specific vehicle (including the other vehicle) and occupant and driver information. Thus, the overall cost of an accident investigation would include essentially the present costs plus those associated with the provision of crash recorders. 
The numbers game must be considered as well in the consideration of crash recorder Installations. The actual number of accidents that would be available for analysis would be a marked attenuation from the total number of crash recorder installations (Figure 3). Assume that recorders were installed in 100,000 automobiles. Nomore than 1 in 4 of these automobiles would be involved in any sort of accident annually. This reduces the number of accident cases with crash recorder information to no more than 25,000. If it is further assumed that the accidents of principal interest are those of more than minor severity, for example, tow-away accidents (approximately $12.5 \%$ of all accidents), then only 3125 accidents would be available. If we examined only the highest volume model of the major American manufacturer (approximately 25\%) the number of accidents available would be approximately 781. Further division of these accidents into accident type, direction of impact, etc., would further diminish the numbers. This severe attenuation would be greatly increased for car make and models other than the one with the greatest penetration of the market.

It is recognized that the crash recorder is designed to provide crucially important information on impact environment that has not been otherwise available, at least in quantities with acceptable accuracy, However, there is now available another method, as discussed below, for obtaining this information with accuracies that appear excellent. Both methods should be compared in staged crash tests and considered for some possible joint use as mutually reinforcing data sources. However, the computer aided system, with its outputs of a detailed scene description and an accurate reconstruction of the accident, offers the most promise, as a fundamental element of a continuing data gathering system. 
ANNUAL CRASH RECORDER INSTALLATIONS

VEHICLES INVOLVED IN ANY ACCIDENT

Figure 3 CRASH RECORDER EQUIPPED AUTOMOBILES IN ACCIDENTS 
With support from NHTSA, this on-scene accident investigation and reconstruction system has been developed and demonstrated (Figure 4), An automated range-finder transit with associated computer hardware and readout (Figure 5) provides a drawing of the accident scene and supplemental accident information as required (Figure 6). These physical evidence data are transmitted via a radio-telephone link to a centrally located computer which returns a reconstruction of the accident (Figure 7).

In actual reconstructions of staged accidents, this investigators tool has faithfully reproduced the accident sequence with impact speed and speed change reconstructions of 2-3\% accuracy. With this system, police investigation teams can generate high quality accident data in the course of performing their normal police functions. Yet the system has been found, during field trials by police personnel, to actually ease the tasks of scene measurement and reporting. Thus, both the users of accident data and the police can benefit from adoption of this system.

The economics of adopting the system would be extremely attractive from the viewpoint of elimination of labor costs in the generation and reporting of accident data for research purposes. The end product is already in digital format for statistical analysis.

The nature of the output from the van also lends itself directly to a central data bank or regional data banks receiving reconstructed accidents and supplementary data over existing telephone lines. This continuous updating of current data is particularly attractive. At present, the best a state can do, those few that can supply merged accident tapes, is provide a year's data six-eight months after year's end. A dedicated data collection center, such as presently sponsored by NHTSA, can provide computer tape updates of collected, augmented police reported data every three months with a three month delay. 


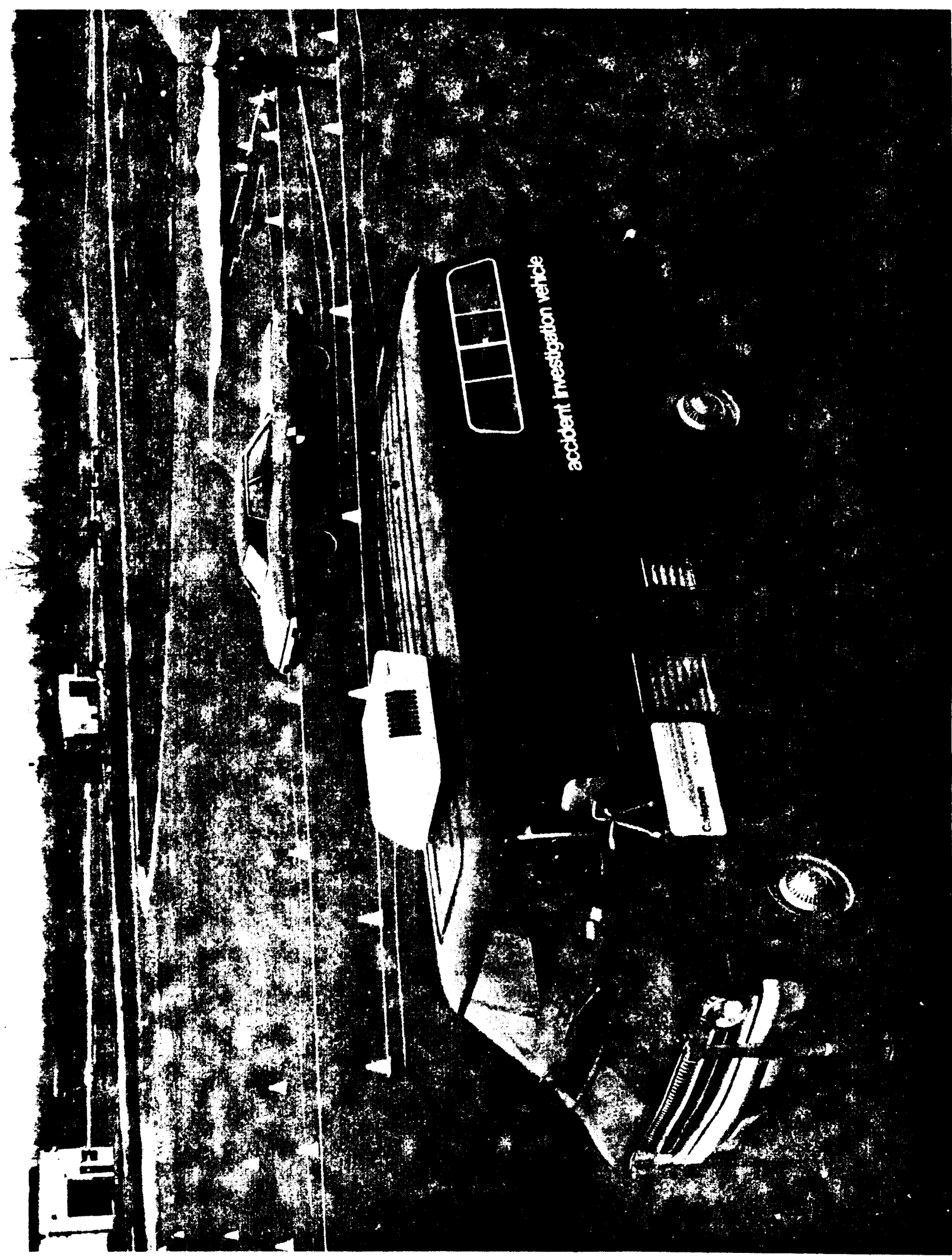

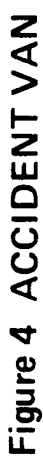




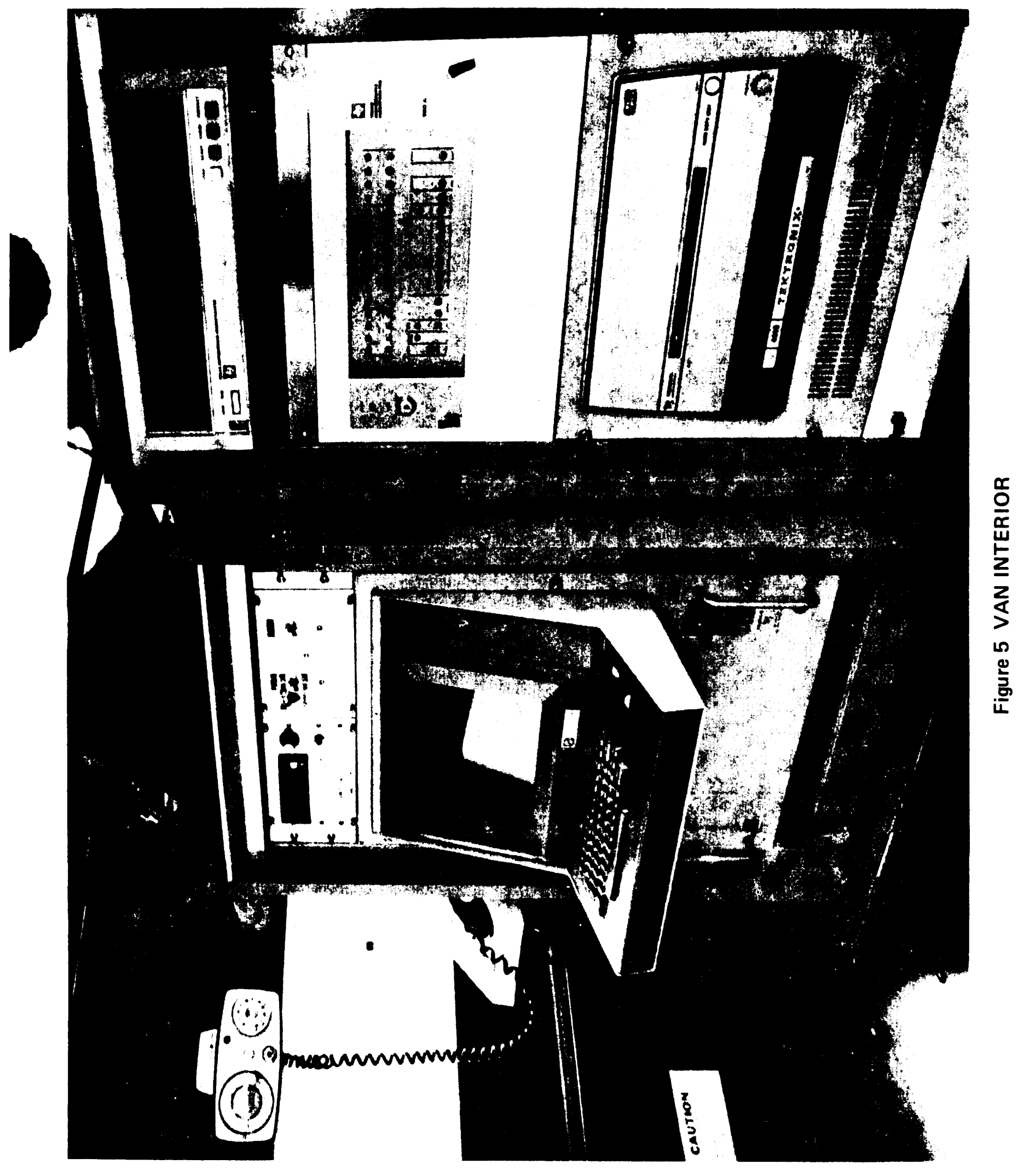




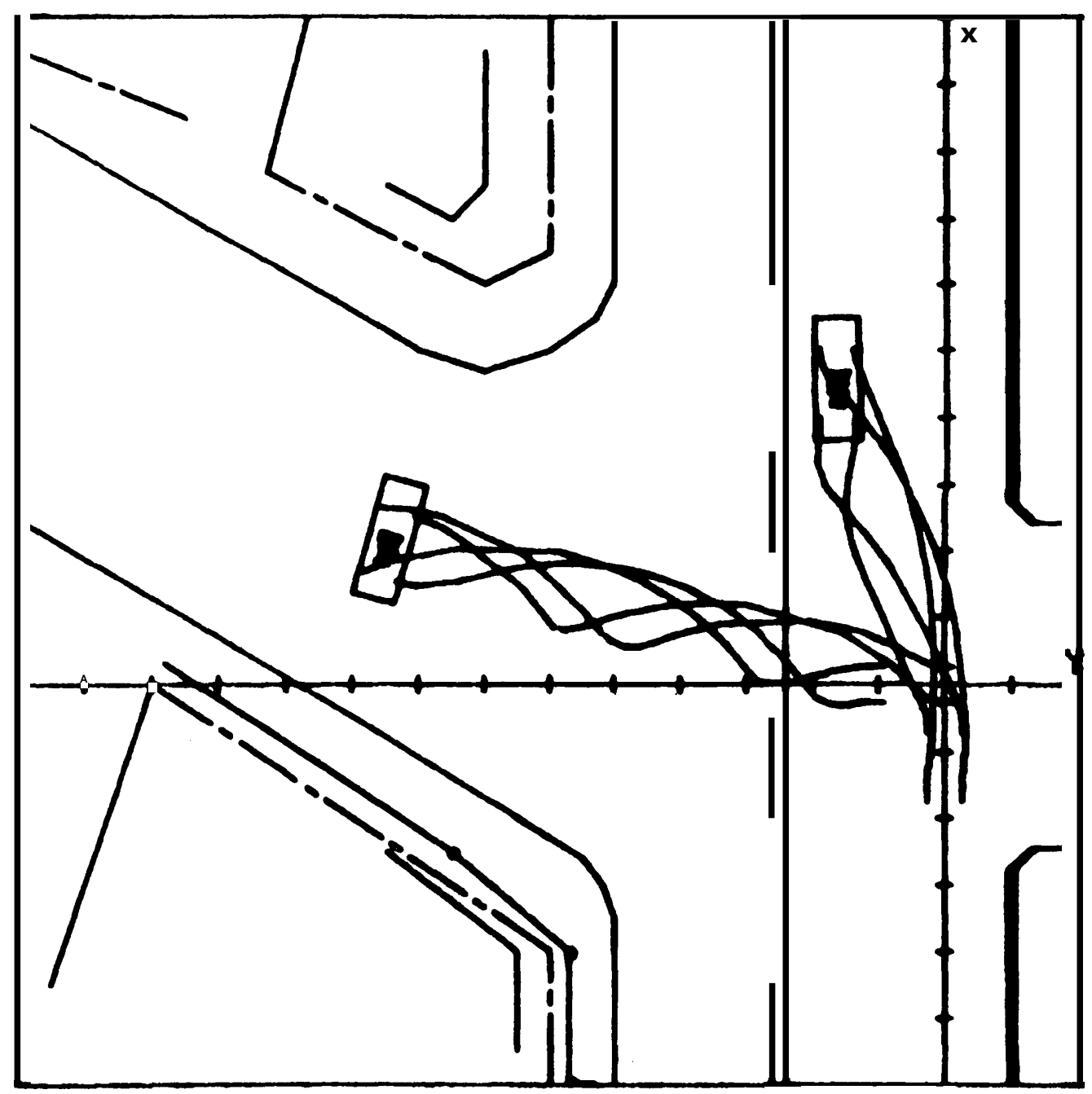

FIGURE 6 SCENE AND ACCIDENT RECONSTRUCTION 
GRAPH C DISPLAY OF OUTPUTS OF-

ACCIDENT RECONSTRUCTION

COLLISION AND TRAJECTORY

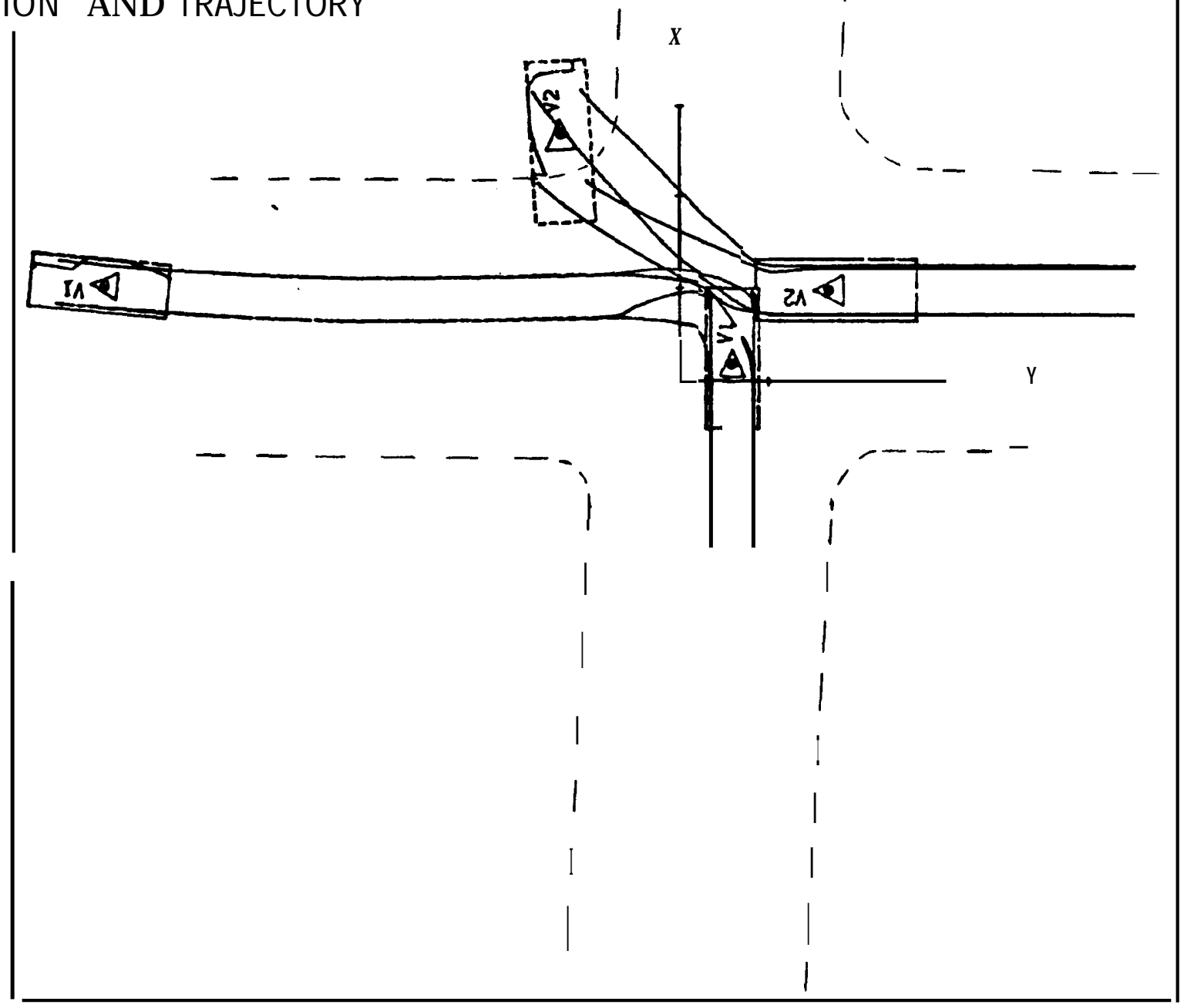

AXIS INTERVALS ARE 10. FEET

\begin{tabular}{|c|c|c|c|c|c|c|c|c|c|c|c|c|}
\hline \multicolumn{7}{|c|}{ RECONSRUCTED POSITIONS AND VELOCITIES AT IMPACT } & \multicolumn{4}{|c|}{ DISPLAYED FINAL POSITIONS } & \multirow{4}{*}{$\begin{array}{l}\text { VEHICLE } \\
\text { DRMPCE } \\
\text { INDICES }\end{array}$} & \multirow[b]{3}{*}{$\Delta v$} \\
\hline & \multicolumn{2}{|c|}{ C.G. POSITION } & \multirow{2}{*}{\begin{tabular}{|l} 
HEPDING \\
PSII
\end{tabular}} & \multirow[b]{2}{*}{ FWD } & \multirow[b]{2}{*}{ LATERAL } & \multirow[b]{2}{*}{ ANGULAR } & \multicolumn{2}{|c|}{ C.G. PUSition } & \multirow{2}{*}{ HERDING } & \multirow{3}{*}{ REMARS } & & \\
\hline & $x \times 1$ & YCI & & & & & XCIF & YCIF & & & & \\
\hline & FT. & FT. & DEG. & MPH & MPH & DEG/SEd & FT. & FT. & BEG. & & & MPH \\
\hline VEHICLE 1 & 1.9 & 6.0 & -0.0 & 24.0 & 0.0 & 0.0 & 10.3 & -63.5 & -84.6 & $\begin{array}{l}\text { IN WOTIEN AI } \\
3.5 \text { SEC PFTER } \\
\text { INITIRL CENTACT }\end{array}$ & $\begin{array}{lll}02 & \text { R Y E H } \\
0 & 4 \text { R Z E H } \\
\end{array}$ & $\begin{array}{l}20.0 \\
10.2\end{array}$ \\
\hline VEHJCLE * 2 & 10.0 & 16.8 & -90.0 & 36.8 & 0.0 & 0.0 & 26.8 & -13.2 & -3.4 & VEHICLE AT REST & $\begin{array}{l}\text { IILTEEHL } \\
09 L P E H 3\end{array}$ & $\begin{array}{l}14.9 \\
6.9^{9}\end{array}$ \\
\hline
\end{tabular}




\section{Data Collecti on System}

The mobile accident van will be ready for general police use after some additional field trials. The accident reconstruction computer model (SMAC), as incorporated in the van reconstruction software and hardware, has been distributed and is in extensive use; additional validation for a variety of accident situations is planned. The total system works and works very well. It is appropriate to consider how it might be incorporated in a complete data collection system that would provide greatly improved and accurate accident data with the quantity and content required for surveillance of standard's effects on accident consequences.

strategically located data centers have been suggested for the collection of regional data samples of the multilevel type. An appropriate distribution of accident vans for use by police investigators within each of these regions would provide continuous data into regional data banks and/or to a single data bank.

There are two primary options for van configurations. Police investigators can be equipped with either a Scene Van or a Reconstruction Van. The Scene Van would provide a description of the physical evidence and supplementary accident data (Figure 6). Hard copies of this information in appropriate format would be available as the police report. In addition, all data would go on tape cassettes to be forwarded to the particular data center for reconstruction of the accident by the SMAC model. The reconstructed accident information would supply the center's data bank. Appropriate retrieval and analysis programs would provide immediate analyses as required. 
Reconstruction Vans, with either self-contained reconstruction capability (more comprehensive on-board computing equipment) or radio link to a regional time-share computer or computers would by-pass the step of accident reconstructions at the data center. Also, a more desirable feedback to the accident investigator at the scene would be available. (Asuccessfully reconstructed accident is the best check of the completeness and accuracy of the scene data.) Each reconstructed accident data set would be stored (short term) within the van and transmitted, when convenient, to the data center at available terminal locations (already present at police agencies).

A rough approximation of the cost for two assumed data collection systems is given in Figure 8. These are given to provide an approximate range of system costs for collection of 100,000 cases annually. The cost of a radio link reconstruction van system would be somewhat less than the selfcontained van with a resulting overall cost close to that of the scene van system. Final selection among these alternatives should consider, in addition to basic costs, operational factors including the advantages of program updating and modifications with either the scene Van or the radio-link Reconstruction Van and the overall data improvement that would result from the Reconstruction Van.

Regardless of the system selected, costs per case of less than $\$ 100$ are estimated. This appears to be quite a bargain. The system would provide 100,000 cases per year for whatever investigation criteria is desired, e.g., tow away cases. Costs per case are essentially independent of data sample size. The assumed rate of cases per van per year is conservative, considering that police agencies operate 24 hours per day. 


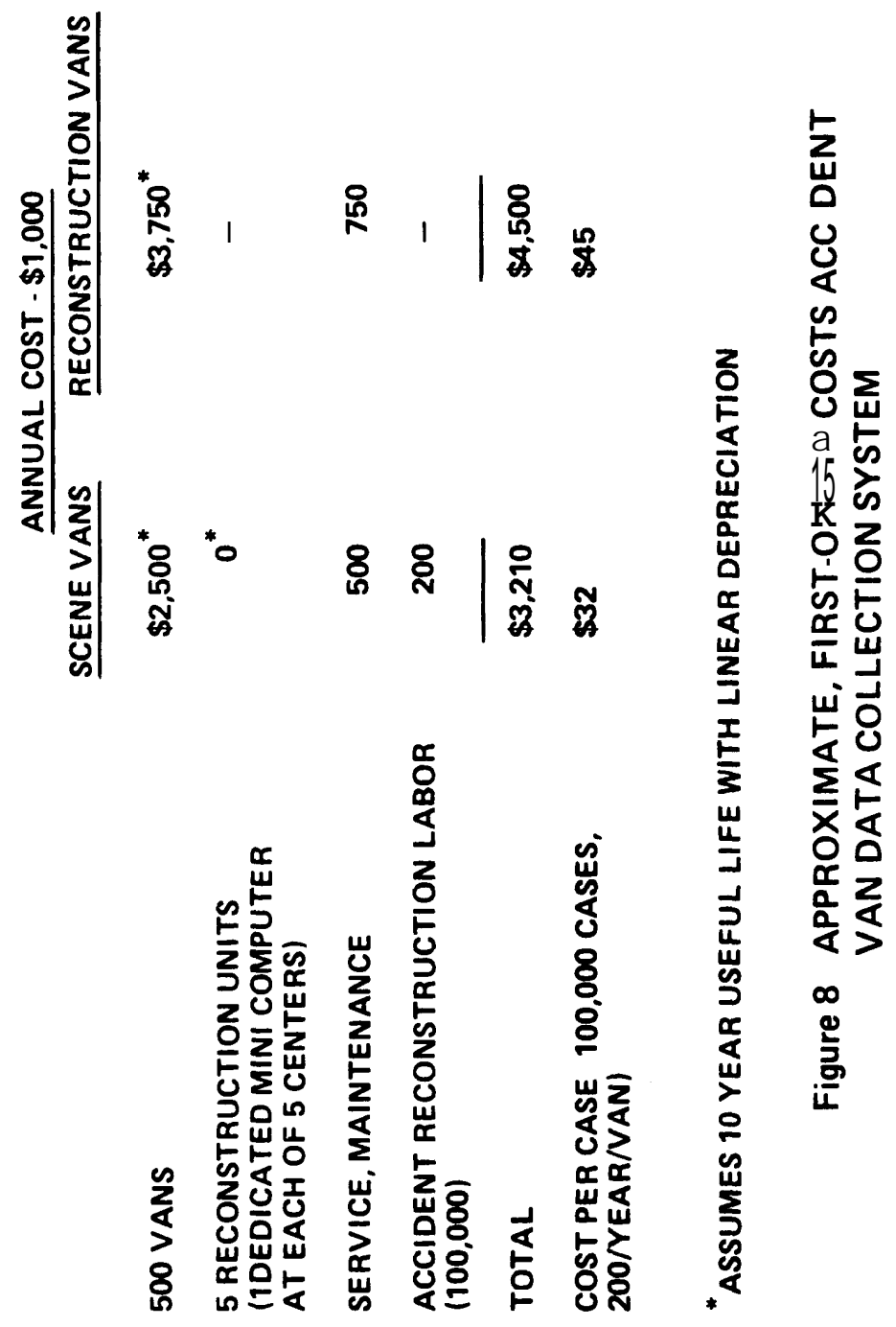


Obviously missing from the estimates of Figure 8 are labor costs for data acquisition at the scene. It is assumed that police would do the investigations. With police use of vans for their own investigative purposes with improved efficiencies over the present, acceptance of the vans should be readily realized.

Based upon our experience to date, we believe the usefulness of this mobile system to the police themselves can be demonstrated and there is no concern that they cannot properly operate the equipment. Implementation of a total collection system employing this scene data gathering capability will provide NHTSA with the information needed. 
APPENDIX J

MASS ACCIDENT DATA ACQUISITION AND WHY IT'S NEEDED

John Versace

FORD MOTOR COMPANY

January 16, 1975

$-119-$ 
MASS ACCIDENT DATA ACQUISITION AND WHY IT'S NEEDED

\section{OTA Automobile Collision Data Workshop \\ John Versace \\ Ford Motor Company \\ January 16, 1975*}

Accident data have been collected for a long time, and we have learned a great deal from them. These data aid in establishing safety need and proper priority of effort. Government, industry, and the public can benefit from more knowledge regarding the real world of traffic. However, times change and designs change, and we believe the present rate of gathering accident information on current designs and events is not adequate. Large amounts of data, carefully collected so as to assure representativeness, are needed. In addition, special kinds of data, more accurate than numerous, perhaps, are also needed to fill in some significant research lacks.

\section{Approaches to Data Collection}

There are three basic approaches to data programs, with some variations. First, the researcher might incisively phrase the particular questions that are going to be asked of the data, and he would design a data collection program to answer those questions. A point of particular significance in this approach is that the data collection program is then part of an integrated research project. For example, both the MVMA and NHTSA have, during the past year, been conducting a study to measure the accident performance of the 1974 interlock type of restraint in comparison to the 1973 system. The number of items of data collected in each case were deliberately kept few so that investigative resources could be allocated toward getting as many cases as possible -instead of much data on fewer cases.

\footnotetext{
*With additions, January 22, 1975.
} 
The second type of approach would be to run the study like a controlled experiment, in which the hardware to be evaluated would be assigned to members of the public in such a way that there would be both broad representativeness of use and freedom from bias, those not receiving the device being the control group. This approach is seldom practical, although manufacturers sometimes are able to equip certain cars with experimental features prior to their full market introduction in order to develop field experience with them. Again, the data collection is integrated into the research project. The third approach to data collection -- and the one I believe we are concerned with here -- is to create a data file which is a microcosm, in all its particulars, of the real world. This approach is independent of any particular research project; its purpose is for the data file to "become" the real world insofar as any researcher is concerned. Different researchers will dip into that data file to answer questions which may arise as issues emerge, issues perhaps unforeseen by those who devised the data collection scheme. Such a method requires highly detailed recording of data on an enormous number of variables. This allows for variables previously disregarded to now be investigated, and also allows the researcher to control confounding effects by selecting for comparison only those cases in which the effect of the extraneous variables cancels out. The most desirable kind of data collection approach, providing sufficient resources can be brought to it, is this third type. If resources are not sufficient, then probably the first type of approach -- in which the data program is tailored for the specific questions to be asked of it -- would be most appropriate.

$\underline{\text { Uses for Data }}$

Among the uses for accident data -- and each use has its own requirement on scope and precision -- are: (i) evaluating the safety performance of 
past and current safety designs, and most importantly, verifying that required countermeasures have, in fact, been effective; (ii) determining if particular safety problems are of such magnitude that countermeasures are needed and supporting the specifics of rulemaking; and (iii) supplying normative information about accident occurrence so the future effect of countermeasures not yet designed or produced can be anticipated and a wise policy regarding them be instituted.

In regard to this last point -- anticipating future performance -let's consider an example. It is easy to conclude that if the 30 -mph crash test requirement contributes to reducing death and injury, then surely an increase to 40,50, perhaps even $60 \mathrm{mph}$ would be proportionately better. But there is very little information available that would unequivocally support such a conclusion. Because there obviously are no cars on the road meeting such advanced requirements, we cannot test this conclusion by comparing their casualty rate to cars meeting only the 30 mph criterion -- assuming we had accident data collection and analysis procedures adequate to the task. Because there are no such cars, resort must be made to calculation.

Two things are needed to make such calculations: real inputs of population exposure -- drawn from accident data -- and theoretical system models. Validity of the models will of course be an important matter to consider.

Need for Population Exposure Data

Being able to determine whether, or in what way, to increase the test requirements of crash performance standards, or to inaugurate any rule, depends upon our being able to predict the probable effect of such actions in the future. particularly lacking as an input to any calculation of future effects, is an accurate estimate of the dynamic environment to which people are exposed. 
The particular form of the exposure variable most useful for calculating the magnitude of need and in estimating the future effects is the probability distribution of collision speed (with all types of likely obstacles.)

Ordinary accident investigation data can be useful in estimating crash speeds, given some care in adjusting for the mechanical nature of the struck object. However, derived speed estimates from accident reports quickly lose reliability as impacts other than head-on are considered. The ogival cumulative distribution of barrier-equivalent speed has been a prominent part of most analyses aimed at estimating population exposure and hence need, and in calculating the probable effectiveness of different restraints. A single shape and location of this curve has not been accepted among all its users. The absence of this one item of information on occupant exposure can make what should be a factual matter rather a matter of contentious advocacy. It is our belief that a crash recorder supplement to a general accident data program has the potential to assist in clarifying this particular area of need.

\section{Accuracy of Crash Severity Data}

For a successful program of crash severity determination, there must also be the right protocol for defining an accident so that the resulting distribution of measurements is not biased upwards by deliberately selecting only "interesting" cases -- an unfortunate characteristic of most data sets available today. If the speed distribution is incorrectly displaced upscale, or inflated due to errors of measurement, there will appear to be many more high speed crashes than really occur; the result will be to lean toward excessively high crash requirements, with resulting cost-effectiveness being less than it appears. While precision of measurement of crash speed is important in estimating the speed distribution, it is even more important that there be no bias in the data collected. 
It may be useful here to distinguish between the accuracy of measurement and the accuracy of estimation, in the statistical sense. The former refers to the degree of correctness in any one reading, and the average measurement error is an index of this quality. Accuracy of estimation, for data analysis purposes, refers to the relative absence of bias in the sample of data: i.e., that the sample values fairly reflect the population from which they were drawn: that the sample distribution can be accepted as an estimate of the population distribution because there are no funnies in it which warp it, or skew it, or displace it except for the action of random influences.

Different data purposes place different requirements on measurement accuracy. Crash recorder data presumably are more accurate than other indices of collision severity, such as the measured vehicle deformation or the Vehicle Damage Index (VDI). Whether such accuracy is required depends on the type of study. For many purposes, plan view photographs of the case and struck vehicle would be a significant improvement over VDI, as they would allow for an energy-derived calculation of severity.

When comparing injury outcome between accident cases with, as compared to without, a side guard beam, for example, we would want to control for collision severity because the degree of injury is correlated with collision severity. The control could be effected either mathematically or by partitioning the sample of casesingroups of equal collision severity. Controlling on collision severity will do two things: increase the efficiency of the comparison and eliminate the bias that results from fortuitous concentration of milder collision cases among one or another of the groups under comparison.

Because the degree of injury depends on many factors other than impact severity --such as restraint use, occupant age, and adventitious 
posture -- the correlation of injury with the collision severity control variable is necessarily going to be less than perfect. As a result, increases in the precision of measurement of collision severity will not proportionally improve the efficiency of making the comparison when using it as a control variable. So, it is not so important to have high precision when doing routine accident comparison studies. The crash recorder has a different utility, and its evaluation should be based on other considerations.

Crash Recorder Use

Acrash recorder will have utility for at least three types of studies. The first, as already mentioned above, is to provide correct normative information about such things as -- and particularly for correctly establishing -- the occupant exposure in terms of the probability distribution of collision speeds. To make such a determination requires a research project to be defined with this as its objective; the project could be based on the crash recorder as a particular tool of unusual usefulness. The research project could terminate when the determination has been made. Since the accuracy provided by the crash recorder is not essential for the kind of data-adjusting purposes described in the paragraph above -- i.e., in order to provide a control variable for accident case comparisons -- it would not be needed as a permanent part of a national data collection program. It should be viewed primarily as a research tool used for fairly particular purposes in a particular research program, more than an instrument for general accident investigation.

Another use for the crash recorder would be in research programs for establishing human tolerance to impact and to aid in establishing dynamic specifications for impact test devices. Thus, crash recorder data could be used as inputs in the programming of experimental crash tests or computersimulated tests. These studies would determine the design characteristics needed in the test devices (e.g., crash dummies) so they would yield test 
readings comparable to those experienced by actual accident victims. This kind of research requires data that are in dynamic physical form -- not rating scale indexes or qualitative descriptions. This usage of crash recorders would be contained within a research program designed to that end, and except for considerations of administrative efficiency, not be an intrinsic part of the national accident data collection system.

Still another useful purpose for the crash recorder would be to calibrate or to improve the more subjectively determined indexes which are now commonly used in accident investigation. Again, once that calibration has been effected, there would be no on-going necessity for the crash recorder.

Other Data Needs

There are two other areas of safety evaluation to which there has been inadequate attention. The first is to measure the overlapping and interactive effect of different safety requirements: e.g., strength of door fixtures and occupant restraints. Some safety evaluations, carried out in different studies, can count the same persons as being saved more than once by different means in each study, so that the total of the saved casualties might even exceed the population at risk. Our own studies have had this problem.

But even more significant is the almost total lack of information regarding the safety benefit in the 100-series federal standards. The whole concept of accident causation and avoidance needs to be clarified: to date it has been expressed more figuratively than in quantitative terms which will relate to vehicle design. Lack of good ideas in this area suggests that a conceptual breakthrough must be made before we are able to properly attribute that part of causation/reduction to the vehicle and its design, separate from the mediating influence of the driver and of the roadway, and so cost- 
effective countermeasures can be imposed at the right place in the system for each aspect of accident causation, and in such a way -- and this is crucial -that the specific effect can be evaluated, both prospectively and retrospectively, in accident data.

Procedures for establishing the safety effectiveness of both the current and proposed 100-series standards should be a major research challenge to the government and industry in the years to come. Current government accident avoidance research emphasis is to experimentally compare different vehicles on arbitrary control tasks. But programs of a different type are also needed, programs that will define measures of accident avoidance performance and then from that establish minimum criterion levels for performance, but the kind of performance that can be validated by accident statistics in the long run. For example, the effectiveness of existing braking and handling capability has not been definitely established in a real world context, much less the need for any changes. This is admittedly a difficult area in which to do research; there are very difficult conceptual problems. It is here, especially, that an interdisciplinary approach is needed.

Need for Greater Quantity of Data

Over the years, the Safety Administration has done an admirable job of developing in-depth studies (referred to as multidisciplinary accident investigations) of limited numbers of accidents, providing some information on how effectively certain designs may be functioning in specific instances. On the other hand, these special studies have not adequately revealed from a national viewpoint safety effectiveness on a representative basis. Thus, the accident teams which are employed for these in-depth studies can usually give a reasonably accurate description of any one accident -- and sometimes its causes or at least the causes of the injuries -- but they are not satisfying 
our current pressing need for a comprehensive estimate of the nationwide accident picture.

A detailed and highly precise description of any one accident cannot by itself reveal where the overall priorities lic. There are three reasons why accident data must be collected in great quantity: First, there is considerable variability in the injury resulting from accidents that are, on the surface, similar; second, some accident features are quite infrequent and thus comparisons are often based on so little data they are unreliable; and third, we have to account for so many factors which can affect the outcome of each accident.

The first of these reasons -- variability in injury among similar accidents -- is seen when some people can get out of a total wreck and walk away with only minor injuries while in other crashes people sometimes die even though the car is so little damaged it can be driven away. A great number of crashes must be examined so that the entire range of injuries in any one type of crash can be accounted for.

secondly, certain events are relatively rare because most accidents are of comparatively low intensity and the injuries are of correspondingly low grade. It has been common to combine the counts of severely injured cases with the counts of fatalities in order to get a large enough total count to allow reliable comparisons to be made. Furthermore, some factors of interest -- such as restraints -- have had a relatively low rate of usage so not many cases have been available for investigation. It was only until B. J. Campbell, at North Carolina, was able to examine a few hundred thousand cases that he could find enough applicable ones to reliably detect the profound effect of the lap belt on the fatality rate -- as distinguished from its effect on the rate of severe injury or the rate of combined severe-plus-fatality. The base 
fatality rate is quite a bit less than one percent; he found an overall 70 percent reduction in that rate in the lap-belted cases.

The third reason for needing a lot of data is the presence of numerous variables which affect the accident. The art of doing research and arriving at findings and conclusions about any aspect of accident or injury prevention is still fairly experimental. It is experimental because we do not have unequivocal, established scientific methods to cope with the present accident data. The reason for this is most of it fails to satisfy the basic requirements of analysis: that comparisons be made on an "all else equal" basis. By "all else equal" I mean that conclusions about the effectiveness of, say, the side guard beam must be made on data from crashes involving the same kind of vehicles in the same kind of trajectory with the same kind of people at risk, etc. However, given the diversity of vehicle models, it takes a lot of accident chasing to find enough crashes of the same type, of the same severity, and with the same type of vehicles and drivers, etc. -- that is, in which all else is equal. Mathematical adjustment of the data can take care of some confounding of variables in the data, but to be confident a considerable degree of representativeness in the original data is still needed.

Not the least consideration for achieving the proper representativeness of data is that there should be standardized definitions and protocols used by all the investigating agencies. Since a future investigator will query the data file as a microcosm of the universe of accidents, it would be most disagreeable that cases which are essentially similar were described in the same file differently only because the data were collected by different agencies using their own interpretations. 


\section{Need for Scientific Sampling}

Not only is an increased quantity of data required but the sampling of the accident universe must be by sophisticated protocol. The last of the three reasons given above implies the need for a disciplined approach to the data, to avoid ending up with data which are biased in the factors underlying them. That requires a scientific approach to data collection, not just pouring more dollars into it and cranking Up the administrative machine to get a bigger program going but doing it in the same old way. Data gathering programs must be designed by the same people as will design the analyses that will be applied to the data. No less expertise than the Census Bureau applies, or the Gallup Poll, will suffice. Fortunately, NHTSA has been bringing in very competent people of late, people who know that a data collection scheme must be designed from the start with the method of analysis of the resulting data a key determiner of how the data should be gathered.

\section{It is the Government who Should Collect Data}

Mass accident data acquisition, processing, analysis, and broad scale distribution requires great effort and much resource. Only the federal government has the necessary resource and easy access to the agencies which can supply information. Furthermore, it seems that it is the responsibility of the federal government to assemble data which will allow an accurate public review of the real dimensions of the crash and injury problem on our highways.

We appreciate the difficulty of developing and implementing a large scale, comprehensive plan for the acquisition of detailed data on motor vehicle related injuries and fatalities. We are aware that the Safety Administration has over the past several years developed and implemented a portion of such a plan which is related to fatalities. This effort has resulted in what is known 
as the "Fatality Analysis File. " We believe that data from most of the 50 states is going into that file and are hopeful that all interested parties will have access to that file in order that we all may comprehend the true and detailed dimensions of the fatality problem in the United States.

The Safety Administration has also requested funds for a large scale field survey of automobile accidents in which crash recorders would be employed. The data from this program is equally important to that from the Fatality Analysis File and would provide an accurate determination of the crash speeds at which the several levels of injury and fatality occur and can be employed as a basis for defining the performance levels needed in crashworthiness standards. We support a crash recorder program.

Certain fundamental questions cannot be answered without first having an adequate base of public data: What do we really know about the need for increased performance -- increased performance on the types of test criteria in the rules -- based on what is happening out there on the highway? What will be the effect on injury at lower speed levels when systems designed for a high speed compliance test are used? What are the proper speed levels to target for? While accident data are important, they are of course insufficient in themselves; other questions must still be considered: Can we mass produce these cars to provide such protection at reasonable cost? Should we approach an increased performance level in one massive jump or would we be better served to work toward it incrementally? What lead times are required to achieve these goals? These are obvious questions that should be considered before such rules are proposed.

In summary, we believe it is necesary to greatly expand accident data collection, in a well-disciplined scientifically devised program. Crash recorders cannot supplant an accident investigation program. Crash recorders will 
be most useful in research projects whose ends specifically require the dynamics information which only such a tool can provide rather than in general data collection programs. There is a great challenge to undertake new studies of need in the accident avoidance area; indeed, new concepts, of pragmatic utility and based on what is actually happening on the roads, are needed in order to get a grasp on the whole issue of vehicle control and its relation to accidents. It is the government which has the responsibility and the resources for carrying out such programs. 
APPENDIX K

\title{
POSITION STATEMENT
}

ON AN

EX1/4AMDED. LOW-COST NATIONAL ACCIDENT DATA COLLECTION PROGRAM

\author{
J.R. Cromack \\ B.J. Campbell \\ L. Patrick \\ B. O'Neill
}

February 7, 1975 


\section{POSITION STATEMENT}

ON

AN EXPANDED, LOW-COST NATIONAL ACCIDENT DATA COLLECTION PROGRAM February 7, 1975

J. Robert cromack Southwest Research Institute:

B. J. Campbell. Highway Safety Research Center, University of North Carolina; Lawrence Patrick, Wayne State University; Brian O'Neill, Insurance Institute for Highway Safety.

present real-world accident data have some deficiencies and limitations for both researchers and policymakers. Despite these limitations, much progress has been made on the basis of these data and useful information will continue to be obtained from these sources. However, much can and should be done to improve realworld accident data.

One major contribution would be the development of a large scale accident data base, possibly modeled on the data base developed at the Highway Safety Research Center of the University of North Carolina. This would require the upgrading of police accident reporting in a number of states and combining the data into a single base that could be assessed both by researchers and policymakers. Ideally, real-world accident data in such a base should include a measure, or measures, of both crash and injury severity.

At the present time the only available measure of crash severity is obtainable from the vehicle deformation or crush appropriately defined in relation to the manner of damage. Crash severities derived from vehicle deformation or crush can, however, only be compared among vehicles of the same make and model. It is possible that future research will enable the grouping of similar types and styles of vehicles with respect to crash 
Appendix K

Page 2

severities so derived, but at present there are no strong objective data to support such comparisons. Additional controlled laboratory type experimentation is needed to verify crash severity measures obtained from vehicle deformation or crash.

Meanwhile there are additional descriptors of real-world accidents that could be valuable to both researchers and policymakers. Crash recorders could provide such additional data. It seems likely that sophisticated recorders will continue to be too expensive to be deployed in the very large numbers needed to substantially augment present real-world data. Serious efforts should be devoted towards the development and large scale deployment of very inexpensive crash recorders that are designed to record a small number of Parameters that can be related to the severity of the crash.

The present measures of injury severity obtained from police accident reports are far from satisfactory and considerable efforts should also be devoted to upgrading these measures. Ideally, injuries should be classified either by the Abbreviated Injury scale and its derivatives such as the Injury severity Score or other appropriate injury scales.

A better understanding of the nature and effect of traffic accidents can result from an expanded low Cost, well planned National Accident Data Collection program. The increased availability of data so derived will provide a higher confidence in the results derived from analysis of these data. It should be a major goal of such an effort to investigate the correlation between injury and damage, a topic presently not addressed due to inadequate data, but one that promises Significant clarification to the problem of injury causation. 


\section{SOUTHWEST RESEARCH INSTITUTE \\ 8500 CULEBRA ROAD • POST \\ OFFICE \\ DRAWER \\ 28510 \\ SAN \\ ANTONIO, TEXAS \\ 78284 \\ February 7, 1975}

Mr. Howard P. Gates, Jr.

Economics and Science Planning

1200 - 18th Street, NW

Washington, D. C. 20036

Dear Mr. Gates:

Enclosed is the approximate concensus of the persons working on the assigned Issue No. 2. In the interest of time, I am sending you this document without final approval from each of the members. They will, however, receive copies of this letter and should they object too strenuously to any of the final changes or corrections, I feel certain you will hear from them.

In all fairness to them, I must state that I added the last paragraph based on my own convictions. It probably represents (at least in general) their views but this is the major divergence from the last draft position statement that was circulated. Incidentally, Larry Patrick did not have an opportunity to comment on the position statement after making several original contributions at our meeting on January 17.

None of the participants indicated an intention to take a position on Federal funding or inducements. Again, it was a pleasure to work with you and the other individuals at the workshop. I look forward to future meetings.

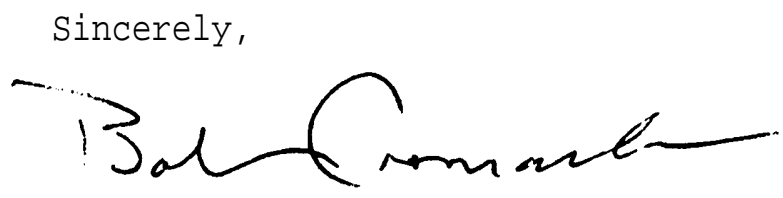

J. Robert Cromack, Manager Vehicle Safety Section Department of Special Projects Automotive Research Division

$\mathrm{JRC}: \mathrm{mr}$

Enclosure

CC: Lawrence Patrick

B. J. Campbell

Brian O'Neill 


\section{POSITION STATEMENT - ISSUE 2}

Present real-world accident data have some deficiencies and limitations for both researchers and policymakers. Despite these limitations, much progress has been made on the basis of these data and useful information will continue to be obtained from these sources. However, much can and should be done to improve real-world accident data.

One major contribution would be the development of a large scale accident data base, possibly modeled on the data base developed at the Highway Safety Research Center olf the University of North Carolina. This would require the upgrading of police accident reporting in a number of states and combining the data into a single base that could be assessed both by researchers and policymakers. Ideally, real-world accident data in such a base should include a measure, or measures, of both crash and injury severity.

At the present time the only available measure of crash severity is obtainable from the vehicle deformation or crush appropriately defined in relation to the manner of damage. Crash severities derived from vehicle deformation or crush can, however, only be compared among vehicles of the same make and model. It is possible that future research will enable the grouping of similar types and styles of vehicles with respect to crash severities so derived, but at present there are no strong objective data to support such comparisons. Additional controlled laboratory type experimentation is needed to verify crash severity measures obtained from vehicle deformation or crush.

Meanwhile there are additional descriptors of real-world accidents that could be valuable to both researchers and policymakers. Crash recorders could provide such additional data. It seems likely that sophisticated recorders will continue to be too expensive to be deployed in the very large numbers needed to substantially augment present realworld data. Serious efforts should be devoted towards the development and large scale deployment of very inexpensive crash recorders that are designed to record a small number of parameters that can be related to the severity of the crash.

The present measures of injury severity obtained from police accident reports are far from satisfactory and considerable efforts should als o be devoted to upgrading these measures. Ideally, injuries should be classified either by the Abbretiated Injury scale and its derivatives such as the Injury severity score or other appropriate injury scales. 
A better understanding of the nature and effect of traffic

accidents can result from an expanded low cost, well planned National Accident Data Collection program. The increased availability of data so derived will provide a higher confidence in the results derived from analysis of these data. It should be a major goal of such an effort to investigate the correlation between injury and damage, a topic presently not addressed due to inadequate data, but one that promises significant clarification to the problem of injury causation. 
APPENDIX L

RESOLUTION

$\mathrm{OF}$

THE NATIONAL MOTOR VEHICLE SAFETY ADVISORY COUNCIL

November 14, 1974

-139 - 


\section{A Resolution of the}

\section{National Motor Vehicle Safety Advisory Council}

(A body advisory to the Secretary of Transportation)

November 14, 1974

\section{Whereas, analysis of the cost/benefits of revising standard 208 to require passive restraints has produced limited field evidence of the life saving value of passive restraints, includ- ing air bags; and}

Whereas, the analysis indicates that mathematical projection and tests with dummies do not predict with sufficient accuracy the potential value of these restraints in actual use; and

Whereas, there is likelihood that indignation over installation of passive restraints may eventually result in public pressure for the removal 'of such restraints after huge investment is made in them, as in the case of the seat belt interlock; and

Whereas, the mandated addition of yet another costly feature to new automobiles would be a financial hardship to the American consumer who must depend on automobiles for transportation; therefore be it

RESOLVED, that this Council recommends that the secretary make a concerted effort to come to an agreement with industry on a plan that would result in increased passive restraint usage on the road and defer acall for rulemaking with respect to passive restraints until such time as further actual experience with them on the highways proves that they will reduce deaths and injuries. 
APPENDIX M

THE NEED FOR STANDARD1ZATION

IN REPORTING COLLISION DAMAGE AND INJURY

IN TRAFFIC ACCIDENTS

J. Robert Cromack

January $16 \& 17,1975$ 
THE NEED FOR STANDARDIZATION IN REPORTING COLLISION DAMAGE AND INUURY

\section{IN TRAFFIC ACCIDENTS}

Presented by J. Robert Cromack at the Cquision DaTg Wlorkshop Conference, RoSSLYN (ARLINGTON) VIRGINIA, JaNUARY I6 AND 1\%, 1975.

THE IMPORTANCE OF COLLCTING ACCURATE AND MEANINGFUL ACCIDENT DATA CAN BE MEASURED ONLY IN TERMS OF THE NEED FOR OR BENEFITS DERIVED FROM WHAT WE LEARN FROM ANALYSES OF THESE DATA, IF THE DATA ARE SELECTED FROM AN ATYPICAL SAMPLE OF THE GENERAL POPULATION, THEN THE CONCULSIONS WE DRAW FROM STUDYING THEM ARE APPLICABLE ONLY TO THE SAMPLE, SimilarLY, IF THE DATA ACQUIRED DO NOT ENTIRELY SATISFLY THE NEEDS OF THE STUDY, THEN ONCE AGAIN WE MAY BE UNABLE TO DRAW APPROPRIATE CONCLUSIONS, FOR EXAMPLE, QUESTIONS CONCERNING INUURY CAUSATION CANNOT BE ANSWERED WHEN INUURY REPORTS ARE STRATIFIED SIMPLY ACCORDING TO THE CATEGORIES "PROBABLY NOT INUURED," "PROBABLY INUURED," OR "KILLED,"

CONCLUSIONS EVOLVED FROM SUCH STUDIES MAY LEAD US TO MAKE INAPPROPRIATE RECOMMENDATIONS OR FORMULATE INVALID REGULATIONS, UNFORTUNATELY, EXCEPT FOR CERTAIN SPECIALIZED STUDIES IN WHICH DATA WERE SPECIFICALLY GATHERED FOR THE PURPOSE, MOST DATA DERIVED FROM STATE AND LOCAL POLICE RECORDS NOW COMPILED IN THE MANOR ACCIDENT DATA FILES, HAVE MANY OF THESE DEFICIENCIES OF INCOMPLETENESS, INACCURACY, AND LACK OF COORDINATION OF ELEMENTS OF INTEREST,

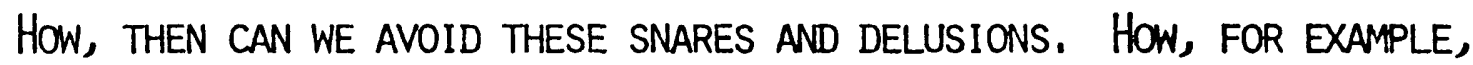
CAN CRASH INDUCED INJURIES IN THE FIELD BE RELIABLY COMPARED WITH LABORATORY SIMULATED INJURIES TO CADAVERS AND ANIMALS IF THE FIELD INJURY DATA ARE EITHER POORLY DOCUMENTED OR ENTIRELY LACKING, I DON'T MEAN TO IMPLY THAT THERE ARE NOT SOME GOOD DATA COLLECTED IN THE FIELD, BUT UNFORTUNATELY, THERE ARE GENERALLY NOT ENOUGH GOOD CURRENT DATA COLLECTED TO BE STATISTICALLY USEFUL. THE ANSWER, OF COURSE, IS TO COLLECT MORE AND BETtER DATA. ONE MOST IMPORTANT AREA OF INTEREST TO ALL OF US WHO HAVE BEEN WORKING TO REDUCE INJURY SEVERITY IN ACCIDENTS IS THE RELATIONSHIP OF VEHICLE 
IMPACT INTENSITY TO RESULTING INJURY TO OCCUPANTS. RIGHT NON MASS ACCIDENT DATA ARE COLIECTET AIMOST ENTIRELY BY THE POLICEMAN CALLED TO THE SCENE OF THE ACCIDFNT. SUMMARIES OF THESE POLICE DATA tell US THAT THERE WERE " $X$ " NUMBER OF ACCIDENTS, "Yy" NUMBER OF INJURIES, "Z" FATALITIES-THEY SAY THAT: SO MANY ACCIDENTS HAPPENED AT NIGHT, ON A RURAL ROAD, THAT WAS UNDER CONSTRUCTION,

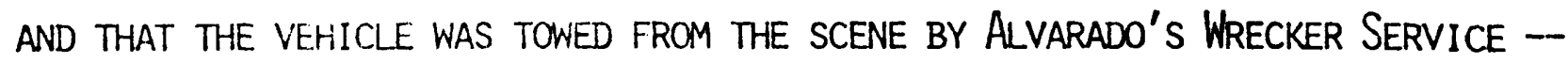
ALL VERY INTERESTING, BUT WHAT KIND OF A PICTURE DO THESE ELEMENTS OF INTELLIGENCE GIVE US OF THE ACCIDENT SEVERITY, IN FACT, DO THEY PROVIDE ANY MEASURE OR MEASURES OF ACCIDENT SEVERITY,

I BELIEVE THAT TWO VERY IMPORTANT MEASURES OF THE SEVERITY OF AN ACCIDENT ARE: THE EXTENT OF PERSONAL INJURY AND VEHICLE DAMAGE. INUURY AND DAMAGE CAN BE QUANTIFIED AND WHEN THESE QUANTIFICATIONS ARE COMBINED SPECIFICALLY WITH OTHER ROUTINE INFORMATION NORMALLY COLLECTED AT THE POLICE INVESTIGATION LEVEL, A VAST ARRAY OF USEFUL INFORMATION CAN BE EVOLVED.

WHILE VARIOUS SCALES, INDICES AND METHODS HAVE BEEN USED TO QUANTIFY OCCUPANT INUURY AND VEHICLE DAMAGE, THE TWO MOST VERSATILE AND, IN MY OPINION, VALUABLE, aRE THE ABBrEVIATED INUURY SCALE (1) (for INUURY QUANTIFICATION) AND

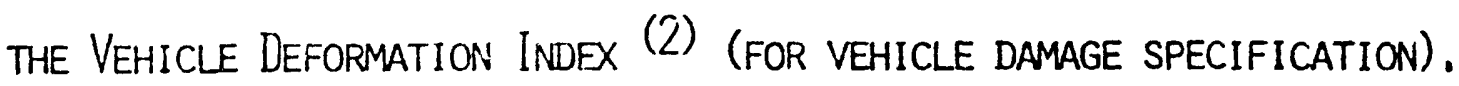
The AbBreviated InuUry Scale, or AIS as it is often referred to, is a method developed by the AMercian Medical Association to describe personal INJURY, NUMERICAL INJURY CODES ARE APPLIED TO SPECIFIC TRAUMA IN SPECIFIC ANATOMICAL REGIONS; FOR EXAMPLE, A COMPOUND FRACTURE OF THE LEFT HUMERUS MIGHT RATE AN AIS LEVEL 3. THE INCREASING NUMBERS FROM ZERO TO SIX INDICATE INCREASING SEVERITY OF THE SPECIFIC LESION. THESE CODES WERE DEVELOPED BY PHYSICIANS WHO CONSIDERED SUCH FACTORS AS: ENERGY DISSIPATION AS A CAUSE OF THE TRAUMA, THREAT TO LIFE RESULTING FROM THE TRALMA, POSSIBILITY OF PERMANENT IMPAIRMENT, THE TREATMENT PERIOD REQUIRED FOR HEALING, AND THE INCIDENCE OF SUCH INUURIES OCCUIRRING IN THE ROUTINE TREATMENT OF TRAUMA 
FROM ROUTINE TRAFFIC ACCIDENTS AS BASED ON THE EXPERIENCE OF THE ATTENDING PHYSICIANS. THE AIS CODES ARE ASSIGNED ONLY BY MEDICAL AND PARA-MEDICAL PERSONNEL,

Vehicle damage is quantified using the Vehicle Deformation IndeX, CaLled the VDI, deVeloped by the Society of Automotive Engineers, The VDI IS A COMPREHENSIVE DAMAGE DESCRIPTION TECHNIQUE IN WHICH A SIX COMPONENT, SEVEN CHARACTER ALPHANUMERIC CODE IS USED TO DESCRIBE: THE GENERAL DIRECTION OF FORCE, GENERAL AREA OF DEFORMATION, SPECIFIC HORIZONTAL AND VERTICAL AREAS OF DAMAGE, THE TYPE OF DAMAGE DISTRIBUTION, AND THE EXTENT OF DAMAGE, A VDI CODE OF 12FCER2 INDICATES THAT THE VEHICLE RAN HEAD-ON INTO A NARROW OBJECT, SUCH AS POLE, CAUSING CENTRAL DAMAGE TO THE FRONT OF THE VEHICLE AND THE CONTACT DAMAGE EXTENDED BACK APPROXIMATELY ONE-THIRD THE LENGTH OF THE HOOD.

USE of the Vehicle Deformation IndeX by a diverse group of investigators WITH ONLY MINIMAL TRAINING, WAS SHOWN TO BE FEASIBLE IN A STUDY OF 520 ACCIDENT CASES COLLECTED BY 33 TEAMS REPRESENTING NINE EUROPEAN AND NORTH American nations in the Pilot Study on Road Safety $(3,4)$. In this controlled STUDY, ACCIDENT INVESTIGATORS CORRECTLY APPLIED THE VDI TO DAMAGED VEHICLES IN APPROXIMATELY THREE-FOURTHS OF THE CASES. LESS THAN 5\% OF THE CASES CONTAINED INVALID INFORMATION. THE AUTHORS OF THE REPORT CONCLUDED THAT THE VDI COULD BE APPLIED EFFECTIVELY AT THE POLICE LEVEL 90 TO $95 \%$ OF THE TIME IN REGULAR USE, (5)

THE DAMAGE AND INJURY SCALES WERE STUDIED FURTHER IN A SPECIAL PROGRAM in Bexar County, Texas, during the six-month period ending May 30, 1973. The AUTOMATED DATA FILE FROM THIS STUDY CONTAINS INFORMATION ON NEARLY 5500 ACCIDENTS INVOLVING OVER 10,000 VEHICLES AND 15,000 OCCUPANTS. THE CORRELATION BETWEEN INJURY SEVERITY AND VEHICLE DAMAGE WAS STUDIED AND GROSS PATTERNS WERE EVIDENT WHEN THE TWO VARIABLES WERE COMPARED ON SELECTED BASIS. $(6,7)$ 
WITH REASONABLE ASSURANCE, INUURY SEVERITY COULD BE PREDICTED ON THE BASIS OF OBSERVED DAMAGE EXTENT. I HASTEN TO ADD, HOWEVER, THAT THIS STATEMENT MUST BE ACCEPTED IN VIEW OF MANY OTHER QUALIFYING FACTORS, GROSS STATISTICS WERE REPORTED BECAUSE WE SIMPLY DID NOT HAVE A DATA FILE OF SUFFICIENT SIZE TO PRODUCE STATISTICALIY SIGNIFICANT RESULTS IN ANY DEGREE OF REFINEMENT,

A RECOMMENDATION OF THIS STUDY, WHICH I NOW PROPOSE FOR CONSIDERATION OF THIS GROUP IS: USING NOW OBTAINABLE LARGER QUANTITIES OF ACCIDENT DATA, CONDUCT FURTHER STUDIES AIMED AT REFINING THE INUURY SEVERITY PREDICTION POTENTIAL OF THE VDI COLLISION DAMAGE CLASSIFICATION TECHNIQUE USED IN CONJunction with the AbBreviated InuUry Scale; promulgate the Vehicle Deformation INDEX AS THE STANDARD COLLISION DAMAGE CLASSIFICATION TOOL FOR USE BY POLICE IN REPORTING VEHICLE DAMAGE IN TRAFFIC ACCIDENTS; INTRODUCE PROGRAMS WHICH

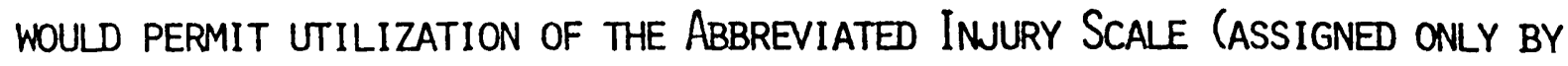
MEDICAL AND PARA-MEDICAL PERSONNEL) IN CONNECTION WITH POLICE REPORTS IN MAJOR TRAUMA TREATMENT CENTERS, 
-146- 


\section{APPENDIX N}

\section{REGULATORY RULEMAKING}

BASED ON LESS THAN TOTAL INFORMATION

David Morganstein

CENTER FOR AUTO SAFETY

and

L.A. Goldnuntz

ECONOMICS \& SCIENCE PLANNING, INC.

February 21, 1975

(date of receipt)

$-147$. 


\section{REGULATORY RULEMAKING}

BASED ON LESS THAN TOTAL INFORMATION

David Morganstein, Center for Auto Safety,
and L. A. Goldmuntz, Economics \& Science Planning, Inc.

Received February 21, 1975

Estimation of the costs and benefits expected from regulatory programs is complicated by a lack of precise information. Several areas where a lack of knowledge exist are: the methods to be used by those regulated to meet the requirements; the efficacy of the methods chosen; the details which enter into the pricing effort of changes brought about by the regulation; alterations in the initial conditions which may occur over time, causing unpredictable variations in costs or benefits; the effectiveness of the regulation in achieving the desired benefits; and the impacts the regulation might have in other areas.

One subject not frequently addressed is the variation of the process to be regulated. If a population characteristic is timevarying, the potential benefits may be similarly varying. In such a situation, the possible conflicting conclusions that might be arrived at must be considered. There are well known tools, such as decision theory, which may provide a better conclusion than some undefined subjective process. Thus, the cost, the need or the value of additional data collection can be evaluated in light of its potential for clarifying the issues.

Nevertheless, governmental expectations are sufficiently high and the public demand sufficiently intense that programs may proceed even though complete information is unavailable or unattainable. After programs have been in place for some period, improvements 
may be realized more slowly than initial expectations. Ensuing discussions are polarized around industry and the regulatory agency: Is industry using unnecessarily expensive methods, and not choosing methods most likely to meet the intent of the regulation? Or on the other hand, are bureaucrats acting to enlarge their domain or justify their existence as a regulator? Or is there a lack of communication between industry, the regulators and the public so that there is little understanding of the issues and therefore little progress in resolving them?

Advocates may reference controlled laboratory experiments to estimate the efficacy of a regulation. They argue that the learning process will improve the methods used to meet the intent of the regulation and lower costs. Cynics question the extent to which laboratory experiments represent the real world. When cynics argue that the introduction of a new technology has a price tag which will ultimately be paid by the public, the advocates counter that the withholding of such technology has its own price tag. Clearly, there are societal costs to be borne without the protection of the regulation, with inadequate regulation or with excessive regulation. These issues have no general answers but require analysis case by case at each stage of the development of the regulation.

Analyses of the complex issues can best be carried out by a number of independent professional sources working independently. These efforts should then be compared, and the analyses and reasons for proceeding or not proceeding with a suggested program should be subject to public scrutiny. The consumer is potentially victimized when information is in the hands of any one monolithic organization, be it a regulatory agency or an industry. The consumer may also tend to be victimized by oversimplified sensationalized commentary by either side to the debate. 
Regulatory Rulemaking

Appendix N p. 3

The consumer has to rely on the different perspectives within society to accomplish the various analyses that expose the issues. We believe this pluralism can then lead to modifications of various points of view and perhaps lead to an eventual crystallization of the issues in a form that can be more readily understood by the public. At this point, it is essentially a public or political decision as to whether to proceed or not to proceed with any given regulatory program. The public interest is served best by having the issues fully explored from many points of view by many independent sources in estimating the potential costs and benefits of proposed regulatory programs. 


\section{APPENDIX $\mathbf{0}$}

\section{AUTOMOBILE COLLISION DATA WORKSHOP: AGENDA \\ SCHEDULED PRESENTATIONS \\ SALIENT RESIDUAL ISSUES}

January $16 \& 17,1975$ 
TENTATIVE AGENDA

AUTOMOBILE COLLISION DATA WORKSHOP

Part I. Data Requirements.

(a) Collision data needed for the design of crashworthy passenger cars including the restraint system, and to permit compliance testing; kinds of information, their relative importance, and precision required.

(b) Collision data needed for rational regulatory rulemaking; kinds and amounts of information, priorities, precision.

(c) Adequacy of the existing collision data base and the utility of data being gathered by current methods.

(d) Statistical requirements: rate at which data should be gathered to be timely in the environment of a temporallyvarying car-design population; the data file size to assure statistical significance when divided into cells of interest; time to accrue the required data file as a function of sampling rate; statistical adequacy of current and proposed programs.

(e) Dollar-equivalent benefits of adequate data; costs of not having data or using incorrect data.

Part II. Data Gathering Techniques and Programs.

(f) Crash recorders: capabilities, costs and limitations of alternative designs and programs.

(g) Accident reporting: extent, accuracy, costs and limitations; potential and cost of improving reporting accuracy.

(h) utility, cost and limitations of computer crash simulation. 
Tentative Agenda

Page -2-

(i) Derivation of crash data statistics through correlation of laboratory crashes with real world experience; clinical investigations; adequacy, accuracy, cost and limitations of these approaches.

Part III. Public, Legal and Legislative Reactions.

(j) The potential impact of crash recorders on tort claim settlement.

(k) The reaction of public interest groups to alternate collision-data-gathering programs.

(1) The legislative history of collision data gathering proposals and programs. 


\section{SCHEDULED PRESENTATIONS}

$$
\begin{gathered}
\text { AUTOMOBIICE.._COLLISION__DATA_WORKSHOP } \\
\text { January 16, } 1975
\end{gathered}
$$

\section{DATA REQUIREMENTS}

"Mass Accident Data Acquisition and Why It's Needed", John Versace, Ford Motor Company

"Inadequacy of Accident Data to Conduct Meaningful Research", Robert Cromack, Southwest Research Institute

"Need for Better Crash Data", Brian O'Neill, Insurance Institute for Highway Safety

"Collision Data Required to Improve and Evaluate Safet¥", Lawrence Patrick, Wayne State University

"How Data Fits Into the Rulemaking Process", James Hofferberth, National Highway Traffic Safety Administration.

"Adequacy and Limitations of Current Data", Marie Eldridge, National Highway Traffic Safety Admin.

DATA GATHERING TECHNIQUES AND PROGRAMS

"A Discussion of Data Gathering Systems", Edwin Kidd, Calspan Corporation

"How to Make Crash Recorders Support Other Data Collection Programs" B. J. Campbell, Highway Safety Research Center, U. of N. C.

"Crash Recorders: A Solution Seeking A Problem?" James O'Day, Highway Safety Research Institute, U. of Mich.

"NHTSA Crash Recorders", Lynn Bradford, National Highway Traffic Safety Administration

"Automotive Tape Recorder" Charles Conlon, AVCO Systems Division

"All Solid State Triaxial Accelerometer for Crash Testing", Louis Roberts, Transportation Systems Center 


\section{Economics \\ \& Science \\ Planning}

1200 18th Street, N.W. Washington, D.C. 20036 Telephone: 202-223-8444

J anuary 20, 1975

AUTOMOBILE COLLISION DATA WORKSHOP January 16-17, 1975

A number of major issues surfaced at the January 16, 1975 Automobile Collision Data Workshop. The following people have agreed to write brief position papers on these issues and to forward them to Economics \& Science Planning, Inc., before February 1, 1975:

ISSUE 1

Estimate the potential societal cost of not having better accident data than available from current resources.

From the point of view of the automobile manufacturer:

(Working separately)

- John Versace, Ford Motor Co.

- Richard Wilson, General Motors Corp.

From the point of view of the regulator:

- James Hofferberth, NHTSA

\section{ISSUE 2}

What are the advantages of an expanded low cost national accident data collection program that might provide 600,000 to amilion reports per year? How would such a data program be organized? Are there any models for such a data program? What Federal funding or inducements would be appropriate to achieve it?

(Working together)

- Brian O'Neill, Insurance Institute for Highway Safety

- Lawrence Patrick, Wayne State University

- B. J. Campbell, Highway Safety Research Center

- Robert Cromack, Southwest Research Institute

Cable ... ESPINC

Telex . . . 248482 
Auto Collision Data Workshop

January 20, 1975

Page -3-

ISSUES TO BE CONSIDERED BY THE

OFFICE OF TECHNOLOGY ASSESSMENT

IN ITS RESPONSE TO THE HOUSE

APPROPRIATIONS COMMITTEE ARE

THE FOLLOWING :

1. How much has NHTSA spent in each of the past three years to gather accident data? Is that data sufficient, or is further data on the characteristics of automobile collisions necessary for effective NHTSA standards-setting? If the existing data base is inadequate; in what ways is it inadequate?

2. An evaluation of the type of data being produced by existing crash recorders and an explanation of how this data is being used by NHTSA should be conducted.

$3^{*}$ If the data base is inadequate, how might an adequate data base be obtained and what are the consequences associated with obtaining the data in different ways (including the possibility of not obtaining the necessary data)? The cost effectiveness of the crash recorder and the crash impact approaches proposed by NHTSA should be examined.

4. Secondary consequences of implementing these or other programs should be identified and evaluated. Examples of these secondary consequences include legal questions associated with the existence of actual physical data from an accident and the potential value (to driver training programs) of a knowledge base concerning how drivers actually respond in accident situations. For each type of approach investigated, the implementation costs to the Federal Government, industry and consumers should be identified. 
Auto Collision Data Workshop

January 20, 1975

Page - 2-

\title{
ISSUE 3
}

Define the role of crash recorders in capturing field data needed to evaluate and calibrate accident investigators reports, crash tests, and crash simulation.

Gene Mannella, NHTSA

James O'Day, Highway Safety Research Institute, University of Michigan

Edwin Kidd, Calspan Corporation

\section{ISSUE 4}

what is the statistical rationale for the number of recorders proposed for procurement and installation by NHTSA? Is the number appropriate to the calibration uses described in 3 above? injury and fatality prevention rulemaking? damageability rulemaking or assessment?

\author{
Gene Mannella, NHTSA \\ Don Mela, NHTSA
}

\section{$\underline{\text { SSUE } 5}$}

Reliable data is sometimes unavailable to the extent desired when a regulatory action may seem to some to be desirable. What general policy guidelines if any can be developed to guide regulatory actions in an environment of imperfect data.

David Morganstein, Center for Auto Safety

Lawrence Goldmuntz, Economics and Science Planning 


\section{APPENDIX P}

LETTER FROM JOHN GARRETT

CALSPAN CORPORATION

AND

ATTACHMENT

March 12, 1975 


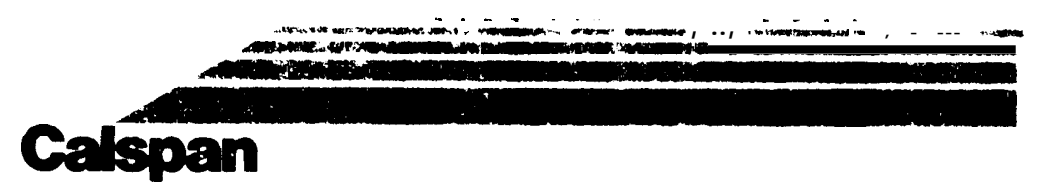

March 12, 1975

Air Mail

Dr. Lawrence Goldmuntz

Economics and Science Planning

1200 18th Street, N.W.

Washington, D.C. 20036

Dear Dr. Goldmuntz:

Following our telephone conversation about two weeks ago, I gathered some material on our use of police photography for estimation of vehicle damage severity and/or speed, as I had agreed. The material is attached to this letter. To provide background, and some additional detail, I have summarized relevant information below.

We first became concerned with the problem of assessing accident severity in our Automotive Crash Injury Research (ACIR) program in the early to mid-1950's. At that time, we developed an accident Severity Index (Attachment A) based on damage to the vehicle. The police provided interior and exterior photographs of the accident vehicle but the ratings were made by a small staff of trained Calspan (then Cornell) personnel. This procedure tended to minimize the inter-coder variability that would have resulted if thousands of police had rated the accidents. Also, it was not necessary to train police to code, but only to take the proper photographs. Thus, training costs were kept low.

Accuracy of ratings were further assured through the use of fairly extensive computer edit procedures. "Illegal" (impossible) codes resulted in a case being returned for checking. Consistency checks also were used, i.e., a case that was rated minor could not have severe overall damage to the car elsewhere or any damage to basic structure such as the chassis. Low probability events that were inconsistent with the severity also required a recheck of the case. Thus, a fatality in a case where the severity rating for the vehicle was minor, warranted a check. Some corrections were made automatically, but many errors required a recheck.

The reliability of rating procedures also was checked periodically by ACIR to ensure that rater variability was kept to a minimum. A copy of one report on this subject (Attachment B) is enclosed. 
Dr. Lawrence Goldmuntz

March 12, 1975

Bob Campbell later developed the TAD scale which is used by police in North Carolina and several other states. Here, all ratings are made by police in the field. Bob's studies have shown that they do rather well, but I think that I would prefer the additional control which our system provides.

The Collision Deformation Code (CDC) developed by G.M. generally succeeded the earlier systems for use by many researchers and the in-depth teams. In some ways this always seemed odd to me since the in-depth teams had measurements of the actual vehicle damage which were more accurate than the CDC. This scale clearly is too complicated for police use in the field. However, we have compared CDC ratings obtained by our personnel from police photographs with those obtained by an experienced invetigator rating the CDC from actual inspection and measurement of the vehicle. The results were quite good (Attachment $C$, pages 37-56) and we would have confidence in ratings provided by such a system. Again, ratings were made by a small staff of Calspan personnel with appropriate checks to maintain accuracy.

We later summarized available data from Calspan crash tests in a first attempt to develop an aid for estimating speed from vehicle damage (Attachment D). The amount of useful data was limited and the approach was dropped when additional inputs were not forthcoming.

Development of the SMAC program by Ray McHenry permitted accurate estimates of impact speeds, but requires such information as vehicle damage, point of impact and vehicle rest positions. Use of the Calvan simplifies the collection procedure for police and ensures accuracy. Ray is now working on a simplified version of the START program for SMAC which, it appears, may provide reasonably accurate speed estimates. A brief description appears in Attachment $E$.

Data collection cost was another point that we discussed. The cost of our most recent program to collect police photographs (last year) was approximately $\$ 5,000$ for 1,200 cases. Costs include only purchase and processing of film. We have purchased relatively inexpensive Instamatic cameras (\$20-25) for police use, with good results. Generally, one camera per car is needed.

In our discussion, you also mentioned the possible use of templates for measuring the vehicle damage photographed. We explored this, but it is quite difficult to do without an overhead shot of the vehicle or the use of photogrammetry. If we go that far, then I believe that the Calvan would be competitive in terms of cost and would provide far better data. 
Dr. Lawrence Goldmuntz

March 12, 1975

This has become a rather lengthy letter with many attachments, but since I agree that the use of police photographs can provide good vehicle damage/speed data, I have tried to provide what useful information I can. It may still be sketchy for your purposes, however. If so, I will be pleased to provide any additional information that we have available,

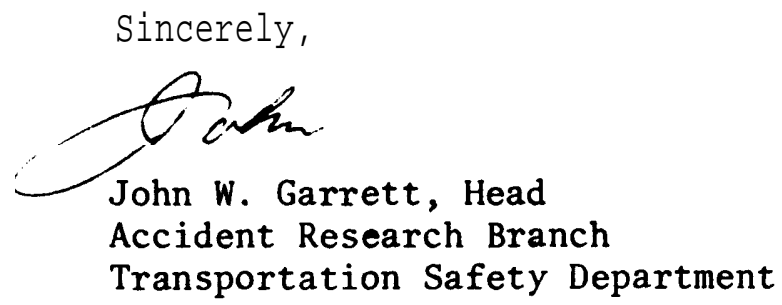

JWG : jem

Attachments 
Introduction

The method of rating acriden averity ocribed he we was developed for use in the Automotive Crash Injury Research pregram (ACIR) of Cornell Aeronautical $i$ aboratoxy, Inc. Thus far, 31 states have participated in the program. In this study, acrident data are reporteci by participating state police on a report form designed by AOJR. Police also provide photographs of the vehicle irterior and exterio: Morical data aroprovided by the physicians who attendi the injured viction.

The description of the rating system which follows was prepared for use by ACIR case araiyst:. Ir assesing vehiclo damage, photographs of the car and pertinent information fin the accident leport form are used. The report form piovides suformation corcerning daiage to various structural elements of the car, ach as the chassis frame, engine or mounts, firewall, floor, etc., which an not always visible in photographs. This information is essential if ar arcute apratas of vehiche damage is to be made.

Although the ACIR accident data have been collected by thousands of police officers throughout the country, rating of accident severity and survivability has becm perfomed by a few ACIR cuse anyets. Thus, variability in rating can be minimined and closer co al aritained over the process.

\section{Discussion of Rating Method}

The rating of accidert severity and survivability represents an effort to classify accident-irvolved cars not only in terms of damage but in te rms of the potential survival of occupants. Each car in an accident is evaluated and rated individually since scverity and potential survivability often differ even for cars involved in the same accident. Data on wich the evaluation is based are obtained from a series of interior and exterior photographs of the car, and from the accident report form which describes the accident and provides additional information on certain structural components: engine, engine mounts, chassis frame, firewall, front wheels, floor, etc. Accident severity and survivability are rated only when adequate photographs and sufficient accident inforrsation are available. When adequate photographs or accident data are not availabie, cases are classed as NAC (not able to rlassify).

The classification of accident severity and survivability requires an assessment of the type and amount of car damage, type of components affected, and the influence of this damage on potential survival of car occu- 
pants. Accident severity and survivability are rated semi -independently although in fact they are inextricably related. Broadly speaking, accident severity is classified in terms of the type, extent and area (side, rear, etc. ) of the car damaged, whereas survivability is classified in terms of occupant environment, i.e., whether there is collapse or invasion of the compartment. Accident severity and survivability are not mutually exclusive categories, as is shown in the gross relationship between $\mathrm{c}$ a $\mathrm{r}$ damage, accident severity, and survivability.

In classifying accident severity a six-point scale (below) ranging from minor to extreme is used. In descriptive terms, damage ranges from denting and scratching of surface metal to complete disintegration or crushing of the car. Thus, the accident severity rating rises progressively as damage increases and more of the structural elements of the car are affected.

Accident Severity and Survivability Scale

Car Damage

○
Accident

Severity

Survivability y

Sheet Metal Damage

No damage to basic structure; no invasion of compartment.

Structural elements progressively involved; compartment may, or may not $t_{s}$ e invaded.

Complete Destruction

\section{Minor \\ Mode rate \\ Moderately \\ Severe}

Severe

Extreme 1 y

Severe"

Extreme
Survivable

Survivable

Survivable, Questionable or Partial

Survivable, Questionable, or Partial

Survivable, Questionable, Partial, or Non -Survivable Non-Survivable 
When an accident is rated minor or mode rate in severity it is conside red survivable. Moderately severe, severe or extreme 1 y severe acci dents may also be survivable, or survivability may be rated as questionable or partial. Extremely severe accidents may also be classified as nonsurvivable. Extreme accidents are always regarded as non- survivable be cause they involve almost complete destruction of the car. A more detailed description of both accident severity and survivability is provided in the sections which follow.

$\underline{\text { Accident Severity }}$

o Minor

Damage is most often confined to the sheet metal surface of the car although bumpers may be slightly dented, headlights or taillights broken, radiator grill bent or broken, ornamental molding torn free. When forces are applied to sheet metal, damage may be de scribed in such terms as "small dent", "slight deformation", scratches ", etc. Such damage is con side red minor whether a small or large area of the car is affected. Minor severity accidents never involve structural components of the car.

1 Mode rate

Damage most often involves sheet metal, but such structures as bumpers, bumper guards, or radiator grill may be damaged. Sheet metal or grill damage may be described as "slight buckling", "pushed in" "crumpled", or "torn". For stronger components -- such as a steel burn per -- descriptive phrases such as "large dent", "twisted", or "bent" might be used. In accidents of mode rate severity, structural components of the car are undamaged.

\section{$1 \quad$ Moderately Severe}

Damage involves forces sufficiently great so that stronger structural elements as well as sheet metal are affected. Usually sheet metal begins to collapse and, depending on the area of impact, comer posts, center posts, or chassis frame may be deformed.

\section{$1 \quad$ Severe}

Damage in this category always involves collapse or marked displacement of structural elements, as well as c rushing or telescoping of sheet metal. This grade of accident severity often involves penetration of compartment are as 'either as a result of direct impact, or as a result of displacement of other parts of the car due to impact or overturn. 


\section{- Extremely Severe}

Damage to the impacted area in these accidents is very extensive. Structural elements and sheet metal in the affected areas are gene rally crushed. There is considerable telescoping of the impacted area, and there is usually some invasion or collapse of the compartment.

\section{- Extreme}

This category is reserved for accidents so severe that the automobile involved is almost completely demolished, and often is scarcely recognizable as an automobile. Damage may be de scribed as almost complete disintegration or crushing of the entire car. Photographs of extreme dam age are not provide $\mathrm{d}$ in the figure illustrating accident severity because all damage beyond that illustrated for extremely severe is considered extreme.

\section{Survivability}

The concept of survivability is based on the assumption that survival is dependent on the compartment area remaining essentially intact. In rating survivability, it is recognized that other forms of protection -interior redesign, padding, lap belt and harness, or even other devices as yet not available -- may be required in order to fully capitalize on the potential survivability afforded by the compartment. Without a reasonably intact environment, however, there is no assurance that occupants could survive even with other protective devices. The criteria used in determining survivability, there fore, are the degree of compartment collapse and its influence on the normal seated position areas, i. e. , whether there would be sufficient space for Survival if all seats had been occupied by persons seated in a normal, upright position, and all occupants had remained in their seats. In brief, whether the area surrounding each seat in the car could still hold an upright occupant.

Data concerning the actual fate of automobile occupants indicate that many occupants die in accidents that are relatively mild and, conversely, some occupants survive even when the car is demolished. Although all cars in the ACIR study contain at least one occupant, in classifying survivability the presence or absence of occupants, as well as the fate of those occupants actually present in the car, is ignored. In effect, the car is rated without considering the number of occupants or whether they lived or died. Thus, occupants may survive a non- survivable accident, or may die in a survivable accident.

A "survivable "rating signifies that the compartment (occupant are a) was essentially intact and that there was no c rushing or invasion of the compartment. As the compartment area collapses or is progressively invade $d$ by surrounding structure, survivability may be classified as survivable, questionable, partial, or non- survivable. Survivability categories and the appropriate accident severity categories are described below. 
When the re is little or no invasion of the compartment area, survivability for all occupant areas is normally assumed. Minor and moderte accident severities, by definition, must be conside red survivable. Moderately severe, severe, and extremely severe accidents may be survivable if the re is little invasion of the compartment. An extreme accident (again, by definition) cannot be considered survivable. (Rated survivable: Front photographs - minor, moderate, moderately severe; Side minor, moderate, moderately severe, severe; Rollover - minor, moderate, moderately severe.)

\section{- Questionable Survivability}

When the area surrounding one or more seated positions is somewhat compressed, but the re is some doubt as to whether one or more normally seated persons could survive, survivability is conside red questionable. This classification may be used only with moderately severe, severe, and extremely severe accidents. (Rated questionable survivability: Side

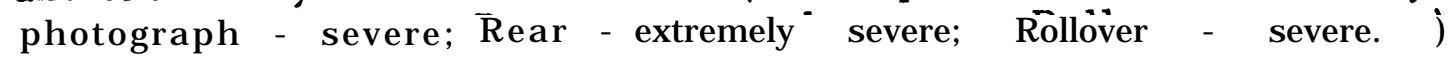

\section{- Partially Survivable}

This category is used when one or more, but not all) seated posi tions are compressed to such a degree that it is considered non-survivable for a normally se ate d person. This classification may be used only with mode rate 1 y severe, severe, and extremely severe accidents. (Rated partially survivable: Side photograph - extremely Severe.)

\section{- Non-Survivable}

When the entire compartment is compressed or invaded to such an extent that there is insufficient room for an occupant seated upright in all the normal seating areas, the accident is considered non- survivable. Extremely severe accidents may be classified as non-survivable, and extreme accidents must be so classified. (Rated non-survivable: Front photograph - extremely severe; Rollover - extremely severe. ) 


\section{Classification}

Code

Survivable

Minor

Moderate

Moderately severe

Sever e

Extremely severe

Non- survivable

Extremely severe

Extreme

E

Partially survivable

Moderately severe

Sever e

Extremely severe

L

$\mathrm{M}$

$\mathrm{N}$

Questionable survivability

Moderately severe

Severe

Extremely severe 
FRONT

MINOR

MODERATE

MODERATELY SEVERE

SEVERE

EXTREMELY SEVERE
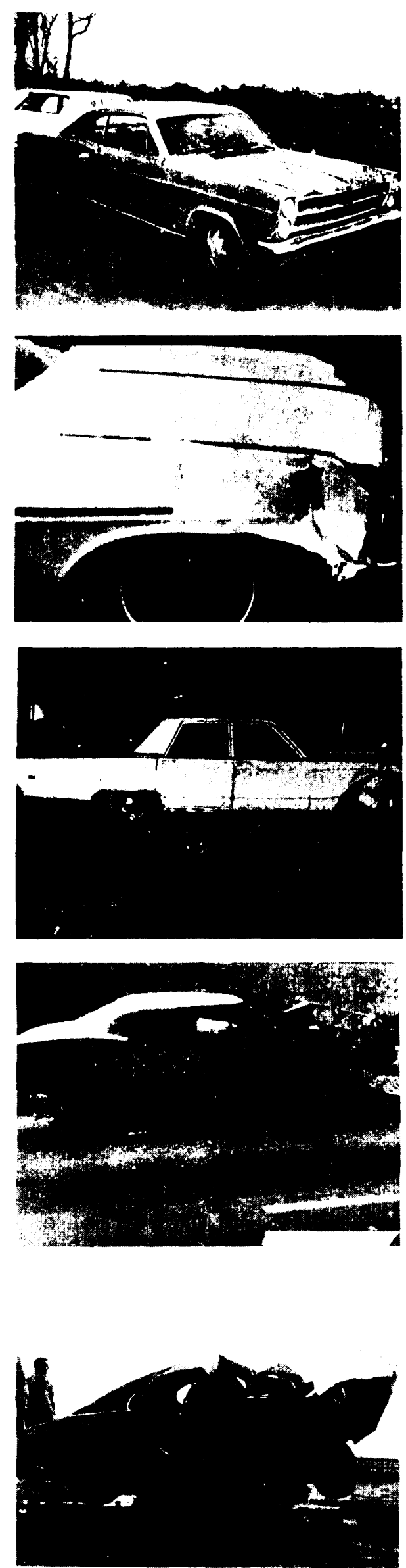

\section{SIDE}
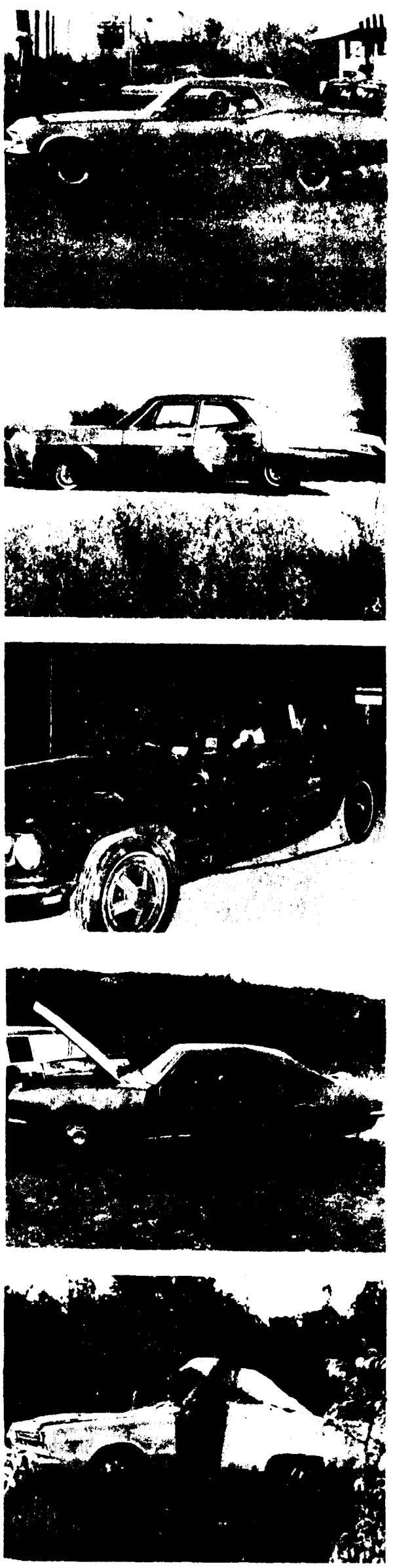


\section{SEVERITY}

\section{REAR}

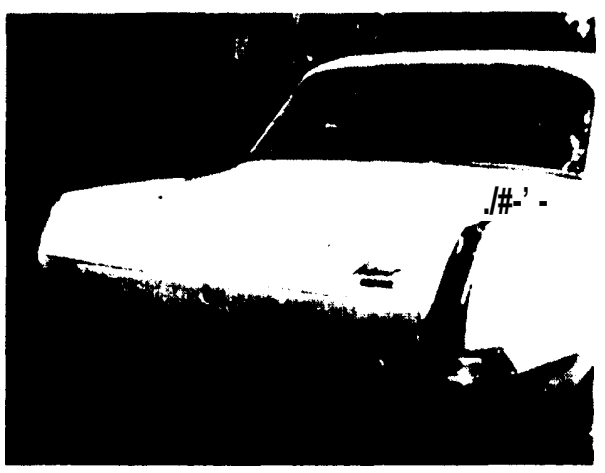

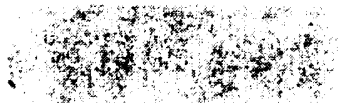
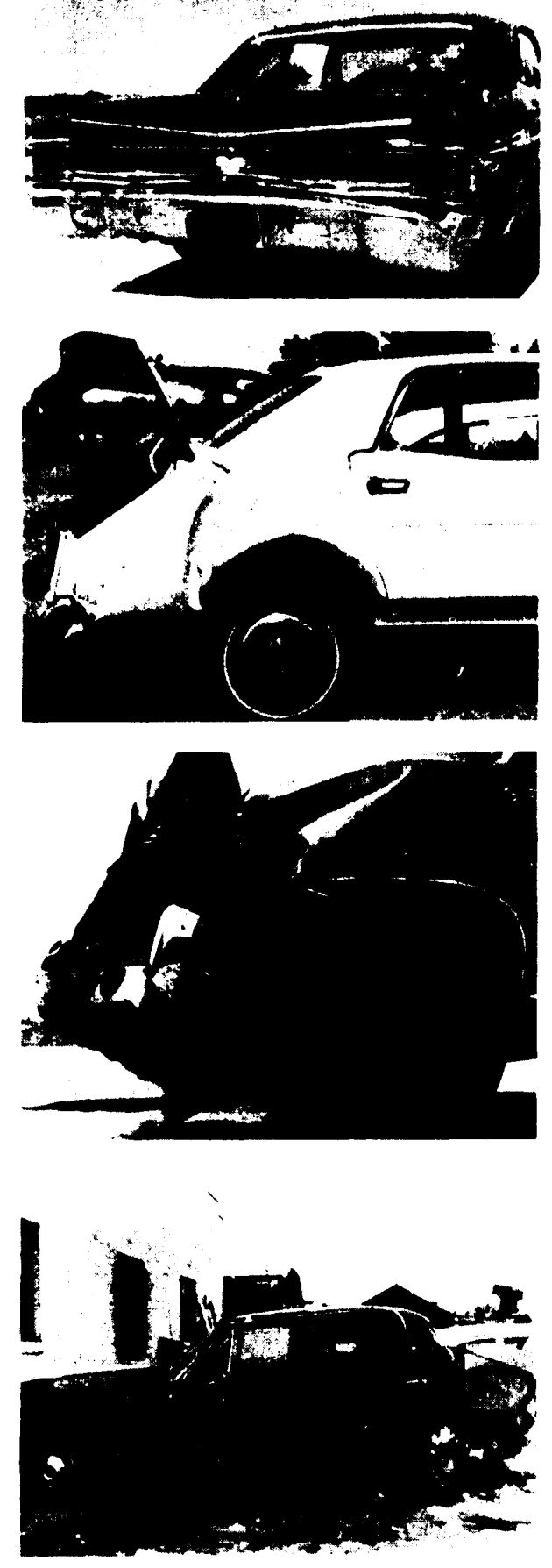

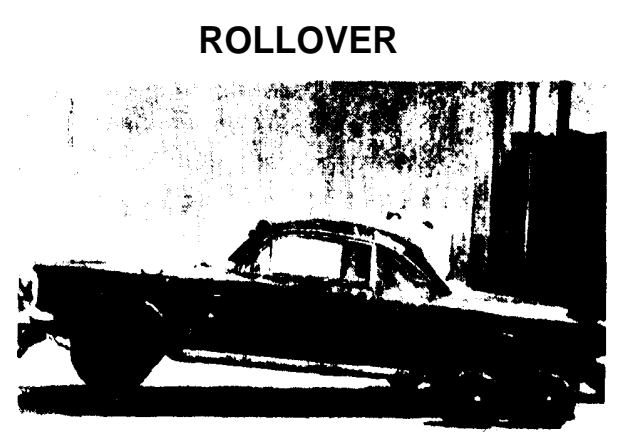

MINOR

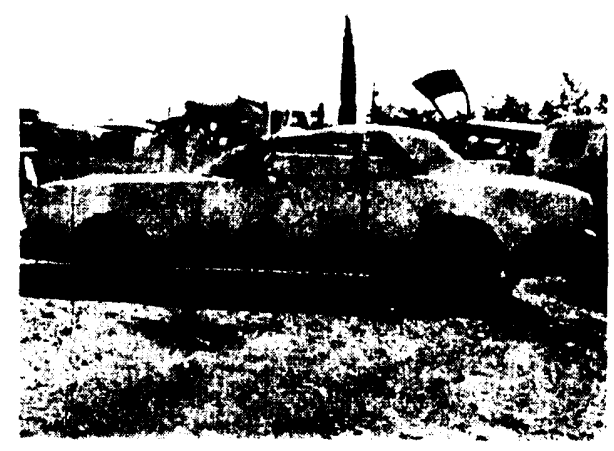

MODERATE

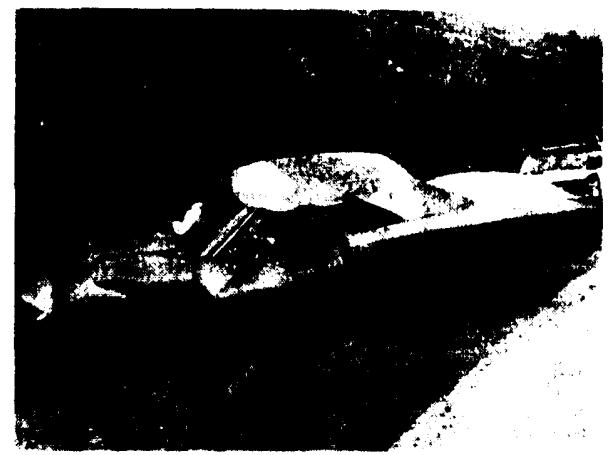

MODERATELY SEVERE

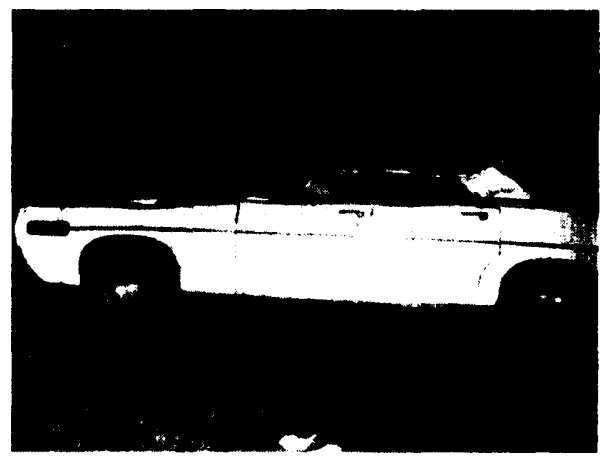

SEVERE

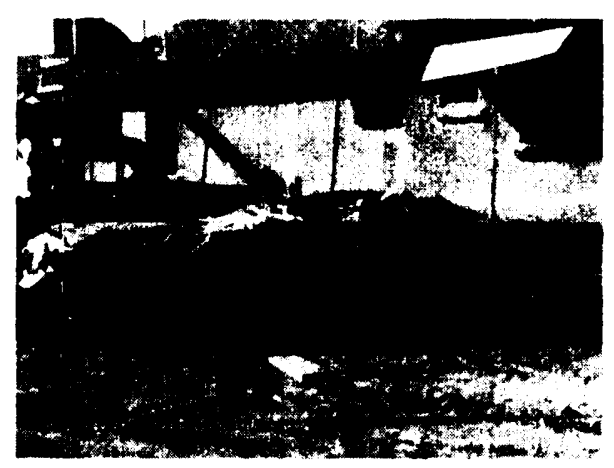

EXTREMELY SEVERE 